$$
\begin{gathered}
\text { Coordinado por: } \\
\text { Victoria Tur-Viñes } \\
\text { María José González-Río } \\
\text { Ruth-s. Contreras-Espinosa } \\
\text { Jóvenes / Medios y cultura } \\
\text { colaborativa }
\end{gathered}
$$

Cuadernos Artesanos de Comunicación / 157

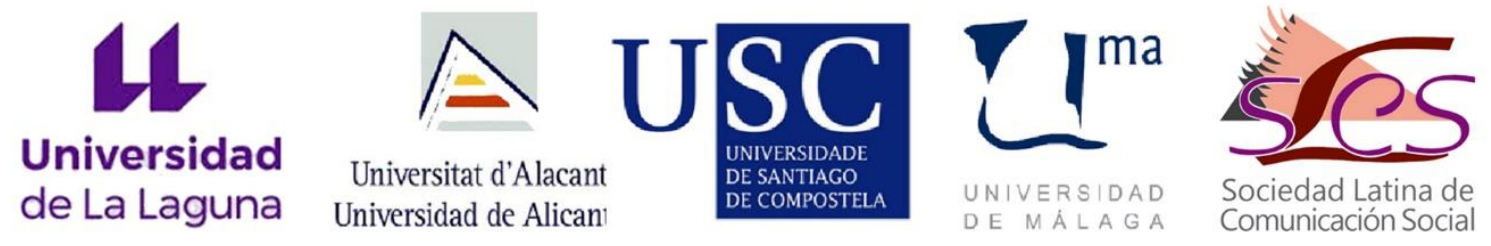




\section{Cuadernos Artesanos de Comunicación \\ Coordinador editorial: José Manuel de Pablos - jpablos@,ull.edu.es \\ Comité Científico \\ Presidencia: José Luis Piñuel Raigada (UCM) \\ Secretaría: Milena Trenta}

- José Cisneros (Benemérita Universidad Autónoma de Puebla, BUAP)

- Bernardo Díaz Nosty (Universidad de Málaga, UMA)

- Carlos Elías (Universidad Carlos III de Madrid, UC3M)

- Paulina B. Emanuelli (Universidad Nacional de Córdoba, UNC)

- José Luis González Esteban (Universitas Miguel Hernández de Elche, UMH)

- Marisa Humanes (Universidad Rey Juan Carlos, URJC)

- Juan José Igartua (Universidad de Salamanca, USAL)

- Xosé López (Universidad de Santiago de Compostela)

- Maricela López-Ornelas (Universidad Autónoma de Baja California, UABC)

- Octavio Islas (Universidad de los Hemisferios, Ecuador)

- Javier Marzal (Universidad Jaume I, UJI)

- José Antonio Meyer (Benemérita Universidad Autónoma de Puebla, BUAP)

- Ramón Reig (Universidad de Sevilla, US)

- Miquel Rodrigo Alsina (Universidad Pompeu Fabra, UPF)

- Xosé Soengas (Universidad de Santiago de Compostela)

- José Luis Terrón (Universidad Autónoma de Barcelona, UAB)

- José Miguel Túñez (Universidad de Santiago, USC)

- Victoria Tur (Universidad de Alicante, UA)

- Miguel Vicente (Universidad de Valladolid, UVA)

- Ramón Zallo (Universidad del País Vasco, UPV-EHU)

- Núria Almiron (Universidad Pompeu Fabra, UPF)

- Francisco Campos Freire (Universidad de Santiago de Compostela)

\footnotetext{
* Queda expresamente autorizada la reproducción total o parcial de los textos publicados en este libro, en cualquier formato o soporte imaginables, salvo por explícita voluntad en contra del autor o autora o en caso de ediciones con ánimo de lucro. Las publicaciones donde se incluyan textos de esta publicación serán ediciones no comerciales y han de estar igualmente acogidas a Creative Commons. Harán constar esta licencia y el carácter no venal de la publicación.
}

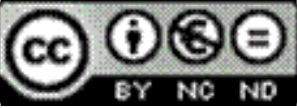

Este libro y cada uno de los capítulos que contiene (en su caso), así como las imágenes incluidas, si no se indica lo contrario, se encuentran bajo una Licencia Creative Commons Atribución-No Comercial-Sin Derivadas 3.0 Unported. Puede ver una copia de esta licencia en http://creativecommons.org/licenses/by-nc-nd/3.0/ Esto significa que Ud. es libre de reproducir y distribuir esta obra, siempre que cite la autoría, que no se use con fines comerciales o lucrativos y que no haga ninguna obra derivada. Si quiere hacer alguna de las cosas que aparecen como no permitidas, contacte con los coordinadores del libro o con el autor del capítulo correspondiente.

* La responsabilidad de cada texto es de su autor o autora. 
Coordinado por:

Victoria Tur-Viñes, María José González-Río, Ruth-S.

Contreras-Espinosa

\section{Jóvenes / Medios y cultura colaborativa}

Forma de citar este libro

V Tur-Viñes/M J González-Río/R S Contreras-Espinosa (Eds.). (2019). Jóvenes / Medios y cultura colaborativa. Cuadernos Artesanos de Comunicación, cac157. La Laguna (Tenerife): Latina.

DOI: $10.4185 / \operatorname{cac} 157$

Cuadernos Artesanos de Comunicación / 157

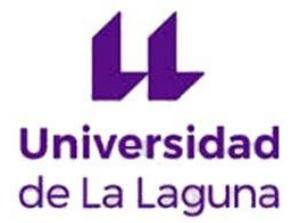

de La Laguna

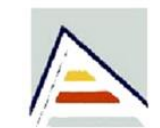

Universitat d'Alacant Universidad de Alican
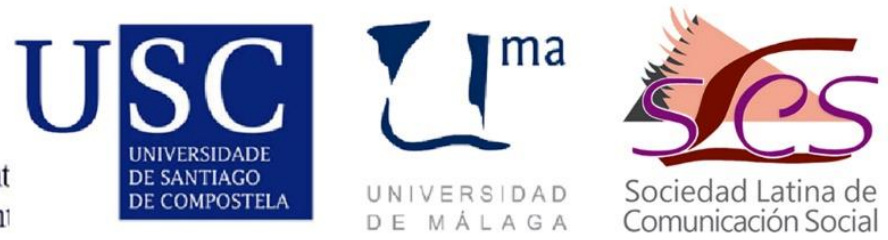
CAC $157^{\circ}$ - Jóvenes / Medios y cultura colaborativa

Coordinado por: Victoria Tur-Viñes/María José González-Río/Ruth-

S. Contreras-Espinosa

| Precio social: $11,80 €$ | Precio en librería. 15,35€ |

Editores: Javier Herrero y Milena Trenta

Diseño: F. Drago

Ilustración de portada: Fragmento del cuadro "Mujer de

Fuenteventura", de Vale (Bolonia).

Imprime y distribuye: F. Drago. Andocopias S. L.

c/ La Hornera, 41. La Laguna. Tenerife.

Teléfono: 922250554 | fotocopiasdrago@,telefonica.net

Edita: Sociedad Latina de Comunicación Social - edición no venal

- La Laguna (Tenerife), 2019 - Creative Commons

http://www.revistalatinacs.org/14SLCS/portada2014.html

Descargar en pdf:

http://www.cuadernosartesanos.org/\#157

Protocolo de envío de manuscritos con destino a CAC: (la colección que corresponda)

http://www.cuadernosartesanos.org/protocolo.html

ISBN - 13: 978-84-17314-16-3

DL: TF-455-2019

DOI: $10.4185 / \operatorname{cac} 157$ 


\section{Jóvenes, medios y cultura colaborativa}

\section{Resumen}

Se exploran las intersecciones entre la sociabilidad, los valores compartidos y las formas de organización de los adolescentes en red, así como los usos de los medios digitales y sus habilidades como consumidores de medios y creadores. La transferencia de conocimiento que se realiza desde el entorno digital a otras esferas de la vida impulsa un nuevo entorno de conocimiento denominado alfabetismo transmedia propiciado por un contexto extremadamente tecnológico y accesible. La familia, la escuela y la propia sociedad deben atender esta nueva forma de vivir, aprender y comunicar. Ante este fenómeno de enorme actualidad y proyección futura se presenta una compilación de diez textos científicos en la que han participado 26 autores de 12 universidades, nacionales e internacionales. Los adolescentes y las producciones amateur basadas en el entorno tecnológico digital; las fronteras entre el ocio y el aprendizaje informal en línea; las producciones/creaciones transmediáticas de los jóvenes; los jóvenes en cuanto prosumidores; las reflexiones críticas sobre los menores y su relación con la tecnología y los medios digitales y, por último, los comportamientos, la participación, los valores y riesgos de los menores jóvenes en la red, han sido el objetivo de las contribuciones en su conjunto.

\section{Palabras claves}

Jóvenes, aprendizaje, alfabetización transmedia, tecnología, cultura participativa

\section{Forma de citar este libro:}

Victoria Tur-Viñes, María José González-Río, Ruth-S. ContrerasEspinosa (Coords). (2019): Jóvenes / Medios y cultura colaborativa. Colección Cuadernos Artesanos de Comunicación, 157. La Laguna (Tenerife): Sociedad Latina de Comunicación Social. 


\section{INDICE}

Prólogo

1. La fuga de los millennials de la televisión lineal

Enrique Guerrero Pérez.

2. Uso de Twitter en los MOOC: Nuevas formas de interacción juvenil y su influencia en el aprendizaje

Carmen Marta-Lazo et al

3. La audiencia activa en la ficción transmedia: plataformas, interactividad y medición

Jorge Várquez. Herrero

4. Educación Transmedia. De los contenidos generados por los usuarios a los contenidos generados por los estudiantes

Carlos A. Scolari et al.

5. Adolescentes, redes sociales y universos transmedia

Julián de la Fuente Prieto et al..

6. Vampiros en la Red. El robo de la cultura juvenil

Roberto Aparici et al.

7. Jugadores, escritores e influencers en redes sociales

María José Establés et al.

8. Usos del WhatsApp en el estudiante universitario español

JF Fondevilla-Gascón et al.

9. ¿Cómo interactúan los adolescentes con los videojuegos? Preferencias y habilidades performativas

Juan Manuel Muñoz et al

10. Alfabetismos transmediales y habilidades colectivas de participación. Estrategias de producción creativa y gestión del ocio de fans de Star Wars

José Manuel Corona et al.

\section{El contenido de este libro ha sido sometido a un proceso de revisión de doble ciego por pares, semejante al sistema de revisión de un artículo científico para un journal.}




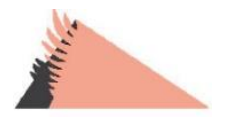 \\ Prólogo}

Victoria Tur-Viñes

$\mathrm{E}$ NTRETENIMIENTO, Comunicación y Educación desdibujan sus fronteras en un momento temporal en el que la tecnología de la Comunicación y la Información facilita un consumo mediático ubicuo, a demanda y compartido.

La práctica docente, sometida a la alternancia caprichosa de los vaivenes de políticas erráticas, hace esfuerzos fallidos por resultar actual y comprender la realidad de los menores discentes. Pero, el encargo educativo no reside solo en los centros educativos; la familia, la sociedad y los medios participan de forma decisiva en la formación de los jóvenes. Esta es la primera realidad que impulsa el concepto de cultura participativa. La cultura que lo envuelve todo y descubre nuevos caminos para desarrollar conocimientos, senderos que se alejan de las concepciones tradicionales de enseñanza y aprendizaje. Una cultura que convierte cada acto de consumo en agente proveedor potencial de conocimiento y, con ello, a los actores involucrados en el mismo, a los medios por los cuales se expresa, expone y es accesible y a los contenidos que lo configuran. Todos son, a la vez, protagonistas e inductores de un proceso de aprehensión del mundo marcado por el aprendizaje. Es un acto de consumo mediático porque suele necesitar de algún medio para materializarse $\mathrm{y}$, por otro lado, también es mediado porque, como consumidores, los menores necesitan orientación o guía del tutor o adulto, aunque sea frecuente que los iguales cumplan esa función. Es, en este último caso, cuando descubrimos una segunda acepción en el concepto de cultura participativa. Los compañeros iguales, con experticia adquirida mediante autoaprendizaje, experimentación personal y altas dosis de ensayo y error, se erigen en guías improvisados pero facultados, de sus compañeros. 
Todo este fenómeno está propiciado por una cultura en constante movimiento, que se mueve al ritmo de la innovación tecnológica, siempre inexplorada del todo porque su esencia es inagotable. El factor relacional (Gabelas y Marta, 2013) que hace evolucionar las TIC en TRIC completa una tercera consideración de la cultura participativa. La importancia que reviste la construcción de relaciones sólidas, emocionales y emocionantes, en los espacios de aprendizaje y acceso al conocimiento, garantizan la apropiación individual de la cultura circundante y explican la intensidad de la inmersión en los procesos de descubrimiento y exploración necesarios.

La investigación académica y el método científico pueden ayudar en estos nuevos entornos de aprendizaje aportando evidencias científicas que permitan diseñar mejores políticas educativas. También pueden contribuir al impulso de nuevas formas de hacer en el ámbito docente así como orientar en la disminución de la brecha existente entre las metodologías educativas con base en lo analógico y las metodologías digitales. La aspiración última es conocer las prácticas naturales y espontáneas que impulsan a los menores a buscar información, explorarla y adquirirla para transformarla en nuevas producciones genuinas, que evidencien conocimiento y competencia. Una vez conocidas, trasladarlas al modelo educativo actual solo exige la creatividad e involucración de los docentes, características ambas frecuentes en los perfiles de los profesionales en activo.

En la era transmedia, los jóvenes encuentran un entorno favorable para el despliegue de sus competencias tecnológicas. Navegan de forma eficiente en las redes digitales donde aprenden, intercambian, opinan y se socializan; solucionan problemas en los videojuegos; crean y distribuyen sus producciones, audiovisuales o escritas, en plataformas colaborativas y, con frecuencia, impulsan, alimentan y extienden el fenómeno fan con base en su competencia tecnológica y una ilimitada necesidad de compartir. Las formas de crear y colaborar en la red permiten considerar a los jóvenes como activos prosumidores (Toffler, 1980) que consumen y producen al mismo tiempo. Explorar las investigaciones actuales orientadas a conocer la sociabilidad, los valores compartidos y las formas de organización de los adolescentes en red así como los usos de los medios digitales y sus habilidades como consumidores de medios y creadores resulta tentador y apasionante. La 
transferencia de conocimiento que se realiza desde el entorno digital a otras esferas de la vida impulsa un nuevo entorno de conocimiento que denominaremos alfabetismo transmedia propiciado por un contexto extremadamente tecnológico y accesible. La familia, la escuela y la propia sociedad deben atender esta nueva forma de vivir, aprender y comunicar.

Ante este fenómeno de enorme actualidad y proyección futura se hizo una llamada de textos que versaran sobre los siguientes temas: adolescentes y producciones amateur basadas en el entorno tecnológico digital; las fronteras entre el ocio y el aprendizaje informal en línea; las producciones/creaciones transmediáticas de los jóvenes; jóvenes prosumidores; reflexiones críticas sobre los menores y su relación con la tecnología y los medios digitales, y comportamientos, valores y riesgos de los menores jóvenes en la red. La llamada no pasó desapercibida para proyectos como el titulado Transalfabetismos. Competencias transmedia y estrategias informales de aprendizaje de los adolescentes (ref. CSO2014-56250-R, Mineco, España) coordinado por Carlos Scolari desde la Universidad Pompeu Fabra de Barcelona (España). El anuncio tuvo como resultado la recepción de veintidós textos que se sometieron al habitual proceso de revisión científica, doble par ciego. Una selección de diez textos se compila en este volumen en el que han participado veinteséis autores de doce universidades, nacionales e internacionales.

Los textos que integran esta compilación pivotan sobre tres ejes diferenciados: la comprensión de los jóvenes como generación en cambio, el alfabetismo transmedia y las formas de consumo preferente de algunos medios.

En el primer eje, el lector podrá disfrutar dos textos. El primeo de ellos lo firma Enrique Guerrero y, bajo el título La fuga de los millennials de la televisión lineal analiza la evolución del consumo televisivo lineal de la llamada generación millennial y lo compara con el visionado online. También aborda el perfil de público y la afinidad de ese target con los canales de los principales operadores comerciales de televisión en España. Los resultados confirman el trasvase de audiencias y la fuga del público joven -y de los ingresos asociados- hacia otros servicios de entretenimiento audiovisual más personalizables e interactivos. Como consecuencia, los operadores de televisión reconocen estar poniendo 
en práctica nuevas estrategias que afectan a la esencia de su negocio y de su identidad.

Comparte objeto de estudio el texto Vampiros en la red. El robo de la cultura juvenil, firmado en coautoría por Roberto Aparici, David García-Marín y Natalia Díaz-Delgado. Frente a los numerosos estudios sobre las competencias y las estrategias que los jóvenes desarrollan en los entornos digitales y en su relación con las franquicias culturales en el seno de sus universos transmedia, este texto ofrece un análisis crítico sobre la mercantilización de la creatividad que los jóvenes despliegan en la Red. Los entornos digitales ofrecen escasas posibilidades de democratización del discurso público. La producción mediática de los jóvenes online suele estar basada en actos de falsa participación, ya que sus posibilidades de influencia son muy limitadas. A la vez, sus acciones en estos entornos digitales sirven para el sustento del capitalismo cognitivo a través de procesos de alienación y trabajo gratis que tienen como resultado la aparición de un feudalismo informacional que transfiere los bienes generados por la cultura juvenil desde el intelecto colectivo a las manos privadas. Es un texto que agita conciencias y provoca la reflexión.

El alfabetismo transmedia y sus dinámicas motivan la segunda agrupación de cuatro textos. El primeo de ellos está firmado por Jorge Vázquez-Herrero, Ana González-Neira y Natalia Quintas-Froufe y se titula La audiencia activa en la ficción transmedia: plataformas, interactividad y medición. El objeto de estudio es la serie de RTVE Si fueras tú, primera serie de ficción nativa, interactiva, transmedia. Se realiza un análisis de los soportes y plataformas oficiales que conforman el universo transmedia de la serie de ficción y se reflexiona sobre $r$ las posibilidades de interacción y la actividad de la audiencia en cada una de ellas. Los datos muestran que Facebook e Instagram concentran la mayor parte de la actividad del universo transmedia, y se identifica una rutina semanal en la combinación de plataformas y la integración de la audiencia activa. Los autores concluyen verificando la imposibilidad de cuantificar de forma estandarizada la audiencia transmedia y apuntan los desafíos del futuro más inmediato.

El segundo texto de este segundo bloque lleva por título Educación transmedia. De los contenidos generados por los usuarios a los contenidos generados por los estudiantes, una aportación firmada 
en coautoría por Carlos-Alberto Scolari, Nohemi Lugo-Rodríguez y María-José Masanet. El texto repasa y reflexiona sobre el concepto transmedia para evitar abusos semánticos y avanza en una caracterización de las posibles aplicaciones de las lógicas de las narrativas transmedia a los procesos de aprendizaje. Según declaran los autores, el análisis se ubica en el cruce entre educación, medios, narrativa y culturas participativas.

El tercer texto de temática relacionada con la alfabetización transmedia viene de la mano de Julián de la Fuente-Prieto, Pilar Lacasa-Díaz y Rut Martínez-Borda bajo el título Adolescentes, redes sociales $y$ universos transmedia: alfabetización mediática en contextos participativos. Los autores estudian los procesos de alfabetización mediática de los jóvenes a través de comunidades de prácticas en contextos participativos mediante el uso de discursos digitales que posibilitan la creación de universos transmedia. Logran reconstruir el sistema de actividad de un taller de creación audiovisual dirigido a adolescentes entre 8 y 14 años en un laboratorio ciudadano. Se presentan interesantes evidencias de las estrategias no formales de educación mediática, los roles que adoptan los jóvenes como usuarios de redes sociales y la creación de contenidos transmedia basados en la experiencia de mundos narrativos.

El cuarto texto enfocado a la esfera transmedia es una aportación internacional procedente de México que se titula Alfabetismos transmediales y habilidades colectivas de participación. Estrategias de producción creativa y gestión del ocio de Fans de Star Wars y está avalado por José-Manuel Corona-Rodríguez. Enfocado en la redefinición de la experiencia educativa, el texto investiga la producción de alfabetismos transmediales a partir de las habilidades participativas colectivas de una comunidad de fans. Se delimitan los conceptos de producción creativa y gestión del ocio. La producción creativa aborda un tipo de producción realizada por los fans que cruza lo mediático, virtual y presencial de sus prácticas, y la gestión del ocio aborda las estrategias desarrolladas para la utilización del tiempo y de la cultura emocional compartida. Reviste interés la propuesta de seis dimensiones de los alfabetismos transmediales sustentada por la dimensión colectiva de la participación. El autor 
sugiere que las habilidades colectivas de participación transforman las posibilidades educativas a través de la transmedialidad.

Agrupados en el tercer eje temático, encontramos cuatro textos que exploran la actividad de los adolescentes en cuatro esferas de consumo preferente: Twitter, redes sociales en general, WhatsApp y videojuegos.

El Uso de Twitter en los MOOC: Nuevas formas de interacción juvenil y su influencia en el aprendizaje motiva el título de la contribución realizada por Carmen Marta-Lazo, Diana Valero-Errazu y José Antonio Gabelas-Barroso. Las nuevas formas de interacción de los jóvenes dentro de un entorno de aprendizaje no formal como los MOOC motivan el texto. Los autores plantean identificar la influencia de la retroalimentación a través de Twitter en el aprendizaje de los estudiantes. Se realiza un análisis de regresión múltiple para determinar qué factores tienen mayor efecto sobre el aprendizaje $y$, posteriormente, determinar en qué medida influye la retroalimentación, tanto dada como recibida, en diferentes variables: compromiso, motivación, participación, disfrute/satisfacción, autoevaluación y resultados de aprendizaje, mediante un contraste de medias por segmentos. Dispensar retroalimentación a través de Twitter influye positivamente en el aprendizaje, mientras que recibirlo pasivamente no obtiene resultados concluyentes. Tanto la motivación y la participación de los estudiantes como la satisfacción con el uso del diálogo de Twitter tienen un efecto positivo sobre el aprendizaje, según se revela en este texto.

$\mathrm{M}^{\mathrm{a}}$ José Establés, Mar Guerrero-Pico y Ruth-Sofía Contreras-Espinosa firman un texto sobre Jugadores, escritores e influencers en redes sociales: procesos de profesionalización entre adolescentes. Las autoras asumen que la evolución de la industria mediática ha precipitado profundos cambios en la forma en que los adolescentes desarrollan sus competencias y acceden a la producción transmedia. Sugieren la aparición de una zona gris donde los hobbys mediáticos devienen en oportunidades de profesionalización para los jóvenes, y en oportunidades de beneficio económico para las industrias. Se detectan tres ámbitos de profesionalización: videojuegos, escritura creativa y redes sociales con sus propias dinámicas con respecto al género de los adolescentes y los recursos y plataformas utilizados. Los adolescentes que emprenden procesos de profesionalización son una minoría y, 
dentro de este grupo, es fundamental fortalecer las competencias que les permitan comprender en qué medida su trabajo beneficia económicamente a las compañías de comunicación.

Usos del WhatsApp en el estudiante universitario español. Pros y contras, es el título de la propuesta de Joan-Francesc FondevilaGascón, Joaquín Marqués-Pascual, Pedro Mir-Bernal y Marc PoloLópez. El objetivo de la investigación es analizar de qué manera impacta el uso de los servicios de mensajería instantánea en el entorno universitario español y qué consecuencias positivas y negativas genera en el comportamiento estudiantil. El texto se enfoca en determinar el uso que se les da a los mensajes de texto convencionales, así como a otras opciones de la mensajería instantánea (como puede ser la voz o las imágenes). Asimismo, se analizaron algunos impactos en el entorno académico como, por ejemplo, el posible estrés que genera en el comportamiento humano. En los resultados, destacan la comodidad y la gratuidad de WhatsApp que impulsan su uso en el entorno educativo. Se constata que la mayoría de los estudiantes utiliza este tipo de aplicaciones de mensajería instantánea también para cuestiones relacionadas con los asuntos universitarios -aparte de su vida personal-. Los autores observan que un porcentaje muy alto de los grupos analizados pertenece a algún chat grupal relacionado con los estudios o está incluido en grupos de conversación sobre materias académicas.

¿Cómo interactúan los adolescentes con los videojuegos? Preferencias y habilidades performativas es la pregunta que motiva el título de la colaboración de Juan-Manuel Muñoz-González y Blas Segovia Aguilar. En este estudio se analiza la influencia de los videojuegos en procesos de socialización de adolescentes, en especial el desarrollo de hábitos de seguridad, dedicación y preferencias de uso de menores españoles de 12 a 17 años. Los principales resultados muestran que los adolescentes españoles presentan una actitud de indiferencia en cuanto a la adopción de hábitos de seguridad en el consumo de videojuegos. Los autores constatan que los chicos están más motivados en el uso de videojuegos que las chicas y proponen algunas claves para estudiar las causas por las que se dan este tipo de preferencias. 
Todas las contribuciones construyen un volumen novedoso, original y actual, rico en reflexiones e ideas impregnadas de recorrido futuro. Esperamos que el lector descubra su utilidad y encuentre espacios sugerentes de investigación.

\section{Referencias}

Marta Lazo, C., \& Gabelas Barroso, J. A. (2013). Intermetodología educomunicativa y aprendizaje para la vida. Comein. Revista de los estudios de Ciencias de la Información y Comunicación, 22.

Toffler, A. (1980). La tercera ola (A. Martín, trad.). Barcelona: Plaza \& Janés. 


\title{
La fuga de los millennials de la televisión lineal
}

\author{
Enrique Guerrero Pérez \\ Universidad de Navarra (España) eguerrero@unav.es
}

Cómo citar: Crespo-Pereira, V. (2018). La fuga de los millennials de la televisión lineal. En V Tur-Viñes/M J González-Río/R S Contreras-Espinosa (Eds.) Jóvenes / Medios y cultura colaborativa. Cuadernos Artesanos de Comunicación, cac157, pp 15-31. La Laguna (Tenerife): Latina. DOI: $10.4185 /$ cac157

\begin{abstract}
s
Introducción. La televisión pasa por un momento histórico debido al importante proceso de transformación en el que se encuentra, derivado de la convergencia con internet y de las cualidades disruptivas de las innovaciones tecnológicas. Metodología. Este artículo analiza la evolución del consumo televisivo lineal de la llamada generación millennial en comparación con el total de la audiencia y el impacto que en esta actividad tiene el visionado online. También se aborda el perfil de público y la afinidad de este target con los canales de los principales operadores comerciales de televisión en España. Para ello se combinan metodologías cuantitativas - datos de audimetría de Kantar Media y una encuesta online original sobre consumo audiovisual a una muestra representativa de la población internauta española- y cualitativas entrevistas semiestructuradas a responsables de estrategia digital de los principales grupos televisivos privados y de una multichannel network-. Resultados y conclusiones. Los resultados confirman el trasvase de audiencias y la fuga del público joven $-\mathrm{y}$ de sus ingresos asociadoshacia otros servicios de entretenimiento audiovisual más
\end{abstract}


personalizables e interactivos. Como consecuencia, los operadores de televisión reconocen estar poniendo en práctica nuevas estrategias que afectan a la esencia de su negocio y de su identidad.

\section{Keywords}

televisión; internet; audiencias; hábitos audiovisuales; millennials.

\section{Contents}

1. Introducción. 2. Metodología. 3. Resultados. 3.1. Evolución del consumo televisivo. 3.2. Perfil de público de los canales de televisión y afinidad. 3.3. La transformación de los operadores de televisión: youtubización. 4. Conclusiones. 5. Agradecimientos. 6. Referencias.

\section{Introducción}

L

A INNOVACIÓN tecnológica siempre ha tenido un impacto de calado en el sector del entretenimiento audiovisual, tanto desde la perspectiva del guion -narrativa trasnmedia- (Scolari, 2013) como de la producción (Francés, 2015), distribución, comercialización (Doyle, 2016) y consumo. Así, por ejemplo, la convergencia digital ha dado como fruto la fusión de tres grandes industrias que previamente eran independientes: la audiovisual, la informática y la de telecomunicaciones (López Villanueva, 2011). En concreto, de la fusión de la televisión e internet ha surgido un nuevo modelo televisivo online e interactivo que permite un consumo personalizado a través de una amplia variedad de pantallas (Diego, Guerrero y Etayo, 2014). El visionado conectado implica una experiencia global de entretenimiento multiplataforma derivada de la convergencia de la tecnología digital, las redes sociales y los medios convencionales (Holt y Sanson, 2014).

La televisión vive una etapa histórica de su evolución caracterizada por: a) un aumento muy significativo de la oferta de contenidos; b) el acceso a ellos a través de múltiples dispositivos conectados (fijos y móviles); y c) el surgimiento de disruptivos hábitos de consumir los contenidos que potencian la personalización e interactividad. Por ejemplo, la televisión social es una muestra fehaciente de ello (Gallego, 2013). De este modo, se convierte el visionado en una experiencia compartida a 
través las redes sociales y se generaliza el fenómeno de la segunda pantalla, revitalizándose el directo como ingrediente esencial del medio y el concepto de evento televisivo (Guerrero, 2015), compatible también con el auge del consumo de contenidos bajo demanda.

Algunos autores se refieren a esta nueva fase del medio, que pivota sobre un modelo mixto online y offline, como la era del post-broadcasting (Tse, 2016). Y otros incluso discuten que deba seguir denominándose "televisión" (Uribe-Jongbloed, 2016), pues la metamorfosis derivada de su fusión con internet es de tal calado, que parece razonable plantearse si no estamos ante un nuevo medio.

No obstante, no puede entenderse este cambio en toda su complejidad si no se tiene en consideración el contexto social en el que se inserta, una cultura convergente y participativa en la que los medios de comunicación comparten el protagonismo con audiencias activas (Jenkins, 2006a y b). En este marco, destaca el rol desempeñado por los sectores más jóvenes de la población, pioneros en el uso de las novedades tecnológicas y en la consolidación de las nuevas formas de consumo audiovisual (González y López, 2011). Estos cambios implican la conversión del clásico telespectador en programador y productor de contenidos, es decir, en consumidor y creador al mismo tiempo (crossumer) (Romero y Gil, 2008).

En este sentido, destaca especialmente el rol desempeñado por el público millennial, también conocido con otras etiquetas como nativos digitales, Net generation -en alusión al impacto de internet y la tecnología digital en su desarrollo personal- (Tapscott, 2009), generación "Me" por su visión egocéntrica- (Torrado, Ródenas y Ferreras, 2011), o generación $\mathrm{C}$-en referencia a conceptos relevantes para este público que comienzan por la letra "C" como los contenidos y la creatividad entre otros- (Hardey, 2011).

Tradicionalmente, la segmentación de la población por generaciones ha seguido un patrón de clasificación por rangos de edad (Ferguson y Green, 2016) en función de las experiencias compartidas. Sin embargo, en esta ocasión, la pertenencia a esta generación no viene tanto determinada por la edad -véase por ejemplo el caso de aquellas denominadas con las letras $\mathrm{X}$ o $\mathrm{Y}$-, como por haber crecido en un mundo construido en torno a las tecnologías digitales (Hardey, 2011). 
Por este motivo, las edades exactas que comprende la generación millennial cambian de un autor a otro, aunque existe cierto consenso en considerar que los pertenecientes a este segmento de la audiencia nacieron entre principios de la década de los 80 y mediados o finales de los 90 -algunas fuentes incluso incluyen a personas nacidas a finales de los 70 (New Strategies Editors, 2012)-. Es evidente, por tanto, que nos encontramos ante un grupo de población diverso, muy heterogéneo (Álvarez Monzoncillo y López Villanueva, 2017). Hardey (2011) destaca tres aspectos distintivos de este grupo poblacional:

a) La conexión a medios digitales desde cualquier lugar.

b) El vínculo entre el contenido generado por el usuario y las redes sociales.

c) La creencia de que las experiencias, opiniones y recomendaciones de otros son la mejor garantía a la hora de tomar decisiones de compra.

Además, los millennials representan un target cuyas preferencias audiovisuales se extienden más allá de la oferta de contenidos profesionales. Debido a este motivo, los operadores de televisión han visto cómo este perfil de público ha sido seducido por la oferta de plataformas dominadas por contenido amateur o semiprofesional. El poder de servicios en línea como YouTube ha contribuido a la aparición de un nuevo perfil de productor: el youtuber. Cada vez más profesionalizado (Elorriaga y Monge, 2018), destaca como un auténtico reclamo para el público joven y para las marcas comerciales interesadas en este target, que se muestra escurridizo, y para el que los canales de televisión convencionales ya no son referentes ni resultan atractivos. Estas circunstancias han obligado a los operadores tradicionales a reinventarse para adaptarse a un entorno más competitivo, y a adoptar nuevas políticas estratégicas de producción y difusión de contenidos, que han tenido un impacto incluso en su identidad como medios y como empresas.

En este artículo se analiza la evolución del consumo de televisión del target millennial en comparación con el total de la audiencia, para analizar el perfil y la afinidad de público de los canales de televisión, y cómo esos hábitos de visionado afectan a las decisiones estratégicas de las empresas audiovisuales. 


\section{Metodología}

La metodología aplicada para abordar el objeto de estudio mencionado combina herramientas cuantitativas y cualitativas. Además, se ha revisado la bibliografía de referencia sobre el impacto de la innovación tecnológica en los hábitos de consumo de medios, la irrupción de nuevos agentes en la industria y en el mercado audiovisual, así como sobre el perfil del público millennial.

Respecto a las fuentes cuantitativas, en primer lugar, se han consultado los datos de la audimetría televisiva realizada por Kantar Media en España, y se ha analizado esa información con el software Instar Analytics. En concreto, se comparan los hábitos de visionado del total de la población (individuos de 4 años o más) con el target millennial (se ha optado por el margen de edad más amplio posible en función de los parámetros antes indicados, seleccionándose la población nacida entre 1980 y el año 2000). Además, el análisis se centra en los principales grupos de televisión privados, Atresmedia y Mediaset, y específicamente en sus canales que se han mantenido en emisión de manera ininterrumpida de 2013 a 2017.

En segundo lugar, se incluyen algunos resultados de un cuestionario online original lanzado en diciembre de 2016, y dirigido a la población internauta española en el contexto de un proyecto de investigación más amplio sobre hábitos de consumo audiovisual. Para ello, se ha partido de la definición de "internauta" de la AIMC (Asociación para la Investigación en Medios de Comunicación): usuarios entre 14 y 65 años que han accedido a internet al menos una vez durante el último mes. Sin embargo, para este trabajo solo se han tenido en cuenta las respuestas de quienes tenían entre 18 y 35 años de edad, y que podrían encuadrarse en la categoría de millennials. De esta forma, la muestra final se compone de 518 encuestados representativos de la población de referencia, con cuotas proporcionales preestablecidas por edad, sexo y región. El error muestral se estima en un 3,1\% - con supuestos de varianza máxima- y 95\% de confianza, obteniéndose una alta tasa de respuesta del cuestionario $(59,8 \%)$.

Esta información cuantitativa ha sido complementada, desde una perspectiva cualitativa, con aquella aportada por entrevistas semiestructuradas a los responsables de las plataformas online de los 
principales operadores de televisión comercial en España, Mediaset y Atresmedia, y a la directora de operaciones de una de las principales multichannel networks (MCN) de contenido en español, 2 btube.

Así el presente artículo aborda su objeto de estudio desde un planteamiento que combina metodologías cuantitativas y cualitativas, e implicando a todos los actores involucrados: usuarios, profesionales y expertos académicos.

\section{Resultados}

\subsection{Evolución del consumo televisivo}

El incremento de la oferta de canales de televisión, la situación de crisis económica o la celebración de importantes eventos deportivos, entre otros factores, contribuyeron a que, en 2012, en España, se batiera el récord histórico de consumo televisivo. De media, aquel año se vieron 246 minutos de televisión por persona y día según Kantar Media. Hasta entonces, el incremento del visionado audiovisual online parecía no restar minutos a la televisión convencional, y se apuntaba a una complementariedad total de pantallas (Guerrero, 2015). Sin embargo, el punto de inflexión lo encontramos en 2013, año a partir del cual el consumo televisivo lineal desciende de modo progresivo y generalizado hasta la actualidad, resultando especialmente acusado entre los públicos más jóvenes. En solo cinco años, el visionado de televisión se redujo en 21 minutos de media por persona y día, hasta quedarse en los 225 minutos en 2017 (tabla 1) -sin contabilizar el consumo diferido ni el de invitados en los hogares con audímetro, para poder analizar exactamente el mismo dato durante los años del presente estudio-. En contraste, en el lustro previo, de 2007 a 2012, esa misma cifra creció en 23 minutos, pasando de 223 minutos en 2008 al mencionado récord de 2012.

Este descenso del consumo de televisión tradicional coincide con la popularización de los reproductores en línea de catch-up TV de los principales operadores de televisión con su correspondiente aplicación (app): RTVE a la carta de RTVE, Atresplayer de Atresmedia y Mitele de Mediaset. Entre 2011 y 2013 consolidan su oferta multiplataforma y online, en un periodo en el que la audimetría solo contabilizaba el consumo lineal en el televisor tradicional, pues no fue hasta 2015 cuando Kantar Media empieza a incluir en sus datos el visionado 
diferido de contenidos, aunque de modo muy limitado, pues solo se consideraba aquel realizado en televisores conectados (smart tv) y no en el resto de pantallas (por ejemplo, móviles o tabletas).

En 2014, se produce una eclosión de la televisión de pago en España debido a la inclusión de este servicio en las ofertas combinadas de móvil, fijo e internet de las empresas de telecomunicaciones. Así, por ejemplo, en marzo de ese año, se lanzó Movistar Fusión TV, movimiento que se reforzó en 2015 con la adquisición de Canal +, originando la marca Movistar+. Esta acción fue replicada posteriormente por importantes competidores como Vodafone u Orange. En buena medida, el atractivo de esas ofertas combinadas no se encontraba solo en el acceso a un listado de canales de televisión convencionales, sino en sus servicios de valor añadido asociados, como sus plataformas conectadas multidispositivo, que además de ofrecer el contenido televisivo, ampliaban su catálogo de vídeo bajo demanda con otros títulos. Con este movimiento, los propios operadores de televisión -gratuitos y de pago- lanzaron servicios que en cierto sentido competían con las emisiones lineales de sus canales, en un momento en el que, como ya se ha mencionado, buena parte de ese visionado aún no era tenido en cuenta por la audimetría.

Gráfico 1. Evolución de la media del consumo de minutos diarios de televisión lineal (Maud)

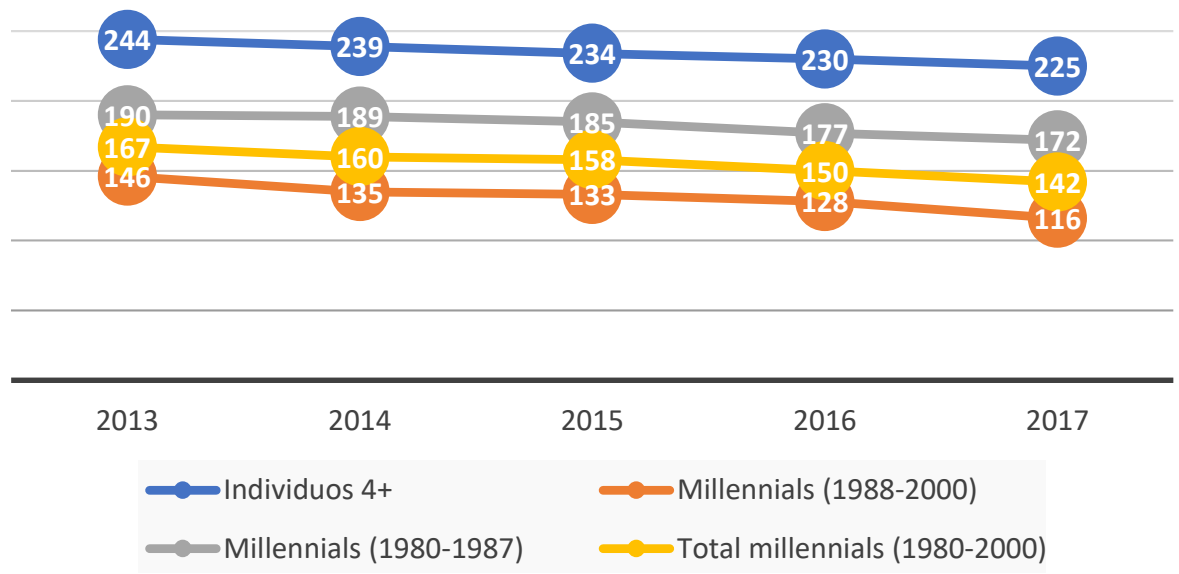

Fuente: Elaboración propia con datos de Kantar Media.

Nota: No se incluye el visionado en diferido ni el realizado por invitados.

Además, en 2015, irrumpe en España la oferta de nuevas plataformas de suscripción de vídeo bajo demanda (S-VOD u OTT [Over-The-Top 
Television]) como Netflix, a la que se sumaron, en 2016, HBO España y Amazon Prime Video, y Sky en 2017. A estos servicios hay que añadir los ya presentes en el mercado como Filmin o Rakuten TV (antes Wuaki TV), entre otros, y la presencia de populares plataformas para compartir vídeo online como YouTube. En consecuencia, el mercado español pasó, en tan solo unos años, de un estado de escasez a una situación de sobreoferta audiovisual.

Estas plataformas de visionado a la carta destacan como una opción muy atractiva para la generación conectada, pues les permite ser protagonistas de su propia dieta audiovisual en un contexto multipantalla: deciden qué, cómo, dónde y cuándo ver los contenidos. Sin embargo, si bien es cierto que se multiplican las ventanas de acceso al contenido, también lo es que se complica el reto de conseguir captar la atención de la audiencia por la condición multitarea de este público. Su atención frente a la pantalla está cada vez más fragmentada y, a su vez, es más intermitente, puesto que es compartida con otros dispositivos. Algunos estudios apuntan a que más del 60\% de quienes consumen contenidos online usan de modo habitual una segunda pantalla durante el visionado (Guerrero, Diego y Kimber, 2017). Así, por ejemplo, para los nativos digitales, ver la televisión mientras conversan a través de las redes sociales y de aplicaciones de mensajería -como WhatsApp-, o usar estos servicios en relación a los contenidos que se visionan, se ha convertido en una actividad habitual (Guerrero, Diego y Kimber, 2017). El objetivo no es otro que el de satisfacer la necesidad de sentirse siempre conectados (Dias y Teixeira-Botelho, 2016).

A continuación, nos vamos a centrar en cómo evoluciona el tiempo de visionado de la televisión tradicional, comparando a la población general con el target millennial. Desde 2013, como queda reflejado en el gráfico 1, decrece el consumo televisivo de un modo continuo y estable, sin descensos bruscos, en todos los públicos analizados.

La línea superior registra la evolución del tiempo de visionado del total de la población (individuos de 4 o más años). Las líneas inferiores reflejan el consumo del público millennial en su conjunto (nacidos entre 1980 y el año 2000), y en dos tramos: nacidos entre 1980 y 1987 (el último año del estudio tenían 30-37 años), y entre 1988 y 2000 (con 1729 años en 2017). La tabla 1 contiene esta misma información, pero 
con las cifras concretas desglosadas año a año durante el periodo 20132017.

Tabla 1. Evolución de la media del consumo de minutos diarios de televisión lineal (Maud)

\begin{tabular}{|c|c|}
\hline \multicolumn{2}{|l|}{2013} \\
\hline Individuos 4+ & 244 \\
\hline 13 a 25 años & 146 \\
\hline 26 a 33 años & 190 \\
\hline 13 a 33 años & 167 \\
\hline \multicolumn{2}{|l|}{2014} \\
\hline Individuos 4+ & 239 \\
\hline 14 a 26 años & 135 \\
\hline 27 a 34 años & 189 \\
\hline 14 a 34 años & 160 \\
\hline \multicolumn{2}{|l|}{2015} \\
\hline Individuos 4+ & 234 \\
\hline 15 a 27 años & 133 \\
\hline 28 a 35 años & 185 \\
\hline 15 a 35 años & 158 \\
\hline \multicolumn{2}{|l|}{2016} \\
\hline Individuos 4+ & 230 \\
\hline 16 a 28 años & 128 \\
\hline 29 a 36 años & 177 \\
\hline 16 a 36 años & 150 \\
\hline \multicolumn{2}{|l|}{2017} \\
\hline Individuos 4+ & 225 \\
\hline 17 a 29 años & 116 \\
\hline 30 a 37 años & 172 \\
\hline 17 a 37 años & 142 \\
\hline
\end{tabular}

Fuente: Elaboración propia con datos de Kantar Media.

Nota: Desde 2015, Kantar Media contabiliza el consumo diferido en smart TV, que es de 3 minutos diarios en 2015 y 2016, y de 4 minutos en 2017. Además, en este último año, también aporta el dato de visionado de invitados en los hogares con audímetro, que alcanza los 11 minutos al día. No obstante, en esta tabla, solo se contabiliza el 
consumo lineal y sin invitados para poder ver la evolución del mismo dato anualmente.

Como se desprende tanto del gráfico 1 como de la tabla 1, el consumo del público joven es notablemente inferior al del global de la población de forma mantenida en el tiempo. No obstante, su descenso es tan solo un poco más acusado que el del total de individuos, pues ambos reducen el tiempo de exposición a la televisión de un modo similar (las líneas descienden de modo paralelo), a excepción del último año, en el que se acelera esta tendencia. Si en 2013 el sector más joven de los millennials consumía 98 minutos menos al día que el individuo medio, en 2017 esta diferencia se incrementa hasta los 109 minutos, una cifra considerable. En general, cuanto más joven es el target analizado, menor es su visionado de televisión lineal.

Tabla 2. Influencia del visionado online en el consumo de televisión lineal (2016)

\begin{tabular}{lcc}
\hline & Millennials & Individuos 4+ \\
\hline $\begin{array}{l}\text { Sí afecta, veo más horas de TV } \\
\text { tradicional }\end{array}$ & $5,9 \%$ & $5,5 \%$ \\
\hline $\begin{array}{l}\text { Sí afecta, veo menos horas de TV } \\
\text { tradicional }\end{array}$ & $73,4 \%$ & $63,4 \%$ \\
\hline $\begin{array}{l}\text { No afecta, veo las mismas horas } \\
\text { de TV tradicional }\end{array}$ & $20,7 \%$ & $31,1 \%$ \\
\hline Total & $100 \%$ & $100 \%$ \\
\hline
\end{tabular}

Fuente: Elaboración propia.

En el periodo temporal estudiado, aún no se percibe ningún indicio de que pueda producirse un "efecto boomerang", es decir, no parece que los cambios en los hábitos de visionado sean una cuestión temporal motivada por la joven edad del público, de tal modo que cuando ese target envejezca, vuelva a consumir mayor tiempo de televisión convencional. Más bien, el patrón de consumo se mantiene en el tiempo, y conforme menos edad tiene la audiencia, menos minutos dedica a la televisión lineal. Así que no puede concluirse de momento que vaya a revertirse el cambio en las pautas de consumo audiovisual. En este sentido, si se mantiene la tendencia, es de esperar que el público de más edad, en un futuro próximo, consuma el contenido televisivo 
de un modo muy diferente a como lo hacen las personas mayores en la actualidad.

La tabla 2 evidencia que el visionado audiovisual online tiene un impacto directo en el tiempo dedicado a la televisión convencional, especialmente en el caso del target millennial. Más del 63\% de la población que ve contenidos en internet reconoce que dedica menos tiempo a la televisión por ese motivo. Esta cifra se dispara por encima del $73 \%$ en el caso de los millennials. Además, hay que tener en cuenta que, según datos de este mismo estudio, casi el total de usuarios menores de 25 años $(97,5 \%)$ reconoce ver contenidos online, y que esta cifra se mantiene por encima del $90 \%(92,6 \%)$ si se toma en consideración la población de menos de 35 años, mientras que la media de la población se sitúa en torno al 80\% (Guerrero, Diego y Kimber, 2017).

Algunas investigaciones previas, de autores como Jiyoung (2013), confirman también ese trasvase de audiencias del televisor tradicional a las pantallas conectadas y sus servicios audiovisuales en línea. En este sentido, no solo el contenido profesional disponible online en las plataformas de catch-up TV compite por el tiempo del público, también hay que tener en cuenta aquellos vídeos generados por los propios usuarios, pues un elevado porcentaje de los millennials visiona de modo habitual este tipo de contenidos en internet, rozando el $90 \%$ en el tramo entre los 18 y los 25 años de edad (tabla 3).

Tabla 3. Rango de edad de los millennials que ven vídeos en YouTube o similares (2016)

\begin{tabular}{cc}
\hline Entre 18 y 25 & $88 \%$ \\
\hline Entre 26 y 30 & $79 \%$ \\
\hline Entre 31 y 35 & $72 \%$ \\
\hline $\begin{array}{c}\text { Pearson Chi2(2) }=14,69 \text { p }=0,001 . \\
\text { Fuente: elaboración propia. }\end{array}$
\end{tabular}

Sin embargo, aunque la tendencia es descendente, el consumo televisivo lineal aún se mantiene en cifras elevadas (gráfico y tabla 1): casi cuatro horas de media al día por persona en el caso del total de la población; tiempo que se reduce a casi dos horas y media para el target 
millennial. En consecuencia, la televisión sigue destacando como una de las principales vías para hacer llegar contenidos a grandes audiencias a pesar de la compleja situación por la que atraviesa. No obstante, no todos los canales lineales presentan el mismo perfil de público.

\subsection{Perfil de público de los canales de televisión y afinidad}

Los grupos televisivos son empresas multimedia y multicanal. Desde 2005, con el relanzamiento de la Televisión Digital Terrestre (TDT) en España y la concesión de nuevas licencias, los principales operadores privados de televisión pasaron de tener un solo canal a varios. Desde la perspectiva de la programación, esto tuvo importantes consecuencias, no solo por el incremento de la oferta, sino también porque, en cierto sentido, los canales de un mismo grupo competían entre sí. Para minimizar este riesgo y ofrecer programaciones complementarias, los operadores optaron por la estrategia de segmentación de su oferta, dirigiendo cada canal a una serie de targets

diferentes. En consecuencia, el perfil de público de cada uno de ellos varía en función de variables como el sexo o la edad. La tabla 4 registra la evolución del perfil de los canales de los principales grupos audiovisuales privados en España, Mediaset y Atresmedia, que se han mantenido en emisión durante todo el periodo analizado (2013-2017). Para ello, se tiene en cuenta exclusivamente la edad como variable demográfica, considerándose por un lado el target de referencia (millennials nacidos entre 1980 y el año 2000), y por otro el resto de la población.

Si se comparan los perfiles de público de los diferentes canales de ambos grupos, se concluye que las cadenas que tienen un mayor porcentaje de millennials entre su audiencia son Neox -Atresmedia- y Factoría de Ficción (FDF) -Mediaset-. En el lado opuesto, La Sexta y Antena 3 en el caso de Atresmedia, y Telecinco y Energy de Mediaset -en este último canal se produce un descenso muy acusado del perfil millennial en los dos últimos años, motivado por principalmente por cambios en la programación-, son las ofertas con menor porcentaje de este target entre sus espectadores durante la mayor parte del periodo temporal estudiado. Si comparamos ambos grupos, considerando el conjunto de sus canales, Mediaset aventaja levemente a Atresmedia en público millennial. 
Tabla 4. Evolución del perfil de público de los canales de televisión de Mediaset y Atresmedia (edad)

\begin{tabular}{|c|c|c|c|c|c|c|c|c|c|c|c|c|}
\hline \multirow{2}{*}{2013} & \multicolumn{7}{|c|}{ Mediaset } & \multicolumn{5}{|c|}{ Atresmedia } \\
\hline & Telecinco & Cuatro & Boing & Divinity & Energy & FDF & Grupo & Antena 3 & La sexta & Neox & Nova & Grupo \\
\hline 13-33 años & 14,6 & 21,4 & 18,1 & 25,5 & 26,9 & 32,7 & 19,6 & 16 & 14,2 & 42,6 & 23,2 & 18,7 \\
\hline Resto & 85,4 & 78,6 & 81,9 & 74,5 & 73,1 & 67,3 & 80,4 & 84 & 85,8 & 57,4 & 76,8 & 81,3 \\
\hline \multirow{2}{*}{2014} & \multicolumn{7}{|c|}{ Mediaset } & \multicolumn{5}{|c|}{ Atresmedia } \\
\hline & Telecinco & Cuatro & Boing & Divinity & Energy & FDF & Grupo & Antena 3 & La sexta & Neox & Nova & Grupo \\
\hline 14-34 años & 15,5 & 21,2 & 17,9 & 21,2 & 25 & 32,1 & 19,7 & 15,9 & 15 & 40 & 20,4 & 18,5 \\
\hline Resto & 84,5 & 78,9 & 82,1 & 78,8 & 75 & 67,9 & 80,3 & 84,1 & 85 & 60 & 79,6 & 81,5 \\
\hline \multirow{2}{*}{2015} & \multicolumn{7}{|c|}{ Mediaset } & \multicolumn{5}{|c|}{ Atresmedia } \\
\hline & Telecinco & Cuatro & Boing & Divinity & Energy & FDF & Grupo & Antena 3 & La sexta & Neox & Nova & Grupo \\
\hline $15-35$ años & 16,8 & 19,4 & 18 & 20,3 & 22,7 & 31,3 & 19,7 & 15,9 & 15,4 & 37,3 & 19,9 & 18,3 \\
\hline Resto & 83,2 & 80,6 & 82 & 79,7 & 77,3 & 68,7 & 80,3 & 84,1 & 84,6 & 62,7 & 80,1 & 81,7 \\
\hline \multirow{2}{*}{2016} & \multicolumn{7}{|c|}{ Mediaset } & \multicolumn{5}{|c|}{ Atresmedia } \\
\hline & Telecinco & Cuatro & Boing & Divinity & Energy & FDF & Grupo & Antena 3 & La sexta & Neox & Nova & Grupo \\
\hline 16-36 años & 16,9 & 18,8 & 14,6 & 18,2 & 12,7 & 29,2 & 18,4 & 14,8 & 15 & 38,7 & 18,9 & 17,7 \\
\hline Resto & 83,1 & 81,2 & 85,4 & 81,8 & 87,3 & 70,8 & 81,6 & 85,2 & 85 & 61,3 & 81,1 & 82,3 \\
\hline \multirow{2}{*}{2017} & \multicolumn{7}{|c|}{ Mediaset } & \multicolumn{5}{|c|}{ Atresmedia } \\
\hline & Telecinco & Cuatro & Boing & Divinity & Energy & FDF & Grupo & Antena 3 & La sexta & Neox & Nova & Grupo \\
\hline 17-37 años & 15,2 & 19,2 & 15,4 & 18,5 & 12,9 & 29,2 & 17,7 & 14,4 & 14,1 & 36,4 & 18 & 17 \\
\hline Resto & 84,8 & 80,8 & 84,6 & 81,5 & 87,1 & 70,8 & 82,3 & 85,6 & 85,9 & 63,6 & 82 & 83 \\
\hline
\end{tabular}

Fuente: Elaboración propia con datos de Kantar Media.

Nota: Se incluyen solo los canales de cada grupo que han estado en emisión durante los años que abarca el estudio. Se excluyen por tanto B Mad de Mediaset, y Atreseries y Mega de Atresmedia.

Esta conclusión, extraída de los perfiles de público, es confirmada por la afinidad, un índice usado habitualmente en la audimetría televisiva para analizar el grado de proximidad existente entre un canal o programa de televisión y un determinado tipo de público en función de sus intereses o gustos de visionado. Según Kantar Media, la afinidad se calcula dividiendo el rating del target de referencia -en este caso el público millennial- entre el rating del total de individuos, y multiplicando el resultado por 100. Si la cifra obtenida es 100 o superior, el target se considera afín. De este modo, cuanto mayor sea el resultado, más afín será el público seleccionado; y cuanto menor sea toda cifra resultante 
inferior a 100, menos afinidad tendrá ese sector de la audiencia respecto al canal o programa analizado.

Se ha calculado la afinidad del target de referencia (millennials), tanto en su conjunto como en dos tramos de edad -los mismos que en la tabla 1-, para los canales de Atresmedia y Mediaset con mayor y menor porcentaje de este tipo de público en su perfil (tabla 4) durante el periodo completo analizado (2013-2017). Así, la tabla 5 refleja el grado de afinidad con Telecinco, La Sexta, Neox y FDF.

Tabla 5. Evolución de la afinidad de los millennials a los canales de Mediaset y Atresmedia con mayor y menor perfil de público de este target

\begin{tabular}{|c|c|c|c|c|}
\hline \multicolumn{5}{|c|}{2013} \\
\hline & Telecinco & La Sexta & Neox & FDF \\
\hline 13 a 25 años & 49,3 & 40,7 & 191,7 & 147,3 \\
\hline 26 a 33 años & 69,3 & 75,7 & 147 & 112 \\
\hline 13 a 33 años & 58,7 & 57,1 & 170,8 & 130,8 \\
\hline \multicolumn{5}{|c|}{2014} \\
\hline & Telecinco & La Sexta & Neox & FDF \\
\hline 14 a 26 años & 52,4 & 39,1 & 163,4 & 140,9 \\
\hline 27 a 34 años & 72,5 & 83,2 & 155,2 & 113,5 \\
\hline 14 a 34 años & 61,8 & 59,8 & 159,5 & 128,1 \\
\hline \multicolumn{5}{|c|}{2015} \\
\hline & Telecinco & La Sexta & Neox & FDF \\
\hline 15 a 27 años & 59,2 & 40,8 & 151,8 & 134,4 \\
\hline 28 a 35 años & 76 & 84,5 & 145,2 & 114,2 \\
\hline 15 a 35 años & 67,1 & 61,5 & 148,7 & 124,8 \\
\hline \multicolumn{5}{|c|}{2016} \\
\hline & Telecinco & La Sexta & Neox & FDF \\
\hline 16 a 28 años & 61,50 & 42,2 & 157,4 & 121,5 \\
\hline 29 a 36 años & 74,4 & 80,1 & 151,2 & 110,2 \\
\hline 16 a 36 años & 67,5 & 59,8 & 154,4 & 116,2 \\
\hline \multicolumn{5}{|c|}{2017} \\
\hline & Telecinco & La Sexta & Neox & FDF \\
\hline 17 a 29 años & 53 & 38,3 & 131 & 117,1 \\
\hline 30 a 37 años & 67,8 & 75,3 & 158,1 & 112,7 \\
\hline 17 a 37 años & 59,9 & 55,6 & 143,6 & 115 \\
\hline
\end{tabular}

Fuente: Elaboración propia con datos de Kantar Media.

Estos datos ponen de relieve el bajo índice de afinidad que tienen los millennials con Telecinco y La Sexta, en contraste con el buen resultado obtenido por Neox y FDF. Esto es así especialmente entre el sector 
más joven del target de referencia, aunque su afinidad respecto a estos últimos canales haya también disminuido desde el primer al último año del estudio.

Se puede concluir, por tanto, que parte de la oferta televisiva lineal de los principales operadores en España sí que resulta de interés para los millennials. Su aceptable nivel de consumo televisivo -algo inferior a las dos horas y media al día- y la afinidad a determinados canales demuestran que aún siguen encontrando en la televisión convencional su propio reducto. Sin embargo, los datos aquí recogidos también ponen en evidencia el trasvase de audiencias del televisor tradicional a otras pantallas conectadas y la fuga de los públicos más jóvenes, que han modificado sus hábitos de visionado y que encuentran en internet ofertas competidoras que les resultan más atractivas. Ante esta situación, ¿cómo han reaccionado las empresas televisivas?

\subsection{La transformación de los operadores de televisión: youtubización}

La innovación tecnológica ha propiciado la convergencia de la televisión e internet, obligando a los principales agentes del sector televisivo a adaptarse a un nuevo ecosistema hiperconectado y multipantalla, y a reposicionarse como marcas de referencia en un mercado audiovisual con más competidores.

La relación de los principales canales y productores de contenidos audiovisuales con algunos de ellos, como YouTube, nunca ha sido fluida, y ha estado plagada de numerosos conflictos por incumplimientos del copyright (Kim, 2012). Aunque YouTube fue lanzada como una plataforma para compartir vídeos producidos por los usuarios, desde sus inicios, tanto sus creadores originales como Google -tras su adquisición- mantuvieron el objetivo de convertirla en un medio de contenido profesional que compitiera con las principales empresas televisivas (Kim, 2012). El principal motivo por el que optó por comenzar por el producto amateur es porque así podía crecer rápidamente tanto en catálogo como en audiencia. El objetivo no era otro que el de alcanzar, como mínimo, una audiencia similar a la de los canales de televisión para, a partir de ahí, comercializar también contenido profesional de los grandes productores (Vonderau, 216). Sin embargo, los principales proveedores de vídeos profesionales siempre 
han mantenido una política restrictiva en este sentido, obligando a YouTube a lanzar su propio servicio de contenido premium bajo suscripción -Red-(Cunningham, Craig y Silver, 2016).

En la práctica, YouTube se ha convertido en un competidor más entre los operadores de televisión, basando su modelo de negocio en los ingresos publicitarios, en vez de destacar como una auténtica alternativa (Cunningham, Craig y Silver, 2016).

Al mismo tiempo que YouTube aspiraba a contar con un catálogo relevante de contenido profesional, los operadores de televisión iniciaron un proceso inverso de youtubización, imitando las estrategias de la plataforma de Google (Kim, 2012). Ante la fuga detectada de público joven, que reconoce que consume menos televisión tradicional debido a la mayor oferta audiovisual online (tabla 2), y dada la escasa rentabilidad proporcionada por el revenue share instaurado por Google, que no distingue entre contenido profesional y amateur (Vonderau, 2016), los grupos televisivos optaron por poner en marcha sus propias plataformas online dedicadas al contenido producido por youtubers: Flooxer (2015) de Atresmedia y mtmad (2016) o Yasss (2017) de Mediaset. De este modo aspiraban a llegar, al menos en parte, a ese target joven al que no logran atraer con la televisión tradicional, y a captar parte de la inversión publicitaria destinada a internet. En un movimiento similar, el operador público, Televisión Española (TVE), lanzó en 2017 Playz, su plataforma digital para contenidos transmedia e interactivos dirigidos a un perfil joven, aunque en esta ocasión el catálogo se componía íntegramente de contenido de factura profesional producido exclusivamente para el medio online.

Ana Bueno, directora de contenidos multimedia de Mediaset España, confirma que el contenido disponible en mtamd nace directamente para internet, y que responde a un formato de vídeo más "corto, rápido y fresco", aunque siempre "muy cuidado" - a diferencia de YouTube. Y añade que va dirigido especialmente a la generación millennial y a la que le sigue, la llamada generación $\mathrm{Z}$, aunque también a otros públicos, dado que el cambio en los hábitos de visionado se ha extendido ya a otras edades.

Desde Atresmedia, Rubén Vara, director de marketing y audiencias multimedia, define Flooxer como "una plataforma de vídeo corto y 
premium, muy orientada a los nativos digitales, a los millennials". A diferencia de YouTube, donde caben todo tipo de propuestas, ellos apuestan por "contenidos variados, que creen marca, que permitan asociar a Flooxer una serie de valores basados en la calidad y el respeto a la audiencia, y que ofrezca un entorno seguro a los anunciantes". Su primer eslogan, "acostúmbrate a lo bueno", incidía en este mensaje. Según su testimonio, las razones principales por las que un grupo televisivo lanza un servicio al estilo de YouTube son las siguientes:

1) El incremento exponencial del consumo de vídeo online.

2) El nacimiento de un nuevo modo de entretenimiento audiovisual y de nuevos creadores de contenidos en internet.

3) La necesidad de mejorar la rentabilidad de los vídeos producidos para el medio online, dado el escaso margen ofrecido por YouTube a sus socios profesionales.

4) El crecimiento del visionado de contenidos audiovisuales en movilidad.

En definitiva, según Vara, Flooxer es una plataforma complementaria de la televisión lineal y de su servicio de catch-up TV, Atresplayer, que a diferencia de Flooxer, está especializado en contenido televisivo y de extensa duración. No compiten, por tanto, ni por contenidos, ni por la audiencia. Así pues, aunque durante el prime time televisivo el visionado de este tipo de productos también es elevado, su consumo preferente tiene lugar en "micro-momentos" como los traslados o las esperas durante las horas centrales del día. Además, tampoco se busca un trasvase de audiencia de un medio a otro.

En este contexto, surge un nuevo agente en la industria audiovisual: las multichannel networks. Las MCN son agregadores de contenidos intermediarios que gestionan un amplio catálogo de canales de youtubers -dirigidos a nichos de público-, y que a cambio de un porcentaje de los ingresos generados por publicidad, ofrecen a los creadores de contenidos servicios de producción, comercialización, análisis de datos, representación, gestión del talento, marketing, relaciones públicas e, incluso, formación -con el objetivo de profesionalizar la figura del youtuber- (Cunningham, Craig y Silver, 2016; Vonderau, 2016). Aunque las MCN gestionan una mínima parte del contenido 
disponible en YouTube, dado el proceso de profesionalización indicado, es el más valioso y el que cuenta con más suscriptores, el público de mayor fidelidad (Vonderau, 2016). Tal es así, que tanto YouTube, a través de iniciativas como YouTube Spaces, como los operadores de televisión convencionales han decidido también ejercer este papel de intermediación entre los creadores de contenidos, las marcas y la audiencia, produciéndose un fenómeno de integración vertical.

Blanca Formáriz, directora de operaciones de una de las principales MCN de contenido en español, 2btube, confirma que el origen de las MCN se debe a múltiples factores, destacando los siguientes:

1) La fuga del público joven de la televisión convencional obliga a las marcas a buscar medios alternativos a través de los cuales alcanzar este target.

2) El creador de contenidos o youtuber establece un vínculo emocional muy fuerte con sus seguidores, de tal modo que destaca como un gran prescriptor. Esta cualidad los convierte en una figura especialmente relevante para los anunciantes.

3) El incremento exponencial de la inversión publicitaria en medios digitales.

Además, Formáriz también confirma que la actividad de las MCN va más allá de la relación con YouTube y con otras plataformas para compartir vídeos en internet, y hace mención a acuerdos con los principales grupos televisivos. En este sentido, el objetivo es, no tanto trasvasar audiencias, como "construir puentes" entre los universos de la televisión convencional y los servicios audiovisuales en línea, especialmente en el caso de aquellos contenidos dirigidos a la población más joven.

Todo ello apunta a que la industria audiovisual online se encuentra en un momento crucial, al ser un sector en crecimiento y en maduración, en el que todos los participantes intentan asumir roles propios de otros agentes, en un proceso de búsqueda de su identidad y de su viabilidad. Para referirse a este contexto, algunos autores han acuñado el concepto de "nueva ecología de pantallas" (Cunningham, Craig y Silver, 2016). Otros apuntan incluso a una burbuja del vídeo (Vonderau, 2016), ante la creciente oferta audiovisual en línea, al sumarse a YouTube y los 
operadores de televisión convencionales, plataformas de vídeo bajo demanda como Netflix, Amazon Prime Video, HBO o Sky. A todo ello hay que añadir la irrupción de otras poderosas empresas tecnológicas como Apple o Facebook en el negocio audiovisual, que cuentan no solo con una amplia cartera global de usuarios, sino también con una fortaleza financiera difícil de igualar.

\section{Conclusiones}

El sector del entretenimiento audiovisual, y más en concreto el televisivo, se encuentra en un momento histórico y crucial para su futuro. Los retos planteados por la disruptiva innovación tecnológica y, sobre todo, por los hábitos audiovisuales de los sectores más jóvenes de la audiencia han impulsado la transformación de los principales agentes que intervienen en la industria y en el mercado audiovisual. Los operadores de televisión hace tiempo que dejaron de ser medios de comunicación televisivos monocanales para convertirse en polifacéticas empresas multimedia de contenidos audiovisuales, que compiten con todo tipo de productos relacionados con el entretenimiento.

Los sectores más jóvenes de la población -millennials y generaciones venideras de menor edad- muestran un comportamiento audiovisual que prioriza los servicios siempre conectados y personalizables, frente a las ofertas rígidas y cerradas. Se sienten atraídos por aquellos productos que les otorgan un papel activo, no solo como consumidores, sino también como programadores y productores, situándoles en el núcleo de las historias que les interesan.

La fuga de este perfil de público de la televisión lineal, la popularización de todo tipo de dispositivos conectados desde los que acceder en cualquier momento y lugar a contenidos audiovisuales, el nacimiento de nuevos y pujantes competidores, y el crecimiento de la inversión publicitaria online han obligado a las empresas de televisión a replantear sus estrategias, su oferta e, incluso, su identidad.

Los datos aquí recogidos demuestran un descenso notable y constante en el consumo televisivo tradicional -casi 20 minutos menos de visionado por persona y día en el periodo analizado-, especialmente acusado en el caso del público joven -media hora menos en tan solo cinco años-, abriéndose una brecha generacional. Los millennials ven 
casi una hora y media menos de televisión al día que el telespectador promedio. A su vez, más del $90 \%$ ve de modo habitual contenidos audiovisuales online, cifra que se dispara casi al 100\% en el tramo de la audiencia cuya edad es inferior a los 25 años. Además, más del 70\% del target analizado reconoce que el visionado en internet tiene un impacto directo en el consumo de televisión lineal, que se ve considerablemente reducido.

Si bien los perfiles de público y afinidad permiten concluir que hay canales televisivos lineales que aún interesan a este sector del público, no es menos cierto que la afinidad de los millennials con los grandes operadores comerciales de televisión en España es bastante baja según los datos de audimetría de Kantar Media. Tal es así, que los programadores llegan incluso a no dar prioridad a este segmento del público a través de sus canales convencionales, envejeciendo la edad de su audiencia conscientemente mediante decisiones de programación.

Ante esta realidad, y puesto que no hay evidencias que indiquen que el público joven cambiará sus hábitos audiovisuales para volver a la televisión lineal, los operadores de TV han iniciado un proceso estratégico de reconversión. Así han expandido el núcleo de su negocio para abrazar todo tipo de productos y servicios relacionados con el entretenimiento audiovisual y el arte de contar historias, programando cada contenido en su ventana adecuada, y alcanzando cada target en la pantalla oportuna y en el momento certero, sin que trasvasar audiencias de un dispositivo a otro sea el objetivo prioritario. Televisión e internet se han fusionado para siempre dando como fruto un modelo audiovisual transmedia, interactivo, siempre conectado, personalizable y de oferta amplia, auspiciado por un público joven y ávido de protagonismo.

El negocio del entretenimiento audiovisual cambia a un ritmo vertiginoso y se enfrenta a retos inciertos. La incipiente irrupción en el sector de grandes gigantes tecnológicos abre aún más interrogantes en una industria y en un mercado pujantes, aunque a la vez de alto riesgo. 
- Este artículo es producto del proyecto de investigación "Identificación de los motivos de consumo de los contenidos audiovisuales de ficción y entretenimiento en el mercado español", financiado por el Ministerio de Economía y Competitividad del Gobierno de España, durante el periodo 2016-18 (CSO2015-64615-R).

\section{Agradecimientos}

Se agradece la colaboración en el tratamiento de los datos presentados en este artículo a: Sandra Martínez y Nerea Guerediaga (Kantar Media, España), David Kimber (Universidad de los Andes, Chile) y Begoña Campo (alumna colaboradora).

\section{Referencias}

Álvarez Monzoncillo, J.M. y López Villanueva, J. (2017).

"Entretenidos, dispares, participativos, empoderados, vigilados y furtivos" en Álvarez Monzoncillo, J.M. y de Haro, G. (2017). Millennials. La generación emprendedora. Barcelona: Ariel y Fundación Telefónica.

Cunningham, S., Craig, D. y Silver, J. (2016). "YouTube, multichannel networks and the accelerated evolution of the new screen ecology". Convergence, 22(4), 376-391. DOI: $10.1177 / 1354856516641620$.

Dias, P. y Teixeira-Botelho, I. (2016). "Multi-screening: Prácticas emergentes, motivaciones y expectativas", Redes.com, (13), 273291.

Diego-González, P., Guerrero-Pérez, E. y Etayo-Pérez, C. (2014).

"Televisión conectada en España: contenidos, pantallas y hábitos de visionado". Revista Mediterránea de Comunicación, 5(1), 179-199. DOI 10.14198/MEDCOM2014.5.1.10.

Doyle, G. (2016). "Digitization and changing windowing strategies in the television industry: negotiating new windows on the world". Television and New Media, 17(7), 629-645. DOI $10.1177 / 1527476416641194$.

Elorriaga Illera, A. y Monge Benito, S. (2018). "La profesionalización de los Youtubers: el caso de Verdeliss y las marcas". Revista Latina de Comunicación Social, 73, 37-54. DOI: 10.4185/RLCS2018-1244. 
Ferguson, D. A. y Greer, C. F. (2016). "Reaching a moving target: How local TV stations are using digital tools to connect with generation C'. International Journal on Media Management, 18(3-4), 141-161. DOI: 10.1080/14241277.2016.1245191.

Francés i Domènec, M. (2015). "Hacia un nuevo consumo audiovisual: TV e Internet" en Francés i Domènec, M., Llorca Abad, G. y Peris Blanes, A. La televisión conectada en el entorno transmedia. Pamplona: Eunsa.

Gallego, F. (2013). "Social TV analytics: nuevas métricas para una nueva forma de ver televisión". index. comunicación, 3(1), 13-39.

González Aldea, P. y López Vidales, N. (2011). "La generación digital ante un nuevo

modelo de televisión: contenidos y soportes preferidos". Anàlisi, 44, 31-48.

Guerrero, E. (2015). "Un laberinto de pantallas para cautivar al público" en Medina, M. La audiencia en la era digital. Madrid: Fragua.

Guerrero, E., Diego, P. y Kimber, D. (2017). “Hooked on lit screens". El profesional de la información, 26(6), 1108-1117. DOI 10.3145/epi.2017.nov.10.

Hardey, M. (2011). "Generation C. Content, creation, connections and choice". International Journal of Market Research, 53(6), 749770. DOI 10.2501/IJMR-53-6-749-770.

Holt, J. y Sanson, K. (2014). Connected Viewing. Selling, Streaming \& Sharing Media in the Digital Era. New York: Routledge.

Jenkins, H. (2006a). Convergence Culture: Where Old and New Media Collide. New York: New York University Press.

Jenkins, H. (2006b). Fans, Bloggers, and Gamers: Exploring Participatory Culture. New York University Press.

Jiyoung, C. (2013). "Do online video platforms cannibalize television? How viewers are moving from old screens to new ones". Journal of advertising research, 53(1), 71-82. DOI:10.2501/JAR-53-1-071082 .

Kim, J. (2012). "The institutionalization of YouTube: From usergenerated content to professionally generated content". Media Culture \& Society, 34(1), 53-67. DOI:

10.1177/0163443711427199. 
López Villanueva, J. (2011). “La reconfiguración de la cadena de valor" en Álvarez Monzoncillo, J.M. La televisión etiquetada: nuevas audiencias, nuevos negocios. Barcelona: Ariel.

New Strategist editors (2012). Millennials: Americans born 1977 to 1994.

Ithaca: New Strategist, 2012.

Romero, F. y Gil, F. (2008). Crossumer, claves para entender al consumidor español de nueva generación. Madrid: Ediciones Gestión 2000.

Scolari, C. (2013). Narrativas transmedia: cuando todos los medios cuentan. Barcelona: Deusto.

Tapscott, D. (2009). Grown up digital: How the net generation is changing your world. New York: MacGraw-Hill Professional.

Torrado, S., Ródenas, G. y Ferreras, J.G. (2011). Yo, mí, me, conmigo. El triunfo de la Generation Me en los discursos comunicacionales. Sevilla, Zamora, Salamanca: Comunicación Social.

Tse, Y. (2016). “Television's changing role in social togetherness in the personalized online consumption of foreign 'TV'. New Media \& Society, 18(8), 1547-1562. DOI: $10.1177 / 1461444814564818$.

Uribe-Jongbloed, E. (2016). "El cambio mediático de la televisión: Netflix y la televisión en teléfonos inteligentes". Palabra Clave, 19(2), 358-364. DOI: 10.5294/pacla.2016.19.2.1.

Vonderau, P. (2016). "The video bubble: Multichannel networks and the transformation of YouTube”. Convergence, 22(4), 361-375. DOI 10.1177/1354856516641882.

\section{Otras fuentes}

Kantar Media (2012-2017). Datos de audimetría televisiva en España.

\section{Entrevistas}

Ana Bueno, directora de contenidos multimedia de Mediaset España, 02/12/2016.

Blanca Formáriz, directora de operaciones de 2btube, 23/11/2016.

Rubén Vara, director de marketing y audiencias multimedia de Atresmedia, 24/11/2016. 



\title{
Uso de Twitter en los MOOC: Nuevas formas de interacción juvenil y su influencia en el aprendizaje
}

Carmen Marta-Lazo - Universidad de Zaragoza, España cmarta@unizar.es

Diana Valero - Universidad Antonio de Nebrija. dvalero@nebrija.es José Antonio Gabelas Barroso - Universidad de Zaragoza, España jgabelas@unizar.es

Cómo citar: C Marta-Lazo, D Valero-Errazu, J A Gabelas Barroso (2018): "Uso de Twitter en los MOOC: Nuevas formas de interacción juvenil y su influencia en el aprendizaje. En V Tur-Viñes/M J González-Río/R S ContrerasEspinosa (Eds.) Jóvenes / Medios y cultura colaborativa. Cuadernos Artesanos de Comunicación, cac157, pp 39-61. La Laguna (Tenerife): Latina. DOI: $10.4185 / \operatorname{cac} 157$

\begin{abstract}
s
Este artículo analiza las nuevas formas de interacción de los jóvenes dentro de un entorno de aprendizaje no formal, en la enseñanza a través de MOOC. El objetivo es identificar la influencia de la retroalimentación a través de Twitter en el aprendizaje de los estudiantes. Metodología: en primer lugar, se realiza un análisis de regresión múltiple para determinar qué factores tienen mayor efecto sobre el aprendizaje y, posteriormente, determinar en qué medida influye la retroalimentación, tanto dada como recibida, en diferentes variables: compromiso, motivación, participación, disfrute/satisfacción, autoevaluación y resultados de aprendizaje, mediante un contraste de medias por segmentos. Resultados: se constata que dar retroalimentación a través de Twitter influye
\end{abstract}


positivamente en el aprendizaje, mientras que recibirlo pasivamente no obtiene resultados concluyentes. Discusión y conclusiones: tanto la motivación y la participación de los estudiantes como la satisfacción con el uso del diálogo de Twitter tienen un efecto positivo sobre el aprendizaje.

\section{Keywords}

Twitter; MOOC; Retroalimentación; Interacción; Engagement, Aprendizaje colaborativo.

\section{Contents}

1. Introducción. 1. 1. La interacción y la retroalimentación como parte del aprendizaje activo. 1.2. Twitter como herramienta educativa. 2. Metodología. 2.1. Hipótesis. 2.2. Características de la muestra y obtención de los datos. 2.3. Medición de las variables. 3. Resultados. 3.1. Análisis factorial exploratorio y de fiabilidad sobre las variables exógenas y endógena. 3.2. Análisis de regresión múltiple. 4. Conclusiones. 5. Bibliografía

\section{Introducción}

— L USO de las redes sociales es cada vez mayor, especialmente penetración de las redes en España alcanzó un 86\% (Statista, 2018), siendo Facebook y Twitter las más usadas. Esto implica nuevas formas de lenguaje y de interacción con un importante potencial pedagógico.

Las redes sociales se incorporan cada vez más a la pedagogía como un medio para el aprendizaje colaborativo en línea. En relación con Twitter, una de las redes más utilizadas, como lo señalan algunas investigaciones, el microblogging tiene el potencial de fomentar la participación, el compromiso y una reflexión más profunda, así como el aprendizaje colaborativo en diferentes escenarios de aprendizaje (Gao, Luo y Zhang, 2012), incluso apareciendo como redes informales de apoyo entre pares en línea (Badge, Johnson, Moseley, \& Cann, 2012). Las posibilidades dialógicas y la autoría colectiva, con herramientas como Twitter, permiten un desarrollo multimedia interesante. "La premisa desde la cual comienza es crear espacios que faciliten la exploración, la participación, el análisis crítico y la 
producción individual y colectiva, todo con un componente destacado de recreación. Por lo tanto, la reflexión y la creación están interconectadas, teniendo en cuenta también la búsqueda del aprendizaje lúdico" (Marta-Lazo \& Gabelas Barroso, 2016: 144).

Al mismo tiempo, el aprendizaje individualista, en sentido unidireccional y conductista, ha cedido en las últimas décadas a un modelo constructivista en el que el alumno es el arquitecto y protagonista de su proceso formativo. Los nuevos medios y redes sociales han hecho posible llevar el paradigma de aprendizaje un paso más allá, siendo el conectivismo (Siemens, 2005) uno de los modelos más relevantes en las nuevas formas de aprendizaje. Igualmente, entre los factores más importantes en el aprendizaje destacan las relaciones que se establecen, tanto con los profesores como con los compañeros, que permiten un aprendizaje más horizontal y dialógico y en las que redes sociales como Twitter pueden ser utilizadas pedagógicamente.

Esta investigación tiene como objetivo analizar las razones por las cuales esta red social es interesante como una forma de generar retroalimentación significativa entre los estudiantes, teniendo en cuenta las siguientes variables: compromiso, motivación, participación, disfrute / satisfacción, autoevaluación y resultados de aprendizaje. Con este fin, seleccionamos un MOOC cuyo tema está totalmente adaptado a lo que deseamos estudiar, titulado "Comunicación y aprendizaje móvil", en el marco del "E-learning, Communication and Open-Data" (ECO), con la participación de 26 socios, incluidas universidades de diferentes países, como la Sorbona, Manchester, Zaragoza, Valladolid y el Politécnico de Lisboa, entre otros (Marta-Lazo, Frau-Meigs \& Osuna-Acedo, 2018).

\section{1. La interacción y la retroalimentación, como parte del aprendizaje activo}

El aprendizaje activo se define como "el resultado de un intento deliberado y consciente por parte del profesor para causar que los estudiantes participen abiertamente en una lección" (Pratton y Hales, 1986: 211). Este se refiere a las prácticas que involucran a los estudiantes en el proceso de aprendizaje e incluye técnicas donde los estudiantes hacen más que escuchar una conferencia pasivamente. El aprendizaje activo implica hablar y escuchar, escribir, leer y reflexionar, 
y puede mejorar los resultados sobre los formatos tradicionales (Knight y Wood, 2005; Yoder y Hochevar, 2005). De acuerdo con la teoría generativa de aprendizaje, los estudiantes aprenden mejor cuando participan en el procesamiento cognitivo activo (Mayer y Wittrock, 2006; Prince, 2004).

Uno de los más importantes beneficios del aprendizaje activo es el aprendizaje colaborativo, que ocurre cuando los estudiantes trabajan juntos en pequeños grupos hacia un objetivo común, la creación de significado, que exploran un tema o la mejora de las habilidades (Prince, 2004). El aprendizaje colaborativo se define como una filosofía de aprendizaje que involucra el intercambio de conocimientos, experiencias y la autoridad, en la que los estudiantes enseñan y aprenden unos de otros y desarrollan una interdependencia positiva (Panitz, 1999). Esto hace que aumente la capacidad de pensar críticamente (Angeli, Valanides, y Bonk, 2003) y los estudiantes se vean animados a participar en dar la respuesta, explicando y justificando su opinión (Garrison, Anderson, y Archer, 2001). En este contexto, los estudiantes se convierten en agentes activos en su proceso de aprendizaje y colaboran en la creación de su propio conocimiento, aumentando la probabilidad de que todos los miembros del grupo aprendan la materia y disminuyendo la de que sólo unos pocos estudiantes entiendan el material (Sóller, 2001).

Promover la interacción y la retroalimentación es crucial, ya que conduce a un aprendizaje más eficaz (Bannan-Ritland, 2002; Erickson y Siau, 2003), convirtiéndose en unas fuentes de éxito en la educación (Chou, 2003; Siau, Sheng, y Nah, 2006). En esta línea, Blasco et al. (2012) señalan que el aprendizaje colaborativo "ocurre cuando los estudiantes trabajan juntos en grupos pequeños hacia un objetivo común, crear significado, explorar un tema o mejorar las habilidades" (Blasco et al, 2012, p. 105). Surge bajo la idea de que la colaboración y la cooperación funcionan mejor para lograr ciertas competencias que la competencia entre estudiantes o el trabajo individual. Por ejemplo, el aprendizaje colaborativo desarrolla la capacidad de pensar críticamente (Angeli, Valanides y Bonk, 2003), porque se alienta a los estudiantes a participar dando la respuesta, explicando y justificando sus opiniones (Garrison, Anderson y Archer, 2001). 
Esto puede parecer más difícil de abordar en un contexto virtual, pero existe un acuerdo de que "una de las estrategias que debe desarrollarse con teleformación es el aprendizaje colaborativo y cooperativo, y esto inicialmente implica el empoderamiento de la creación de un sentido de comunidad entre los diferentes participantes, que serán al mismo tiempo la base de una comunidad virtual" (Cabero, 2006, p.8).

El aprendizaje colaborativo, tanto en persona como en línea, no es simplemente "trabajo en grupo", este trabajo debe alinearse para obtener 5 condiciones: interdependencia positiva (los estudiantes entienden y comparten que solo pueden lograr un resultado determinado si trabajan juntos); interacción de promoción (los estudiantes apoyan el aprendizaje de los demás); responsabilidad individual y grupal (los resultados individuales de los miembros del grupo deben reflejar el conocimiento del grupo, de modo que se alienta al grupo a apoyar en cada momento al miembro que necesita más ayuda y no a que cada miembro del grupo solo adquiera una parte del conocimiento); habilidades sociales (como comunicación o liderazgo), y; procesamiento grupal (intercambio y reinterpretación de información de forma colectiva y retroalimentaria) (Johnson, Johnson y Holubec, 2013).

Al tratar de aplicar estos 5 componentes, hay dos puntos principales: interacción y retroalimentación. Los estudiantes necesitan trabajar juntos, para interactuar, pero para hacerlo con éxito necesitan continuamente dar y recibir comentarios, tanto del maestro como de los compañeros.

Promover la interacción y la retroalimentación es crucial ya que conduce a un aprendizaje mejor y más efectivo (Bannan-Ritland, 2002; Erickson y Siau, 2003), convirtiéndolo en una fuente clave de éxito en la educación (Chou, 2003; Siau, Sheng y Nah, 2006). Este concepto ha sido considerado como uno de los principales problemas pedagógicos en el aula, especialmente para las clases más grandes y los cursos relacionados con la tecnología.

En la enseñanza virtual, la interacción se desarrolla mediante el uso de herramientas y redes virtuales que permiten el contacto no físico, en el sentido que sugiere el conectivismo (Siemens, 2005), con respecto a la distribución del conocimiento y al aprendizaje como un proceso de 
crecimiento en una comunidad virtual (Conole, Galley, \& Culver, 2011). En el presente análisis, el objeto de estudio es la interacción que se proyecta y establece durante el proceso de aprendizaje por parte de los estudiantes en un MOOC, utilizando la red social Twitter como herramienta de discusión y retroalimentación.

\subsection{Twitter como herramienta educativa}

Los usos de esta red social pueden ser positivos o negativos, dependiendo de cómo se utilice. "En este complejo entramado de interrelaciones, confluyen un gran elenco de oportunidades y amenazas, de manera exógena, y se advierten determinadas fortalezas y debilidades, en relación con la vertiente endógena" (Marta-Lazo, Gabelas \& Grandío, 2015: 72).

Desde el punto de vista positivo, se advierte que el efecto del aprendizaje en colaboración activa en el desempeño estudiantil es mayor cuando se combina con el uso de la tecnología (Stowell \& Nelson, 2007). Otros autores comparten este punto de vista sugiriendo que, cuando los estudiantes utilizan las tecnologías, incorporan un mayor índice de colaboración en su proceso de aprendizaje (Kryder, 1999). El crecimiento en el uso de la tecnología para promover el aprendizaje colaborativo ha atraído a un número cada vez mayor de estudios (Resta y Laferrière, 2007), que proporcionan colectivamente apoyo a la idea de que la tecnología mejora los procesos de aprendizaje (Kreijns, Kirschner, y Jochems, 2003).

Es evidente y está ampliamente aceptado que los métodos de aprendizaje tradicionales pueden obstaculizar las interacciones en el aula (Cotner, Fall, Wick, Walker, y Baepler, 2008). El limitado tiempo de clase, la disposición fija de los asientos y las reservas de los estudiantes sobre hablar en clase han sido identificados como barreras importantes frente a la interactividad en el aula (Draper y Brown, 2004; Liu, Liang, Wang, Chan, y Wei, 2003). Sin embargo, el avance de la tecnología ha cambiado la forma en que los estudiantes y el profesor interactúan en el aula, y ha proporcionado nuevas oportunidades para mejorar la interactividad.

Twitter es una poderosa herramienta para impulsar las Redes de Aprendizaje Personales (PLN), que conducen al llamado aprendizaje 
conectado o aprendizaje en red (Dirckinck-Holmfeld, Hodgson, \& McConnell, 2012; Tur \& Marin, 2015).

De acuerdo con la enumeración planteada por Duque, Pérez y Guevara (2012:29), son 5 las características que hacen que Twitter pueda utilizarse para la educación y el aprendizaje: La ágil interacción entre profesores y alumnos (Junco, 2010; Stepanyan et al., 2001); la superación de espacio físico y temporal para interactuar emitiendo, leyendo y recibiendo mensajes (Stie-ger y Burger, 2010); lo posibilidad de volver a esos mensajes emitidos, leídos y recibidos y su monitoreo (Ebner et al., 2010); el propio formato multimedia que facilita la comunicación y el aprendizaje (Grosseck y Holotescu, 2010).

Dentro de su uso en la educación, concretamente en educación superior, destacan las investigaciones en dos ámbitos, por un lado, aquellas que promueven la relación de los estudiantes con la institución y la imagen de ésta; por otro lado, las centradas específicamente en los beneficios educativos que tiene para el estudiante. En nuestro caso nos centramos en éstas últimas. Entre sus beneficios en el uso educativo destacan:

(1) Permite superar los límites físicos de la clase en la interacción con el profesorado, responder en tiempo real a los problemas de los estudiantes y difundir información actualizada del curso (Kassens-Noor, 2012; Ebner, Lienhardt, Rohs\& Meyer, 2010). Permite mayor conexión entre los estudiantes y el contenido del curso, promoviendo que el estudiante pase más tiempo en el curso y promoviendo mayores y más profundas discusiones sobre el contenido del curso entre los estudiantes (Domizi, 2013; Wright, 2010; Kassens-Noor, 2013).

(2) Promueve un mayor engagement con el curso, especialmente cuando el profesorado del curso también está involucrado (Junco, Elavsky \& Heiberger, 2013; Greenhow \& Robelia, 2009).

(3) Promueve una comunicación continua y transparente, facilitando la retroalimentación inmediata (Ebner, Lienhardt, Rohs\& Meyer, 2010).

(4) Permite un trabajo más flexible entre los compañeros, independientemente del espacio físico o temporal (Ebner, Lienhardt, Rohs\& Meyer, 2010). 
(5) Promueve la creación de una community of learners y la posibilidad de conectar con una red de profesionales que pone en práctica lo tratado en el curso, aumentando el sentido de comunidad y mejorando las posibilidades de construir relaciones y aumentar la comunicación (Lomicka \& Lord, 2012; Wright, 2010; Dunlap \& Lowenthal, 2009; Holo-tescu y Grosseck, 2010).

(6) Profundamente ligado con lo anterior, el uso de Twitter como herramienta educativa aumenta las interacciones sociales y las conexiones tanto entre los alumnos como con el profesorado, incluso promoviendo una conexión más allá de la académica (Muñoz, Pellegrini-Lafont \& Cramer, 2014; Dunlap \& Lowenthal, 2009).

(7) Para el profesorado permite la documentación del proceso (Ebner, Lienhardt, Rohs \& Meyer, 2010).

De igual forma que tiene unas importantes ventajas, la literatura se ha hecho eco de los riesgos del uso de Twitter en el aula, entre los que destacan el hecho de que tiene una restricciones de uso muy marcadas, por ejemplo en extensión de los mensajes, lo que limita en cierto modo la capacidad de interaccionar (Ebner et al., 10).Igualmente para los propios estudiantes presenta problemas de privacidad, especialmente cuando son menores de edad (Grosseck y Holotescu 2008), y problemas derivados de un mal uso por parte de los estudiantes como pueden ser su carácter distractor o porque no lo tomen en serio como herramienta educativa (Shafique et al., 2010; Clarke, 2012). Igualmente, Grosseck y Holotescu (2008) hace referencia a que Twitter, lejos de permitir fortalecer el grupo, puede dificultar el trabajo grupal en tareas específicas.

Por todo ello, autores como Kirschner \& Karpinski (2010) o Junco, Heiberger, \& Loken, (2011) señalan que el uso de las redes sociales como herramienta educativa es controvertido y que puede suponer un aumento de los resultados negativos y una reducción de las horas dedicadas al estudio.

A pesar de los posibles efectos negativos se ha demostrado que el uso de Twitter puede influir positivamente en el proceso de aprendizaje [Grosseck, 09; Rankin 2009; Ebner, 10; Schroeder, 10] siendo mayor el acuerdo en torno al uso de Twitter como herramienta de comunicación 
en la interacción entre alumnos y entre estos y el profesorado ((Rodríguez, García, Ibáñez, González, \& Heine, 2009; Bazzo de Espíndola, Struchiner, \& Rabetti, 2010; Shafique, Anwar, \& Bushra, 2010; Özsoy, 2011; Carpenter, 2014).

El uso de las redes sociales es especialmente apropiado e interesante en Massive Online Open Courses (Massive Online Open Courses), donde se ha demostrado que la interacción es significativa entre iguales y la red es útil como medio para promover el aprendizaje colaborativo (Castaño Garrido, Maiz Olazabalaga, y Garay Ruiz, 2015).

Además, los MOOC basados en la construcción de conexiones internas y externas permiten a los estudiantes no solo resolver problemas, sino también mejorar sus propias habilidades de autoaprendizaje gracias a la gestión y organización que deben desarrollar continuamente para encontrar soluciones de colaboración que se adapten a cada situación particular de aprendizaje, en la que las interacciones a través de entornos como Twitter se basan en el llamado "Factor relacional" (Osuna-Acedo, Marta-Lazo \& Frau-Meigs, 2018).

\section{Metodología}

\subsection{Dialéctica Twitter}

Para llevar a cabo la investigación nos servimos de la dialéctica Twitter, técnica que describimos a continuación.

Uno de los principales objetivos del MOOC "Comunicación y aprendizaje móvil", que nos sirve de análisis de caso para esta investigación, tenía como propósito: "Aprender a comunicarse de manera efectiva, lúdica, creativa y educativa en comunidades de aprendizaje en redes sociales y a través de los dispositivos móviles". Por ello, entre otras metodologías de aprendizaje llevadas a cabo en distintas redes sociales, diseñamos como primera actividad para la puesta en contacto con el alumnado una "Dialéctica Twitter". La finalidad de esta práctica era dialogar respecto a uno de los temas del primer módulo, la educación mediática, mediante el uso del hashtag común \#ECO_CAM_1a.

La mecánica consistía en desarrollar una conversación en línea sobre un tema general, que permitiera el análisis en la experimentación, desde y con la propia red, mediante la inclusión de argumentos sobre la 
función de la educación mediática en un contexto de aprendizaje móvil. Este diseño conversacional tenía por objeto comenzar el MOOC mediante el diseño de una práctica de creación de un discurso procomún sobre un mismo tema, mediante una técnica de autoría colectiva en cadena. En dicha actividad, los alumnos retroalimentaban a sus propios pares, mediante la inclusión de respuestas activas a los tuits, que podían consistir en dar o recibir feedback, dependiendo del sentido del diálogo. De esta forma, se trata de despertar el interés por el intercambio de información sobre un mismo tema, incluyendo en ocasiones entradas, enlaces u otras aportaciones.

Así, el feedback dado se relacionaba con el número de interacciones en las que el alumno respondía con nuevos mensajes a sus compañeros, o bien asentía su discurso mediante un me gusta o lo proyectaba mediante un retuit. Por el contrario, el feed back recibido se producía en sentido inverso, cuando otros compañeros llevaban a cabo estas acciones respecto a un tuit propio.

Esta práctica era promovida en un inicio por los docentes de dicho módulo, para ofrecer las pautas del funcionamiento de la actividad y despertar interés en los alumnos para realizarla. Como premio, una vez realizado un seguimiento por parte de los propios alumnos, mediante la co-evaluación, si se había superado la práctica, se iban consiguiendo insignias. Cabe destacar que más de un tercio de los alumnos que cumplimentaron el cuestionario eran jóvenes, que habían completado el MOOC, por lo que su rendimiento fue efectivo y lograron resultados positivos.

\subsection{Hipótesis}

Partimos de las siguientes hipótesis:

Hipótesis 1: El engagement del alumno tiene un efecto positivo sobre el aprendizaje

Hipótesis 2: La motivación del alumno tiene un efecto positivo sobre el aprendizaje

Hipótesis 3: La participación en clase del alumno tiene un efecto positivo sobre el aprendizaje 
Hipótesis 4: La auto-evaluación que realiza el alumno sobre su aprendizaje tiene un efecto positivo sobre el aprendizaje

Hipótesis 5: El disfrute del alumno con el uso de la dialéctica en Twitter (satisfacción) tiene un efecto positivo sobre el aprendizaje

Por lo tanto, el modelo de actitud del estudiante hacia el aprendizaje a través de Twitter es tal y como se indica a continuación:

$$
\begin{aligned}
\mathrm{R} . \mathrm{A}=\beta_{0} & +\beta_{1} E N G A G+\beta_{2} M O T+\beta_{3} P A R T+\beta_{4} \text { AUTOEV } \\
& +\beta_{5} \text { DISFR }+\varepsilon_{i}
\end{aligned}
$$

Donde

BETA, es la constante

R.A, variable a explicar: resultados de aprendizaje

ENGAG: engagement

MOT: motivación

PART: participación en clase

AUTOEV: auto-evaluación

DISFR: disfrute del alumno con el uso de la dialéctica en Twitter (satisfacción)

\subsection{Características de la muestra y obtención de los datos}

En la Tabla 1, queda recogida la ficha técnica del estudio. Como puede observarse, la muestra total ha sido de 91 estudiantes, todos ellos matriculados en el curso MOOC titulado "Comunicación y aprendizaje móvil”, y que representan el 38\% de los estudiantes del MOOC. El método utilizado para la recogida de la información ha sido un cuestionario online auto-administrado, el procedimiento de muestreo fue por conveniencia y la fecha de realización del trabajo de campo correspondió a los meses (marzo-abril 2016). El cuestionario fue completado por los estudiantes que finalizaron el curso y participaron en la actividad de la dialéctica Twitter, de ellos aproximadamente 2/3 
eran menores de 30 años. Respecto a su nivel educativo y experiencias previas con el uso de Twitter es preciso señalar que el 11\% no habían terminado todavía sus estudios universitarios, el 45\% eran graduados y el 44\% habían cursado un master o doctorado. Igualmente, a pesar de que el 90\% habían utilizado Twitter con anterioridad, solo el 47\% lo habían utilizado como herramienta educativa.

Tabla 1. Ficha técnica

\begin{tabular}{|l|l|}
\hline Tamaño muestral & $\begin{array}{l}191 \text { alumnos (40,65\% hombres y 59,35\% } \\
\text { mujeres) }\end{array}$ \\
\hline $\begin{array}{l}\text { Método de recogida } \\
\text { de la información }\end{array}$ & Cuestionario online auto-administrado \\
\hline $\begin{array}{l}\text { Procedimiento de } \\
\text { muestreo }\end{array}$ & Muestreo por conveniencia \\
\hline $\begin{array}{l}\text { Fecha de } \\
\text { realización }\end{array}$ & Marzo-abril del año 2016 \\
\hline
\end{tabular}

\subsection{Medición de las variables}

La revisión de la literatura es la que permite seleccionar los ítems considerados para cada una de las variables exógenas del modelo propuesto (ver Tabla 2). Estos indicadores son una adaptación al contexto específico de los entornos de aprendizaje MOOC y a la utilización de Twitter.

Tabla 2. Relación de variables e ítems

Variable

Engagement

(Este curso...)
Ítem

Referencias

Blasco-Arcas, Buil, Hernández-

Ortega \& Sesé (2013);

(x2) Me ha hecho sentir valioso

(x3) Este curso ha favorecido mis relaciones personales con mis iguales y mis profesores

(x1) Ha hecho que sienta que mis opiniones se han tenido en cuenta en este curso Higgins, Hartley, \& Skelton, 2002);

Greenhow \&

Robelia (2009); Junco, Heibergert, 


\begin{tabular}{|c|c|c|}
\hline & & $\begin{array}{l}\text { \& Loken (2011); } \\
\text { Johnson (2011) }\end{array}$ \\
\hline $\begin{array}{l}\text { Motivación } \\
\text { (el uso de } \\
\text { Twitter...) }\end{array}$ & $\begin{array}{l}\text { (x4) Incrementa mi entusiasmo } \\
\text { por estudiar el material de este } \\
\text { curso } \\
\text { (x5) Me motiva más para } \\
\text { aprender en este curso } \\
\text { (x6) Me motiva para } \\
\text { relacionarme con el contenido } \\
\text { del curso }\end{array}$ & $\begin{array}{l}\text { Blasco-Arcas, } \\
\text { Buil, Hernández- } \\
\text { Ortega \& Sesé } \\
\text { (2013); López } \\
\text { Zapico \& Tascón } \\
\text { Fernández (2013) }\end{array}$ \\
\hline $\begin{array}{l}\text { Participación } \\
\text { en clase }\end{array}$ & $\begin{array}{l}\text { (x7) Me hace sentir más } \\
\text { implicado en el curso } \\
\text { (x8) Percibo que hay más } \\
\text { participación en clase } \\
\text { (x9) Incrementa mi interés en } \\
\text { lo que hacemos }\end{array}$ & $\begin{array}{l}\text { Blasco-Arcas, } \\
\text { Buil, Hernández- } \\
\text { Ortega \& Sesé } \\
\text { (2013); Dunlap \& } \\
\text { Lowenthal (2009); } \\
\text { Rinaldo, Tapp, \& } \\
\text { Laverie, (2011); } \\
\text { Munoz, Pellegrini- } \\
\text { Lafont, \& Cramer } \\
\text { (2014), Knox } \\
\text { (2014) }\end{array}$ \\
\hline $\begin{array}{l}\text { Autoevaluació } \\
\mathrm{n}\end{array}$ & $\begin{array}{l}\text { (x10) Me resulta más sencillo } \\
\text { saber si domino el material de } \\
\text { clase } \\
\text { (x11) Hace que me sienta más } \\
\text { seguro de cómo voy en clase } \\
\text { (x12) Me ayuda a determinar } \\
\text { más fácilmente como lo estoy } \\
\text { haciendo en el curso }\end{array}$ & $\begin{array}{l}\text { Blasco-Arcas, } \\
\text { Buil, Hernández- } \\
\text { Ortega \& Sesé } \\
\text { (2013); Grossec \& } \\
\text { Holotescu (2008); } \\
\text { Caldwell (2015); } \\
\text { Tur \& Marín } \\
\text { (2015) }\end{array}$ \\
\hline $\begin{array}{l}\text { Disfrute con la } \\
\text { dialéctica } \\
\text { Twitter }\end{array}$ & $\begin{array}{l}\text { (x13) He disfrutado utilizando } \\
\text { la dialéctica Twitter }\end{array}$ & $\begin{array}{l}\text { Blasco-Arcas, } \\
\text { Buil, Hernández- } \\
\text { Ortega \& Sesé } \\
\text { (2013); Zerega- } \\
\text { Garaycoa (2015) }\end{array}$ \\
\hline
\end{tabular}




\begin{tabular}{|c|c|c|}
\hline $\begin{array}{l}\text { Resultados de } \\
\text { aprendizaje }\end{array}$ & $\begin{array}{l}\text { (x14) Los temas tratados en el } \\
\text { curso a través de Twitter me } \\
\text { han ayudado a completar mi } \\
\text { formación } \\
\text { (x15) Lo abordado en Twitter } \\
\text { me ha servido para descubrir } \\
\text { nuevos aprendizajes } \\
\text { (x16) Las dinámicas de Twitter } \\
\text { me han ayudado a avanzar en } \\
\text { mi aprendizaje }\end{array}$ & $\begin{array}{l}\text { Blasco-Arcas, } \\
\text { Buil, Hernández- } \\
\text { Ortega \& Sesé } \\
\text { (2013); Ophus \& } \\
\text { Abbitt, (2009); } \\
\text { Ebner, Lienhardt, } \\
\text { Rohs, \& Meyer } \\
\text { (2010); Junco, } \\
\text { Elavsky, \& } \\
\text { Heibergert (2013); } \\
\text { Abella García \& } \\
\text { Delgado Benito } \\
\text { (2015) }\end{array}$ \\
\hline
\end{tabular}

Todos los indicadores están medidos a través de una escala tipo Likert de 7 puntos. Nótese que las variables exógenas engagement, motivación, participación en clase y autoevaluación han sido medidas a través de 4 ítems, mientras que la variable disfrute con la dialéctica Twitter está medida con un solo ítem. Además, la variable endógena resultados de aprendizaje ha sido medida a través de 3 ítems.

\section{Resultados}

A continuación, se presentan los resultados de la investigación obtenidos a través del programa estadístico SPSS 22.0. En primer lugar, se realiza un análisis factorial exploratorio (AFE). A continuación, se procede a realizar análisis de regresión múltiple (ARM). Todo con el objetivo de contrastar las hipótesis propuestas.

\subsection{Análisis factorial exploratorio y de fiabilidad sobre las variables exógenas y endógena}

Se han realizado los análisis factoriales exploratorios (AFE) para cada una de las cuatro variables exógenas propuestas (nótese que la variable disfrute presenta un único item y no requiere realizar AFE) y para la variable endógena objeto de estudio. Se observa que existe unidimensionalidad para todas las variables. Además, para todos los casos la varianza explicada es superior al 70\% y las cargas factoriales y los coeficientes Alpha de Cronbach presentan valores superiores al mínimo 
recomendado (ver Tabla 3). De este modo, se refleja así la consistencia interna de las escalas unidimensionales obtenidas (Hair et al., 1999).

Tabla 3. Resultados del AFE y Alfa de Cronbach de las variables exógenas y endógena

\section{(Variable 1 ) Engagement \\ Factor Varianza \\ 1 explicada Cronbach}

(x1) Ha hecho que sienta que mis

opiniones se han tenido en cuenta $\quad 0,918$

en este curso

(x2) Me ha hecho sentir valioso

$0,905 \quad 84,39 \% \quad 0,906$

(x3) Este curso ha favorecido mis

relaciones personales con mis

0,934

iguales y mis profesores

\section{(Variable 2 ) Motivación \\ Factor Varianza Alfa \\ 1 explicada Cronbach}

(x4) Incrementa mi entusiasmo

por estudiar el material de este

curso

0,928

(x5) Me motiva más para aprender en este curso

0,922

$79,98 \%$

0,874

(x6) Me motiva para relacionarme

con el contenido del curso

0,830

(Variable 3 ) Participación en clase

Factor Varianza

Alfa

1 explicada Cronbach

(x7) Me hace sentir más implicado

en el curso

0,947

(x8) Percibo que hay más

participación en clase

0,922

$89,25 \%$

0,939

(x9) Incrementa mi interés en lo que hacemos

0,965

(Variable 4) Autoevaluación

$\begin{array}{ccc}\text { Factor } & \text { Varianza } & \text { Alfa } \\ 1 & \text { explicada } & \text { Cronbach }\end{array}$


(x10) Me resulta más sencillo saber si domino el material de clase

(x11) Hace que me sienta más seguro de cómo voy en clase

(x12) Me ayuda a determinar más fácilmente como lo estoy 0,950

haciendo en el curso

$$
0,952 \quad 89,95 \% \quad 0,944
$$

(Variable endógena) Resultados de aprendizaje
Factor Varianza Alfa 1 explicada Cronbach

(x14) Los temas tratados en el curso a través de Twitter me han ayudado a completar mi 0,947 formación

(x15 ) Lo abordado en Twitter me ha servido para descubrir nuevos aprendizajes

(x16) Las dinámicas de Twitter me han ayudado a avanzar en mi aprendizaje

$0,963 \quad 91,83 \% \quad 0,955$

\subsection{Análisis de regresión múltiple}

La unidimensionalidad de las variables exógenas y de la variable endógena sirve para justificar el uso de las mismas a través de las puntuaciones de los componentes que han sido extraídos para cada una de ellas. De este modo, se procede a realizar el contraste del modelo y las relaciones supuestas entre las variables a través de un análisis de regresión múltiple (ARM). Se utiliza para ello el procedimiento Stepwise por pasos que permite testar la multicolinealidad entre las variables.

Los resultados del coeficiente de determinación $R^{2}$ ajustado quedan recogidos en la Tabla 4. Como puede observarse, las variables exógenas explican el $77,9 \%$ de la variabilidad de los resultados de aprendizaje del 
alumno. Las variables motivación, participación en clase y disfrute del alumno resultan determinantes para los resultados de aprendizaje.

En este sentido, se observa que la motivación tiene una influencia positiva $\left(\beta_{2}=0,314\right)$ en la variable resultados de aprendizaje. Este hecho nos lleva a aceptar la Hipótesis 2. Además, las variable participación en clase $\left(\beta_{5}=0,355\right)$ y disfrute del alumno con la dialéctica Twitter $\left(\beta_{5}=0,225\right)$ ejercen una influencia positiva sobre la variable endógena, es decir, sobre los resultados de aprendizaje. De este modo aceptamos las Hipótesis 3 y 5. Sin embargo, las variables engagement y autoevaluación no determinan los resultados de aprendizaje del alumno. Por lo tanto, rechazamos la Hipótesis 1 y la Hipótesis 4 (ver Tabla 5).

Por último, es importa destacar el orden de importancia de las variables exógenas para explicar la variabilidad de la variable endógena. Así, se observa que la participación en clase es la variable que más determina los resultados de aprendizaje del alumno. La motivación y el disfrute del alumno se sitúan en segundo y tercer lugar, respectivamente.

Tabla 4. Resultados del ARM resultados de aprendizaje

Coeficientes no estandarizados

Error

\begin{tabular}{ccccc} 
Modelo & $\mathrm{B}$ & estándar & $\mathrm{t}$ & Sig. \\
\hline 1 (Constante) & $-6,475 \mathrm{E}-$ &, 055 &, 000 & 1,000 \\
& 17 & & & \\
Motivación &, 852 &, 056 & 15,338 &, 000 \\
\hline 2 (Constante) & $-1,413$ &, 374 & $-3,783$ &, 000 \\
Motivación &, 603 &, 083 & 7,257 &, 000 \\
Disfrute &, 260 &, 068 & 3,820 &, 000 \\
\hline 3 (Constante) & $-1,224$ &, 364 & $-3,364$ &, 001 \\
Motivación &, 314 &, 126 & 2,489 &, 015 \\
$\begin{array}{l}\text { Disfrute } \\
\text { Participación }\end{array}$ &, 225 &, 066 & 3,395 &, 001 \\
en clase &, 355 &, 120 & 2,957 &, 004 \\
\hline
\end{tabular}


Tabla 5. Resultados del contraste de Hipótesis

Hipótesis propuesta

Resultado

Hipótesis 1: El engagement del alumno tiene un efecto positivo sobre el aprendizaje

SE RECHAZA

Hipótesis 2: La motivación del alumno tiene un efecto positivo sobre el aprendizaje

SE ACEPTA

Hipótesis 3: La participación en clase del alumno tiene un efecto positivo sobre el aprendizaje

SE ACEPTA

Hipótesis 4: La auto-evaluación que realiza el alumno sobre su aprendizaje tiene un efecto SE RECHAZA positivo sobre el aprendizaje

Hipótesis 5: El disfrute del alumno con el uso de la dialéctica en Twitter (satisfacción) tiene un SE ACEPTA efecto positivo sobre el aprendizaje

\section{Objetivo 2:}

Una vez establecido que la motivación, el disfrute y la participación en clase son las variables que, según nuestro análisis, influyen en el aprendizaje nos planteamos un segundo objetivo que es determinar en qué medida influye la retroalimentación, tanto dada como recibida, en estas variables.

Hemos partido de la hipótesis de que los alumnos que obtienen una mayor retroalimentación serán los que obtengan mayores puntuaciones

Con el objetivo de hacer un estudio exploratorio de esta situación hemos llevado a cabo un análisis de diferencia de medias entre grupos a través del contraste no paramétrico de Kruskall-Wallis. Para ello, se ha utilizado el programa estadístico SPSS 22.0

Se han establecido cuatro categorías para lo cual se ha pedido a los estudiantes que respondieran el número de la retroalimentación dada y recibida (número de twits/retwit, comentario y marcado como favorito) estableciendo en función de ello cuatro grupos: Ninguno; de 1 a 5; de 6 a 10, más de 10. 
Tabla 6. Retroalimentación dada y recibida por el estudiante

\section{Retroalimentación Retroalimentación dada recibida}

D.

\begin{tabular}{|c|c|c|c|c|c|}
\hline & & Media & típica & Media & D. típica \\
\hline \multirow{4}{*}{$\begin{array}{l}\text { Incrementa mi } \\
\text { entusiasmo } \\
\text { por estudiar el } \\
\text { material de } \\
\text { este curso (x1) }\end{array}$} & ninguno & 4,5 & 1,08 & 4 & 1,732 \\
\hline & de 1 a 5 & 5,29 & 1,051 & 5,24 & 1,05 \\
\hline & de 6 a 10 & 5,44 & 0,726 & 5,5 & 0,941 \\
\hline & más de 10 & 5,88 & 0,947 & 5,78 & 0,902 \\
\hline \multirow{4}{*}{$\begin{array}{l}\text { Me motiva } \\
\text { más para } \\
\text { aprender en } \\
\text { este curso (x2) }\end{array}$} & ninguno & 4,7 & 1,16 & 4,33 & 2,082 \\
\hline & de 1 a 5 & 5,56 & 1,183 & 5,47 & 1,172 \\
\hline & de 6 a 10 & 5,22 & 0,833 & 5,36 & 0,929 \\
\hline & más de 10 & 5,79 & 0,977 & 5,78 & 0,951 \\
\hline \multirow{4}{*}{$\begin{array}{l}\text { Me motiva } \\
\text { para } \\
\text { relacionarme } \\
\text { con el } \\
\text { contenido del } \\
\text { curso (x3) }\end{array}$} & ninguno & 5,4 & 1,43 & 4,67 & 2,517 \\
\hline & de 1 a 5 & 5,58 & 1,069 & 5,63 & 1,058 \\
\hline & de 6 a 10 & 5,33 & 1 & 5,43 & 1,016 \\
\hline & $\begin{array}{l}\text { Más de } \\
10\end{array}$ & 6,17 & 0,565 & 6,13 & 0,458 \\
\hline \multirow{4}{*}{$\begin{array}{c}\text { Me hace sentir } \\
\text { más implicado } \\
\text { en el curso } \\
(\mathrm{x} 4)\end{array}$} & ninguno & 4,6 & 1,174 & 4,33 & 2,082 \\
\hline & de 1 a 5 & 5,27 & 1,026 & 5,2 & 1,02 \\
\hline & de 6 a 10 & 5,22 & 0,972 & 5,43 & 1,089 \\
\hline & $\begin{array}{l}\text { Más de } \\
10\end{array}$ & 5,75 & 1,032 & 5,65 & 0,982 \\
\hline \multirow{4}{*}{$\begin{array}{l}\text { Percibo que } \\
\text { hay más } \\
\text { participación } \\
\text { en clase (x5) }\end{array}$} & ninguno & 4,4 & 0,966 & 4 & 1,732 \\
\hline & de 1 a 5 & 5,25 & 1,021 & 5,16 & 1,027 \\
\hline & de 6 a 10 & 5,44 & 0,726 & 5,57 & 0,852 \\
\hline & $\begin{array}{l}\text { Más de } \\
10\end{array}$ & 5,88 & 1,154 & 5,78 & 1,126 \\
\hline \multirow{4}{*}{$\begin{array}{l}\text { Incrementa mi } \\
\text { interés en lo } \\
\text { que hacemos } \\
\text { (x6) }\end{array}$} & ninguno & 4,7 & 1,16 & 4,33 & 2,082 \\
\hline & de 1 a 5 & 5,44 & 1,183 & 5,31 & 1,14 \\
\hline & de 6 a 10 & 5,33 & 1 & 5,64 & 1,151 \\
\hline & $\begin{array}{l}\text { Más de } \\
10\end{array}$ & 5,79 & 1,062 & 5,74 & 1,01 \\
\hline \multirow{3}{*}{$\begin{array}{c}\text { He disfrutado } \\
\text { utilizando la }\end{array}$} & ninguno & 4,9 & 1,37 & 4 & 2 \\
\hline & de 1 a 5 & 5,25 & 1,361 & 5,27 & 1,358 \\
\hline & de 6 a 10 & 5,44 & 0,726 & 5,5 & 0,855 \\
\hline
\end{tabular}


\begin{tabular}{cl|ll|rr} 
dialéctica & Más de & & & & \\
Twitter (x7) & 10 & 6,04 & 0,751 & 5,96 & 0,706 \\
\hline
\end{tabular}

Las variables utilizadas y la muestra son las mismas que las utilizadas en el primer objetivo que se plantea en el artículo y por tanto han sido medidas a través de una escala tipo Likert de 7 puntos, pero centramos el análisis en las 3 variables que a través del estudio 1 se ha demostrado que tienen influencia en el aprendizaje, es decir: participación en clase, disfrute y motivación.

En la Tabla 6, se recogen los resultados del contraste de medias para las 7 variables en función de los 4 grupos de estudiantes segmentados según el número de retroalimentaciones dadas y recibidas. Para ello se ha utilizado el contraste no paramétrico de Kruskall-Wallis, ya que las pruebas de Normalidad indican que las variables no siguen una distribución de frecuencias de tipo Normal. En dicho contraste, la Hipótesis Nula a contrastar propone que no existen diferencias en las puntuaciones medias de cada variable según el grupo al que pertenece cada alumno mientras que la Hipótesis alternativa señala lo contrario, es decir, sí existen diferencias significativas en las puntuaciones medias para cada variable según el grupo de pertenencia del alumno.

Los resultados del análisis muestran notables diferencias en las puntuaciones medias considerando el número de retroalimentaciones dadas y recibidas como variable de segmentación. En este sentido se observa que los alumnos que pertenecen al grupo que no han recibido o dado ninguna retroalimentación tienen puntuaciones medias inferiores a los otros grupos de alumnos en todas las variables. Siendo especialmente significativa la diferencia con respecto a los alumnos que han señalado que una retroalimentación superior a 10. En concreto, esta diferencia es superior a un punto con respecto al grupo con mayor retroalimentación para todas las variables, tanto cuando el estudiante da la retroalimentación como cuando la recibe.

Sin embargo, cuando se analizan diferencias entre los alumnos que pertenecen al Grupo 2 con respecto a los alumnos del Grupo 3 se observa que las diferencias no son superiores a un punto para ninguna de las variables y, de hecho, aunque en general sí que se observa que influye el número de las retroalimentaciones, esta relación no es siempre positiva. 
Entre los alumnos que han recibido y dado mayor retroalimentación se observa que dan las puntuaciones medias más altas para todas las variables. En este sentido destacan las variables (x7) he disfrutado utilizando la dialéctica Twiter $(6,04 ; 5,96)$ y (x3) Me motiva para relacionarme con el contenido del curso $(6,17 ; 6,13)$. Siendo las variables más significativas las mismas tanto en la retroalimentación dada como en la retroalimentación recibida.

Como puede observarse, cuanto mayor es la retroalimentación tanto dada como recibida, mayores son las puntuaciones medias obtenidas en las 7 variables analizadas. Esto significa que la retroalimentación tiene influencia directa en cada una de las variables propuestas.

Tabla 7. Contraste Kruskall-Wallis

RETROALIMENTACIÓN RETROALIMENTACIÓN DADA RECIBIDA

\section{Ítems p-value Hipótesis p-value Hipótesis}

\begin{tabular}{|c|c|c|c|c|}
\hline $\begin{array}{l}\text { Incrementa mi entusiasmo por estudiar } \\
\text { el material de este curso (x1) }\end{array}$ & 0,005 & $\begin{array}{c}\text { Rechazar } \\
\text { Hipótesis } \\
\text { Nula }\end{array}$ & 0,041 & $\begin{array}{c}\text { Rechazar } \\
\text { Hipótesis } \\
\text { Nula }\end{array}$ \\
\hline $\begin{array}{l}\text { Me motiva más para aprender en este } \\
\text { curso (x2) }\end{array}$ & 0,062 & $\begin{array}{c}\text { Rechazar } \\
\text { Hipótesis } \\
\text { Nula }\end{array}$ & 0,329 & $\begin{array}{c}\text { Retener } \\
\text { Hipótesis } \\
\text { Nula }\end{array}$ \\
\hline $\begin{array}{l}\text { Me motiva para relacionarme con el } \\
\text { contenido del curso }(\mathrm{x} 3)\end{array}$ & 0,041 & $\begin{array}{c}\text { Rechazar } \\
\text { Hipótesis } \\
\text { Nula }\end{array}$ & 0,059 & $\begin{array}{l}\text { Retener } \\
\text { Hipótesis } \\
\text { Nula }\end{array}$ \\
\hline $\begin{array}{l}\text { Me hace sentir más implicado en el } \\
\text { curso }(\mathrm{x} 4)\end{array}$ & 0,026 & $\begin{array}{c}\text { Rechazar } \\
\text { Hipótesis } \\
\text { Nula }\end{array}$ & 0,073 & $\begin{array}{l}\text { Retener } \\
\text { Hipótesis } \\
\text { Nula }\end{array}$ \\
\hline $\begin{array}{l}\text { Percibo que hay más participación en } \\
\text { clase (x5) }\end{array}$ & 0,034 & $\begin{array}{c}\text { Rechazar } \\
\text { Hipótesis } \\
\text { Nula }\end{array}$ & 0,193 & $\begin{array}{c}\text { Retener } \\
\text { Hipótesis } \\
\text { Nula }\end{array}$ \\
\hline $\begin{array}{l}\text { Incrementa mi interés en lo que } \\
\text { hacemos }(\mathrm{x} 6)\end{array}$ & 0,003 & $\begin{array}{c}\text { Rechazar } \\
\text { Hipótesis } \\
\text { Nula }\end{array}$ & 0,026 & $\begin{array}{c}\text { Rechazar } \\
\text { Hipótesis } \\
\text { Nula }\end{array}$ \\
\hline $\begin{array}{l}\text { He disfrutado utilizando la dialéctica } \\
\text { Twitter (x7) }\end{array}$ & 0,076 & $\begin{array}{c}\text { Rechazar } \\
\text { Hipótesis } \\
\text { Nula }\end{array}$ & 0,218 & $\begin{array}{c}\text { Retener } \\
\text { Hipótesis } \\
\text { Nula }\end{array}$ \\
\hline
\end{tabular}

** Significativo para $\mathrm{p}<0,1$ 
Por último, los resultados del contraste no paramétrico de KruskallWallis indican que la Hipótesis Nula se rechaza para las 7 variables propuestas en la investigación ( $\mathrm{p}$-value $<0,1$ ) en el caso de la retroalimentación dada. Sin embargo, en el caso de la retroalimentación recibida los resultados son diferentes y la hipótesis nula se rechaza para las variables: Incrementa mi entusiasmo por estudiar el material de este curso (x1), Me motiva para relacionarme con el contenido del curso (x3), Me hace sentir más implicado en el curso (x4) y Incrementa mi interés en lo que hacemos (x6).

\section{Conclusiones}

En la presente investigación, hemos podido concluir que, si bien en el caso de la retroalimentación, todas nuestras hipótesis preliminares han sido confirmadas, para los comentarios recibidos, los resultados no son concluyentes. Es decir, se ha demostrado que dar comentarios a través de Twitter influye positivamente en el aprendizaje, pero no se ha confirmado que recibirlos influya de la misma manera.

Significativamente, el hecho de interactuar activamente, así como dar retroalimentación, tiene una influencia positiva, mientras que recibir pasivamente, no es concluyente.

Todo ello es especialmente importante en el caso de los jóvenes, pues ya hemos podido comprobar cómo en su caso, tiene un mayor impacto educativo dar retroalimentación que recibirla, es decir, involucrarse activamente en la actividad a través de Twitter e interaccionar con los otros compañeros tiene un mayor impacto que recibir feedback, lo que contrasta con la visión de que los jóvenes solo buscan la reafirmación a través de las redes, un mayor número de "me gusta" o "likes", etc. Si bien a nivel social quizás sean ciertas esas afirmaciones, a nivel educativo para los alumnos jóvenes la valoración de sus compañeros a través de Twitter tiene menos impacto.

En cuanto a las variables analizadas, hemos podido corroborar y validar las hipótesis relacionadas con el hecho de que el uso del diálogo en Twitter tiene un efecto positivo sobre el aprendizaje, tanto en lo que respecta a la motivación como para impulsar la participación, así como para el disfrute o la satisfacción del alumnado. Por el contrario, ni el compromiso ni la autoevaluación que los estudiantes hacen sobre su aprendizaje tienen un efecto positivo en el mismo. 
La retroalimentación tradicionalmente asociada en el contexto de los medios de comunicación de masas, a una naturaleza bidireccional, en el caso que nos ocupa, integrado en un contexto de social-media, es multidireccional. Lo cual abre diferentes perspectivas de estudio en el ámbito de la educomunicación, y permite optimizar las interacciones entre los participantes.

- Investigación financiada: Este artículo ha sido elaborado en el marco de la investigación desarrollada en proyecto europeo ECO, situado dentro del Competitiveness and Innovation Framework Programme (CIP-ICT-PSP.2013 Theme 2: Digital content, open data and creativity, Obj 2.3.a: Piloting and showcasing excellence in ICT for learning for all) y dentro del Grupo de Investigación en Comunicación e Información Digital (GICID), S29_17R, perteneciente al Gobierno de Aragón y financiado por el Fondo Social Europeo.

Fecha de Inicio de investigación: enero de 2016. Fecha de finalización: 30 de septiembre de 2017.

\section{Referencias}

V. Abella García \& V. Delgado Benito (2015): "Aprender a usar Twitter y usar Twitter para aprender". Revista de currículum y formación de profesorado, 19 (1), 364-378.

C. Angeli, N. Valanides, \& C. J. Bonk (2003): "Communication in a Web-based conferencing system: The quality of computermediated interactions". British Journal of Educational Technology, 34(1), 31-43.

J. Badge, S. Johnson, A. Moseley \& A. Cann (2012): "Observing emerging student networks on a microblogging service". Journal of Online Learning and Teaching, 7(1), 90-98. Accesible en http://jolt.merlot.org/vol7no1/cann_0311.htm

B. Bannan-Ritland (2002): "Computer-Mediated Communication, eLearning, and Interactivity: A Review of the Research". Quarterly Review of Distance Education, 3(2), 161-79.

M. Bazzo de Espíndola, M. Struchiner \& T. Rabetti (2010): "Integra ção de Tecnologias de Informação e Comunicação noEnsino: Contribuições dos Modelos de Difusão e Adoção de Inovaçõe s para o campo da Tecnologia Educacional". Relatec: 
Revista Latinoamericana de Tecnología Educativa, 9(1), 89-

106. Accesible en http://campusvirtual.unex.es/cala/editio/.

L. Blasco-Arcas, I. Buil, B. Hernández-Ortega \& F.J. Sesé (2013):

"Using clickers in class. The role of interactivity, active

collaborative learning and engagement in learning

performance". Computers and Education, 62,102-110.

J. Cabero (2006): "Bases pedagógicas del e-learning". RUSC, Revista de Universidad y Sociedad del Conocimiento, 3(1), 1-10.

J. M. Caldwell (2015): Going where students are: Comparing faculty and student uses and perceptions of social networking in education.

Chattanooga, Tennessee: University of Tennessee at

Chattanooga.

J. P. Carpenter (2014): "Twitter's capacity to support collaborative

learning". Int. J. of Social Media and Interactive Learning

Environments, 2(2), 103-118. DOI:

10.1504/IJSMILE.2014.063384

C. Castaño Garrido, I. Maiz Olazabalaga \& U. Garay Ruiz. (2015):

"Redes sociales y aprendizaje cooperativo en un MOOC".

Revista Complutense de Educación, 26, 119-139.

C. Chou (2003): "Interactivity and interactive functions in web-based learning systems: a technical framework for designers". British Journal of Educational Technology, 34(3), 265-279.

G. Conole, R. Galley, \& J. Culver (2011): "Frameworks for

Understanding the Nature of Interactions, Networking, and

Community in a Social Networking Site for Academic

Practice". IRROLD, International Review of Research in Open and

Distance Learning, 12(3), 119-138.

S. H. Cotner, B. A. Fall, S. M. Wick, J. D. Walker \& P. M. Baepler (2008): "Rapid feedback assessment methods: Can we improve engagement and preparation for exams in large

C. L. Dirckinck-Holmfeld, V. Hodgson, \& D. Mcconnell (Eds.). (2012): Exploring the Theory, Pedagogy and Practice of Networked Learning. New York: Springer. DOI:10.1007/978-1-4614-04965

D. P. Domizi (2013): "Microblogging to foster connections and community in a weekly graduate seminar course". TechTrends, 57(1), 43-51. 
S. W. Draper \& M. I. Brown (2004): "Increasing interactivity in lectures using an electronic voting system". Journal of Computer Assisted Learning, 20(2), 81-94.

A. P. G. Duque, M. E. D. M. Pérez \& F. G. L. De Guevara (2012): "Usos de Twitter en las universidades iberoamericanas". Relatec: Revista Latinoamericana de Tecnología Educativa, 11(1), 27-39.

J. C. Dunlap \& P. R. Lowenthal (2009). "Tweeting the night away: Using Twitter to enhance social presence". Journal of Information Systems Education, 20(2), 129.

M. Ebner, C. Lienhardt, M. Rohs, \& I. Meyer (2010): "Microblogs in Higher Education-A chance to facilitate informal and processoriented learning?”. Computers \& Education, 55(1), 92-100.

J. Erickson \& K. Siau (2003): "E-ducation". Communications of the ACM, 46(9), 134-140.

D. R. Garrison, T. Anderson \& W. Archer (2001): “Critical thinking, cognitive presence, and computer conferencing in distance education”. American Journal of Distance Education, 15(1), 7-23.

J.A. Gabelas Barroso, J.A. (2010). "Escenarios virtuales, cultura juvenil y educomunicación 2.0”, en Aparici, R. (coord.). Educomunicación 2.0. Gedisa. Barcelona.

F. Gao, T. Luo \& K. Zhang (2012): “Tweeting for learning: A critical analysis of research on microblogging in education published in 2008-2011". British Journal of Educational Technology, 43(5), 783-801.

C. Greenhow \& B. Robelia (2009): “Old communication, new literacies: Social network sites as social learning resources". Journal of Computer-Mediated Communication, 14(4), 1130-1161.

G. Grosseck (2009): "To use or not to use web 2.0 in higher education? World Conference on Educational Sciences". Procedia Social and Behavioral Sciences, 1, 478-482. DOI: 10.1016/j.sbspro.2009.01.087

G. Grosseck \& C. Holotescu (2008). "Can we use Twitter for educational activities?" Proceedings of the Fourth International Scientific Conference eLearning and Software for Education, Bucharest, Romania. 
G. Grosseck \& C. Holotescu (2010): "Microblogging multimedia-based teaching methods best practices with Cirip.eu." Procedia-Social and Behavioral Sciences, 2(2), 2151-2155. J.F. Hair, R.E. Anderson, R.L. Tatham, \& W.C. Black (1999): Análisis multivariante. Madrid: Prentice Hall.

R. Higgins, P. Hartley, \& A. Skelton (2020): “The Conscientious Consumer: Reconsidering the role of assessment feedback in student learning". Studies in Higher Education. 27 (1), 53-64.

Holotescu \& G. Grosseck (2010): "Learning to microblog and microblogging to learn. A case study on learning scenarios in a microblogging context". Proceedings of The 6th International Scientific Conference eLearning and Software for Education Bucharest (15-16). Bucharest, Romania.

K. A. Johnson (2011): “The effect of Twitter posts on students' perceptions of instructor credibility". Learning, Media and Technology, 36(1), 21-38, DOI: 10.1080/17439884.2010.534798

D. W. Johnson, R. Johnson \& E. Holubec (2013): Cooperation in the classroom (9th ed.). Edina, MN: Interaction Book Company

R. Junco, C. M. Elavsky \& G. Heibergert (2013): "Putting twitter to the test: Assessing outcomes for student collaboration, engagement and success". British Journal of Educational Technology, 44(2), 273-287.

R. Junco, G. Heibergert \& E. Loken (2011): “The effect of Twitter on college student engagement and grades". Journal of Computer Assisted Learning, 27(2), 119-132.

E. Kassens-Noor (2012): "Twitter as a teaching practice to enhance active and informal learning in higher education: The case of sustainable tweets". Active Learning in Higher Education, 13(1), 921.

P. A. Kirschner \& A. C. Karpinski (2010): "Facebook ${ }^{\circledR}$ and academic performance". Computers in Human Behavior, 26(6), 1237-1245.

J. Knox (2014): "Digital culture clash: "Massive" education in the Elearning and Digital Cultures MOOC". Distance Education, 35(2), 164-177. DOI: 10.1080/01587919.2014.917704

K. Kreijns, P. A. Kirschner \& W. Jochems (2003): "Identifying the pitfalls for social interaction in computer-supported collaborative learning environments: A review of the research". Computers in Human Behavior, 19(3), 335-353. 
L. G. Kryder (1999): Integrating Computer Literacy: Why and What Can Be Done. Business Communication Quarterly, 62(2), 81-86.

T. C. Liu, J. K. Liang, H. Y. Wang, T. W. Chan \& L. H. Wei (2003): "Embedding educlick in classroom to enhance interaction". Proceedings of International Conference on Computers in Education (ICCE), 117-125.

L. Lomicka \& G. Lord (2012): “A tale of tweets: Analyzing microblogging among language learners". System, 40 (1), 48-63.

M. A. López Zapico \& J. Tascón Fernández (2013): “El uso de Twitter como herramienta para la enseñanza universitaria en el ámbito de las ciencias sociales. Un estudio de caso desde la historia económica". Education in the knowledge society (EKS), 14 (2), 316-345.

C. Marta-Lazo, J.A. Gabelas Barroso \& M. Grandío (2015): “La dimensión de recepción e interacción en la enseñanza universitaria española de educación mediática. En VVAA, La educación mediática en la universidad española (Eds., J Ferrés Prats \& M.J. Masanet). Madrid: Gedisa.

C. Marta-Lazo \& J.A. Gabelas Barroso, (2016): Comunicación Digital. Un modelo basado en el Factor R-elacional. Barcelona: UOC Press.

C. Marta-Lazo, D. Frau-Meigs \& S. Osuna-Acedo (2018):

"Collaborative lifelong learning and professional transfer. Case study: ECO European Project”. Interactive Learning Environments, 1-13.

R. E. Mayer \& M. C. Wittrock (2006): "Problem solving". Handbook of Educational Psychology, 2, 287-303.

L. R. Muñoz, C. Pellegrini-Lafont \& E. Cramer (2014): “Using Social Media in Teacher Preparation Programs: Twitter as a Means to Create Social Presence". Penn GSE Perspectives on Urban Education, 11(2), 57-69.

T. Panitz (1999): Collaborative versus Cooperative Learning: A Comparison of the Two Concepts Which Will Help Us Understand the Underlying Nature of Interactive Learning. Accesible en http:/ / files.eric.ed.gov/ fulltext/ED448443.pdf

J. Pratton \& L. W. Hales (1986): "The effects of active participation on student learning". The Journal of Educational Research, 79(4), 210-215. 
M. Prince (2004). "Does active learning work? A review of the research". Journal of Engineering Education (Washington), 93, 223232.

P. Resta \& T. Laferrière (2007): “Technology in support of collaborative learning”. Educational Psychology Review, 19(1), 6583.

S. B. Rinaldo, S. Tapp, \& D. A. Laverie (2011): "Learning by Tweeting". Journal of Marketing Education, 33(2), 193-203.

A. Rodríguez, E. García, R. Ibáñez, J. González \& J. Heine (2009): "Las TIC en la educación superior: estudio de los factores intervinientes en la adopción de un LMS por docentes innovadores". RELATEC: Revista Latinoamericana de Tecnología Educativa, 8 (1), 35-51

F. Shafique, M. Anwar \& M. Bushra (2010): "Exploitation of social media among university students: A case study“. Webology, 7 (2).

K. Siau, H. Sheng \& F. F. H. Nah (2006): "Use of a classroom response system to enhance classroom interactivity". Education, IEEE Transactions on, 49 (3), 398-403.

G. Siemens (2005): "Connectivism: A learning theory for the digital age". International Journal of Instructional Technology and Distance Learning, 2(1), 3-10.

J. R. Stowell \& J. M. Nelson (2007): "Benefits of electronic audience response systems on student participation, learning, and emotion". Teaching of Psychology, 34(4), 253-258.

K. Stepanyan, K. Borau \& C. Ullrich (2010): “A social network analysis perspective on student interaction within the Twittermicroblogging environment". Proceedings of Advanced Learning Technologies (ICALT), 2010 IEEE 10th International Conference, 70-72.

S. Stieger \& C. Burger (2010): "Let's go formative: Continuous student ratings with Web 2.0 application Twitter". Cyberpsychology, Behavior, and Social Networking, 13(2), 163-167.

G. Tur \& V. I. Marin (2015): "Enriqueciendo el aprendizaje con social media: las percepciones del alumnado sobre Twitter usado en una actividad de debate". NAER New Approaches in Educational Research, 4(1), 51-59. 
J. D. Ophus \& J. T. Abbitt (2009): "Exploring the potential perceptions of social networking systems in university courses". Journal of Online Learning and Teaching, 5(4), 639-648.

S. Osuna-Acedo, C. Marta-Lazo \& D. Frau-Meigs, (2018). "De sMOOC a tMOOC, el aprendizaje hacia la transferencia profesional: El proyecto europeo ECO”. Comunicar, 26(55), 105-114.

S. Özsoy (2011): "Use of New Media by Turkish Fans in Sport Communication: Facebook and Twitter". Journal of Human Kinetics, 28, 165ᄀ-176.

Statista (2018): Penetración de las redes sociales en España de 2010 a 2017. Accesible en https://es.statista.com/estadisticas/474955/redes-socialestasa-penetracion-usuarios-prevision-espana/

N. Wright (2010): “Twittering in teacher education: Reflecting on practicum experiences". Open Learning, 25(3), 259-265.

M. M. Zerega-Garaycoa (2015): "Un “tuiterazo" por la independencia: una experiencia del uso de Twitter para la enseñanza de Historia". AtoZ, novas práticas em informação e conhecimento, 4(2), 74-83. DOI: 10.5380/atoz. v4i2.43596 enrollment courses?" Journal of Science Education and Technology, 17(5), 437-443. 



\title{
La audiencia activa en la ficción transmedia: plataformas, interactividad y medición
}

Jorge Vázquez-Herrero [- Universidade de Santiago de Compostela (España) - jorge.vazquez@,usc.es

Ana González-Neira - Universidade da Coruña (España) agonzalezn@udc.es

Natalia Quintas-Froufe - Universidade da Coruña (España) n.quintas.froufe@udc.es

Cómo citar: J Vázquez-Herrero, A González-Neira, N Quintas-Froufe (2019): "La audiencia activa en la ficción transmedia: plataformas, interactividady medición. En V Tur-Viñes/M J González-Río/R S Contreras-Espinosa (Eds.) Jóvenes / Medios y cultura colaborativa. Cuadernos Artesanos de Comunicación, cac157, pp 69-99. La Laguna (Tenerife): Latina. DOI: $10.4185 / \operatorname{cac} 157$

\begin{abstract}
s
Introducción. Los cambios en el panorama televisivo han dado pie a nuevas formas de producción y de consumo que imponen desafíos en la monitorización de la audiencia. Este artículo profundiza en las transformaciones de la medición de audiencia a través del estudio de caso de la serie de RTVE Si fueras tú, primera serie de ficción nativa, interactiva, transmedia. Metodología. Se realiza un análisis de los soportes y plataformas oficiales que conforman el universo transmedia de la serie de ficción para posteriormente estudiar las posibilidades de interacción y la actividad de la audiencia en cada una de ellas. Resultados. Los datos muestran que Facebook e Instagram concentran la mayor parte de la actividad del universo transmedia,
\end{abstract}


además se identifica una rutina semanal en la combinación de plataformas y la integración de la audiencia activa. Discusión y conclusiones. Se constata la imposibilidad de cuantificar de forma estandarizada la audiencia transmedia y se señalan retos de futuro.

\section{Keywords}

Audiencia transmedia; RTVE; televisión pública; medición de audiencia; participación.

\section{Contents}

1. Introducción. 2. Productos transmedia en televisión. 3. Metodología.

4. Resultados. 4.1. Descripción de las plataformas y soportes y sus posibilidades de interacción. 4.1.1. Facebook. 4.1.2. Instagram. 4.1.3. Twitter. 4.1.4. WhatsApp. 4.1.5. YouTube. 4.1.6. Spotify. 4.1.7. Televisión convencional. 4.1.8. Película. 4.1.9. La web Playz. 4.2. Consumo de la serie. 5. Discusión y conclusiones. 6. Notas. 7. Referencias.

\section{Introducción}

— N los últimos años la televisión se ha visto obligada a redefinir su Unaturaleza impulsada por los cambios tecnológicos y empresariales. Los dispositivos móviles, la hiperconectividad, la web 3.0, las redes sociales y la aparición de nuevos actores en el sector han propiciado nuevas formas de visionado resumidas en la máxima anywhere, anytime, any device propias de la televisión líquida (QuintasFroufe \& González-Neira 2016).

Se han alterado los factores básicos que definían tradicionalmente la televisión como eran el tiempo (el espectador ya no está sujeto a una parrilla para el consumo de un espacio), el lugar (el acceso a internet facilita el consumo en soportes que van más allá del televisor como son la tableta, ordenador o los teléfonos inteligentes) y los emisores (junto a las cadenas tradicionales conviven otros operadores de muy diversa naturaleza como Movistar+, Vodafone Tv, Facebook, HBO, Netflix o Amazon).

En este contexto mediático una de las mayores preocupaciones del sector son los hábitos de consumo de los jóvenes, no solo por lo que 
se refiere al presente, sino en cuanto serán protagonistas del futuro y actores de la economía de los próximos años. Diversos estudios apuntan al progresivo abandono de la televisión convencional por parte de los jóvenes si bien, siguen siendo consumidores muy activos de productos audiovisuales.

Esta realidad obligó a los actores tradicionales, es decir, a las cadenas consagradas, a introducir cambios en la creación, producción y distribución de contenidos audiovisuales (Lamelo, 2016). Apostaron por nuevos productos como la aplicación de la realidad virtual, la gamificación del contenido, las series transmedia, interactivas, los documentales interactivos, las webseries, en los que se invierte en la interactividad que a su vez favorece la fidelización (Tur-Viñes, 2015). El objetivo de toda esta innovación es buscar a la audiencia joven en otras realidades, otros formatos y mantenerlas fieles a los productos emitidos, frente a la competencia de nuevos players como $\mathrm{HBO}$ o Netflix. Algunas de las características de los millennials definen las estrategias adoptadas recientemente. Se trata de un sector de la población eminentemente digital, que prioriza la experiencia de usuario. Están acostumbrados a la interactividad, a ser productores de mensajes en lugar de pasivos espectadores, a consumir con el móvil en la mano mientras emiten nuevos mensajes. Este público joven con amplia experiencia digital demanda algo más que el simple visionado. Se interesan por nuevas experiencias transmedia que aúnen los diferentes prismas en los que discurre su rutina como son las redes sociales, la web o la gamificación y que se favorezca su capacidad productora de mensajes. Como indica Scolari (2014), "las narrativas transmedia, en este contexto, se presentan como una posible solución -seguramente no la única- para afrontar la atomización de las audiencias".

La interactividad y la participación son requisitos imprescindibles para un público muy acostumbrado a compaginar su papel de receptor y emisor de mensajes. Como ya indicaba Jenkins hace más de 15 años "Younger consumers have become information hunters and gatherers, taking pleasure in tracking down character backgrounds and plot points and making connections between different texts within the same franchise" (Jenkins, 2003). 
Se hace necesario, por lo tanto, poner en marcha otras herramientas para afrontar estas nuevas realidades televisivas transmedia, así como estudiar qué estrategias se están empleando para favorecer la captación de esta audiencia (Herrero de la Fuente, 2017). Como indica Davis (2013) en cada apuesta innovadora existe una preocupación por el retorno económico de la inversión realizada (Cascajosa, 2016; Simons, 2014). De ahí la importancia de disponer de datos que avalen el éxito o fracaso de una producción. El sector audiovisual precisa esos datos no solo como moneda de cambio ante la publicidad sino como elemento de análisis de las nuevas estrategias que se ponen en marcha dirigidas principalmente al público más joven.

\section{Productos transmedia en televisión}

El proceso de convergencia y la cultura de participación han propiciado la difusión de numerosas producciones transmedia (Costa, 2016). El panorama antes descrito ha favorecido la apuesta por diferentes experiencias transmedia, entendidas como aquellas que desarrollan su narrativa a través de diferentes plataformas, soportes o canales que se complementan entre sí al tiempo que se favorece la interacción del espectador en el desarrollo narrativo del producto (Jenkins, 2003). Por lo tanto, este concepto de productos transmedia para televisión agrupa una vertiente de desarrollo narrativo en plataformas variadas, así como un componente imprescindible de interactividad del usuarioespectador (García, 2011) que a su vez puede dar lugar a la creación de comunidades de fans (Lacalle \& Castro, 2018). Son estos consumidores, o mejor dicho, prosumidores, los que contribuyen al desarrollo narrativo del producto (Lastra, 2016).

A partir de los trabajos de Jenkins (2003), inspirados en parte por las aportaciones de Kinder (1991) las investigaciones de la comunidad académica se han centrado principalmente en la narrativa transmedia (Saavedra-Bautista, Cuervo-Gómez \& Mejía-Ortega, 2016; Torrico, 2017; Ivars \& Zaragoza, 2018) dejando de lado otras perspectivas como el estudio de las audiencias.

En España han sido objeto de análisis las experiencias transmedia de distintas series de televisión (Costa, 2013; Rodríguez, Ortiz \& Sáez, 2014). El Ministerio del Tiempo (2015-2017) es la que ha concentrado mayor número de análisis (Cascajosa, 2015; Paíno \& Rodríguez, 2015; 
Rodríguez-Mateos \& Hernández-Pérez, 2015; Establés, 2016; SánchezCastillo \& Galán, 2016; Scolari \& Establés, 2017; Cascajosa \& Molina, 2017). Sin embargo, en absoluto fue la primera experiencia en España en apostar por el desarrollo transmedia. En 2011, a raíz de la serie de Antena 3 El Barco, se crearon los twittersodios (Grandío \& Bonaut, 2012; Deltell, Claes \& Osteso, 2013; Fernández, 2013). Otros ejemplos de estudios de este corte son los realizados en torno a Águila roja de RTVE (Costa \& Piñeiro, 2012; Scolari, Jiménez \& Guerrero, 2012; Guerrero, 2014; Franquet \& Villa-Montoya, 2014), Pulseras rojas (TurViñes \& Rodríguez-Ferrándiz, 2014), Isabel (Franquet \& VillaMontoya, 2014; Establés, 2016), Victor Ros (Barrientos-Bueno, 2015; De la Fuente, Cortés \& Martínez, 2016) o Carlos Rey Emperador (Carreño, 2016). En algunos casos se realizaron comparativas con series españolas y otras extranjeras como King fury (Lastra, 2016), Juego de Tronos (Guerrero, 2014), Skins (Grandío \& Bonaut, 2012). Las aportaciones a nivel internacional se completan con trabajos sobre otras series como Lost (Pearson, 2009; Scolari, 2014), Doctor Who (Perryman, 2008), House of Cars (Vasques-Ferreira \& Magalhães-Costa, 2018), Fringe (Guerrero, 2015) y Sanningen om Marika (Denward, 2012). Junto al desarrollo de la estrategia transmedia, varios estudios destacan las aportaciones de los espectadores/fans sobre todo en los estudios acerca de El Misterio del tiempo (Miranda \& Figuero, 2016; Lastra, 2016; Scolari \& Establés, 2017; Torregrosa-Carmona \& Rodríguez-Gómez, 2017), y resaltan su naturaleza prosumidora o el problema de los derechos de autor de los públicos de las narrativas transmedia (DíazNoci \& Tous-Rovirosa, 2012). Si bien el género de ficción ha concentrado gran parte de la atención por los académicos, el fenómeno transmedia también se ha analizado en otro tipo de contenidos como los talent show (Oliva-Rota \& Pérez Latorre, 2011).

Menos atención se ha dedicado a la medición de la audiencia transmedia ya que los estudios abordados desde la perspectiva del público destacan su papel creador sin llegar a establecer métricas de análisis. El proyecto europeo Eurotransmedia ${ }^{1}$ trabajó sobre el desarrollo de metodologías en medición de audiencias. Sobre esta

\footnotetext{
${ }^{1}$ El proyecto europeo Eurotransmedia sobre medición de audiencias se puede consultar en: https://cordis.europa.eu/result/rcn/194555_en.html.
} 
cuestión también cabe destacar las aportaciones de Evans (2011), Davis (2013), Simons (2014), Cascajosa (2016) y Costa (2016).

\section{Metodología}

Ante este escenario de transformación para la televisión, y en relación a una audiencia con comportamientos renovados, las preguntas de investigación que vertebran este estudio son las siguientes:

P.I.1. ¿Cuáles son las plataformas y soportes que conforman el universo transmedia y las posibilidades de interacción que ofrecen como recursos en el escenario transmedia?

P.I.2. ¿Qué acciones se desarrollan desde la producción de una serie para estimular la interactividad y participación de la audiencia transmedia en torno a un producto audiovisual?

P.I.3. ¿Qué mediciones y análisis de la audiencia transmedia y de su consumo se realizan de un producto audiovisual en la actualidad?

P.I.4. ¿Es posible determinar a día de hoy el éxito o fracaso de un producto en función de su audiencia transmedia?

El principal objetivo de este artículo es describir y analizar todos los soportes y plataformas de carácter oficial que se ofrecen desde la producción de una serie de ficción para posteriormente estudiar la actividad de la audiencia en cada una de ellas. De modo que se profundizará en los roles de la audiencia activa y la medición de los impactos comunicativos en un proceso de carácter transmediático.

El objeto de estudio de esta investigación es la webserie Si fueras tú, producida por Atomis Media y RTVE, una adaptación de la serie de ficción neozelandesa Reservoir Hills (2009-2010) realizada por el mismo equipo de El Ministerio del Tiempo. La serie está dirigida a un público juvenil y protagonizada por un reparto joven con gran presencia y seguidores en las redes sociales. La ficción consta de ocho capítulos más un tv-movie final y fue emitida en streaming por la nueva plataforma 
de contenidos digitales de RTVE Playz y La 1 (únicamente el primercapítulo y un tv-movie final ${ }^{2}$ ).

La plataforma de vídeo online Playz, lanzada en octubre de 2017, ofrece contenidos audiovisuales originales e interactivos (principalmente ficción y entretenimiento) destinados a un público joven con el fin de que estos nuevos públicos interactúen en este espacio digital. Playz. pretende ser la apuesta digital de RTVE para competir con otros portales similares como Mtmad (Mediaset) o Flooxer (Atresmedia).

La justificación del objeto de estudio reside, por una parte, en que es la primera serie de ficción nativa interactiva transmedia de producción española. Los usuarios decidían cada semana la trama del guión en función de las votaciones en dos redes sociales, Facebook e Instagram, durante las veinticuatro horas posteriores a su emisión. Según la decisión tomada por el público se escribía y grababa el capítulo que se emitiría la semana siguiente.

Por otra parte, como servicio público de televisión estatal, y tal como se recoge en el Mandato Marco (2008), RTVE debe participar en el progreso tecnológico y utilizar las diferentes tecnologías y vías de difusión desarrollando nuevos servicios interactivos con contenidos de calidad, diversos y equilibrados para todo tipo de público además de alcanzar en el sector audiovisual una posición destacada que garantice la suficiente presencia en la sociedad. Como apuntan Franquet \& VillaMontoya (2014) y Franquet, Villa-Montoya \& Bergillos (2013), ampliar las herramientas que favorezcan la participación de la audiencia, integrando los contenidos derivados de esta participación, es uno de los modos que los organismos de radiodifusión pública tienen para crear estrategias comerciales que les permitan seguir siendo actores principales en esos nuevos escenarios tecnológicos.

La metodología empleada será el estudio de caso (Yin, 1989; Coller, 2000) por ser el más adecuado para las características particulares de la investigación. Asimismo, se realizaron entrevistas a expertos involucrados en la creación de esta serie de ficción y la puesta en marcha de la estrategia digital de la serie como Ignacio Gómez

${ }^{2}$ Cada capítulo duraba en torno a 10 minutos a excepción del primer capítulo (20 minutos) y de la tv-movie final (80 minutos). Los capítulos fueron emitidos semanalmente desde el 11 de septiembre al 30 de octubre de 2017. 
Hernández (director de Director de Análisis y Nuevos Proyectos de RTVE), Pablo Lara (productor transmedia de la serie) y Agustín Alonso (del Departamento de Transmedia y Contenidos Digitales de RTVE).

El análisis de cualquier producción transmedia supone el estudio de sus elementos principales: el universo narrativo, las plataformas de expansión de ese universo y los prosumidores que interactúan con el contenido (Lastra, 2016). Este artículo se centra en el análisis de la audiencia transmedia, por lo que hará especial hincapié en los dos últimos elementos de la tríada antes enunciada.

En una primera fase se identificaron las plataformas y soportes que conforman el universo transmedia de la ficción: la televisión, Facebook, Instagram, Twitter, WhatsApp, YouTube, Spotify y la web Playz. Para el análisis de cada plataforma se creó un libro de códigos específico con categorías comunes (contenido nativo o no; posibilidades de interacción y respuesta del usuario; temporalidad de los contenidos; público objetivo; interconexiones; recursos interactivos; número de usuarios participantes) que permitieran establecer relaciones comparativas entre las plataformas.

Para la recopilación de datos se realizó una monitorización automática a través de la API de Facebook y Twitter y manual en los restantes soportes y plataformas durante el periodo de actividad de la serie, del 4 de agosto al 9 de diciembre de $2017^{3}$.

\footnotetext{
${ }^{3} \mathrm{El}$ seguimiento de todas las plataformas comprendió el periodo activo de la serie: desde el inicio de actividad el 4 de agosto de 2017, con la activación de perfiles, hasta el 9 de diciembre, tras la emisión de la tv-movie. Los datos puntuales, como número de visualizaciones, comentarios o seguidores totales, se corresponden con el cierre de la serie a 9 de diciembre de 2017. Por otra parte, la información relativa a votaciones fue publicada por la serie tras el cierre del periodo de participación del público, 24 horas después del estreno de cada capítulo. En cuanto a los datos facilitados por RTVE relativos a tráfico al sitio web, visitantes únicos y reproducción de vídeos, estos comprenden desde el inicio de la serie hasta una semana tras la emisión del último capítulo.
} 


\section{Resultados}

\subsection{Descripción de las plataformas y soportes y sus posibilidades de interacción}

Tras la recopilación de datos se detallan las acciones emprendidas en los diferentes soportes en los que se desarrolló la ficción.

\subsubsection{Facebook}

Si fueras tú ha empleado Facebook para generar comunidad en torno al producto y favorecer su fidelización. Se trata de una plataforma donde han experimentado con la interacción de los usuarios, además de mantener un canal actualizado de información con avances $y$ videoencuentros con los actores protagonistas antes del estreno. Con cada episodio anunciaron la emisión y estrenaron simultáneamente con el sitio web de Playz, compartieron posteriormente el enlace al capítulo y material extra y de making of, así como notas publicadas en otros medios e información relativa a los actores. Las acciones más singulares en esta plataforma han sido las votaciones -los usuarios han elegido a través de las reacciones de Facebook cómo continuaría la serie en la siguiente semana- y los chats en directo con Alba, la protagonista.

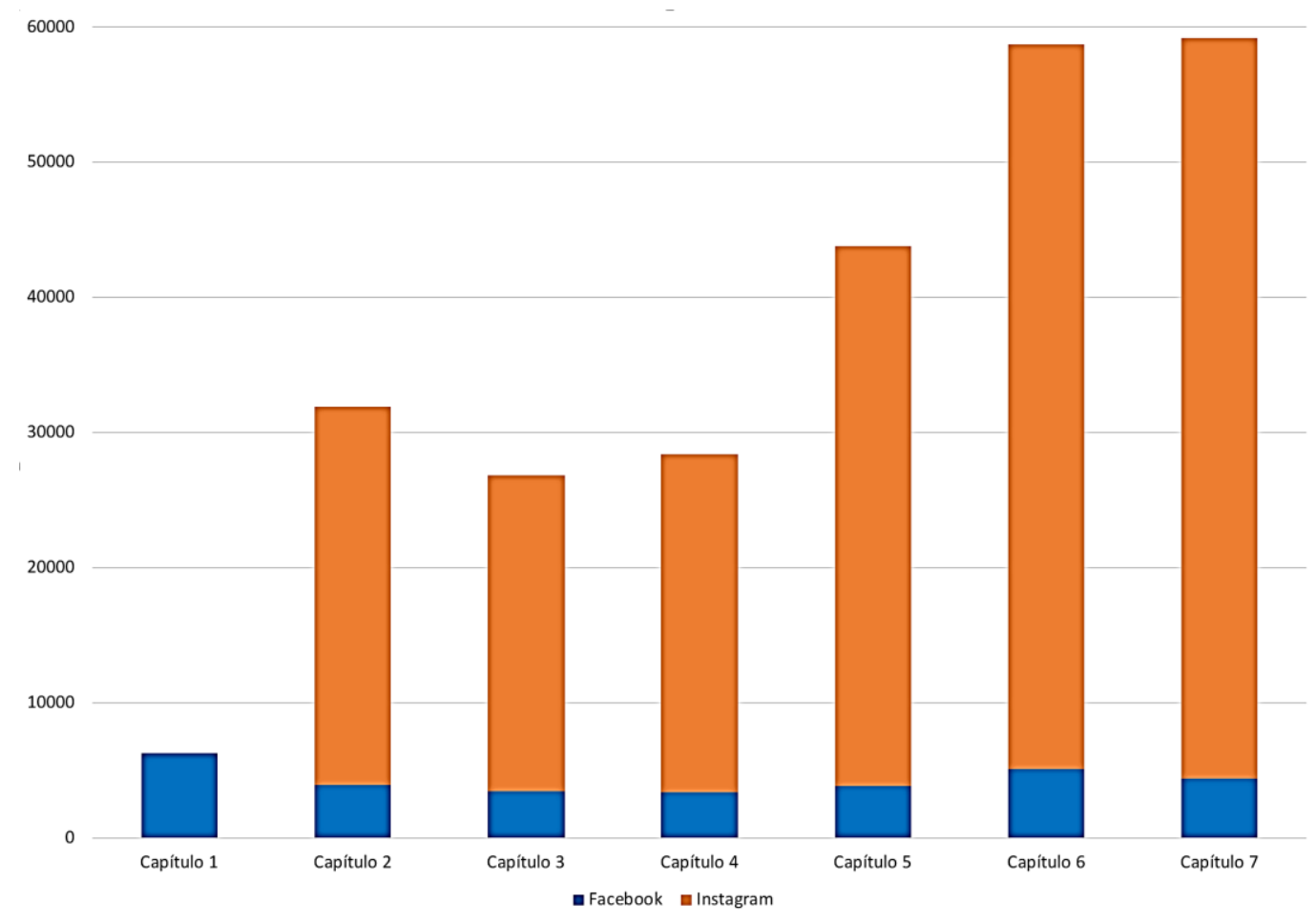


Gráfico 1. Votos del público por red social. Fuente: elaboración propia

Facebook permite, de forma nativa, realizar comentarios, compartir una entrada y reaccionar a ellas. La producción ha demandado la participación de los usuarios en dos momentos fundamentales cada semana: elegir el camino de la historia y mantener un chat en directo con Alba tras el estreno en línea del episodio. El contenido que ha generado mayor actividad son los chats -hasta 76.000 visualizaciones el primero de ellos y 2.500 comentarios-. Los comentarios reflejan opiniones, mencionan a otros usuarios para que vean el contenido o realizan preguntas, en este sentido, el equipo tiende a dar respuesta a las dudas específicas que plantean. Por otra parte, el vídeo es uno de los recursos más empleados ya que el más visto ha alcanzado las 115.000 visualizaciones, que se corresponde con una de las votaciones para decidir la continuación de la serie (9 de octubre de 2017). Estas decisiones son, además, las publicaciones que acumulan mayor número de reacciones.

La característica principal de la serie fue la posibilidad de que el público decidiera cómo continuaría la semana siguiente. En el gráfico 1 se percibe la evolución in crescendo de los votos en Instagram (que se incorpora en la segunda semana), mientras que en Facebook comienza con un ligero descenso para repuntar en los tres últimos capítulos.

La participación muestra una tendencia creciente: tras el primer capítulo se registraron 6.225 votos y el capítulo 7 alcanzó el máximo de 59.206. Una vez que abrieron las votaciones a través de Instagram, la participación desde Facebook quedó como un dato residual, por debajo del 15\%.

En un esfuerzo por trazar conexiones con el resto de plataformas, en la página de Facebook se hizo referencia a Instagram en tres ocasiones: invitando a ver mensajes publicados por Alba con contenido extra y a opinar sobre el final de la serie y su futuro a través de Instagram Stories. Teniendo en cuenta que Playz, como parte del sitio web de RTVE, es el núcleo principal donde se sitúa el contenido, también ha sido vinculado para que los usuarios pudieran consumir bajo demanda los episodios de la serie. Como caso particular, llegaron a compartir un vídeo de YouTube realizado por usuarios sobre las teorías que sostienen el argumento de la serie (13 de septiembre de 2017). 
Facebook juega un papel importante en la estrategia transmedia, en cuanto a espacio de conversación y relación con los usuarios, que han respondido significativamente a aquellos contenidos más característicos y diferenciados -votaciones y directos-. Sin embargo, la estrategia no destaca por conectarse al resto del universo transmedia salvo los casos específicos que se han expuesto. Esta red social está asociada a la creación de comunidad, cuestión que plantea un desafío para su gestión tras la emisión programada de la serie, ya que no hay un seguimiento para la audiencia que llega al producto tras el estreno del último episodio.

\subsubsection{Instagram}

Esta red social ha seguido una pauta muy similar a Facebook, destacando la información relativa a la serie, los personajes y los actores antes de su estreno. Con cada episodio se ha anunciado su disponibilidad bajo demanda, han habilitado las votaciones a partir del segundo capítulo -según la producción en los perfiles oficiales por demanda del público, pues es en Instagram donde se encuentran sus seguidores- y comunicaron los resultados de las mismas. En esta plataforma, destacan los contenidos extra publicados como píldoras que desvelan información complementaria al argumento que se desarrolla en el producto audiovisual: conversaciones en WhatsApp de la protagonista, archivos policiales, escenas no emitidas, etc. Por otra parte, han publicado material de making of, mensajes de los actores y del equipo y avances. Además del perfil oficial de la serie, Alba también tiene el suyo personal, aunque la actividad ha sido baja.

En Instagram han aprovechado su carácter visual para publicar más contenido extra, también a través de las historias efímeras, especialmente para mostrar el rodaje. Destacan los vídeos grabados por los actores para invitar a la fiesta de Halloween -el vídeo de Óscar Casas (otro de los protagonistas) superó las 110.000 reproducciones-, evento en el que participaron fans de la serie, así como otros contenidos relacionados con ellos: la celebración de cumpleaños de Óscar o el resumen de la serie elaborado por María Pedraza (Alba en la ficción). En este sentido cabe destacar que la serie se ha visto beneficiada por el arrastre que provoca la enorme fama que tienen algunos de los protagonistas en las redes sociales. Las opciones nativas para interactuar son el comentario y la reacción, superando los 47.000 
likes en una de las opciones votadas (23 de octubre de 2017) -estas votaciones tuvieron gran acogida y llegaron a los 59.206 votos a través de Instagram en el penúltimo episodio-.

La participación propia de la plataforma se ve enriquecida con iniciativas promovidas desde la producción, como las votaciones o la llamada a enviar opiniones a través de stories. En cuanto a los comentarios, se identifica un volumen considerable -hasta 2.470 en una de las votaciones- y el equipo ha atendido preguntas sobre cuestiones específicas relacionadas con la emisión de la serie.

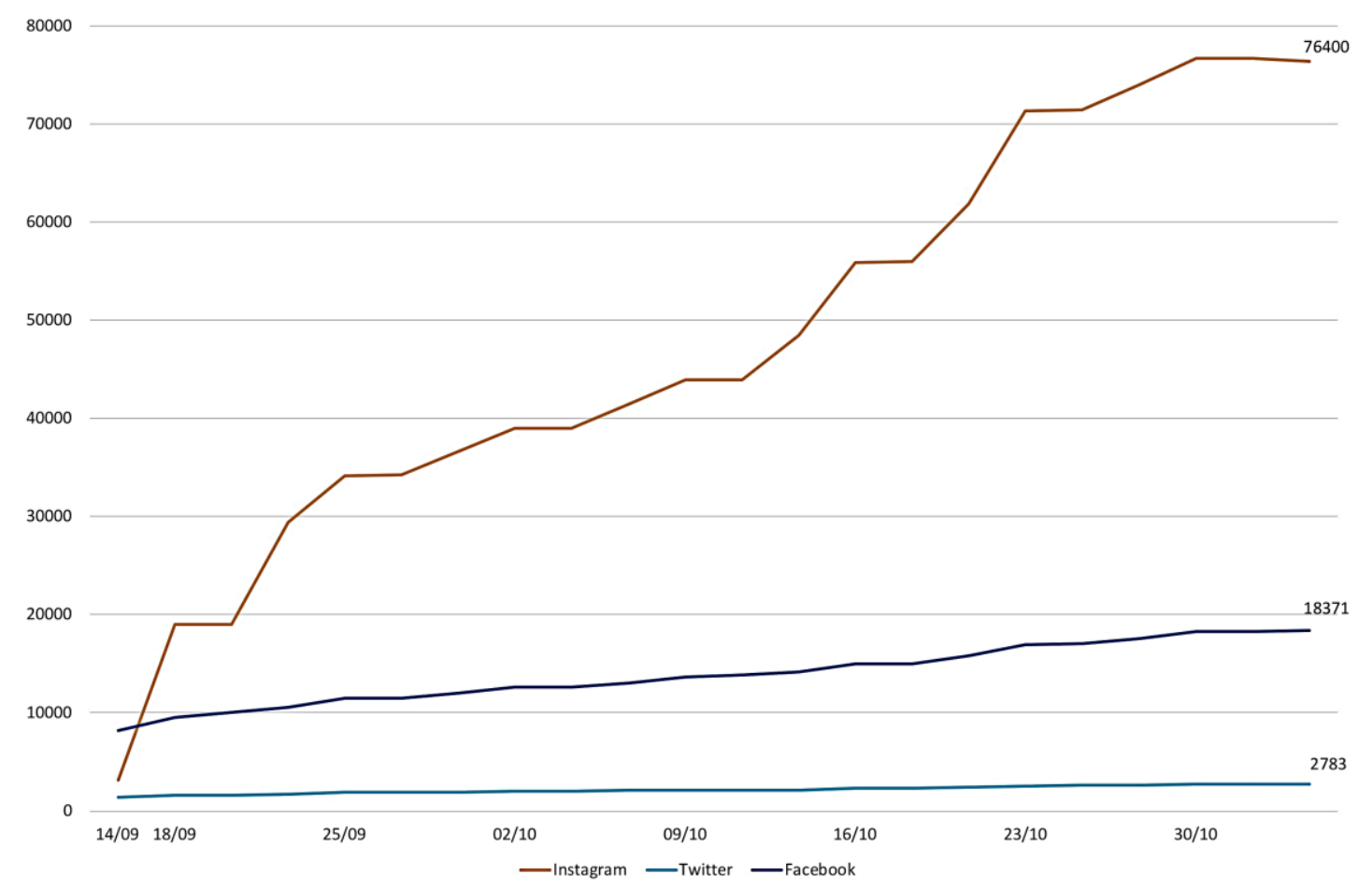

Gráfico 2. Número de seguidores por red social. Fuente: elaboración propia

Esta plataforma facilitó una vía alternativa de comunicación con la protagonista, que contó con un perfil personal de baja actividad. Anunciaron su teléfono para hablar con ella a través de WhatsApp y promovieron la participación de los fans en el rodaje, además de publicar algunos contenidos que solo se encuentran en esta red, entre los que destacan conversaciones o fotos recibidas y vídeos de Alba dirigidos a los espectadores. En general, el contenido se adapta a Instagram pero muestra una alta coincidencia con el publicado en Facebook, lo que dificulta que la audiencia navegue entre plataformas para complementar la experiencia, a lo que se suma que no es posible incorporar enlaces en las publicaciones de esta red. La diferenciación 
se encuentra en las propias características de cada plataforma, más que en la estrategia planteada.

El gráfico 2 demuestra el fuerte tirón que tuvo la serie en Instagram frente a Facebook y Twitter. Mientras en estas dos últimas el número de seguidores se incrementa muy lentamente, Instagram protagoniza una de las plataformas estrella, por lo que la convierten en escenario de las votaciones.

\subsubsection{Twitter}

La rutina en esta red social sigue la pauta de las anteriores, siendo las opciones nativas de Twitter la respuesta o mención, el retuit y la reacción. El volumen total de tuits fue de 1.584, de los cuales 157 fueron con contenido original, el resto eran respuestas o retuits. Publicaron avances, notas en medios, introducciones y promociones de la serie antes del estreno. Con cada episodio emitido, difundieron su estreno y la disponibilidad bajo demanda en RTVE.es, anunciaron las votaciones y sus resultados, así como el chat en directo que se producía en Facebook semanalmente con la protagonista. Entre episodios, en Twitter han apostado por compartir mensajes de usuarios, en ocasiones añadiendo algún comentario, agradecimientos, making of, también mencionando a los propios actores. La mayor parte del contenido se encuentra también en otras plataformas, salvo extras previos al lanzamiento y la mención a la campaña de la Fundación de Ayuda contra la Drogadicción en relación con la serie.

\subsubsection{WhatsApp}

Con la finalidad de crear comunidad y favorecer la fidelización lanzaron la posibilidad de whasappear con la protagonista de la serie, Alba, a través de su número de teléfono. Participaron en esta iniciativa 8.900 seguidores. Sin embargo, la experiencia no fue todo lo satisfactoria que se esperaba, porque no siempre se llegó a establecer la comunicación entre los solicitantes, y en el caso de que esta surgiese, se trataba en realidad de una comunicación unidireccional, en la que se lanzaban mensajes, pero no había diálogo o conversación con los usuarios. Por lo tanto, no se creaba la tan ansiada comunidad que propugnaban los productores. Durante este tiempo, Alba emitió 9 mensajes en los que se instaba a votar, se recordaba el estreno de un 
nuevo episodio y se enviaba material extra como fotografías, si bien en ningún caso es material exclusivo de esta plataforma para el universo transmedia de la serie. La aplicación también fue empleada para canalizar la participación cuando Alba pidió a los usuarios en Instagram que enviaran vídeos para ayudar a su amiga Rocío. Para el productor Pablo Lara no se trató de una buena experiencia, ya que por problemas técnicos no pudieron realizar conversaciones, sino que se originaron monólogos, por lo que no se consiguió el fin inicial.

Quedan al margen de esta investigación los grupos de WhatsApp creados por iniciativa de los propios espectadores.

\subsubsection{You'Tube}

En el lanzamiento de la serie hubo un canal propio, Si fueras tú serie, que disponía de más contenido extra y desapareció durante la emisión de esta ficción, al trasladar parte de los vídeos al canal de Playz y RTVE. En el canal de Playz en YouTube se distribuyeron todos los episodios, la película, así como otros materiales como tráiler y making of. A su vez el canal de RTVE en YouTube difundió material extra de la serie como el videoencuentro con los protagonistas, declaraciones de los actores sobre el final, entrevistas y vídeos explicativos sobre cómo participar. No se trata de ningún material exclusivo ya que bebe de los contenidos difundidos en Playz. Por lo tanto, el canal se ha empleado como extensión del visionado y zona de almacenaje de los capítulos, dándole opción a una vida más larga en la plataforma audiovisual más global. Hasta el 1 de noviembre hubo 1.281.251 reproducciones de capítulos completos (muy cercano a los datos de visionado a través de RTVE de 1.456.037). Es significativo también que los usuarios acudan más a esta plataforma para el consumo en diferido que al propio espacio de Playz:

\subsubsection{Spotify}

La incorporación de esta plataforma se realiza tras casi un mes de emisión de la serie. En las dos listas de reproducción (la BSO y la música que escucha la protagonista, Alba) tuvieron 357 y 266 seguidores respectivamente. Sin duda alguna es la que menos repercusión ha tenido a pesar de haber sido anunciada tanto en Facebook como en Twitter. 


\subsubsection{Televisión convencional}

El primer capítulo se emitió el 11 de septiembre en La 1 de RTVE a medianoche. Obtuvo un $5.9 \%$ de share y fue visto por 576.000 espectadores. Por lo tanto, la apuesta de RTVE, por horario y frecuencia de emisión en sus parillas tradicionales, demuestra que el público generalista no ha sido su objetivo prioritario. Dicha emisión funciona más como herramienta promocional de la nueva producción.

\subsubsection{La película}

Emitida el 8 de diciembre de 2017 también en horario de late night. Se realizó tras agrupar los diferentes capítulos de la serie. Alcanzó prácticamente los mismos datos de audiencia que el primer capítulo de la ficción con un 5\% de share y 567.000 espectadores. Cabe destacar que al no haberse emitido para Cataluña esto provocó una serie de quejas en las redes sociales entre los seguidores.

\subsubsection{La web Playz}

A través del espacio de Playz, el usuario tiene acceso a todos los capítulos, a la película y a material audiovisual extra como making of, videoencuentros, entrevistas, noticias, álbumes y explicación de cómo se puede votar. Esta web tendría que ser la nave nodriza de la producción transmedia en la que se almacena todo el material audiovisual de la serie, no obstante existe contenido que no se recoge allí y favorece la dispersión en las diferentes redes, dificultando un consumo posterior a la emisión en directo. Las posibilidades de participación en la web se limitan a compartir los contenidos en redes sociales.

Con el fin de conocer mejor los niveles de interactividad de la audiencia de Si fueras tú promovidos por la serie, se realizó una comparativa de las opciones que proponían las diferentes plataformas. Para la construcción de la tabla 1 se tomaron como referencia las posibilidades nativas de cada plataforma y los mecanismos creados por la producción para canalizar la participación, además de la clasificación previa de Scolari (2013) sobre el contenido generado por el usuario en la ficción transmedia. 


\begin{tabular}{|c|c|c|c|c|c|c|c|}
\hline Función & Interactividad & Facebook & Instagram & YouTube & Spotify & Web & WhatsApp \\
\hline Seguir/suscribirse & Baja & $\bullet$ & $\bullet$ & $\bullet$ & $\bullet$ & & $\bullet$ \\
\hline Reaccionar & Baja & $\bullet$ & $\bullet$ & $\bullet$ & & & \\
\hline Compartir & Baja & $\bullet$ & app externa & $\bullet$ & $\bullet$ & redes & $\bullet$ \\
\hline Comentar & Baja & $\bullet$ & $\bullet$ & $\bullet$ & & & \\
\hline $\begin{array}{l}\text { Participar en un } \\
\text { vídeochat en directo }\end{array}$ & Media & - & & & & & \\
\hline $\begin{array}{l}\text { Conversar con un } \\
\text { personaje }\end{array}$ & Media & & - & & & & - \\
\hline $\begin{array}{l}\text { Decidir continuación } \\
\text { de la serie }\end{array}$ & Alta & - & - & & & & \\
\hline Participar en rodaje & Alta & & & & & $\bullet$ & \\
\hline $\begin{array}{l}\text { Contenido generado } \\
\text { por el usuario }\end{array}$ & Alta & & & & & & - \\
\hline
\end{tabular}

Tabla 1. Niveles de interactividad de la audiencia. Fuente: elaboración propia

Tras examinar todo el universo transmedia de este producto, se detalló una semana tipo (gráfico 3) para conocer las posibilidades de interacción a disposición de la audiencia en las diferentes plataformas, principalmente en las redes sociales entre las que se producen conexiones reiteradas. Quedan al margen aquellas plataformas que tienen un rol complementario (web, YouTube, Spotify).

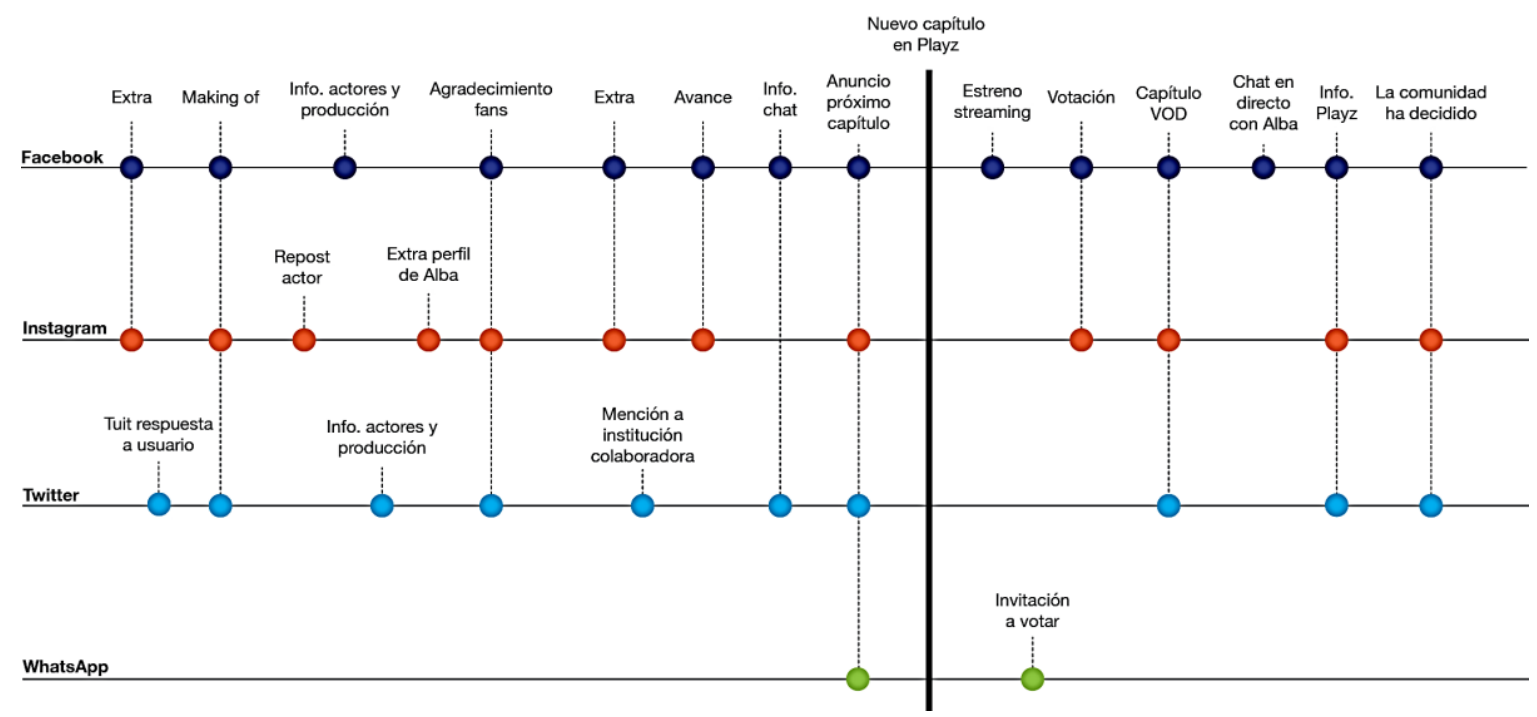

Gráfico 3. Semana tipo de desarrollo transmedia. Fuente: elaboración propia 


\subsection{Consumo de la serie}

Tras conocer la composición del universo transmedia de Sifueras tú, se analizó el consumo de esta serie por parte de la audiencia. De las entrevistas realizadas se concluye que el sentimiento de éxito en TVE es evidente. Las cifras obtenidas por Si fueras tú son las mejores de todos los productos lanzados por Playz hasta el momento del cierre de este trabajo. Durante su emisión hubo 944.486 visitantes únicos que han consumido contenidos de la serie en RTVE.es. Sin duda alguna, el éxito de la serie supone también el éxito para Playz ya que el 70,5\% de estos usuarios entraban por primera vez en la web de RTVE. Cabe indicar también que Instagram fue el soporte estrella de la ficción ya que alcanzó 76.700 seguidores. Además, favoreció también un tráfico de usuarios hacia la web de RTVE.es. De todas las visitas de usuarios nuevos que accedieron a los contenidos de Si fueras tú desde redes sociales, casi el $90 \%(89,7 \%)$ procede de Instagram. Hasta la actualidad, la serie transmedia ha tenido casi 7,7 millones de visualizaciones en el conjunto de las plataformas de distribución y el $71 \%$ de su público son menores de 34 años. De esta cifra, casi 1,6 millones proceden del visionado de la película.

Los datos acerca del consumo en directo en RTVE.es y en Facebook -donde lanzaron el streaming semanalmente- son muy similares, con una ligera caída entre el capítulo 3 y el 5 , repuntando a partir del 6. El capítulo 7 superó con creces al resto y el 8, el último, recuperó el nivel de los anteriores, ligeramente por encima. De los ocho capítulos: tres de los capítulos se vieron en directo más en Facebook mientras que a partir del capítulo 5 la preferencia de los espectadores se concentró en la web de RTVE.

En cambio, las visualizaciones on demand (web y YouTube) relativas al consumo en diferido del mismo día y al día siguiente muestran otra evolución: la línea es claramente ascendente. Solo el capítulo 4 rompió con la tendencia al alza. Por otra parte, hasta el capítulo 4 la mayor parte de las visualizaciones se producía en la web, mientras que a partir del capítulo 6 los datos en ambas plataformas son parejos. Las métricas muestran que YouTube incrementó el número de usuarios on demand a medida que se desarrollaba la ficción hasta el punto de que en el último capítulo igualó prácticamente el visionado de RTVE (103.480 frente a 103.637 espectadores, respectivamente). No obstante, en ambas 
plataformas se observa un incremento progresivo en la mayor parte de los capítulos, ya que en RTVE.es se pasó de 52.342 en el primer episodio a 103.637 en el último, mientras en YouTube el aumento fue aún más notorio al partir de 1.250 y llegar a 103.480 .

Otro de los indicadores de interés es el volumen acumulado de visualizaciones de los capítulos completos, es decir, en directo en las dos plataformas (RTVE.es y Facebook) y en diferido (RTVE.es y YouTube). En total, hubo 2.783.395 visualizaciones hasta el 1 de noviembre, de las cuales un 52,3\% provino del sitio web de RTVE, un $46 \%$ de YouTube y un 1,7\% de Facebook. A la vista de los datos por capítulos, la serie muestra una cierta estabilidad dentro de una caída progresiva. El capítulo 1 alcanzó las 529.863 visualizaciones y el segundo las 381.560, siendo los más vistos. A partir de ahí, fue cayendo hasta las 256.526 del capítulo final. Las métricas sobre visitantes únicos por capítulo reflejan una evolución semejante.

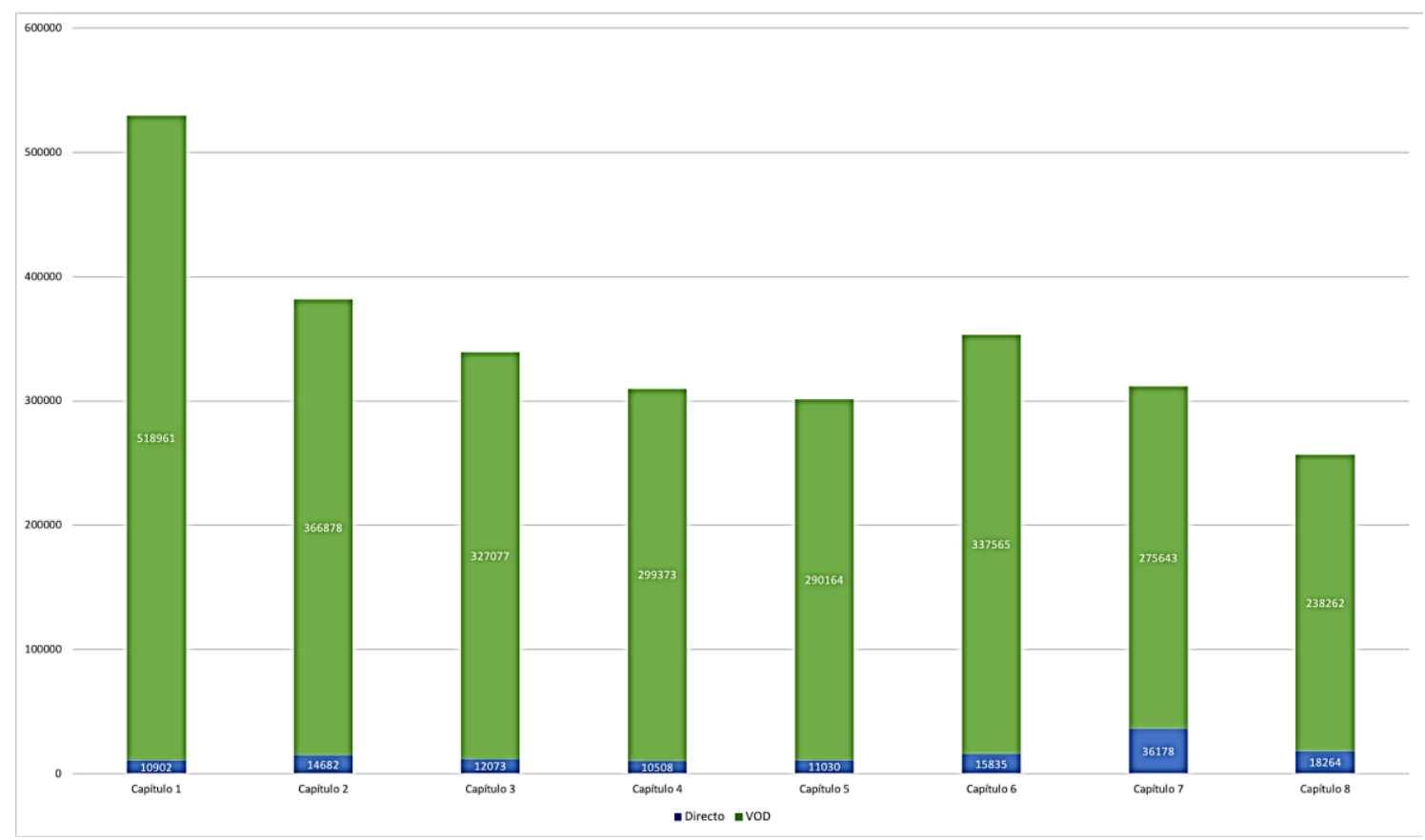

Gráfico 4. Visualizaciones de capítulos completos (directo y en diferido-VOD-). Elaboración propia a partir de datos de RTVE.

Estos datos demuestran que se trata de una serie de claro consumo en diferido. El número de usuarios que ven esta ficción en directo fue notablemente inferior en todos los capítulos a aquellos que la consumieron posteriormente. Ese visionado en diferido se produce principalmente en las primeras 24 horas, que es la franja de tiempo en la que el público puede votar sobre los finales alternativos. 
Otro dato llamativo (gráfico 5) es que el consumo procede principalmente de móviles (56,1\%), frente al 9,3\% de tabletas. Es decir, los dispositivos móviles son la principal fuente de tráfico de visionado de esta serie.

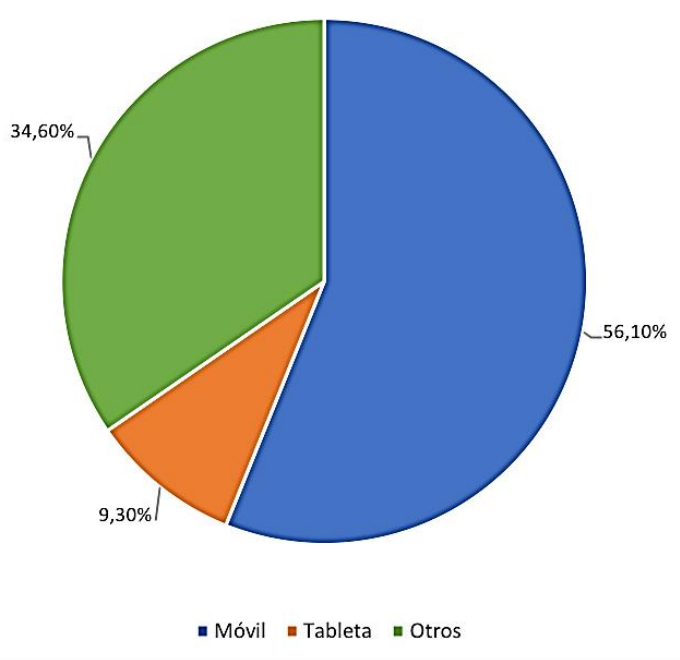

Gráfico 5. Dispositivo de acceso al contenido de Si fueras tú.

Elaboración propia a partir de datos de RTVE.

En referencia a los chats en directo con Alba en Facebook tras el estreno de cada capítulo entre el 1 y el 7, hay una caída progresiva exceptuando el capítulo 6. El capítulo 1 alcanzó las 42.941 reproducciones en directo y el último chat, tras el capítulo 7 , acumuló 5.587. El tiempo medio de visualización es bajo: entre los 41 segundos en el capítulo 7 y los 16 segundos en el capítulo 4.

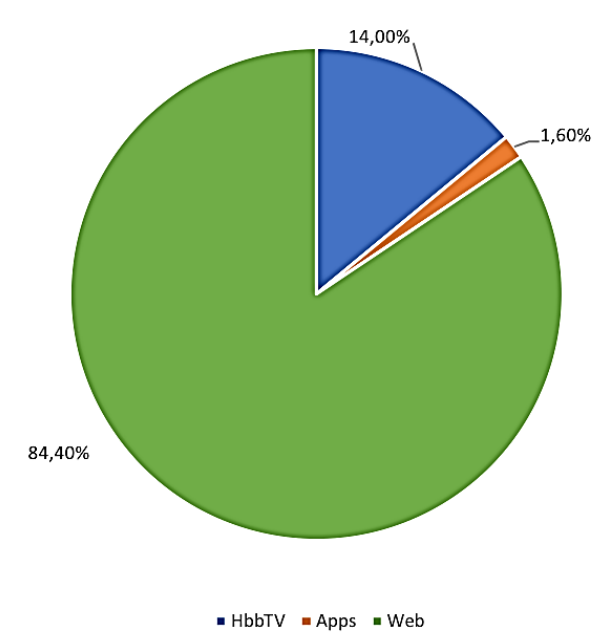

Gráfico 6. Plataforma de consumo de Si fueras tú. Elaboración propia a partir de datos de RTVE. 
La propuesta transmedia de la serie empleó diferentes plataformas, concentrando la mayor parte de contenido en el sitio web de RTVE. Por ello, existe un interés en conocer el perfil del usuario e identificar el origen del tráfico hacia ese espacio. De un total de 944.486 usuarios únicos en RTVE.es, entre el 29 de agosto y el 6 de noviembre, el 29,5\% eran recurrentes y un 70,5\% eran nuevos usuarios, uno de los datos más significativos que deja Si fueras tú. El 49,9\% de los visitantes llegaron a través de buscadores, un 39,8\% desde redes sociales, el resto a través de tráfico directo o enlaces. Del tráfico originado en redes sociales, un $89,7 \%$ proviene de Instagram -red social donde se ubica con mayor precisión el público objetivo de la serie en este momento-, el 8,3\% de Facebook y el resto de You'Tube y Twitter.

El vídeo es el contenido principal en las diferentes plataformas, las reproducciones han variado a lo largo de las semanas, mostrando su pico máximo en la de emisión del capítulo 6, que alcanzó un total de 1.014.055 reproducciones, siendo You'Tube la fuente principal, seguida de RTVE.es. En cuanto al volumen de reproducciones por plataforma, YouTube fue durante el periodo de emisión la que más contribuyó, en segundo lugar Instagram y a continuación el sitio web de RTVE y Facebook. Respecto a la distribución del consumo de vídeo a lo largo de la semana, los datos describen un patrón similar en todas ellas: máximo el día de emisión y caída progresiva el resto de la semana -los 3 ó 4 últimos días de la semana muestran datos mucho más bajos y semejantes-.

El producto transmedia implica un reto por cada una de las plataformas en las que se coloca contenido, pues se localizan públicos diferentes con hábitos distintos según la vía de entrada o el dispositivo de consumo. El tráfico acumulado a los contenidos en RTVE.es fue principalmente a través de la web $(84,4 \%)$, HbbTV $(14,0 \%)$ y apps $(1,6 \%)$; procedente de buscadores $(46,6 \%)$ y redes sociales $(42,8 \%) ; y$ con acceso desde el móvil (56,1\%), tablet (9,3\%) y una considerable franja restante asignada a "otros". Por tanto, el usuario tipo entró a través de la web, haciendo uso de un teléfono móvil y a través de buscadores o redes sociales. 


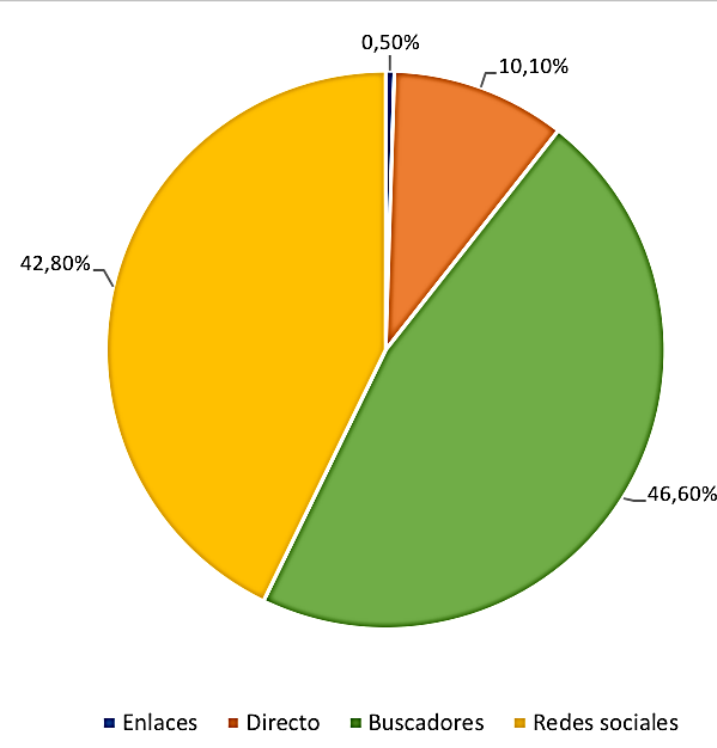

Gráfico 7. Origen del tráfico de Si fueras tú en RTVE.es.

Elaboración propia a partir de datos de RTVE.

La retención de usuarios permite conocer el comportamiento de aquellos que han accedido con anterioridad. Así, el 13,1\% de los usuarios que consumieron vídeo de Si fueras tú en la primera semana de emisión, lo hicieron también en la última. La retención va descendiendo con el paso de las semanas. Respecto al consumo que han realizado los mismos usuarios en RTVE.es, el 10,3\% visualizó contenido de Estoy vivo, el 6,2\% de MasterChef Celebrity 2 y el 6,0\% de El Ministerio del Tiempo.

Por último, las listas creadas en Spotify -una de banda sonora y otra con la música preferida de Alba- acumularon 357 y 266 seguidores respectivamente; el servicio de WhatsApp llegó a 8.900 usuarios; y 576 personas participaron en el concurso para asistir al rodaje del capítulo 7.

\section{Discusión y conclusiones}

Una vez examinado el universo transmedia de la webserie a través de la descripción de las plataformas y soportes seleccionados y las posibilidades de interacción que ofrecen (P.I.1), así como el análisis de las acciones que se desarrollaron desde la producción de la serie para estimular la interactividad y participación de la audiencia transmedia (P.I.2), se ha llegado a las siguientes conclusiones. En primer lugar, se considera que habría que explotar más la naturaleza intrínseca, características y dinámicas propias de cada soporte para evitar la alta 
coincidencia de contenidos detectada que puede llegar a dificultar la navegación y experimentación de los usuarios entre las plataformas. De tal modo que el movimiento de usuarios entre estas se viera beneficiado y favoreciera la creación de comunidad alrededor del producto. Prueba de ello es que los contenidos que mejor han funcionado son los más singulares de cada plataforma (por ejemplo, Facebook Live o las votaciones).

Mientras que en otros proyectos transmedia cada plataforma o soporte puede tratar de captar a una audiencia potencial diferente, en este caso no se observa que haya sido así al reiterar contenidos en las dos plataformas principales (Facebook e Instagram). Para evitar que en el salto de una plataforma a otra se introduzcan elementos que interrumpan el consumo del producto audiovisual, las estrategias de fidelización en cada una deben ser muy fuertes y sólidas. Por ello, se debería permitir que cada plataforma se comportara como una vía de entrada autónoma con material de carácter exclusivo pero que posibilitara a cada usuario trazar conexiones con el resto de soportes.

Dentro del conjunto de plataformas merece ser señalado el papel de YouTube respecto al consumo en diferido de la webserie: se convierte en una de las primeras fuentes de visionado, por encima incluso de la propia web de RTVE. Además, a medida que la webserie avanza se va afianzando como principal plataforma de visionado en el dato acumulado de reproducciones de vídeo, llegando a igualar el número de espectadores de RTVE en lo que respecta a capítulos completos vistos. El caso de Si fueras tú deja entrever la contraposición de una estrategia interactiva transmedia frente a la dinámica de la televisión convencional, vinculada a una emisión lineal y periódica. Como consecuencia, más allá del buen resultado de consumo en diferido, el visionado de la webserie fuera del periodo activo pierde sentido, pues la estrategia llevada a cabo en redes sociales y plataformas complementarias queda detenida al finalizar el lanzamiento de la serie.

En relación al público de la webserie en las distintas plataformas se observa que este es mayoritariamente femenino en todas ellas, aunque las franjas de edad varían en relación a la plataforma a la que se haga referencia, con preeminencia de la comprendida entre 18-24 años. 
En segundo lugar, el caso analizado destaca porque los dos elementos que construyen los productos transmedia, la narrativa y la interactividad, no avanzan en paralelo, sino que la narrativa de la serie se construye a partir de la interactividad y participación del usuario.

En tercer lugar, se ha detectado un uso deficiente del perfil personal de la protagonista Alba al presentar una muy baja actividad en WhatsApp, Instagram o Spotify, desaprovechando así la comunicación directa entre el personaje y la audiencia.

La estrategia transmedia es muy interesante para construir grupos de consumidores leales al producto audiovisual. Sin embargo, en este caso se ha detectado que la comunidad en torno al producto audiovisual se desvaneció y una parte de los usuarios de la webserie dejó de seguir los perfiles oficiales tras finalizar la emisión. La volatilidad de la audiencia dificulta la consolidación de procesos de fidelización de los públicos, de ahí que sea de gran interés conocer cuál es el ciclo de vida del producto audiovisual más allá del periodo de emisión para poder realizar un seguimiento de la audiencia que accede a la webserie una vez finalizada.

Con el fin de resumir los criterios que sostienen una relación transmedia entre la audiencia, el universo narrativo y la producción, a partir del estudio de caso de Si fueras tú, se enumeran los siguientes puntos clave descritos en el análisis:

1. Contenido: las plataformas deben ser únicas, complementarias y constituirse como puntos de entrada al relato; debe existir una estrategia para la concepción de un consumo transmedia.

2. Audiencia: hay un ajuste al público objetivo de cada plataforma y estas son vías de fidelización del público.

3. Participación: es un elemento definitorio de la propuesta transmedia, planificado o espontáneo, muestra niveles de interactividad entre el usuario y el producto.

4. Planteamiento temporal: la estrategia de emisión favorece un consumo periódico, en directo o posterior al estreno.

5. Datos de consumo para la evaluación del éxito respecto a las expectativas planteadas: visualizaciones, dispositivos, perfiles, retención y retorno. 
Emprender un proyecto transmedia es siempre más aventurado, en términos de retorno de la inversión, que un producto audiovisual convencional. Recordemos que estos públicos nativos digitales viven alejados de la televisión convencional, de ahí que la nave nodriza no sea la emisión televisiva convencional. Si fueras tú es claramente una apuesta de RTVE por realizar productos innovadores y cercanos a públicos más jóvenes, con un comportamiento mediático multitarea, y con perfiles en varias redes sociales. Sin embargo, RTVE como medio de comunicación público, tiene la ventaja de no estar tiranizado por la rentabilidad económica de su producción propia, lo que le permite presentar al público proyectos más arriesgados que los de otros grupos empresariales como Mediaset España o Atresmedia.

Tras las entrevistas y el trabajo de campo realizado se puede dar respuesta a la pregunta de investigación (P.I.3) y concluir que, a día de hoy, no existe una métrica estándar capaz de medir la totalidad de la audiencia transmedia. Cada soporte y plataforma dispone de sus propias métricas de análisis, lo que dificulta la posibilidad de establecer un único dato que aborde al conjunto de audiencia transmedia. La complejidad de esta medición es evidente ya que al establecerse entre diferentes soportes y plataformas exige la colaboración de varios actores, no siempre proclives a la comunicación pública de los datos al imponer barreras de protección que limitan el acceso a través de su API. Además, requeriría una estandarización de metodologías y métricas que desembocara en el desarrollo de un sistema de medición multiplataforma.

En consecuencia, sería preciso instaurar otros modos de medición en los que se tuviera en cuenta no solo el consumo audiovisual de la audiencia como ha puesto de manifiesto el caso de El Ministerio del Tiempo, sino también otras acciones antes imposibles de realizar (compartir, comentar, retuitear o guardar). La experiencia de la audiencia en los entornos transmedia actuales les permite interactuar, crear y realizar diversas acciones imposibles para las audiencias del pasado. De ahí que ya no interese únicamente conocer cuantitativamente a la audiencia sino la dimensión cualitativa por ser la más relevante en este nuevo entorno. Por ello, la medición de la audiencia transmedia no debería ser muestral como la audiencia televisiva convencional sino real aplicando técnicas de análisis Big data 
que permitieran rastrear la actividad de cada usuario en cada una de las plataformas y soportes que conforman el universo transmedia para observar cómo interactúan con cada uno y qué es lo que cada uno de ellos le aporta a su experiencia de usuario. De este modo se valoraría la dimensión cuantitativa y también la cualitativa de esta nueva audiencia en el conjunto de las plataformas empleadas.

Por lo tanto, responder a la pregunta de investigación (P.I.4) sobre la posibilidad de determinar si un producto audiovisual como esta webserie ha sido un éxito o un fracaso en función de la audiencia, tal como se realiza habitualmente en la televisión convencional para decidir su renovación, no sería posible en la actualidad debido a:

Por una parte, al ser contenidos desvinculados de los horarios de programación tradicional no se busca reunir a un mayor número de espectadores que la cadena rival ya que en este tipo de consumo no existe la competencia directa entre espacios televisivos como en las mediciones convencionales de televisión.

Por otra parte, desde la producción de la webserie tendrían que responder previamente a otros interrogantes como, por ejemplo: ¿qué número de reproducciones de la webserie se considerarían satisfactorias?, ¿qué número de seguidores podrían ser considerados suficientes?, ¿en qué periodo se mediría la audiencia transmedia?, ¿a quién se quiere llegar? etc... La respuesta a estas cuestiones permitiría poder realizar valoraciones más acertadas sobre los resultados finales de la audiencia de esta webserie.

En próximas investigaciones sería de utilidad analizar los procesos de reelaboración y reapropiación por parte de la audiencia que no se han abordado en este trabajo al no formar parte de la webserie y exceder al objetivo propuesto.

En definitiva, el análisis y medición de la audiencia transmedia se plantea como un reto de futuro que el sector audiovisual debe encarar con celeridad dada la proliferación de producciones transmediáticas a la que se está asistiendo en los últimos años. 
- Investigación financiada. Este artículo está elaborado en el marco de las actividades promovidas a través de la Red Internacional de Gestión de la Comunicación - XESCOM (Referencia: ED341D R2016/019), apoyada por la Consellería de Cultura, Educación e Ordenación Universitaria de la Xunta de Galicia.

\section{Referencias}

M Barrientos-Bueno (2015): “Expansión narrativa de Víctor Ros: Transmedia Storytelling en Twitter". Opción 31, n. 3, pp.161181.

J Carreño (2016): "Narrativas transmedia en la era de la sociedad móvil. Carlos, Rey Emperador". Fonseca 12, pp. 79-

95.http://dx.doi.org/10.14201/ fjc2016127995

C Cascajosa (2015): Dentro de El ministerio del tiempo. Madrid: Léeme.

C Cascajosa (2016): "Buscando al espectador serial

desesperadamente: la nueva investigación de audiencias y la serie El ministerio del tiempo". Dígitos 2, pp. 53-70.

C Cascajosa \& JP Molina (2017): "Narrativas expandidas entre la tradición y la innovación: construyendo el universo transmedial de El ministerio del tiempo". Tropelías: Revista de teoría de la literatura y literatura comparada 27, pp. 120-135.

https://doi.org/10.26754/ojs tropelias/tropelias.2017271544

X Coller (2000): Estudio de casos. Madrid: Centro de Investigaciones Sociológicas.

C Costa (2013): "Narrativas Transmedia Nativas: Ventajas, elementos de la planificación de un proyecto audiovisual transmedia y estudio de caso". Historia y comunicación social 18, pp. 561-574. http://dx.doi.org/10.5209/rev HICS.2013.v18.44349

M Costa (2016): Audiência transmídia: uma proposta de conceituação a partir das telenovelas da Rede Globo. Tesis presentada en la Universidade Federal de Pernambuco (Brasil). Recuperado el 20 de mayo de 2018 de https://repositorio.ufpe.br/handle/123456789/17437

C Costa \& T Piñeiro (2012): "Nuevas narrativas audiovisuales: multiplataforma, crossmedia y transmedia. El caso de Águila Roja (RTVE)". Icono 14 10, n. 2, pp. 6-28. https://doi.org/10.7195/ri14.v10i2.156 
L Deltell, F Claes \& J Osteso (2013): “Audiencias televisivas y líderes de opinión en Twitter. Caso de estudio: El Barco". Estudios sobre el mensaje periodístico 19, n. 1, pp. 347-364.

M Denward (2012): "Broadcast Culture Meets Role-Playing Culture: Consequences for Audience Participation" en The Book of Solmukohta 2008: Playground Worlds: Creating and Evaluating Experiences of Role-Playing Games. Pentagon Press: New Delhi.http://dx.doi.org/10.5209/rev ESMP.2013.v19.n1.4252 $\underline{6}$

C Davis (2013): “Audience Value and transmedia Products" en T Storsul \& A Krumsvik. Media Innovations. Goteborg: Nordicom, pp. 175-190.

J De la Fuente, S Cortés \& R Martínez (2016): "El inicio de la televisión transmedia en España: TVE y Víctor Ros”. Revista de la Asociación Española de Investigación de la Comunicación 3, n. 6, pp. 28-42.

http://www.revistaeic.eu/index.php/raeic/article/view/64

J Díaz-Noci \&A Tous-Rovirosa (2012): “La audiencia como autor: narrativas transmedia y propiedad intelectual del público. Algunas reflexiones jurídicas". El profesional de la información 21, n. 5, pp. 458-467. http://dx.doi.org/10.3145/epi.2012.sep.03

MJ Establés Heras (2016): "Entre fans anda el juego: audiencias creativas, series de televisión y narrativas transmedia”. Opción 32, n. 11, pp. 476-197.

http://produccioncientificaluz.org/index.php/opcion/article/ view $/ 21962 / 21696$

E Evans (2011): Transmedia Television: Audiences, New Media, and Daily Life. New York: Routledge.

E Fernández (2013): "Con el móvil en la mano: la aportación de ANT3. 0 y Twitter a la serie de televisión El Barco", en B. Lloves \& F. Segado (Coords.), I Congreso Internacional de Comunicación y Sociedad Digital. Logroño: Universidad de la Rioja.

R Franquet \& I Villa Montoya (2014): "Cross-Media Production in Spain's Public Broadcaster RTVE: Innovation, Promotion, and Audience Loyalty Strategies". International Journal of Communication 8, pp. 2301-2322. http://ijoc.org/index.php/ijoc/article/viewFile/2621/1203 
R Franquet, I Villa-Montoya \& I Bergillos. (2013): "Public Service Broadcasting's Participation in the Reconfiguration of Online News Content." Journal of Computer-Mediated Communication 18.3, pp. 378-397.

JA García (2011): "Dimensiones y tipología de las actividades de participación de la audiencia en la televisión pública". Ámbitos 20, pp. 175-195.

M Grandío \& J Bonaut (2012). "Transmedia audiences and television fiction: A comparative approach between Skins (UK) and El Barco (Spain)". Participations 9, n. 2, pp. 558-574. http://www.participations.org/Volume $\% 209 /$ Issue $\% 202 / 30$ \%20Grandio \%20Bonaut.pdf

M Guerrero (2014): "Webs televisivas y sus usuarios: un lugar para la narrativa transmedia. Los casos de "Águila Roja" y "Juego de Tronos" en España". Comunicación y Sociedad 21, pp. 239-267.

M Guerrero (2015): "Producción y lectura de fanfiction en la comunidad online de la serie Fringe: transmedialidad, competencia y alfabetización mediática". Palabra Clave, 18(3), pp. 722-745. DOI:

10.5294/pacla.2015.18.3.5.http://comunicacionysociedad.cucs h.udg.mx/index.php/comsoc/article/view/578/599

M Herrero de la Fuente (2017): "Nuevas fórmulas para la televisión en directo: el uso de Facebook Live en Atresmedia". Miguel Hernández Communication Journal 8, pp. 521-563.

B Ivars \& T Zaragoza (2018): "Lab RTVE. La narrativa transmedia en las series de ficción". Revista mediterránea de comunicación 9, n. 1, pp. 257-271.

https://www.doi.org/10.14198/MEDCOM2018.9.1.20

H Jenkins (2003): “Transmedia Storytelling”. MIT Technology Review. Recuperado el 15 de mayo de 2018 de https://www.technologyreview.com/s/401760/transmediastorytelling/

M Kinder (1991): Playing with Power in Movies, Television, and Video Games: From Muppet Babies to Teenage Mutant Ninja Turtles. Berkeley: University of California Press.

C Lacalle \& D Castro (2018): "Fandom televisivo y construcción de identidad. Análisis de los comentarios de las fans españolas y los community managers". Revista Latina de Comunicación Social 
73, pp. 1-18. http://dx.doi.org/10.4185/RLCS-2018-1242

C Lamelo (2016): Televisión social y transmedia. Nuevos paradigmas de producción y consumo televisivo. Barcelona: UOC.

A Lastra (2016): "El poder del prosumidor. Identificación de sus necesidades y repercusión en la producción audiovisual transmedia". Icono 14 14, pp. 71-94. http://dx.doi.org/10.7195/ri14.v14i1.902

Mandato-Marco a la Corporación RTVE previsto en el artículo 4 de la Ley 17/2006, de 5 de junio, de la Radio y la Televisión de Titularidad Estatal, aprobado por los Plenos del Congreso de los Diputados y del Senado (2008). Boletín Oficial del Estado. Obtenido de https://www.boe.es/boe/dias/2008/06/30/pdfs/A2883328843.pdf

J Miranda \& J Figuero (2016): "El rol del prosumidor en la expansión narrativa transmedia de las historias de ficción en televisión: el caso de 'El ministerio del tiempo"'. Index.comunicación 6, n. 2, pp. 115-134.

http://journals.sfu.ca/indexcomunicacion/index.php/indexco municacion/article/view/223/205

M Oliva Rota \& O Pérez Latorre (2011). "Reality game shows y narrativa transmediática: análisis de las estrategias de expansión transmediática de Operación Triunfo y American Idol". En La comunicación pública, secuestrada por el mercado Sociedad Latina de Comunicación Social. (pp. 70-71).

A Paíno \& MI Rodríguez (2015): “La expansión del universo narrativo en las series de ficción. La importancia de la audiencia activa como elemento clave y diferenciador en las narrativas transmedia" en C Mateo \& J Herrero (Coords.) La pantalla insomne. Cuadernos Artesanos de Comunicación, vol. 90, pp. 1023-1048.

R Pearson (2009): Reading Lost: perspectives on a bit television show. IB Tauris.

N Perryman (2008): "Doctor Who and the Convergence of Media: A Case Study in Transmedia Storytelling", Convergence, 14(1), pp. 21-39.

N Quintas-Froufe \& A González-Neira (2016): “Consumo televisivo y su medición en España: camino hacia las audiencias 
híbridas". El profesional de la Información 25, n. 3, pp. 376383.https://doi.org/10.3145/epi.2016.may.07

R Rodríguez, F Ortiz \& V Sáez (2014): “Contenidos transmedia de las teleseries españolas: clasificación, análisis y panorama en 2013”. Comunicación \& Sociedad 27, n. 4, pp. 73-96.

D Rodríguez-Mateos \& T Hernández-Pérez (2015): “Televisión social en series de ficción y nuevos roles del documentalista audiovisual: el caso de 'El Ministerio del Tiempo"'. Index.comunicación 5(3), pp. 95-120.

C Saavedra-Bautista, WO Cuervo-Gómez \& ID Mejía-Ortega (2016): "Producción de contenidos transmedia, una estrategia innovadora". Revista cientifica 1, n 28, pp. 6-16.

S Sánchez Castillo \& E Galán (2016): "Narrativa transmedia y percepción cognitiva en El Ministerio del Tiempo (TVE)". Revista Latina de Comunicación Social, 71, pp. 508-526.

C Scolari (2013): Narrativas transmedia. Barcelona: Deusto.

C Scolari (2014): "Narrativas transmedia: nuevas formas de comunicar en la era digital", en J Celaya, Anuario AC/E de Cultura Digital. Focus 2014: uso de las nuevas tecnologías en las artes escénicas. Madrid: Acción Cultural Española, pp. 71-81.

C Scolari \& MJ Establés (2017): "El ministerio transmedia: expansiones narrativas y culturas participativas". Palabra Clave 20 , n. 4, pp. 1008-1041.

https://doi.org/10.5294/pacla.2017.20.4.7

C Scolari, M Jiménez \& M Guerrero (2012): "Narrativas transmediáticas en España: cuatro ficciones en busca de un destino cross-media". Comunicación \& Sociedad 25(1), pp. 137163.

N Simons (2014): "Audience reception of cross-and transmedia TV drama in the age of convergence". International Journal of Communication 8, pp. 2220-

2239.http://ijoc.org/index.php/ijoc/article/view/2598

J Torregrosa-Carmona \& E Rodríguez-Gómez (2017): “Comunidades de fans y ficción televisiva. Estudio de caso: El ministerio del tiempo". El profesional de la información 26, n. 6, pp. 1139-1148. https://doi.org/10.3145/epi.2017.nov.13

D Torrico (2017): "Estudio bibliométrico de la producción científica sobre narrativa transmedia en España hasta 2016: Análisis 
descriptivo de las 20 principales revistas de comunicación españolas según Google Scholar Metrics (h5)". AdComunica 14, pp. 141-160. http://dx.doi.org/10.6035/2174-0992.2017.14.8

V Tur-Viñes (2015): "Engagement", audiencia y ficción”, en Narraciones sin fronteras: transmedia storytelling en la ficción, la información, el documentaly el activismo social y politico. Sociedad Latina de Comunicación Social, pp. 41-59.

V Tur-Viñes \& R Rodríguez-Ferrándiz (2014): “Transmedialidad, series de ficción y redes sociales: el caso de Pulseras Rojas en el grupo oficial de Facebook (Antena 3. España)". Cuadernos.info 34, pp. 115-131. http://dx.doi.org/10.7764/cdi.34.549

F Vasques-Ferreira \& S Magalhães-Costa (2018): "Cultura da convergência: análise do consumo transmidiático da série House of Cards". Revista Mediterránea de Comunicación 9(1), pp. 273-289.

R Yin (1989): Case studies research. Newbury Park, CA: Sage Publications. 



\title{
Educación Transmedia. De los contenidos generados por los usuarios a los contenidos generados por los estudiantes
}

Carlos A. Scolari - Universitat Pompeu Fabra - Barcelona (España) carlosalberto.scolari@,upf.edu

Nohemi Lugo Rodríguez - Universidad Tecnológico de Monterrey (México)nlugo@itesm.mx

Maria-José Masanet -. Universitat Pompeu Fabra - Barcelona (España) mjose.masanet@,upf.edu

Cómo citar: C A Scolari, N Lugo Rodriguez, M J Masanet (2019):

"Educación Transmedia. De los contenidos generados por los usuarios a los contenidos generados por los estudiantes. En V Tur-Viñes/M J González-Río/R S

Contreras-Espinosa (Eds.) Jóvenes / Medios y cultura colaborativa. Cuadernos Artesanos de Comunicación, cac157, pp 101-124. La Laguna (Tenerife): Latina. DOI: $10.4185 / \operatorname{cac} 157$

\begin{abstract}
s
Introducción: En la última década un fantasma ha recorrido los estudios de comunicación: las narrativas transmedia (transmedia storytelling). Nacida en el ámbito de la investigación sobre los nuevos modelos narrativos participativos, la cualidad de transmedia no tardó en convertirse en un flexible adjetivo que se adhirió a infinidad de sustantivos (ficción transmedia, periodismo transmedia, etc.). En este contexto no tardaron en aparecer experiencias o referencias teóricas a la educación transmedia. Metodología: El presente artículo repasa y reflexiona sobre estos conceptos para evitar abusos semánticos y avanza en una caracterización de las posibles aplicaciones de las lógicas
\end{abstract}


de las narrativas transmedia a los procesos de aprendizaje. Para ello, se analiza un estudio de caso basado en una experiencia de lecto-escritura llevado a cabo en un centro de educación secundaria de Barcelona. Este análisis se ubica en el cruce entre educación, medios, narrativa y culturas participativas. Resultados y conclusiones: La intervención resultó posible y deseable para el aprendizaje y creó una disposición positiva hacia la narrativa.

\section{Keywords}

Narrativa transmedia; alfabetismo mediático; alfabetización mediática; alfabetismo transmedia; alfabetización transmedia; educación transmedia

\section{Contents.}

1. Introducción. 2. De la narrativa transmedia a la educación transmedia. 2.1. Narrativa transmedia: de la ficción a la educación. 2.2. Alfabetismo/alfabetización mediática. 2.3. Alfabetismo/alfabetización transmedia. 3. Estudio de. 3.1. Diagnóstico. 3.2. Diseño de la experiencia. 3.3. Implementación. 3.4. Evaluación. 4. Discusión. 5. Apuntes finales. Bibliografía. Introducción

\section{Introducción}

— $\mathrm{N}$ estos últimos años se ha hablado mucho, quizá demasiado, de las narrativas transmedia (transmedia storytelling). Si bien algunos profesionales e investigadores a veces hacen referencia a "la o el transmedia”, debería quedar claro desde el comienzo que transmedia no es un sustantivo sino un adjetivo que admite diferentes combinaciones (narrativa transmedia, proyecto transmedia, etc.). Por otro lado, mientras la industria cultural se apropiaba del concepto -primero en Estados Unidos, después en Europa y a continuación en el resto del mundo-, algunos investigadores se inspiraron en él para indagar en otras disciplinas como la educación o proponer acciones tendientes a revalorizar las culturas colaborativas en los procesos de aprendizaje (Jenkins et al, 2009, Scolari, 2018). En este contexto: ¿es posible hablar de una alfabetización o educación transmedia? En este artículo se analizan las posibilidades que brinda el concepto de transmedia a la hora de 
repensar los procesos educativos. Más allá de la reflexión conceptual, el objetivo principal del texto es presentar y analizar una experiencia educativa realizada en Barcelona en el período 2014-16.

El texto se divide en tres secciones. En la primera se analiza brevemente el origen del concepto de narrativa transmedia (transmedia storyteling), su expansión más allá del mundo de la ficción y sus posibles aplicaciones en el ámbito educativo. En la segunda sección, como ya se indicó, se analiza una experiencia educativa realizada en una escuela secundaria de Barcelona. La tercera sección propone una discusión crítica de esa experiencia, analizando las posibilidades y limitaciones de la aplicación de la lógica de las narrativas transmedia en situaciones de aprendizaje formal. El texto se cierra con unos breves apuntes finales.

\section{De la narrativa transmedia a la educación transmedia}

En esta sección se describirá brevemente el origen del concepto de narrativa transmedia, se presentarán sus características principales y se revisarán algunas posibles aplicaciones y recuperaciones desde el mundo educativo. Al igual que sucede en las narrativas de ficción o no ficción, habrá que definir claramente qué es alfabetismo transmedia, alfabetización transmedia y educación transmedia para evitar que, debajo de un paraguas semántico a la moda, se promocionen experiencias que tienen poco o nada de transmedia.

\subsection{Narrativa transmedia: de la ficción a la educación}

El concepto de narrativa transmedia (transmedia storytelling) fue introducido por Henry Jenkins en un artículo publicado en la revista Technology Review (Jenkins, 2003). El concepto, retomado por su creador en un texto posterior (Jenkins, 2006), no tardó en ser adoptado por los profesionales y académicos hasta convertirse en la última década en una de las keywords del mundo de la comunicación. A la hora de definirlas, las narrativas transmedia se caracterizan por dos elementos: por una parte, el relato se expande en muchos medios y plataformas; por otro lado, los prosumidores (Toffler, 1980) participan activamente en ese proceso de expansión narrativa (Jenkins, 2003, 2006; Jenkins, Ford y Green, 2013; Scolari, 2009, 2013). Esta producción textual, también conocida como "contenidos generados por usuarios" (usergenerated contents), es uno de los fenómenos más relevantes y destacados 
que emerge de la nueva ecología mediática. Si bien desde tiempos inmemoriales existe este tipo de práctica textual, la llegada de la web y las redes sociales ha puesto en evidencia una verdadera explosión de relatos a cargo de los prosumidores. Volviendo al concepto en cuestión, en pocos años la producción de obras transmedia, que tuvo su origen en el campo de la ficción, no tardó en pasar a la no ficción (documental transmedia, periodismo transmedia, etc.) o el marketing (branding transmedia) (Scolari, 2013).

En este contexto, no es del todo extraño que el adjetivo transmedia también haya aparecido acompañando al sustantivo aprendizaje (transmedia learning o transmedia education). El mismo Henry Jenkins, cuyas investigaciones no se limitan a las producciones de los fans o las tensiones entre la industria de los medios y las culturas colaborativas (Jenkins, 2003, 2006; Jenkins, Ford y Green, 2013), también ha realizado aportes fundamentales para comprender cómo se expresan esas culturas en entornos juveniles y cómo pueden ser recuperadas desde una perspectiva educativa (Jenkins et al, 2009; Jenkins, 2010; Jenkins, Ito y boyd, 2015). En un texto publicado en 2010 Jenkins delineaba un posible cruce entre el transmedia storytelling y las prácticas educativas:

En tanto educadores, tenemos que modelar el uso efectivo de las diferentes plataformas mediáticas en el aula, una práctica que respaldaría lo que Howard Gardner nos ha dicho acerca de las inteligencias múltiples. En este caso, me refiero a la idea de que cada estudiante aprende mejor a través de diferentes modos de comunicación y, por lo tanto, la lección es más efectiva cuando se transmite a través de más de un modo de expresión. Podemos reforzar lo que comunicamos a través de palabras o textos escritos con soportes visuales o actividades. Hacerlo de manera efectiva nos lleva a pensar en cómo múltiples plataformas de comunicación podrían reforzar lo que hacemos en nuestras aulas (Jenkins, 2010).

Si bien reconoce que los principios de las narrativas transmedia, inspirados en gran parte por las lógicas comerciales de la industria cultural, no son trasladables automáticamente al ámbito educativo, Jenkins propone renovar los procesos de enseñanza-aprendizaje 
recuperando algunos aspectos de esas prácticas, al mismo tiempo que se exploran otras dimensiones:

La narrativa transmedia (transmedia storytelling) es solo una de las posibles lógicas transmedia, las cuales también podrían incluir las marcas transmedia (transmedia branding), la actuación transmedia (transmedia performance) y el aprendizaje transmedia (transmedia learning). Seguramente habrá cierta superposición entre estas diferentes lógicas transmedia, pero también diferencias. No dudo que algunos principios se mantengan, pero debemos tener en cuenta que también puede haber otros principios, básicos para la enseñanza/aprendizaje transmedia, que no serán explorados si simplemente tratamos de adoptar para este espacio lo que ya sabemos sobre el entretenimiento transmedia (Jenkins, 2010).

¿Qué características debería tener un proceso de enseñanzaaprendizaje transmedia? Si se toma en cuenta la definición tradicional de transmedia storytelling -un relato que se cuenta en muchos medios y plataformas con la complicidad de los prosumidores (Scolari, 2013), se podría imaginar un proceso de aprendizaje donde la narrativa ya sea el viaje de Cristóbal Colón, la fotosíntesis o la fórmula de la superficie de la esfera- se trabaje en el aula a través de diferentes lenguajes y soportes mediáticos; por otra parte, un proceso de aprendizaje transmedia debería darle relevancia a la producción de contenidos a cargo de los estudiantes. En otras palabras, se trataría de pasar de los user-generated contents a los student-generated contents.

\subsection{Alfabetismo/alfabetización mediática}

El concepto de literacy admite en castellano dos traducciones dado que puede ser entendido como: 1) alfabetismo (sustantivo) o 2) alfabetización (verbo). En el primer caso, el concepto hace referencia a un conjunto de conocimientos que el sujeto puede adquirir y poner en práctica durante su vida. En el segundo, se entiende la literacy como acción, o sea como un aprendizaje que puede desarrollarse en un entorno formal, informal o no formal. En el caso específico de la media literacy, también puede ser abordada desde ambas perspectivas: como conjunto de habilidades y competencias que el sujeto debería poseer para poder hacer frente al entorno mediático de la mejor manera 
posible (alfabetismo mediático), o como programa de formación en medios que los sujetos pueden desarrollar, por ejemplo, dentro de la institución escolar (alfabetización mediática). De hecho, como afirman Gutiérrez y Tyner (2012), teniendo en cuenta la importancia de los medios de comunicación en la educación informal de los niños, adolescentes y jóvenes, es impensable que el entorno educativo formal no adopte una posición en este ámbito. $\mathrm{Y}$ es en este contexto en el que la escuela, además de estudiar y aprender a través de los medios de comunicación, ha considerado necesario analizarlos y comprenderlos. En este sentido, tanto la alfabetización mediática como la educación mediática o digital, entre otros términos, ha tendido a contemplar dos ámbitos: educación en medios y educación con medios. La educación en medios se centra en proporcionar herramientas y habilidades a los sujetos a les adelesentes-para hacer frente al entorno mediático -a través de la comprensión crítica y de la participación activa, que hace referencia a la capacidad de los sujetos de convertirse ellos mismos en productores (Buckingham, 2004)-; la educación con medios se refiere a la introducción y uso de los medios para el aprendizaje, es decir, al uso instrumental de los medios en el contexto educativo. Esta segunda opción, según Buckingham (2004), haría referencia a la tecnología educativa o al uso de los medios como recurso pedagógico y no debería confundirse con la educación mediática porque no tiene que ver con la enseñanza y aprendizaje acerca de los medios.

La media literacy, nacida en los años 1960 como consecuencia de la emergencia de la televisión, por entonces un new media que invadía los hogares y cambiaba las rutinas de consumo y la dieta mediática de los adultos y, sobre todo, niños y adolescentes, ha pasado por diferentes momentos. En su versión más tradicional la media literacy se proponía generar "anticuerpos" para contrarrestar la (supuesta) influencia negativa de la televisión y otros medios de comunicación (Potter, 2005). En este contexto la media literacy era un programa de investigación (identificar "los efectos de la televisión en los niños") y de acción (enseñar dentro del aula a interpretar críticamente los medios y dotar a los televidentes de un mínimo de competencias para moverse con responsabilidad en la mediasfera). Este primer acercamiento, si bien nunca fue totalmente abandonado, no tardó en ser expandido y enriquecido con otros enfoques basados en concepciones menos 
funcionalistas y más críticas con las miradas apocalípticas que solo veían manipulación y alienación en los medios de comunicación.

Por otro lado, en los últimos años los cambios en la ecología mediática -que pueden ser sintetizados en el pasaje de un ecosistema centrado en el broadcasting a otro centrado en el networking (Scolari, 2008)- y la expansión de las culturas colaborativas (Jenkins, 2006; Delwiche y Henderson, 2013) han llevado a un replanteo de los viejos modelos de alfabetismo/alfabetización mediática. Por un lado, el conjunto de competencias y habilidades mediáticas se ha incrementado para incorporar una larga serie de conocimientos vinculados a las tecnologías digitales y las redes (internet literacy, digital literacy, etc.); por otra parte, los procesos de alfabetización mediática se han enriquecido cada vez más con la enseñanza de saberes críticos vinculados al uso de los medios digitales interactivos (por ejemplo, cómo identificar fake news, etc.).

Sin embargo, muchos procesos de alfabetización mediática o digital siguen partiendo de un postulado: los jóvenes serían en cierta forma "víctimas" de los medios y deberían ser "salvados" por los profesoresadultos. La vieja línea de investigación ("los efectos de la televisión en los niños") hoy se ha relanzado bajo nuevos fantasmas: "los efectos de los videojuegos en los niños", "los efectos de las redes sociales en los niños", "los efectos de los dispositivos móviles en los niños", etc. Una forma de huir de esta mirada -o, por lo menos, complementarla con otras perspectivas de abordaje- es interpelar a los jóvenes desde otro lugar: no considerarlos como "víctimas" sino como sujetos activos que están "haciendo cosas" con los medios a su manera, de forma a veces salvaje, pero con mucha pasión y poniendo en práctica un denso conjunto de competencias que no aprehendieron en el sistema educativo formal. Esto no significa que se obvie la necesidad de una educación mediática formal que dote a los jóvenes de las herramientas necesarias para entender y comprender el complejo entorno mediático, sino implica dar valor a las prácticas y conocimientos que ellos ya están adquiriendo por fuera del sistema formal de educación. Igualmente, cabe destacar que el debate alrededor de la definición de la media literacy o de los conceptos relacionados a la educación mediática sigue abierta, como demuestran numerosas investigaciones a su alrededor (por ejemplo: Koltay, 2011; Rogow, 2004). Esto se traduce en la falta de 
una definición precisa y consensuada y en una confusión terminológica que, como señalan Masanet y Ferrés (2015), es al mismo tiempo expresión y causa de una gran disparidad de aproximaciones con sus diferencias en cuanto a prioridades y, por lo tanto, también a lagunas y carencias. Frente a esta situación, Buckingham (2004) nos alerta de la posibilidad de caer en la ambigüedad extrema y generalizada.

\subsection{Alfabetismo/alfabetización transmedia}

$\mathrm{Al}$ igual que la media literacy, podemos entender a la transmedia literacy como: 1) alfabetismo transmedia (sustantivo) o 2) alfabetización transmedia (verbo). En el primer caso, el concepto hace referencia a un conjunto de competencias transmedia (transmedia skills) que el sujeto ha aprendido en entornos no formales e informales, desde redes sociales hasta comunidades de videojugadores, YouTube o foros de discusión. Esta concepción también incluye un programa de investigación con renovadas preguntas en sintonía con la nueva realidad mediática: ¿Qué saben los jóvenes sobre videojuegos? ¿Qué competencias desarrollaron para gestionar sus redes? ¿Qué saberes ponen en práctica a la hora de producir y compartir contenidos en las redes? ¿Cómo aprendieron a hacer todas esas cosas? En el segundo caso, se entiende a la transmedia literacy como programa de acción destinado a recuperar esos conocimientos dentro del entorno educativo formal (Scolari, 2018).

Después de este recorrido conceptual -donde se intentó poner un poco de orden semántico en un terreno a veces proclive a adoptar conceptos de moda-, se puede pasar a describir y analizar una experiencia concreta de educación transmedia para ver cómo se presentan los diferentes componentes que surgieron en esta primera sección.

\section{Objetivos y metodología}

En este artículo se presenta un estudio de caso que forma parte de una investigación mayor realizada entre 2014 y 2016 en un centro público de educación secundaria de Barcelona, el cual se encuentra situado en un distrito caracterizado por tener un nivel de ingresos medio-bajo y un nivel educativo por debajo del promedio, ocupando en 2016 la segunda posición en menor número de alumnos que van a la 
universidad. El centro se fundó hace más de 25 años y atiende a un promedio de 400 alumnos. En los últimos años se ha llevado a cabo un proceso de transformación pedagógica pasando de un modelo educativo tradicional, basado en la clase magistral, a un modelo educativo fundado en el aprendizaje por proyectos.

Los cuatro grandes objetivos de la investigación (Lugo, 2016) en la que se enmarcaba este estudio eran:

1) Explorar si en el centro educativo existían prácticas derivadas de la cultura transmedia que promovieran la educación en medios de manera transversal, es decir, en clases no dedicadas a la educación en medios per se, sino dedicadas al aprendizaje de otras áreas (matemáticas, literatura o ciencias);

2) Detectar en qué clases había potencial para promover la educación transmedia de forma transversal;

3) Explorar las potencialidades educativas de la creación de productos derivados de la cultura transmedia por parte de los alumnos en el contexto educativo;

4) Detectar qué factores se revelaban como promotores u obstáculos para la implementación de la educación transmedia durante el proceso educativo.

Para ello, se planteó un diseño metodológico que combinaba la etnografía y el diseño. Se utilizó un método --el Development and Design Research-- orientado a la acción y a la intervención centrada en el participante (Alias, 2015). Las fases de la investigación incluyeron 1) diagnóstico, 2) diseño didáctico de la experiencia educativa, 3) implementación, y 4) evaluación de la experiencia para enriquecer el diseño o modelo.

Para llevar a cabo la investigación, en primer lugar, se estableció contacto con el centro educativo, se plantearon los objetivos y actividades de la investigación y se acordaron los plazos de trabajo. En segundo lugar, durante el período de observación participante, se detectó que la asignatura de literatura castellana, impartida como materia optativa del área de humanidades, tenía el potencial para 
promover la educación transmedia de manera transversal. Dado que se planteaba una intervención en el aula a través del uso de las narrativas, era más sencillo adaptarse a la dinámica de clase de una asignatura donde ya estaban trabajando la narrativa. A partir de esta observación se solicitó la autorización de la dirección del centro y de la profesora a cargo de la asignatura para desarrollar la intervención en el aula. La profesora aceptó trabajar alrededor de la obra El Quijote de la Mancha y la experiencia se llevó a cabo en 12 semanas. Siendo una asignatura optativa, había únicamente 12 estudiantes (11 chicas y un chico) entre 15 y 16 años.

En la siguiente tabla se especifican las unidades de análisis y las técnicas utilizadas en cada una de las fases de la investigación:

\begin{tabular}{|l|l|}
\hline \multicolumn{1}{|c|}{$\begin{array}{c}\text { Fase de la } \\
\text { investigación }\end{array}$} & \multicolumn{1}{|c|}{ Técnicas y unidades de análisis } \\
\hline Diagnóstico & $\begin{array}{l}\text { Observación participante de } 5 \text { sesiones de clase en el } \\
\text { aula regular y de informática. }\end{array}$ \\
& $\begin{array}{l}\text { - Cuestionario respondido por las estudiantes. } \\
\text { - Entrevista de diagnóstico a la profesora. }\end{array}$ \\
\hline - Ejercicio de mapas de afinidades narrativas y \\
discusión de géneros narrativos realizado por las \\
estudiantes.
\end{tabular}

Tabla 1: Fases de la investigación 
En las siguientes subsecciones se describen con detalle cada una de las fases de la investigación expuestas en la tabla anterior.

\section{Estudio de caso}

\subsection{Diagnóstico}

Durante la fase de diagnóstico se detectaron aspectos relacionados con la filosofía educativa y estilo pedagógico del centro, las preocupaciones de la profesora y las actitudes de las alumnas respecto a la materia y la obra en sí. También se exploraron los hábitos y usos mediáticos de las estudiantes y sus intereses narrativos. Los hallazgos más importantes se detallan y agrupan en los siguientes dos temas:

\section{- Actitudes de profesora y alumnas hacia la narrativa y el aprendizaje de la literatura}

A la profesora le gustaba mucho la literatura, el teatro y el arte en general e intentaba transmitir estos intereses a las estudiantes. Entre sus prácticas habituales destacaba la asignación de ejercicios de creación literaria para corregir la ortografía -pues era un tema que preocupaba a la profesora- y la lectura y acceso a las fuentes originales que se trabajaban a lo largo de la asignatura, rechazando el aprendizaje de la literatura a través de reseñas históricas, tal como se la habían enseñado a ella. A la profesora le interesaba el rigor académico y quería que las estudiantes recurrieran a recursos académicamente sólidos y, por ello recomendaba el Centro Virtual Cervantes (https://cvc.cervantes.es). Una de sus preocupaciones era que El Quijote se incluyera en las pruebas de Selectividad y debieran prepararlo para el examen. Sin embargo, a las alumnas la obra les parecía aburrida y muy difícil de comprender, al igual que las notas al pie o los recursos que les proporcionaba la profesora, que les parecían aún más difíciles. Les desagradaba leer la obra tanto en clase como en casa. Su actitud hacia El Quijote era negativa y estaba, en parte, condicionada por experiencias anteriores. Solo había una excepción, una alumna a la cual sí le agradaba la obra y mencionó que su padre le había enseñado tebeos de la misma cuando era niña.

Uno de los hallazgos más interesantes de la fase de diagnóstico tuvo lugar durante el ejercicio de creación de mapas de afinidades narrativas 
y discusión de géneros, donde las estudiantes compartieron sus gustos e intereses en literatura y narrativa. Durante la actividad emergió que a las estudiantes les gustaba mucho la narrativa. Discutían animadamente sobre diferentes géneros, sobre todo de series de televisión y películas, y opinaban sobre la coherencia, lógica y validez de las tramas, etc. Se conmovían al recordar algunas de las últimas películas que habían visto y recordaban con melancolía las historias de Disney que habían formado parte de su niñez. Preferían la comedia, aunque el romance y el suspenso también eran populares (pero rechazados por algunas participantes). A través de esta actividad se pudo observar que las estudiantes disfrutaban con la narrativa y literatura en su tiempo libre. Pero, por el contrario, no disfrutaban la narrativa que estaban trabajando en clase e incluso se podía observar cierto rechazo a El Quijote.

\section{- Uso de los medios}

A través de la observación en el aula de informática y del cuestionario se observó qué uso hacían las estudiantes de los diferentes dispositivos, plataformas, redes sociales y aplicaciones, así como sus preferencias y hábitos de consumo mediático. Las estudiantes utilizaban los medios sobre todo para expresarse y conectarse con amigos, otorgándoles una función socializadora entre iguales. Su uso para fines académicos se reducía a algunas páginas web o buscadores. Las alumnas declararon que no usaban estos medios para aprender ni por cuenta propia ni en cuestiones escolares. En las sesiones de clase no utilizaban los ordenadores para avanzar en el trabajo escolar, sino para revisar las diferentes redes sociales donde tenían cuentas, como Instagram o Facebook, entre otras. Y una de ellas lo utilizaba para jugar a videojuegos. Se observaba una distracción y dispersión constante en el aula cuando tenían acceso a los medios y esta dispersión en ningún caso estaba relacionada con la obra que estaban trabajando.

\subsection{Diseño de la experiencia}

A partir de los hallazgos en la etapa de diagnóstico, se concretaron los objetivos específicos y prioridades que nutrieron el diseño de la experiencia. Dado que debían ser estrategias de aprendizaje transversal, las actividades debían promover tanto el aprendizaje sobre El Quijote como un proceso de enseñanza-aprendizaje transmedia. 
En base a esto, los objetivos y prioridades fueron:

1) Motivar el interés y la comprensión de la obra a través de la conexión con la cultura de las alumnas y los intereses mediáticos específicos que emergieron durante el ejercicio de diagnóstico (mapa de afinidades);

2) Propiciar la comprensión de El Quijote a través de materiales gráficos y audiovisuales de la obra;

3) Propiciar el uso de medios digitales que aprovecharan sus posibilidades colaborativas tanto para fomentar mayor conocimiento de la obra como para potenciar un proceso de enseñanza-aprendizaje transmedia;

4) Propiciar la apropiación de la obra y la expresión creativa personal.

Para ello, se propuso a la profesora la realización de actividades centradas en la producción de extensiones textuales transmedia, o sea trabajar a partir de la expansión de una narrativa a través de diferentes medios y adaptándose a sus diferentes lenguajes. Estas extensiones proponen como competencia sociocultural principal la apropiación, la cual se define como la capacidad de usar y mezclar contenido creado por otros para crear un mensaje con intenciones comunicativas propias en los ámbitos de la expresión creativa individual o grupal y/o la ciudadana (Jenkins et al., 2009; Ferrés y Piscitelli, 2012; Lugo, 2016).

Para este estudio se consideró apropiado hacer extensiones one-shot que en el mundo de la fanfiction se definen como historias de un solo capítulo. Por su parte, el fanfiction hace referencia a piezas escritas creadas por fans que se centran en personajes de ficción populares y acostumbran a compartirse por Internet (Carson, 2017). Pero el diseño de la experiencia contempló que durante el proceso de creación las alumnas realizaran ejercicios paralelos o previos que las ayudaran en el proceso.

\subsection{Implementación}

A continuación, se describen las actividades realizadas en cada una de las 9 sesiones hasta concluir con las extensiones transmedia one shot y se indican los objetivos de dichas actividades. 


\begin{tabular}{|c|c|c|}
\hline Sesión & Actividad & Objetivos \\
\hline 1 & $\begin{array}{l}\text { Adaptación } \\
\text { hipertextual de un } \\
\text { capítulo de El Quijote. }\end{array}$ & $\begin{array}{l}\text { - Comprender la idea e importancia del } \\
\text { concepto "inteligencia colectiva" (Lévy, } \\
\text { 1997) y su rol en el aprendizaje grupal. } \\
\text { - Convertir un capítulo concreto de El } \\
\text { Quijote en hipertexto con vínculos a } \\
\text { diccionarios para la actualización de } \\
\text { palabras, wikis con la explicación de los } \\
\text { personajes, artículos y blogs sobre la } \\
\text { obra en general o hechos concretos, } \\
\text { etc. El objetivo era facilitar la lectura de } \\
\text { dicho capítulo a otras compañeras y } \\
\text { aprovechar los recursos de los capítulos } \\
\text { adaptados por otras estudiantes. Esta } \\
\text { actividad se podía realizar de manera } \\
\text { individual o en pareja. } \\
\text { - Aprender a compartir y co-crear } \\
\text { documentos en Google Drive. }\end{array}$ \\
\hline 2 & $\begin{array}{l}\text { Ejercicio breve de } \\
\text { escritura colaborativa. } \\
\text { ¿Qué pasaría si Don } \\
\text { Quijote viviera en el } \\
\text { siglo XXI? }\end{array}$ & $\begin{array}{l}\text { - Revisión de los aspectos básicos que } \\
\text { hacen a la obra una novela de caballería } \\
\text { burlesca. } \\
\text { - Comprender los aspectos temáticos y } \\
\text { estructurales básicos de la obra. } \\
\text { - Acercar la obra al propio contexto, a la } \\
\text { actualidad y a las preocupaciones } \\
\text { propias de las estudiantes. } \\
\text { - Comprender el concepto de extensión } \\
\text { transmedia. } \\
\text { - Expresarse de manera lúdica. }\end{array}$ \\
\hline 3 & $\begin{array}{l}\text { Exploración de } \\
\text { adaptaciones de la } \\
\text { obra a novelas } \\
\text { gráficas, ilustraciones } \\
\text { narrativas y a otras } \\
\text { obras gráficas. }\end{array}$ & $\begin{array}{l}\text { - Comprender contenidos concretos de } \\
\text { la obra. } \\
\text { - Explorar partes de la obra que } \\
\text { resultaban interesantes a las estudiantes } \\
\text { independientemente de su inclusión o } \\
\text { no en los capítulos que debían leerse } \\
\text { para la Selectividad. } \\
\text { - Percibir la lectura de la obra como algo } \\
\text { lúdico y ameno. } \\
\text { - Reconocer algunos elementos básicos } \\
\text { de las ilustraciones narrativas y de la } \\
\text { novela gráfica. }\end{array}$ \\
\hline
\end{tabular}




\begin{tabular}{|c|c|c|}
\hline & & $\begin{array}{l}\text { - Asociar y relacionar El Quijote con otras } \\
\text { narrativas de su preferencia. }\end{array}$ \\
\hline 4 & $\begin{array}{l}\text { Revisión crítica de la } \\
\text { obra a través de } \\
\text { mapas mentales. }\end{array}$ & $\begin{array}{l}\text { Reconocer los temas esenciales de la } \\
\text { obra: amistad, ficción y realidad, el } \\
\text { concepto de locura, la ficción y la } \\
\text { adicción, la búsqueda de la justicia, etc. } \\
\text { - Promover la lectura crítica de la obra a } \\
\text { través del análisis de sus } \\
\text { representaciones y mensajes. } \\
\text { Promover la comparación de la obra } \\
\text { con narraciones actuales de su interés. }\end{array}$ \\
\hline 5 y 6 & $\begin{array}{l}\text { Producción de } \\
\text { extensiones one shot. }\end{array}$ & $\begin{array}{l}\text { - Aplicar lo aprendido en las sesiones } \\
\text { anteriores a las extensiones transmedia } \\
\text { one shot de universo alterno con asesoría } \\
\text { de la profesora y de la investigadora. }\end{array}$ \\
\hline 7 & $\begin{array}{l}\text { Adaptaciones a } \\
\text { medios gráficos o } \\
\text { audiovisuales. }\end{array}$ & $\begin{array}{l}\text { - Adaptar el texto a cómic, video, audio, } \\
\text { etc. usando aplicaciones gratuitas (el } \\
\text { proceso continuó en las siguientes } \\
\text { sesiones); } \\
\text { - Apropiación del texto en función de las } \\
\text { propias motivaciones, adaptándolo a un } \\
\text { formato o género con el que se } \\
\text { sintieran más cómodas. }\end{array}$ \\
\hline 8 y 9 & $\begin{array}{l}\text { Terminar las } \\
\text { apropiaciones }\end{array}$ & $\begin{array}{l}\text { - Culminación de las apropiaciones } \\
\text { textuales comenzadas en la sesión } 7 .\end{array}$ \\
\hline
\end{tabular}

Tabla 2: Actividades de la fase de implementación.

\subsection{Evaluación}

Como se explicó en apartados anteriores, la investigación combinó etnografía y diseño, con lo cual era muy importante valorar las experiencias y aprendizajes percibidos por las alumnas y la profesora. Igualmente, importante era analizar qué revelaban los ejercicios y las extensiones transmedia realizadas por las estudiantes.

\section{- Aprendizajes y experiencias percibidas por las alumnas}

Estas evaluaciones se basan en las respuestas de las alumnas a un cuestionario (respondido en parejas), el grupo focal realizado tanto con 
las alumnas como con la profesora, y la entrevista de cierre realizada a la profesora, como se indica en la Tabla 1.

Las alumnas manifestaron haber aprendido sobre la obra y el proceso de educación transmedia. Es importante destacar que en sus comentarios se puede apreciar que aumentó su comprensión de la obra:

"No sabiamos el aspecto tan justiciero de El Quijote".

"Miguel de Cervantes quería burlarse de las novelas de caballerías".

"Con la obra de Don Quijote de la Mancha se acabó el género de la novela de caballerías".

En relación a la educación transmedia, observamos aprendizajes relacionados con la intertextualidad, la navegación transmedia y la tecnología. Por otra parte, un dato importante es que las estudiantes, a través del proceso, descubrieron y dieron valor a sus propias capacidades y conocimientos. Esto las ayudó a sentirse bien consigo mismas y a valorizar unos conocimientos o aprendizajes que eran invisibles para ellas mismas y que siendo ahora visibles las motivaban a seguir explotándolos:

"Hemos visto que se han hecho muchas versiones diferentes de El Quijote, unas totalmente con la misma historia (pero explicadas con cómic o con más fotografias) y luego otras donde, a partir de la versión original, se han inventado otras historias ocurridas en otros lugares o con nuevos personajes o ambientadas en otra época".

"He aprendido que tengo más capacidad de la que pensaba para inventar historias.

"He aprendido que existen aplicaciones para el iPad que están muy bien como por ejemplo para editar fotos y videos, y he aprendido a utilizarlas un poco".

"Yo no bubiera podido hacer una historia asi sola, pero con las pautas pudimos hacerlo".

Además de los aprendizajes fue importante valorar la motivación y la experiencia subjetiva. Todas las alumnas estuvieron de acuerdo en que el ejercicio que más les había motivado fue el mapa de afinidades narrativas, ya que habían podido compartir sus gustos y debatir sobre 
géneros cinematográficos. Además, hicieron comentarios sobre las sesiones de la intervención en general:

"Me gustó no estar siempre sentada. Me gusta expresar mi opinión. Cuando haces las clases los profes dictan. Al final estos ejercicios también te bacen pensar".

"A mi lo que más me gustó fue lo de las tablets".

"Nos gustó bastante escribir historias y a partir de abora puede que comience a escribir más".

Las estudiantes comentaron que cuando se les dieron los nombres de las aplicaciones para que las trajeran ya cargadas a clase, ellas buscaron por su cuenta para qué servían y, por lo tanto, empezaron a ponerlas en práctica por su cuenta. Se divirtieron usándolas y experimentaron con fotos de ellas mismas, añadiendo sonido, etc. Con esto se observa que su motivación hizo que empezaran a aprender sobre las aplicaciones de manera individual antes de que se propusieran las actividades a realizar en clase. La motivación promovió el aprendizaje informal. Posteriormente, en el aula, la investigadora y la profesora dirigieron el uso de las aplicaciones en relación con el trabajo sobre El Quijote.

La profesora mencionó también las apropiaciones como un ejercicio significativo para el aprendizaje:

"Se dan cuenta que lo que hay en El Quijote, que a lo mejor no se lo han leido bien porque es difícil, tiene que ver con la realidad y nos hace vibrar igual. Veo interesante que han trasladado El Quijote, toda la historia, a problemas actuales como el maltrato, la corrupción... No bubo manipulación ni se les dijo haz esto o lo otro. Ellas ven que en El Quijote está todo esto y lo han traspasado".

Aunque reconoció el valor de la experiencia, también señaló los obstáculos que puede presentar para una profesora de literatura hacer ejercicios de este tipo en su clase. Mencionó que los capítulos seleccionados para la Selectividad no siempre son los más interesantes para el alumnado. También destacó la falta de tecnologías y capacitación en los centros y, por último, que los alumnos no están acostumbrados a trabajar en grupo. Finalmente, se refirió a la falta de 
disposición al cambio por parte tanto del alumnado como del profesorado:

"A los alumnos les cuesta cambiar de bábitos y a los profes también. Hay una especie de muro, no infranqueable, pero si es difícil cambiar. Ellos están acostumbrados a usar su ordenador, pero solos, yo creo que eso si se ha movido (...) Yo no me veo formada en esto. Di el paso de usar los ordenadores, pero no estoy formada".

\section{- Análisis de las extensiones transmedia producidas}

En este apartado nos concentraremos en los ejercicios de producción, narrativa y apropiación. Tanto en el ejercicio '¿Qué pasaría si Don Quijote viviera en el siglo XXI?’ (llevado a cabo en la sesión 2) como en las extensiones transmedia one-shot, las alumnas se apropiaron de la obra y la relacionaron con sus intereses.

Retomaron uno o varios temas esenciales de la obra como la amistad, la fantasía, la justicia o la adicción para llevar a cabo sus creaciones. Un tema nuevo que se trató en las discusiones fue el feminismo y en una de las extensiones transmedia apareció la perspectiva de género. Una de las alumnas trató el tema de la enfermedad y otra la adicción a la literatura, actualizando el tema y convirtiéndolo en adicción al juego. En su relato las alumnas explican como Don Quijote y Sancho se conocieron en un casino en Las Vegas y sus problemas de la adicción al juego.

El tema más común fue la amistad entre Don Quijote y Sancho, que se manifestó en la afinidad entre los personajes, en su manera de ser complemento uno del otro, en expresiones de lealtad entre los personajes, etc. Además de actualizar la obra al siglo XXI, en su mayoría las alumnas la situaron en un contexto conocido por ellas: Barcelona. A continuación, se cita un ejemplo de cómo una alumna inició su extensión transmedia:

"Don Quijote era un joven solitario que dedicaba la mayor parte de su tiempo a su trabajo, en una tienda pequeña y oscura. Era su propio negocio, el negocio familiar. Un negocio en que se trataba de reparar impresoras. Asi es, era reparador de impresoras. Don Quijote tiene 39 años, y vive en Barcelona, en un piso pequeño en el centro. Cuando no está en el trabajo, dedica su tiempo a 
leer historias de crimenes o bistorias sobrenaturales. Su sueño era ser criminólogo y resolver los asesinatos. Él siempre ha creído que los crímenes, mayor parte de ellos, son por causas sobrenaturales. Se encierra en un mundo donde se imagina matando a estos seres y resolviendo los crímenes. Pero un día se cansó de imaginar y decidió resolver algún que otro crimen de su ciudad [...]."

En 5 de las 8 historias presentadas, Don Quijote y Sancho se conocen y después inician el viaje. Si bien es posible que la guía de apoyo les sirviera para estructurar de manera general las producciones, resulta interesante ver cómo se apropiaron de diversas formas de la obra. Este fue uno de los hallazgos más reveladores, ya que desveló sus capacidades imaginativas, sus intereses, sus competencias narrativas y tecnológicas, y sus habilidades en relación al manejo de contenidos y recursos literarios. Las estudiantes realizaron el trabajo de manera autónoma y colaborativa y ni la profesora ni la investigadora asesoraron en estos ámbitos. Fue por su propia iniciativa que hicieron un trabajo no solo intertextual en relación con la obra literaria sino aludiendo a géneros televisivos y, además, utilizando las convenciones del género en cuestión (mafia, caza de seres sobrenaturales, vaqueros) para estructurar su historia y actualizar el contenido. De esta manera demostraron conocer aspectos relacionados con los géneros y las estructuras narrativas que ni ellas mismas sabían tener y que fueron valorizados a través de la actividad.

\section{Discusión}

La intervención a través de una práctica de educación transmedia en la asignatura de Literatura resultó no solo posible sino deseable para el aprendizaje y creó una disposición positiva hacia la narrativa. El enfoque en la producción narrativa demostró ser útil para trabajar a partir de las prioridades de las estudiantes que emergieron en el diagnóstico, y fueron la base del diseño pedagógico de la intervención. A partir de los testimonios de las alumnas se puede decir que aumentó tanto la comprensión de la obra como el interés en ella y se potenció el trabajo colaborativo. En algunos casos esto fue más allá e incluso incidió en que tuvieran un concepto positivo de sí mismas como creadoras y dieran valor a algunas de sus prácticas mediáticas. Aun así, las experiencias emocionales previas tienen un peso muy alto en la disposición para disfrutar obras complejas como El Quijote. 
En esta intervención se observó que más que aprender competencias nuevas, las alumnas utilizaron competencias transmedia propias relacionadas con la narrativa y producción. Pero es notorio cómo el diseño pedagógico permitió que ellas utilizaran estas competencias en el aula con el objetivo de aprender sobre la obra. De esta manera, la experiencia promovió no solo la reflexión alrededor de la literatura en general y la ficción en particular, sino que estableció un vínculo real entre los aprendizajes formales e informales al introducir prácticas y competencias transmedia de las estudiantes -llevadas a cabo normalmente en contextos informales- en el contexto de la educación formal.

Los recursos tecnológicos no parecen ser un factor tan decisivo, sobre todo si no se prioriza que el resultado final de este proceso sea un producto digital. Sin embargo, la tecnología parece favorecer la implicación del alumnado y facilitar el trabajo colaborativo.

La mayor motivación de las alumnas se observó en las actividades destinadas a compartir sus gustos, producir y crear. Esto se entiende si se considera que quieren estar activas y ser tomadas en cuenta, como ellas mismas lo expresaron. Pero también apunta a la necesidad de conocer a las estudiantes, sus preferencias, preocupaciones e intereses, con el objetivo de poder motivarlas y acercar los contenidos educativos a sus realidades. También se destaca la necesidad de promover un tipo de lectura que luego les permita una producción no solo creativa sino también crítica. En línea con las reflexiones de Ferrés y Masanet (2015), en la educación mediática es importante fomentar el pensamiento crítico, pero también la actitud crítica, y esto sucede cuando las estudiantes insertan una perspectiva crítica sobre el mundo que las rodea también en sus propias producciones.

Por último, la obligatoriedad parece bloquear tanto la posibilidad de la profesora de escoger los capítulos como la disposición positiva de las alumnas a la obra. Ella misma reconoce que los capítulos asignados para la Selectividad no siempre son los más interesantes. El hecho es que El Quijote tiene mucho que ofrecer al alumnado. A las jóvenes les preocupaba el tema de la justicia, la amistad, la ficción y el género, entre otros contenidos, pero la aproximación a la obra a partir de un ambiente de "obligatoriedad" creaba un rechazo y, por lo tanto, se hacían necesarias otras estrategias de acercamiento. La experiencia 
realizada es un primer paso que ofrece pautas útiles para trabajar en el aula a partir de la motivación y el entretenimiento, poniendo en valor competencias transmedia desarrolladas en entornos informales o no formales.

\section{Apuntes finales}

Es necesario tener en cuenta que lo "formal" y lo "informal", de la misma manera que lo "real" y lo "virtual" -o lo "analógico" y lo "digital"- no son más que oposiciones que, en las situaciones concretas, tienden a superponerse y remezclarse. Si bien resultan de utilidad para el investigador, en cierto punto de la reflexión conviene tomar distancia de ellas. Según David Buckingham (2018): "La distinción binaria entre "formal" e "informal" no nos es particularmente útil. Por definición, la enseñanza de los medios implica un encuentro entre el conocimiento que se puede obtener fuera de la escuela - lo que podríamos llamar "conocimiento vernáculo del día a día" - y el conocimiento más académico, de alto rango, promovido por las escuelas. Entender cómo interactúan estas dos formas de conocimiento (o estas dos variedades de la alfabetización) es algo complejo, y a menudo sorteado con dificultad" (Buckingham, 2018: 7).

En este contexto, si el alfabetismo transmedia tiende a focalizarse en las competencias desarrolladas en ambientes informales, conviene recordar que tanto a nivel analítico como práctico es aconsejable mantener un intercambio constante entre ambos entornos. Por este motivo la alfabetización transmedia, entendida como una praxis educativa, se propone recuperar dentro del aula los saberes desarrollados fuera del entorno formal. Tal como sostiene Buckingham: "Los que más utilizan los medios no son necesariamente los que más alfabetizados están en su consumo. En mi opinión, este tipo de alfabetización también requiere un proceso sistemático de estudio; $y$, para bien o para mal, los colegios siguen siendo instituciones vitales (y sin duda obligatorias) a este respecto" (Buckingham, 2018: 7).

Dicho en otras palabras: si bien en los entornos informales se aprenden a hacer muchas cosas con los medios, esos conocimientos y prácticas deberían ser retrabajadas y complementadas en el circuito formal. Si algo nos enseñan las narrativas transmedia es que el mundo de la industria y la cultura de los fans, si bien tienen lógicas diferentes y a 
menudo opuestas, también se necesitan mutuamente. De la misma manera, la educación transmedia necesita de ese intercambio entre lo que pasa con los medios fuera de la escuela y los procesos de enseñanza-aprendizaje que se dan dentro del aula.

- Este trabajo ha sido financiado por el proyecto I+D+i 'Transalfabetismos. Competencias transmedia y estrategias informales de aprendizaje de los adolescents' (CSO2014-56250-R) del Ministerio de Economía, Industria y Competitividad de España.

\section{Bibliografía}

N Alias (2015): "Designing, developing and evaluating a learning support tool: A case of design and development research (DDR)". SAGE Research Methods Cases. doi:10.4135/978144627305014558820

D Buckingham (2018): "Prólogo", en Carlos A. Scolari (Ed.) Adolescentes, Medios de Comunicación y Culturas Colaborativas. Aprovechando las Competencias Transmedia de los Jóvenes en el Aula. Barcelona: Transliteracy H2020 Research Project. URL: https://transmedialiteracy.org/ D Buckingham (2004): Educación en medios. Alfabetización, aprendizaje y cultura contemporánea. Barcelona: Paidós Comunicación.

C Carson (2017): What is fanfiction and where to find it: Definitions and fan archives. YA Hotline, 104, pp. 5-7.

A A Delwiche \& JJ Henderson (2013): The Participatory Cultures Handbook. Nueva York: Routledge.

J Ferrés, \& M-J Masanet (2015): “A vueltas con la educación mediática", en Joan Ferrés and Maria-Jose Masanet (Ed.) La educación mediática en la universidad española. Barcelona: Gedisa, pp. 10-27

J Ferrés, \& M-J Masanet (2015): "Nuevos retos para la educación mediática", en Joan Ferrés and Maria-Jose Masanet (Ed.) La educación mediática en la universidad española. Barcelona: Gedisa, pp. 137-153

J Ferrés \& A Piscitelli (2012): "Media Competence. Articulated Proposal of Dimensions and Indicators". Comunicar, 19(38), pp. 75-82. doi:10.3916/C38-2012-02-08 
A Gutiérrez \& K. Tyner (2012): "Media Education, Media Literacy and Digital Competence". Comunicar, 19(38), pp. 31-39. doi:10.3916/C38-2012-02-03

H Jenkins (2003): “Transmedia Storytelling. Moving characters from books to films to video games can make them stronger and more compelling". Technology Review, 15 de enero. URL: https://www.technologyreview.com/s/401760/transmediastorytelling/

H Jenkins (2006): Convergence Culture. Where old and new media collide. Nueva York: NYU Press.

H Jenkins (2010): “Transmedia Education: the 7 Principles Revisited". En: Confessions of an Aca-Fan, 21 de junio. URL: http://henryjenkins.org/blog/2010/06/transmedia_education _the_7_pri.html

H Jenkins, R. Purushotma, M Weigel, K Clinton, \& A J Robison (2009): Confronting the Challenges of Participatory Culture. Media Education for the 21st Century. Cambridge (MA): MIT Press.

H Jenkins, S Ford, \& J Green (2013): Spreadable Media: Creating Value and Meaning in a Networked Culture. Nueva York: NYU Press.

H Jenkins, M Ito, \& d boyd (2015): Participatory Culture in a Networked Era. Malden (MA): Polity.

T Koltay (2011): “The media and the literacies: media literacy, information literacy, digital literacy". Media, Culture \& Society, 33(2), pp. 211-221.

https://doi.org/10.1177/0163443710393382

P Lévy (1997): L'Intelligence collective. Pour une anthropologie du cyberespace. Paris: La Découverte.

N Lugo (2016): Diseño de narrativas transmedia para la transalfabetización. (Tesis doctoral). Universidad Pompeu Fabra, Barcelona.

W J Potter (2005). Media Literacy, Thousand Oaks, CA: Sage. F Rogow (2004): "Shifting from Media to Literacy. American Behavioral Scientist", 48(1), pp. 30-34. https://doi.org/10.1177/0002764204267248

C A Scolari (2008): Hipermediaciones. Elementos para una teoría de la comunicación digital interactiva. Barcelona: Gedisa. 
C A Scolari (2009): "Transmedia Storytelling. Implicit consumers, narrative worlds and branding in contemporary media production". International Journal of Communication, 3, pp. 586-606.

C A Scolari (2013): Narrativas transmedia. Cuando todos los medios cuentan. Barcelona: Deusto.

C A Scolari (ed.) (2018): Adolescentes, medios de comunicación y culturas colaborativas. Aprovechando las competencias transmedia de los jóvenes en el aula. Barcelona: Transliteracy H2020 Research Project. URL: https:/ / transmedialiteracy.org/ A Toffler (1980). The third wave: The classic study of tomorrow. New York, NY: Bantam. 


\title{
Adolescentes, redes sociales y universos transmedia: la alfabetización mediática en contextos participativos
}

\author{
Julián de la Fuente Prieto - Universidad de Alcalá, UAH, \\ España julian.fuente@,uah.es \\ Pilar Lacasa Díaz - Universidad de Alcalá, UAH, \\ España p.lacasa@uah.es \\ Rut Martínez-Borda - Universidad de Alcalá, UAH, \\ España rut.martinez@uah.es
}

Cómo citar: J de la Fuente Prieto, P Lacasa Díaz, R Martínez-Borda (2019): "Adolescentes, redes sociales y universos transmedia: la alfabetización mediática en contextos participativos. En V Tur-Viñes/M J González-Río/R S Contreras-Espinosa (Eds.) Jóvenes / Medios y cultura colaborativa. Cuadernos Artesanos de Comunicación, cac157, pp 125-160. La Laguna (Tenerife): Latina. DOI: $10.4185 / \operatorname{cac} 157$

\begin{abstract}
s
Introducción. Analiza los procesos de alfabetización mediática de los jóvenes a través de comunidades de prácticas en contextos participativos y mediante el uso de discursos digitales que posibilitan la creación de universos transmedia. Metodología. Combina técnica de recogida de datos cualitativos mediante la investigación-acción, la etnografía virtual y los métodos visuales. Resultados. Reconstruyen el sistema de actividad de un taller de creación audiovisual dirigido a adolescentes entre 8 y 14 años en un laboratorio ciudadano. Conclusiones. Reflexiona sobre las estrategias no formales de educación mediática, los roles que adoptan los jóvenes como usuarios
\end{abstract}


de redes sociales y la creación de contenidos transmedia basados en la experiencia de mundos narrativos.

\section{Keywords}

Alfabetización mediática; Cultura participativa; Narrativa Transmedia; Investigación-Acción; Etnografía virtual; Sistema de actividad.

\section{Contents}

1. Introducción. 1.1 De la alfabetización mediática al aprendizaje conectado. 1.2. Audiencias jóvenes, creadores y fans. 1.3. Narrativa transmedia y creación de mundos. 2. Método 2.1. Estrategias metodológicas. 2.2. Contexto y participantes. 2.3. Análisis. 3. Resultados. 3.1. Participantes y sus referentes. 3.2. Instrumentos y aplicaciones. 3.3. Reglas y lenguajes. 3.4. Comunidad y participación. 3.5. Roles y expertos. 3.6. Metas y narrativa. 3.7. Creaciones y transmedia. 4. Conclusiones. 5. Bibliografía.

\section{1. introducción}

A PRENDEMOS conectados a nuestro entorno y el de los jóvenes 1 gira alrededor de los medios de comunicación. Internet se ha convertido en un importante contexto para el aprendizaje a través de nuevas prácticas y discursos digitales. La comunicación audiovisual está cada vez más presente en este ecosistema, convirtiéndose al mismo tiempo en herramienta y objeto de alfabetización.

El objetivo general de este trabajo es analizar los procesos de alfabetización mediática entre la gente joven. Nuestra mirada se orienta a contextos no formales donde el aprendizaje se produce de forma colaborativa. De esta manera, nos interesa analizar tanto las prácticas como los discursos audiovisuales que los adolescentes elaboran a través de los nuevos medios. Para ello disponemos de tres objetivos específicos:

1 Identificar estrategias de alfabetización mediática que los jóvenes despliegan en contextos colaborativos.

2 Definir qué funciones adoptan los jóvenes como usuarios de las redes sociales, especialmente en comunidades virtuales. 
3 Describir los contenidos audiovisuales que los jóvenes generan a partir de la creación de mundos transmedia.

Para ello, comenzaremos analizando el marco teórico de estas cuestiones para después realizar un análisis empírico basado en la experiencia directa con adolescentes en un taller de creación digital.

\subsection{De la alfabetización mediática al aprendizaje conectado}

La alfabetización mediática es definida por David Buckingham como "el conocimiento, las habilidades y competencias que se requieren para utilizar e interpretar los medios" (Buckingham, 2004, p. 71). Esto supone desde un punto de vista tradicional, que las personas alfabetizadas mediáticamente tienen la capacidad de leer además de escribir en y desde los medios de comunicación. Pero este autor apunta también que "la educación mediática se propone tanto la compresión crítica como la participación activa" (Buckingham, 2004, p. 21)

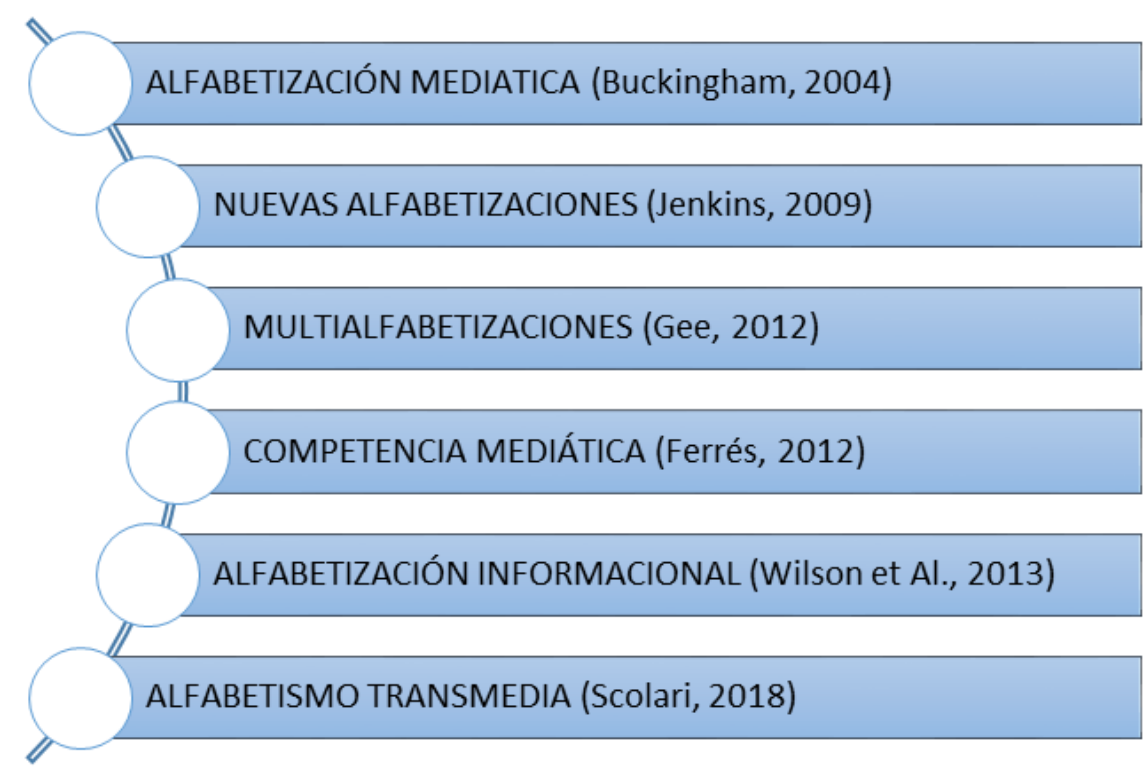

Figura 1: Propuestas de aprendizaje en los medios de comunicación

Este concepto ha sido rápidamente adoptado por la comunidad educativa, en la línea de otras propuestas centradas en la actualización de los currículos escolares como las multialfabetizaciones (Gee, 2012) o las nuevas alfabetizaciones (Jenkins, 2009). En España, una aportación muy relevante es el proyecto sobre competencia mediática (Ferrés, 2012; Rodríguez et al., 2011) que aglutina a un gran número de académicos encargados de definir una serie de indicadores, sobre los que elaborar un análisis cuantitativo del grado de conocimientos, 
habilidades y actitudes de los españoles ante los medios de comunicación. Además, podemos destacar la iniciativa de la UNESCO, proponiendo un currículo orientado a desarrollar la alfabetización mediática e informacional (Wilson, Grizzle, Tuazon, Akyempong, \& Cheung, 2013) que busca un marco común para la educación mediática en el mundo.

La aportación más reciente a estas teorías sobre el aprendizaje a través de los medios de comunicación ha sido el proyecto "Transliteracy" coordinado por Carlos Scolari (2018) en el que se propone una nueva noción de alfabetismo, esta vez poniendo el acento en la convergencia mediática y en los intercambios de aprendizaje informal que se producen sobre todo entre los más jóvenes:

En este contexto, el alfabetismo transmedia se podría entender como una serie de habilidades, prácticas, prioridades, sensibilidades, estrategias de aprendizaje y formas de compartir que se desarrollan y se aplican en el contexto de las nuevas culturas participativas (Scolari, 2018: 17)

Por eso, siguen siendo necesarios estudios que atiendan especialmente estos procesos de alfabetización entre adolescentes y más aún fuera de contextos escolares (Lacasa Díaz, 2018; Livingstone \& Sefton-Green, 2016). Esto nos lleva a buscar una metodología para la educación mediática, que no se limite a una alfabetización funcional, sino que también sea capaz de fomentar prácticas y discursos propios del contexto sociocultural de los jóvenes (Cortesi et al., 2015; Ito-, 2010). En este sentido uno de los modelos más recientes sería el del aprendizaje conectado (Ito et al., 2013), que supone la suma de los intereses personales, la colaboración entre iguales y el desempeño escolar. Se trata de un contexto de aprendizaje que combina entornos reales y virtuales, mediante la creación de una comunidad de prácticas en la que pueden participar cualquier persona:

Este modelo se basa en la evidencia de que el aprendizaje más flexible, adaptativo y efectivo involucra el interés individual, asi como también el apoyo social para superar la adversidad y brindar reconocimiento. Este concepto busca construir comunidades y capacidades colectivas para el aprendizaje. (Ito et al., 2013: 3) 
En este, como en otros modelos subyace la voluntad de establecer un aprendizaje abierto, colaborativo y significativo; cuyo eje de acción es la cultura participativa y la inteligencia colectiva (Carpentier, 2011; Lévy, 1997) Se trata de un modelo que nace en el campo de la psicología así como de la educación y que actualmente está cada vez más arraigado en la comunicación, especialmente en las prácticas y los discursos asociados a los nuevos medios (Burn, 2009; Lowgren \& Reimer, 2013). Por eso, a continuación, analizaremos cómo ésta cultura participativa está influyendo en las audiencias de los medios interactivos.

\subsection{Jóvenes audiencias, creadores y fans}

El tradicional tratamiento de las audiencias mediáticas ha dado paso a una nueva concepción, estableciendo un papel activo del público a la hora de apropiarse y construir los significados de los mensajes presentes en los medios. (Sullivan, 2013; Zeller, Ponte, \& O'Neill, 2014) La clave para entender este proceso es la participación y el papel de las audiencias adolescentes, no sólo en la recepción sino también en la producción de mensajes a través de los medios de comunicación. Es decir, los jóvenes no se caracterizan por ser espectadores de un medio, sino por vivir en un determinado contexto con el que interactúan gracias a los medios. Así lo exponen Richard Butch y Sonia Livingstone (2013):

Los estudios de audiencia han florecido con el surgimiento de un nuevo paradigma de audiencias activas que los restablecieron como actores en sus propias vidas y colocaron los medios en el contexto del microclima de las interacciones sociales entre amigos de la familia y la comunidad, y el paisaje más amplio de hegemonía cultural y resistencia. (Butch y Livingstone, 2013; \#243)

Este nuevo rol de la audiencia ha sido identificado dentro de una cultura participativa (Jenkins, 2009; Jenkins, Ito-, \& Boyd, 2015) a través de diferentes niveles de actividad que nos llevan desde a meramente visualizar un contenido, interactuar con este, involucrarse en su creación o llegar incluso a liderar su difusión. Este matiz a la hora de considerar las audiencias como participantes de los medios de comunicación, nos permite introducir diversos modelos según su compromiso y grado de participación dentro de los medios: 


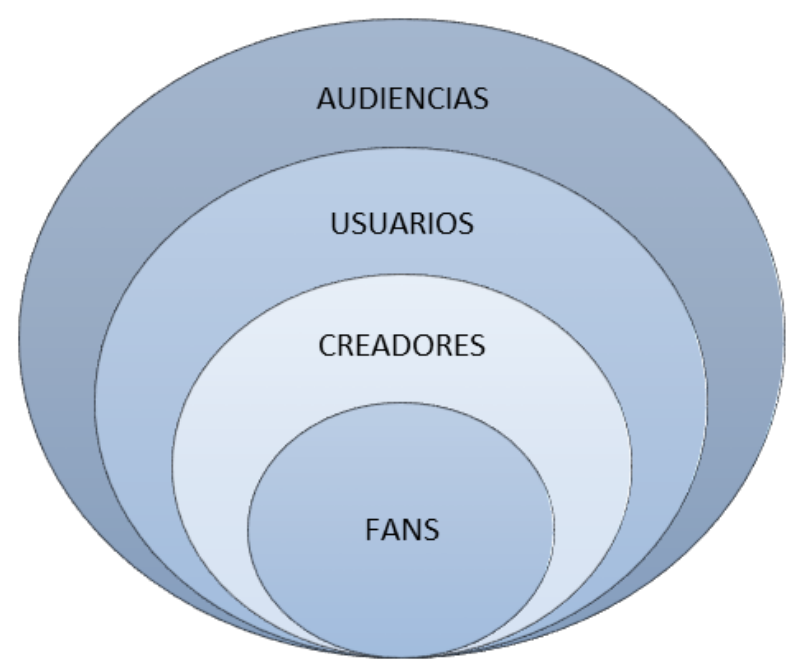

Figura 2: Nuevos modelos de participación en los medios

Numerosos estudios académicos (Duffett, 2013; Gray, Sandvoss, \& Harrington, 2007; Stein, 2015) han identificado la cultura fan como uno de estos modelos especialmente representativos de los nuevos roles que las audiencias adoptan ante los medios de comunicación. Tal y cómo opina Louisa Stein (2015) la audiencia fan no está modelada exclusivamente por la industria de consumo, sino que posee una autonomía propia como usuaria de los medios. Su principal seña de identidad es la apropiación de los contenidos a través de una comunidad que regulan tanto el consumo como la difusión o producción de estos mensajes. Es en estos casos en los que los medios vuelven a convertirse en el contexto donde se producen estas prácticas culturales de interacción entre usuarios y construcción de significado:

La investigación de la audiencia ha revelado la simbiosis arraigada entre la práctica cultural y la perspectiva de ser un fan y la modernidad industrial en general. En lugar de ser un fenómeno transhistórico, el fandom emerge en los estudios históricos como una práctica cultural vinculada a formas específicas de organización social y económica. (Gray et Al., 2007: \#276)

Bien como usuarios, creadores o simplemente consumidores, las audiencias jóvenes cada vez son más activas tanto dentro como fuera de los medios. Esto supone plantearnos cómo estas prácticas están alterando la percepción que tenemos de los propios medios, dando paso a una inmersión total en el contenido. El hilo conductor de nuestras prácticas sociales es la narrativa y su forma de discurso predominante es lo que denominamos Transmedia. 


\subsection{Narrativa transmedia y creación de mundos}

La noción de Transmedia fue propuesta por primera vez por Henry Jenkins a comienzos del siglo XXI a través de su artículo "Transmedia Storytelling" (2003). A partir de aquí, este concepto ha sido constante en su bibliografía, que se ha encargado de explorar desde otros fenómenos como la convergencia mediática (Jenkins, 2008) así como la extensibilidad de contenidos o "spreadbility" (Jenkins, Ford, \& Green, 2013). El éxito de esta propuesta no sólo se justifica en su generalización entre la comunidad académica, sino también en su rápida adopción por parte de la industria de contenidos.

Analizando un poco más profundamente la lógica de este proceso, Carlos Scolari apuesta por identificar dos dimensiones en los fenómenos transmedia (Scolari, Bertetti, \& Freeman, 2014) Por un lado observando la narrativa a nivel textual y por otro lado los medios desde el punto de vista social. Sólo cuando ambas dimensiones convergen tiene lugar la experiencia transmedia.

Es posible identificar al menos dos posibles expansiones: expansiones de medios y expansiones narrativas. Desde su perspectiva, el caso perfecto para la narración transmedia ocurre cuando los medios y las expansiones narrativas convergen en una experiencia narrativa única. (Scolari, Bertetti y Freeman, 2014: 191)

Esta concepción del discurso transmedia nos obliga superar el análisis de la narrativa como relato, para empezar a considerar la narrativa como práctica social. Según Marie-Laure Ryan (2014) no podemos seguir hablando de "story" (historia) sino de "storyworld" (mundo de la historia). Lo cual implica considerar no sólo las tradicionales categorías textuales, sino también las dimensiones culturales de cualquier fenómeno narrativo. Así pues, los significados ya no dependen exclusivamente del contenido, sino también de las prácticas asociadas al mismo:

De esta manera podemos identificar el transmedia con un discurso que combina una experiencia narrativa y social al mismo tiempo. Narrativa desde el punto de vista de la creación de unos personajes, así como un espacio-tiempo de ficción; pero también social porque todas las personas que participan en el fenómeno tienen una inmersión o 
interacción desde el punto de vista mediático. Así lo considera Kalogeras (2014) cuando establece que tanto los consumidores como los productores participan en esta labor de "world-building":

A través del espacio social y tecnológico compartido por el consumidor y el productor, surge el concepto de construcción del mundo transmedia: la creación de un entrelazado de historias que provienen de un universo ficticio impulsado por la industria del entretenimiento. (Kalogeras, 2014: 380)

La creación de mundos o "world-building" representa una actividad simbólica que implica un grado complejo de organización social. No se trata de un proceso cognitivo basado en nuestra propia percepción, sino en una construcción colectiva de un universo de ficción. El discurso transmedia nos permite relacionar los diferentes mundos narrativos que exploramos cada día en una experiencia unificada a través de los medios. En la práctica cada uno de nosotros participa de los diferentes relatos presentes en los medios a través de un discurso propio.

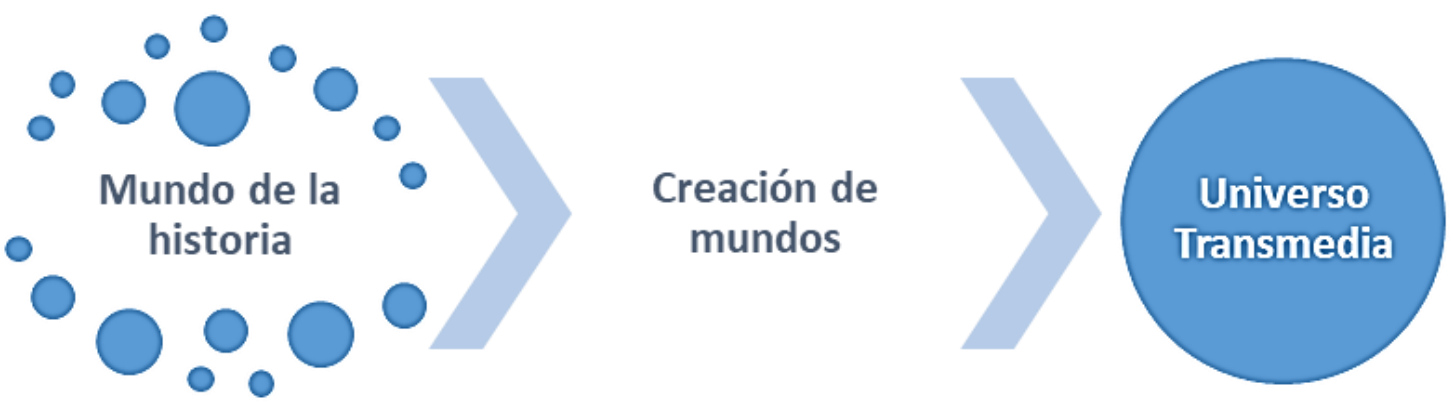

Figura 3: Creación de Universos Transmedia

En este sentido, la lógica industrial a la que antes hacíamos referencia (Bernardo, 2011; Pratten, 2011) continúa segmentando la narrativa a través de los medios para diferenciar los contenidos realizados por fans, derivados de un contenido primario generado por profesionales. Sin embargo, esa lógica no se sostiene desde el punto de vista de usuarios de un mundo transmedia. Tal vez en el mundo de la ficción todavía exista esa brecha entre productores y usuarios, pero en otros ámbitos como la educación el discurso transmedia parece destinado a romper definitivamente los roles asignados tradicionalmente (de la Fuente Prieto, 2014). 
El discurso transmedia transforma la audiencia en usuarios y el consumo en participación. Como práctica social asociada a la creación de mundos nos permite crear comunidades y compartir significados. Pero su verdadera revolución reside en la capacidad superar el contexto tecnológico de los medios, para centrarse en su contexto narrativo. En nuestra experiencia cotidiana los medios funcionan cada vez más como objetos culturales que cómo herramientas tecnológicas.

\section{Método}

Tal y cómo se ha repasado en el marco teórico, nuestra investigación está marcada por las prácticas en los nuevos medios y los discursos asociados a su contexto. Pero además queremos focalizar el estudio en una población especialmente sensible a estos cambios como son los niños y niñas. Los estudios sobre la infancia gozan de una personalidad propia dentro de la investigación social, y en concreto en el ámbito de los medios y su alfabetización (Boyd, 2014; Jenkins et al., 2015) Cada vez son más los trabajos que apuestan por metodologías cualitativas, sobre todo en el ámbito de los nuevos medios de comunicación (Gair \& Van Luyn, 2017; Vittadini et al., 2014)

La metodología cualitativa se caracteriza por su carácter profundo en lugar de extensivo, necesita de la interpretación de los datos analizados y sobre todo suele ser un proceso iterativo en el que cada paso puedo obligar a reformular la investigación. Dentro de este enfoque cada proyecto exige de un diseño específico y la implementación de diversos métodos combinados (Berger, 2016; Maxwell, 2013). Pero por encima de todo, la metodología cualitativa es una apuesta por una epistemología sociocultural, cuyo fin es establecer una explicación antes que unas reglas sobre el mundo en el que vivimos.

Por lo tanto, una investigación empírica en base a estas prácticas debe incluir según Meulenaere y Grove (2016) el estudio de los procedimientos por los que se lleva a cabo, la comprensión del significado que tiene para los participantes, así como la identidad que se establece con los resultados materiales. Sólo si tenemos en cuenta estos factores, podemos interpretar el verdadero sentido de las prácticas en los nuevos medios. 


\subsection{Estrategias metodológicas}

El diseño de investigación sitúa las evidencias en contextos comunitarios, en los que los jóvenes desarrollan una serie de prácticas audiovisuales a través de un proceso de participación. Siguiendo las últimas investigaciones en este campo (Cortesi et al., 2015; Delgado, 2015; Livingstone \& Sefton-Green, 2016) nos enfrentamos al reto de utilizar métodos cualitativos que nos permitan aproximarnos a estos datos:

En primer lugar, debemos asegurarnos que los participantes comprenden nuestra perspectiva de investigación y nosotros su contexto de actividad. Para ello nos propone el uso de métodos participativos, como la Investigacción-Acción (Brites, 2016; McNiff, 2013) que nos permite reflexionar sobre la propia práctica. En este sentido, la planificación del taller se revisa antes de cada sesión de modo que sea un proceso que se adapte a la cultura mediática de los participantes y no viceversa. De esta manera podemos reproducir las prácticas que los jóvenes desarrollan en los medios y al mismo tiempo fomentar procesos de alfabetización a través de los mismos. A la hora de codificar todos estos datos optamos por utilizar fundamentalmente sumarios de investigación.

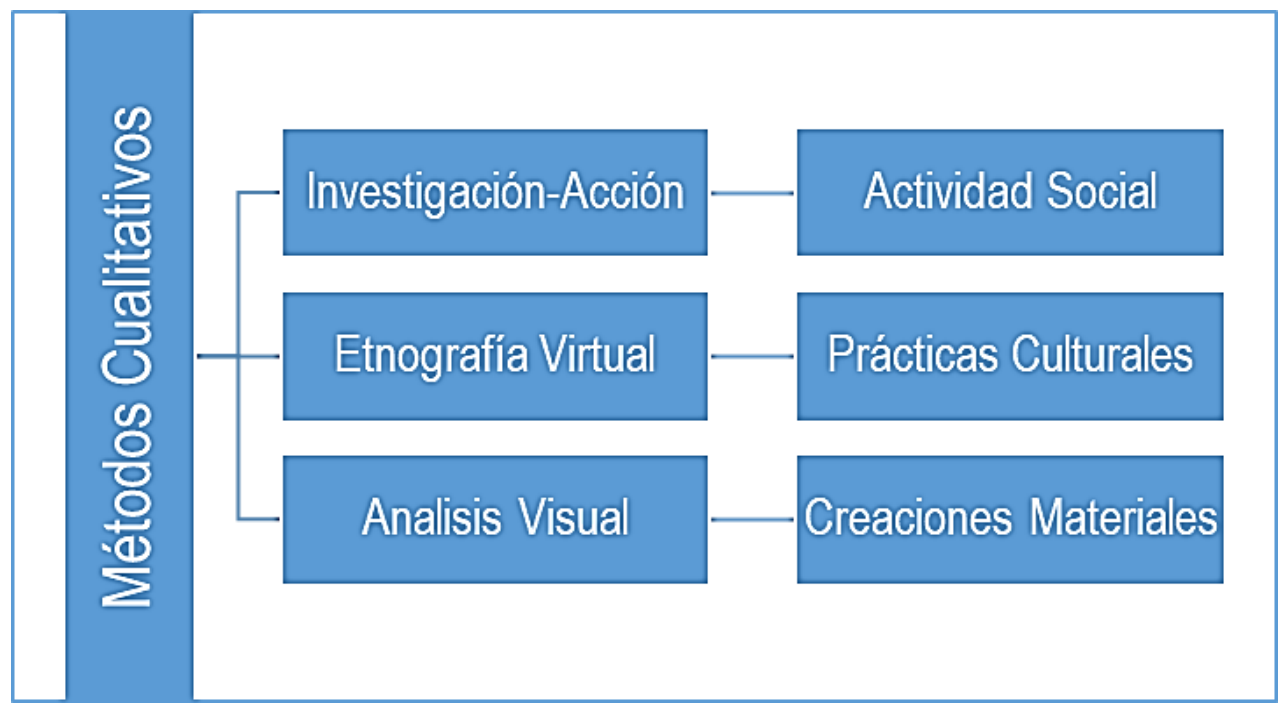

Figura 4: Combinación de métodos para la recogida de datos

Además de considerar a los jóvenes participantes activos y reflexivos, debemos tener en cuenta que no existen barreras entre su actividad fuera y dentro de las redes sociales. Por lo tanto, otro de los métodos a utilizar debe integrar los diferentes planos de interacción que utilizan 
los jóvenes, incluyendo los diferentes contextos, en las que se producen estas prácticas y sobre todo los diversos roles que adoptan dentro de la comunidad. Para ello, según varios autores (Boellstorff, 2012; Pink, 2012) resulta interesante utilizar la Etnografía Virtual. La ventaja que nos ofrece este método es poder combinar el análisis de múltiples datos recogidos mediante un registro audiovisual único.

Por último, necesitamos desarrollar un método de recogida de evidencias sobre los significados que construyen los jóvenes a través de los medios. Por eso es tan importante el uso de Métodos Visuales (Margolis \& Pauwels, 2011; Rose, 2016) que nos faciliten analizar tanto de forma connotativa como denotativa, las representaciones audiovisuales que construyen los jóvenes. Pero, más aún, si estos métodos visuales son participativos, ya que según Gregory Stanczak (2007) suponen una alternativa para que los jóvenes puedan participar tanto en la generación como en la interpretación de sus propios datos visuales.

En definitiva, nuestro diseño de investigación implica la necesidad de combinar una serie de estrategias metodológicas que nos permitan aproximarnos a los datos de forma holística. Es decir, atendiendo tanto a las dimensiones sociales, materiales y culturales de las prácticas que pretendemos analizar.

\subsection{Contexto y participantes}

Nuestro objeto de estudio son las prácticas que los niños y niñas desarrollan dentro de una comunidad de la que forman parte los investigadores. Según Susan Gair y Ariella Van Luyn (2017) este contexto se puede lograr mediante el desarrollo de actividades creativas a través de los nuevos medios y al mismo tiempo en contextos físicos, ambos compartidos por los investigadores. En nuestro caso, decidimos generar estas comunidades de prácticas mediante la realización de talleres de arte digital con niños y niñas en contextos participativos.

En concreto esta iniciativa se desarrolla en el espacio Intermediae (http://intermediae.es); un laboratorio ciudadano que se integra en el centro de creación contemporánea Matadero Madrid. El proyecto supone organizar una serie de talleres dirigidos a adolescentes, a través de los cuales poder desarrollar la creación digital vinculada al espacio comunitario. La intención es que los participantes utilicen las redes 
sociales como instrumentos creativos, mientras los investigadores examinan cómo el entorno y el aprendizaje cooperativo influyen tanto en las obras como en los mensajes que generan.

Los talleres se llevaron a cabo a cabo entre los meses de noviembre de 2014 y mayo de 2015 hasta sumar un total de diez sesiones. La mayoría se desarrollaban un domingo de cada mes durante dos horas y media, pero en algún caso se programó una sesión doble sábado y domingo con los mismos participantes. Se convocaban a través de la programación de Matadero Madrid y estaban abiertos a cualquier preadolescente de entre ocho y catorce años. Los adultos generalmente no participaban en las actividades del taller, pero compartían los mismos espacios con los participantes y se les invitaba a ver las creaciones al final de la sesión.

En un primer momento la única división del trabajo que se introduce en los talleres sería la del gran grupo que incluye a todos los participantes e investigadoras; así como el pequeño grupo que divide a los participantes por edades. No se trata de grupos de edad cerrados, sino más bien una separación entre pequeños, medianos y grandes, que se adapta en cada sesión según el desarrollo de los participantes. Estos pequeños grupos permiten reforzar o adaptar los contenidos vistos en el gran grupo y sobre todo desarrollar la práctica del taller con el apoyo de las investigadoras.
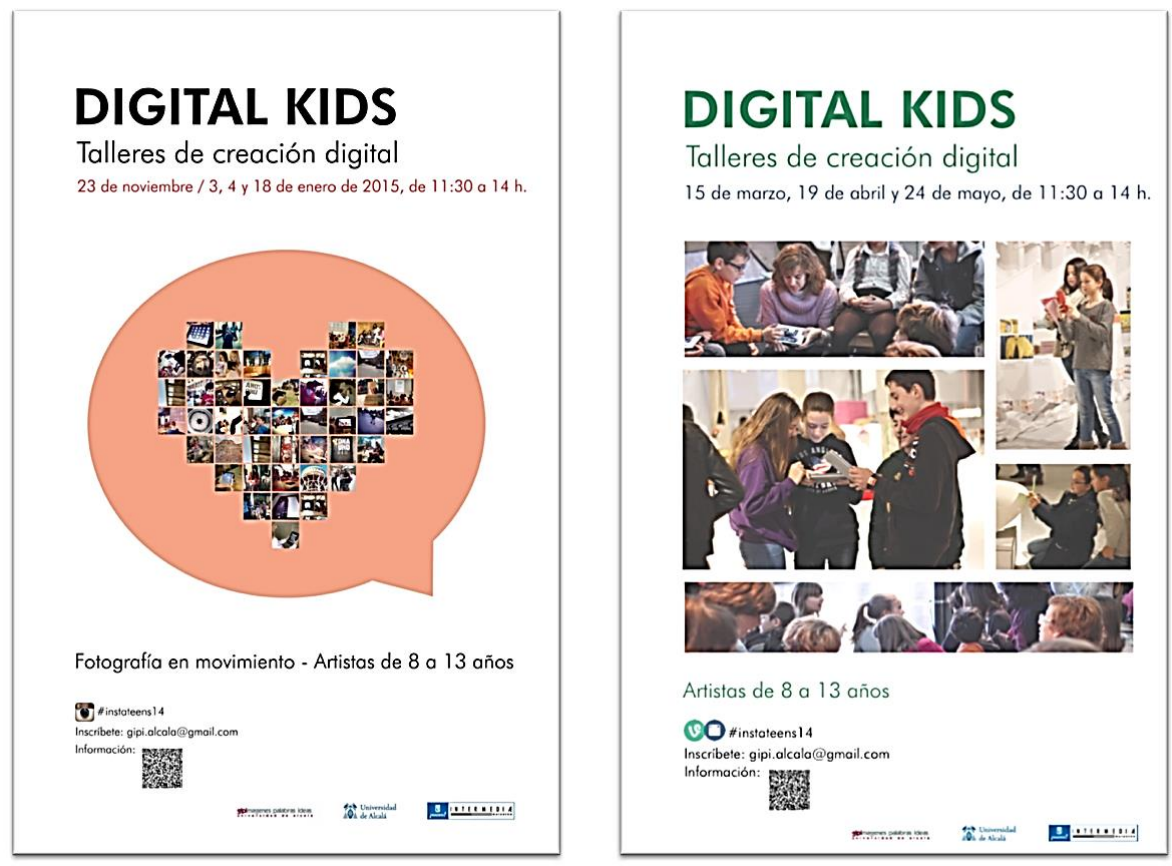

Figura 5: Cartel publicitario de los talleres (Grupo GiPI) 
El número de participantes fue muy diferente en cada sesión, oscilando entre las 10 y 23 personas. A pesar de ello, tanto la infraestructura como el equipo de investigación fue el mismo para todas las sesiones. Se disponía de 21 tabletas para que los participantes pudieran realizar las creaciones audiovisuales que desearan. En ocasiones tuvieron que compartirlas, pero la mayoría de las veces utilizaron una por persona. Estas tabletas disponían de una completa relación de aplicaciones de creación y edición audiovisual. También permitían el acceso a Internet y a las redes sociales, mediante una conexión por tarjeta de teléfono móvil. De esta manera se aseguraba tanto la conectividad como la interactividad entre las aplicaciones.

\begin{tabular}{|c|c|c|c|}
\hline Sesión & $18 / 01 / 2015$ & $08 / 02 / 2015$ & $14 / 03 / 2015$ \\
\hline Participantes & 14 & 10 & 23 \\
\hline Archivos & 105 & 474 & 213 \\
\hline Sumarios & 5 & 4 & 3 \\
\hline $\begin{array}{l}\text { Audio } \\
\text { Investigación }\end{array}$ & $\begin{array}{l}\text { 18:24 (Audio GM) } \\
\text { 38:34 (Audio GP) }\end{array}$ & $\begin{array}{r}28: 35 \text { (Audio } \\
\text { GP) }\end{array}$ & $\begin{array}{r}\text { 1:42:47 (Audi } \\
\text { GP) } \\
\text { 48:04 (Audio } \\
\text { GM) }\end{array}$ \\
\hline $\begin{array}{l}\text { Fotos } \\
\text { Investigación }\end{array}$ & 191 (DSNG) & 182 (DSNG) & 129 (DSNG) \\
\hline $\begin{array}{l}\text { Vídeo } \\
\text { Investigación }\end{array}$ & $\begin{array}{r}2: 17: 12 \text { H. }(\text { Cam } \\
\text { GG) } \\
\text { 1:08:27 H. (Cam } \\
\text { GP) } \\
\text { 1:20:49 H. } \text { (Cam } \\
\text { GM) }\end{array}$ & $\begin{array}{r}2: 12: 12 \text { (Cam } \\
\text { GG1) } \\
1: 23: 01 \text { (Cam } \\
\text { GP) } \\
\text { 49:25 (Cam GM) }\end{array}$ & $\begin{array}{r}2: 22: 25 \text { (Cam } \\
\text { GG) } \\
1: 16: 27 \text { (Cam } \\
\text { GP }) \\
1: 15: 47 \text { (Cam } \\
\text { GM) }\end{array}$ \\
\hline
\end{tabular}

Tabla 1: Datos analizados (Grupo GIPI)

La recogida de datos de carácter etnográfico se lleva a cabo mediante la grabación audiovisual de cada sesión. Se utilizan tres cámaras que graban desde distintos ángulos las situaciones de gran grupo, dividiéndose posteriormente para registrar las actividades realizadas en los pequeños grupos. Cada investigador dispone asimismo de una grabadora de audio que utiliza en los momentos en los que interactúa 
de primera mano con cada participante o en aquellos instantes en los que la cámara de vídeo no se encuentra grabando por cualquier circunstancia. Además, otra investigadora realiza fotografías recogiendo las distintas situaciones que se producen en cada sesión y que servirán como recurso para ilustrar el análisis de datos. Todos estos datos se completan con los sumarios que redacta cada investigador al término del taller, así como las actas de las reuniones de grupo en las que se ponen en común la organización previa. Por último, disponemos del registro de las creaciones audiovisuales realizadas por los participantes que se publican también a través del perfil del grupo de investigación en Vimeo (https://vimeo.com/gipi).

Para el análisis nos vamos a centrar en tres sesiones desarrolladas desde enero a marzo de 2015. Su unidad responde a que en todas ellas se utilizó el vídeo como herramienta creativa a través de distintas aplicaciones que en algunos casos también incorporaban redes sociales. Mediante la metodología propuesta se examina de forma diacrónica las sesiones de 18/1, 08/2 y 14/3 a través de la investigación-acción, etnografía y análisis de contenido.

\subsection{Análisis}

Para llevar a cabo el análisis, necesitamos entender todos los procesos $\mathrm{y}$ actores que intervienen en el taller como un sistema conjunto. Para relacionar todos estos elementos acudimos a la teoría del aprendizaje expandido (Engeström, 2001; Gutiérrez, Engeström, \& Sannino, 2016) que nos permite elaborar un modelo de actividad a través del cual explicar cómo los participantes se involucran en una comunidad de prácticas para generar significados de forma colaborativa en el contexto del taller:

Un sistema de actividad colectivo, mediado por artefactos y orientado a objetos, se toma como la unidad principal de análisis. Las acciones individuales y grupales dirigidas a un objetivo, asi como las operaciones automáticas, son unidades de análisis relativamente independientes pero subordinadas, que finalmente se entienden solo cuando se interpretan en el contexto de sistemas de actividades completos. (Egeström, 2001: 137)

Este Sistema de Actividad (Daniels, Edwards, Engeström, Gallagher, \& Ludvigsen, 2013; Engeström, Miettinen, \& Punamäki, 1999) ha sido 
adoptado por numerosos investigadores para analizar diversos contextos, especialmente educativos. Sin embargo, no se refiere únicamente a experiencias de aprendizaje formal, sino a todas aquellas prácticas que implican el desarrollo conjunto de una innovación dentro de una comunidad. Así representan Engeström y Sannino (2010) este modelo:

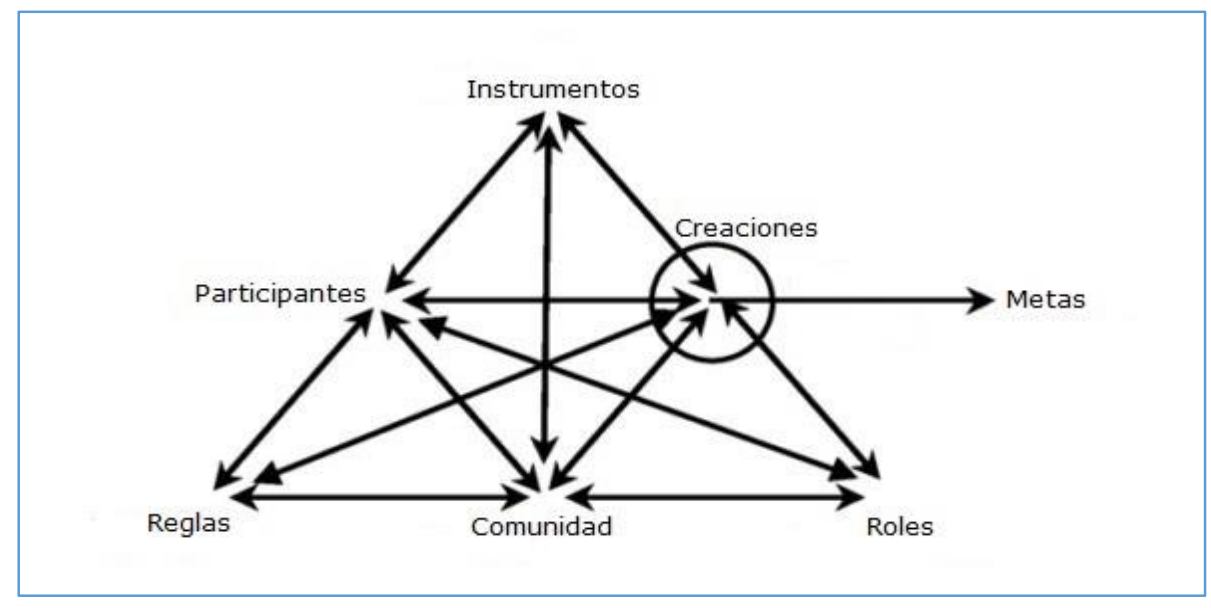

Figura 6: Sistema de actividad basado en Egeström y Sannino (2010)

Para entender este sistema de actividad, debemos comenzar por ubicar a los participantes como sujetos en un lado del modelo. Al otro lado se sitúan sus creaciones mediadas en el vértice superior por los instrumentos considerados como herramientas y signos utilizados. A este sistema hay que añadir un contexto social y cultural, identificado con la comunidad en la base de la pirámide. Esta comunidad se caracteriza por unos roles de trabajo entre expertos y novatos, así como unas reglas que constituyen el uso de unos determinados medios y discursos asociados a estas prácticas. El objetivo final, representado en las metas supone identificar tanto el sentido personal como el significado colectivo de estas prácticas:

Gracias al uso de este modelo, podemos establecer unas categorías previas (participantes, instrumentos, reglas, comunidad, roles, metas y creaciones) sobre las que comenzar a codificar las evidencias que nos aportan los datos recogidos; con la dificultad añadida de que se trata de fuentes de distinta naturaleza textual, visual y auditiva: Los documentos escritos han sido los diarios de investigación, así como los sumarios de las reuniones en grupo. La información visual se ha fundamentado en las fotografías tomadas a lo largo de los talleres. Mientras, el registro 
audiovisual parte de las grabaciones de los diálogos establecidos con los participantes.

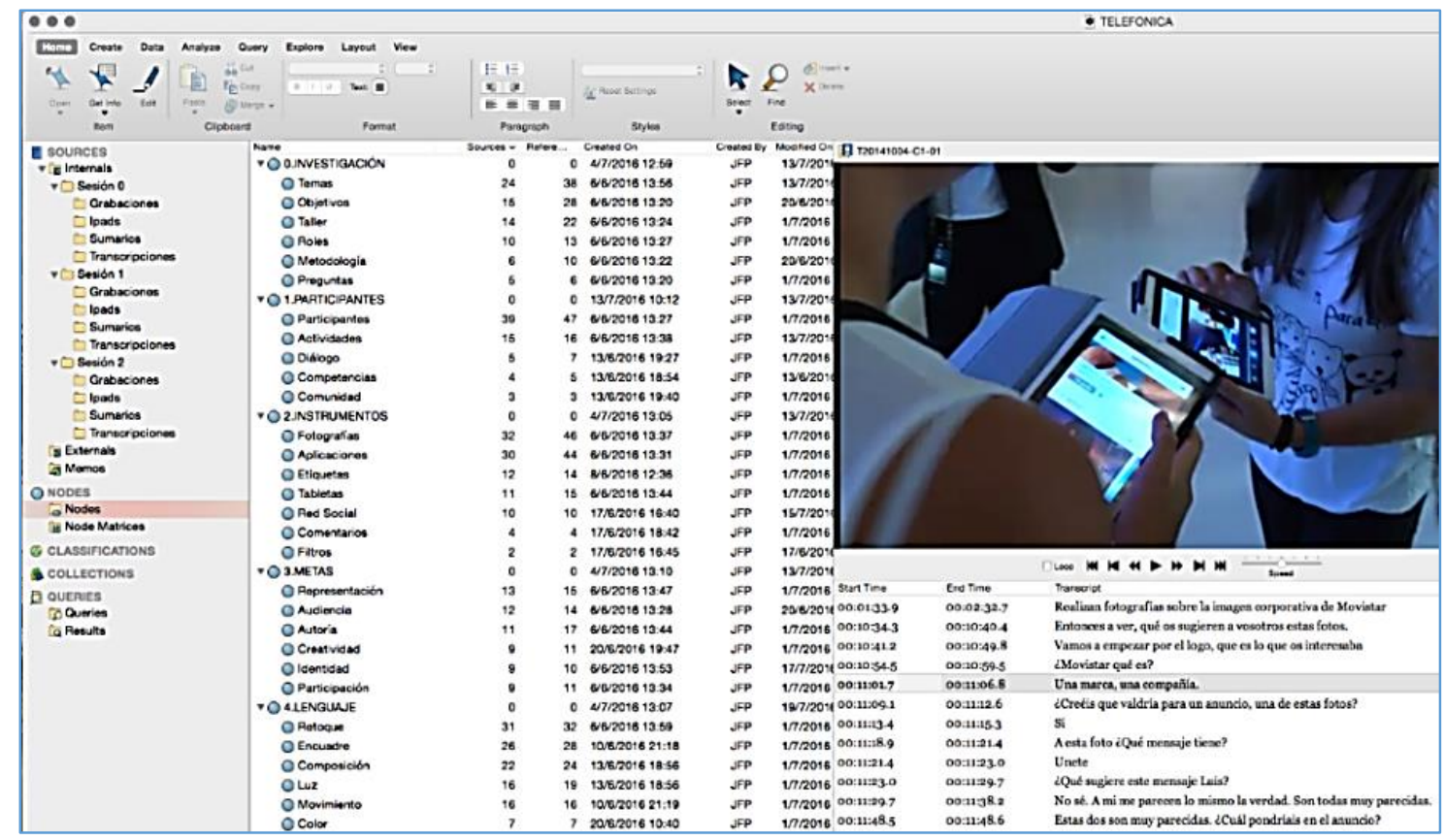

Figura 7: El instrumentos de análisis ha sido Nvivo 10.2

Para este proyecto en particular, hemos decidido utilizar el software NVivo 10.2 que nos permite trabajar al mismo tiempo con texto, fotografías o vídeo. Esto nos ha permitido generar nodos directamente desde las imágenes o el audio, sin necesidad de crear descripciones o memos intermedias. Tan sólo hemos transcrito los diálogos que considerábamos más representativos de cara a su uso en los resultados de investigación. Esta técnica nos ha permitido procesar gran cantidad de interacciones dentro del taller (más de 15 horas) y sobre todo mantener el contexto de cada una de estos eventos analizados. De esta manera, hemos podido triangular los datos extraídos para poder interpretar los resultados de forma narrativa y conceptual (Lacasa, Martinez-Borda, \& Mendez, 2013)

Una vez más, insistimos en que los enfoques sobre los datos, así como los modelos de análisis se entrelazan de forma holística en nuestra interpretación. $\mathrm{Y}$ esto es así porque nuestro objetivo no es tanto obtener unas pautas estructurales de las prácticas analizadas, como explicar las claves que las generan y permiten la reproducción de sus discursos. Los procesos de alfabetización y participación están en la base de esta metodología que requiere partir de lo concreto para identificar modelos generales. 


\section{Resultados}

A continuación, se exponen los resultados de este proyecto de investigación llevado a cabo en Matadero Madrid por el Grupo Imágenes, Palabras e Ideas. Se trata de una experiencia de alfabetización mediática orientada a niños y niñas de entre 8 y 14 años mediante talleres de creación digital. Siguiendo el modelo del sistema de actividad, nos fijaremos en los referentes de los participantes, los instrumentos de creación, las reglas de los lenguajes, la participación en comunidad, los roles derivados del aprendizaje, las metas compartidas y finalmente las creaciones en vídeo realizadas. De esta manera esperamos reconstruir de manera integral las prácticas desarrolladas en el taller de forma colaborativa.

\subsection{Participantes y sus referentes}

La necesidad de contextualizar cualquier práctica obliga a dedicar un momento al comienzo del taller para situar a los niños y niñas en su actividad mediática habitual. Para conocer a los participantes nada mejor que preguntarles por el uso que hacen de Internet y en particular de las redes sociales. Aunque muchos de ellos reconocen que no navegan libremente por la Red debido a su edad, otros sí que son usuarios sobre todo de Instagram. Suele coincidir que los que son más activos en estas redes sociales se reconocen también fans de grupos de música o personajes famosos; mezclando la cultura popular con otras actividades alternativas o emergentes.

Sumario Matadero S., Ref\#1, 08/02/2015

C. que es la experta de esta sesión. Ella nos expone para qué usa ella Instagram. Principalmente para seguir a sus fans, One Direction. Les preguntamos a los niños si son fans de alguien y comienzan a decirnos "youtubers" conocidos como El Rubius.

Sin duda sorprende que sus referentes mediáticos sean celebridades en redes sociales antes que en los medios tradicionales, pese a que el acceso a Internet que tienen los participantes sea más restringido que a la radio o la televisión. La principal evidencia al respecto es que la influencia de Internet como canal es mayor que la de cualquier otro soporte de comunicación. De hecho cuando se les pregunta al 
respecto, no dudan en reconocer a los creadores de contenidos en redes sociales como una profesión remunerada:

Transcripción GG/00 01:23:21-01:24:02 (15/03/2015)

I: ¿Qué es lo que hacen los grandes creadores en las redes sociales?

P: Ganar dinero

$\mathrm{P}^{\prime}:$ Subir vídeos continuamente.

I: Muy buena idea. Trabajan mucho, no suben un vídeo de vez en cuando. ¿Qué más?

I': Suben vídeos sÚper chulos

I: o sea que no puedes subir cualquier vídeo. Tienes que subir muchos vídeos, pero cuidando lo que subes.

En esta transcripción queda patente que para los participantes no todos los usuarios de redes sociales son iguales. Describen un perfil concreto de creadores que denominan "youtuber" a los cuales siguen a través de diferentes redes sociales además de YouTube. Pero incluso alguno de ellos llega a identificarse como uno de estos "youtubers" debido a que también crean contenidos originales para las redes sociales. En concreto se refiere a la modalidad de "gamers" que graban las partidas de un videojuego para después publicarlas:

Sumario Matadero S, Ref\# 3, 18/01/2015

Uno de los niños del taller nos descubre que él es creador de contenidos en YouTube ya que hace vídeos sobre videojuegos. Se graba jugando y los publica. Es evidente que su acercamiento al vídeo no es ajeno, de un modo u otro son creadores de contenidos. La clave por tanto del taller es la de convertirles en buenos creadores de contenidos. La meta para ello será hacer vídeos y publicarlos en redes sociales.

A pesar de ser usuarios activos de las redes sociales, la mayoría de participantes reconocen que todavía les queda mucho por aprender en la creación de contenidos. De hecho, muchos expresan su interés por hacer mejores vídeos para tener más seguidores en las redes sociales. Este interés coincide plenamente con los objetivos del taller y nos permite conectar el aprendizaje con la experiencia de los participantes. 


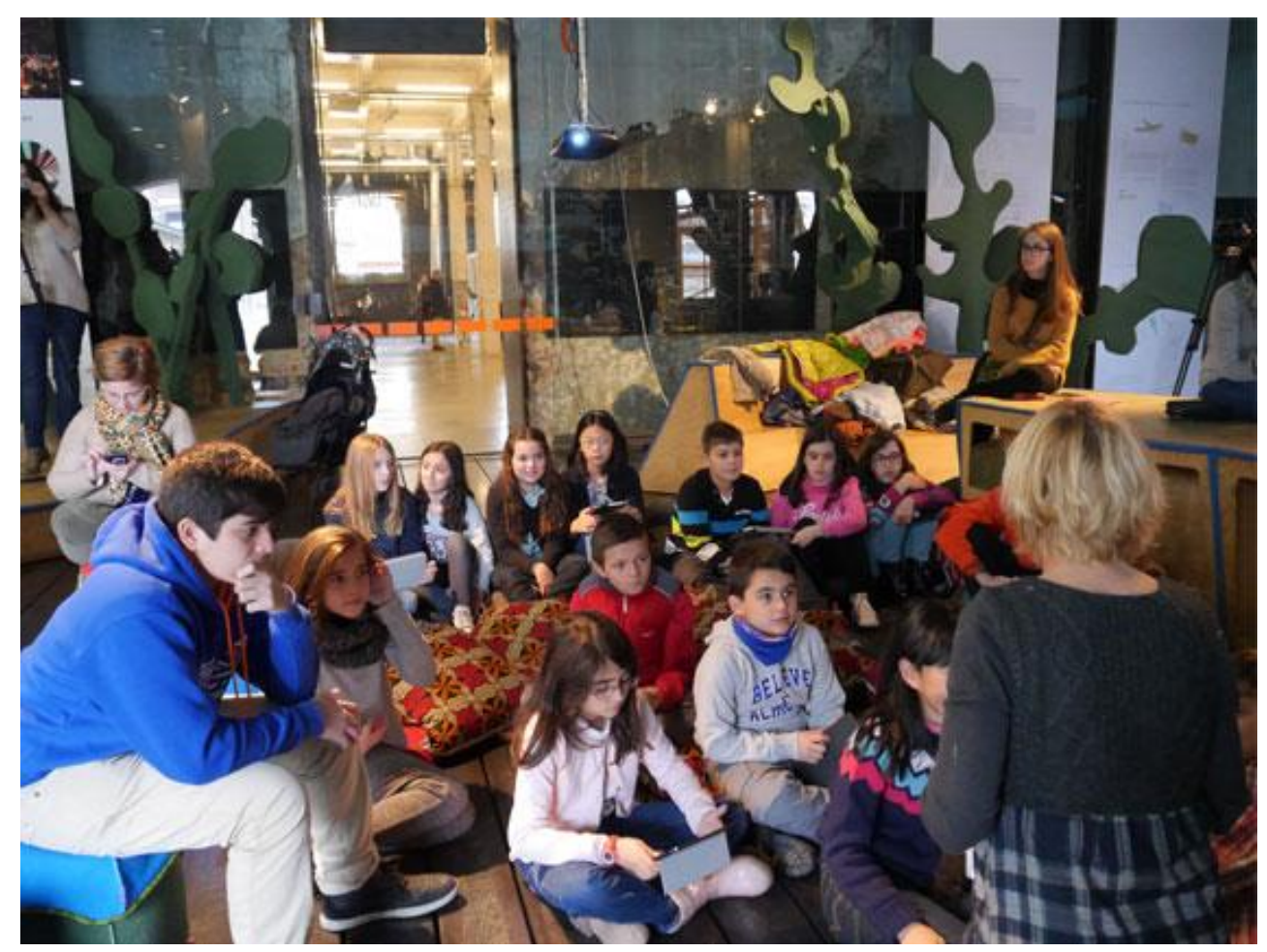

Figura 8: Los participantes y su referentes (Grupo GIPI, 18/01/2015)

\subsection{Instrumentos y aplicaciones}

El siguiente paso dentro de los talleres es entregar las tabletas a los participantes para que exploren su funcionamiento de forma libre. La experiencia previa de los participantes se suele limitar a hacer fotos o vídeos con móviles o equipos domésticos que pertenecen a sus padres. Esto provoca por un lado que la mayoría tenga restringido el pleno dominio de estas herramientas y de los contenidos que crean a través de ellas. Normalmente son los padres los que gestionan sus creaciones dentro del ámbito doméstico, tal y como muestra la siguiente transcripción:

Transcripción GP/02 00:01:16-00:02:47 (15/03/2015)

I: ¿Vosotros habéis hecho vídeos alguna vez o no?

Todos: Si

I: ¿Con qué hacéis los vídeos?

P: Con el móvil de mi madre y el de mi padre

I: ¿Y luego que hacéis con las fotos?

$\mathrm{P}^{\prime}$ : Yo las guardo en el móvil

$\mathrm{P}^{\prime \prime}$ : Las mando al WhatsApp

I: Eso es una red social 
Por lo tanto, muchos participantes desconocen la existencia de redes sociales y su utilidad para crear y compartir contenidos. Por eso, una de las primeras tareas que se lleva a cabo en cada taller es explicar a fondo el manejo de las principales herramientas de vídeo presentes en las tabletas.

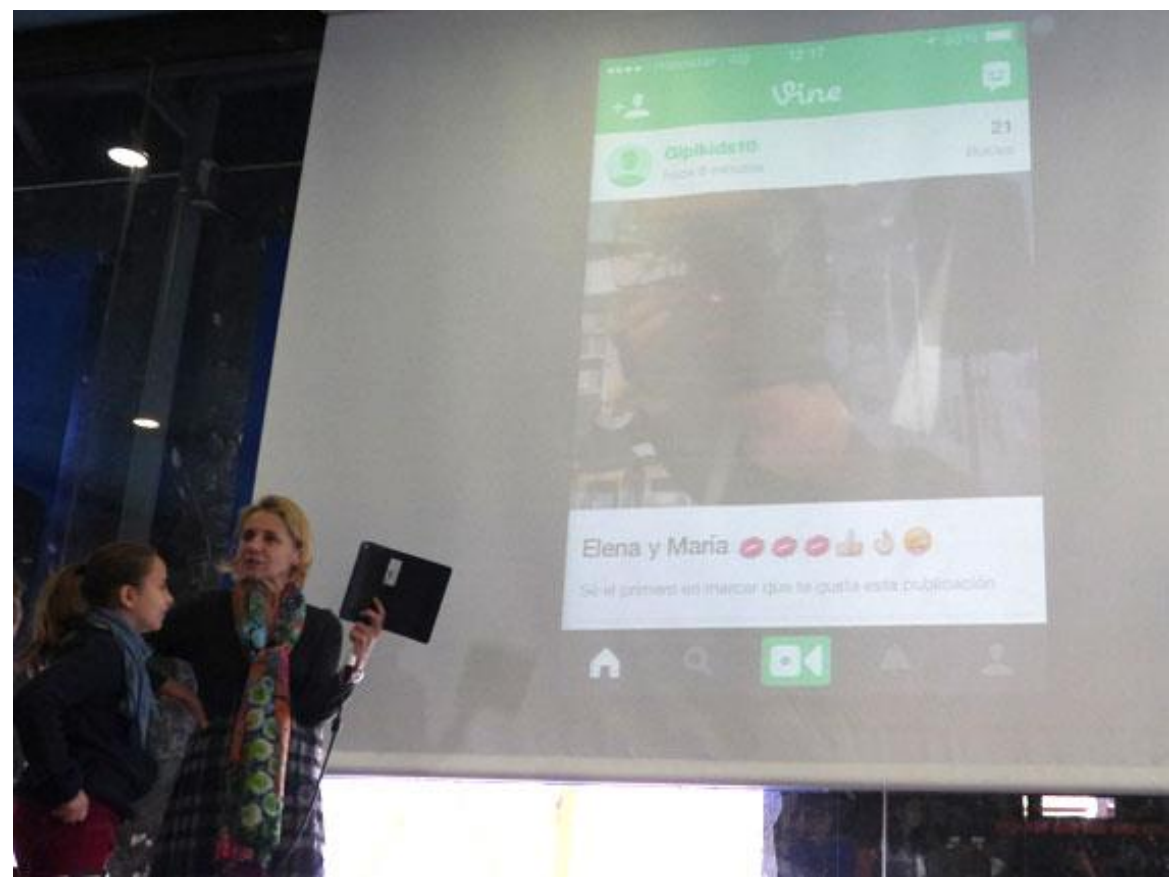

Figura 9: Descubriendo las aplicaciones y redes sociales (Grupo GIPI 08/02/2015)

Esta labor se realiza de forma práctica, reproduciendo en una pantalla tanto la interfaz como los comandos que después deberán utilizar los participantes. Las investigadoras se centran en dos aplicaciones como son Vine e Instagram, de las cuales destacan sobre todo las diferencias de duración y reproducción en las películas:

Sumario Matadero S. Ref\# 2, 18/01/2015

Continúan con el diálogo tratando de hacerles pensar en las diferencias entre las apps, no es lo mismo hacer una foto con el móvil que con la cámara, por ejemplo, por tanto, las posibilidades de cada aplicación también son distintas. Vine, lo más importante que destaca es el bucle, la sensación continuidad. Con Instagram tendremos un principio y un final, y dura más tiempo, quince segundos.

Lo más importante es que estas dos aplicaciones son al mismo tiempo redes sociales y por tanto las posibilidades para crear contenidos están predefinidas a un determinado formato de vídeos. Esto hace que sea 
más fácil su uso por parte de los participantes, pero también por otro lado restringe la libertad creativa en cuanto a la duración o edición del vídeo. Por eso las investigadoras no dudan en proponer utilizar a continuación otra aplicación diferente que ofrece más posibilidades, pero sobre todo no se adscribe a una red social determinada:

Sumario Matadero M.R., Ref\#1, 18/01/2015

les hablamos de iMovie y las preguntas van en torno a si conocen esta aplicación y para qué sirve. La diferencia con Vine e Instagram es que estas aplicaciones sirven para hacer cosas en directo, pero no nos dejan editar. La clave de iMovie es que nos permite mejorar vídeos.

De alguna manera, el paso de los participantes por todas estas aplicaciones supone un proceso de alfabetización que les lleva a fijar los objetivos sobre la red social, para después completar el proceso de aprendizaje sobre la herramienta de edición. La principal evidencia que nos deja este proceso es que resulta necesario diferenciar en cada aplicación su dimensión como herramienta de creación y como red social, si esta la incluye.

\subsection{Reglas y lenguajes}

Fomentar un proceso de alfabetización transmedia implica la utilización de diferentes medios con sus correspondientes reglas. Del mismo modo, el uso de diferentes lenguajes audiovisuales supone una controversia teórica que se les plantea a las investigadoras durante las reuniones de preparación de cada sesión. La primera cuestión al respecto es hasta qué punto la red social condiciona el uso del lenguaje y si lo hace desde el punto de vista de la tecnología o de su impacto social:

Sumario Matadero S., Ref\#2, 18/01/2015

En ocasiones tengo dudas respecto a si la red social se convierte en un simple contenedor de contenidos; si realmente es el medio, o el medio es la imagen y el vídeo, ya que es lo que aprenden a manejar. Aunque sin olvidar que aprenden a manejarlo desde la aplicación y por tanto eso siempre nos lleva a la idea de red social y las 
posibilidades que ofrecen, pero sólo a nivel técnico no desde su parte sociable.

El hecho de haber instrumentado los talleres previos exclusivamente a través de la red social Instagram hace necesario explorar otras herramientas para la creación de contenidos. Tal vez por eso, se apuesta por empezar a disociar las aplicaciones de creación de las redes sociales en las tabletas. El objetivo de esta práctica es que los participantes tomen conciencia de forma separada de los procesos de creación, edición e interacción que realizan.

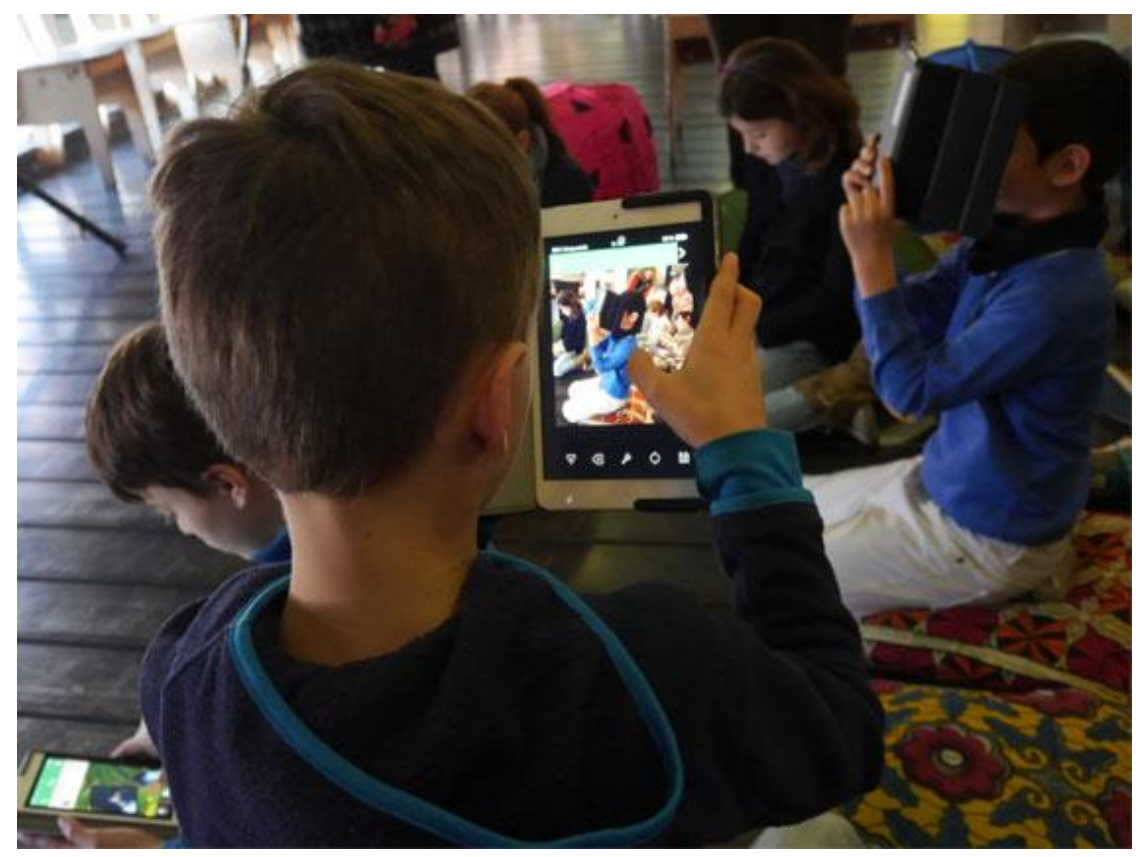

Figura 10: Grabando en vídeo (Grupo GIPI, 18/01/2015)

Por ejemplo, se les propone que creen a partir de un lenguaje que no es específico de las redes sociales que utilizan, como es el sonido. Una de las tareas propuestas durante la segunda sesión era modificar el sonido ambiente de un vídeo mediantes distintos efectos sonoros. Inclusive en la tercera sesión se da la libertad para que los participantes utilicen indistintamente fotografía y vídeo, mientras el resultado sea un contenido audiovisual que pueda ser publicado a través de una red social.

Sumario Matadero M., Ref\#1, 08/02/2015

Se plantea la posibilidad de trabajar vídeos y fotografías en el mismo taller. Este es un tema que no nos habíamos planteado hasta ahora, pero creo que es un acierto y creo 
que es una posibilidad que debemos dejar abierta, es más creo que podríamos jugar con ello y tratar de crear un mensaje en las redes sociales con diferentes lenguajes como foto y vídeo.

De esta manera se trata de fomentar la alfabetización transmedia, mediante la exploración de diferentes lenguajes y sus reglas dentro de cada red social. De hecho, se realiza un gran esfuerzo por transmitir las singularidades de cada lenguaje, en particular en estas sesiones a través del vídeo. Sin embargo, las evidencias demuestran que se puede llegar a la creación audiovisual a través de diferentes recursos y aplicaciones.

\subsection{Comunidad y participación}

Más que generar una comunidad propia en el taller, el fin es que los jóvenes se integren en las comunidades digitales existentes en internet. La participación en la sociedad digital es una de los objetivos más poderosos que podemos plantear dentro del taller. Conseguir que los participantes tengan pleno dominio y capacidad para utilizar las redes sociales según sus propios propósitos. Por eso insistimos mucho a través del diálogo y de la reflexión para que nos cuenten sus inquietudes. La mayoría de investigadoras coincide en que se trata de un primer paso para que la experiencia que van a desarrollar se convierta en una actividad significativa para ellos y no en una mera tarea a completar:

Sumario Matadero S., Ref\#1, 18/01/2015

Nos juntamos en el pequeño grupo, es el primer acercamiento. Nos sentamos todos en círculo y tratamos de dialogar sobre qué cosas les interesan a partir del tema que se ha lanzado en la charla de gran grupo. Surgen temas como; la gente del taller; el arte; los objetivos; la decoración; lo que se hace en el taller

Como vemos, generalmente sus referentes suelen coincidir con elementos próximos e inmediatos a su experiencia dentro del taller. Lo importante en todo caso es que sientan que pueden aportar algo dentro del contexto en el que se sitúan. Durante la sesión de gran grupo se insiste mucho en este sentido, para que no se convierta en una tarea mecánica y razonen los motivos que les llevan a participar en las redes 
sociales. Así lo muestra esta transcripción en la que la investigadora se interesa por sus motivaciones:

Transcripción GG/00 00:08:11-00:08:48 (18/01/2015)

I: Cuando yo subo un vídeo a Internet es para contar algo. ¿Para qué subís vídeos vosotros?

E: Para contar algo, para expresar.

P: Para enseñar a la gente lo que hago

Ahora bien, el objetivo de participación debe ser consciente pero también libre. Cada participante decide si quiere utilizar la red social en un entorno familiar, escolar o abierto a cualquier usuario. De hecho, no se nos ocurre mejor evidencia sobre la adquisición de esta meta que la decisión que toma uno de los participantes de mantener su cuenta privada en las redes sociales. Independientemente de las limitaciones por edad que implica el uso de estas redes, tomar conciencia sobre si quiere utilizar o no de forma pública demuestra que los participantes están plenamente habilitados para interactuar en entornos virtuales:

Sumario Matadero GM, Ref\#1, 15/03/2015

Al final un niño comentó que él prefería tener una cuenta privada. Dialogamos sobre la posibilidad de tener más de una cuenta. Aquí se ve que quizás talleres separando la edad sería mejor. Los pequeños creo que cuestiones como estas no las puede entender y son clave

La evidencia que podemos sacar es que la plena participación en las redes sociales depende no sólo de la capacidad de crear contenidos o comunicarse a través de ellas, sino sobre todo en el uso consciente de lo que supone interactuar con otras personas. En el momento que los participantes equiparan la actividad que desarrollan en las redes con las relaciones que mantienen en su entorno físico, es entonces cuando se produce esta participación plena. 


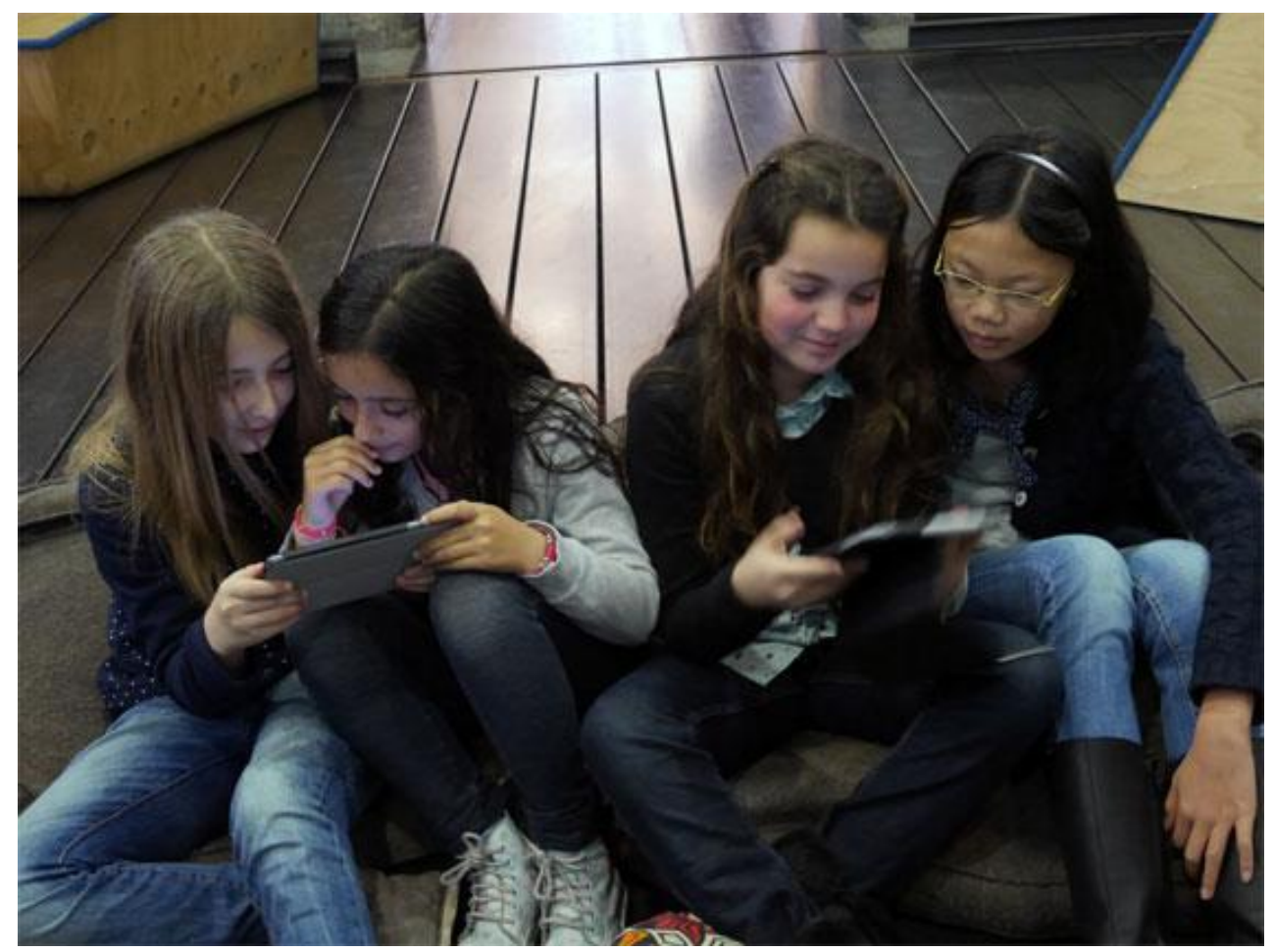

Figura 11: El objetivo final es la participación en la sociedad digital (Grupo GIPI, 18/01/2015)

\subsection{Roles y expertos}

Los únicos roles contemplados en el inicio de los talleres eran los de los investigadores y los participantes. Sin embargo, una de las grandes innovaciones que se introduce en estas sesiones es la figura del experto. Se trata del rol que desempeñan los participantes que ya tienen experiencia previa en el taller y que ayudan tanto a los investigadores como al resto de participantes en su desarrollo. La propuesta se sugiere en una reunión del grupo de investigación y se relaciona con la creación de una comunidad de prácticas tanto dentro como fuera de la red social:

Acta Reunión Grupo GIPI, 1/12/2014

La idea del experto me parece muy interesante. Lo abordaría a dos niveles entre iguales y con un experto como modelo y en dos escenarios, presencial en el taller y virtual, a través de comunidades de fotógrafos en Instagram.

Los expertos se conforman como la mejor evidencia del éxito de esta experiencia de alfabetización mediática. Aun así, hemos de destacar que su rol no es adquirido en la práctica, sino designado en la organización del taller. La evidencia sobre este aspecto es que resulta imprescindible 
establecer una división de labores y tareas entre los asistentes al taller. Sólo cuando cada participante asume la función propia de su experiencia, se produce una actividad de aprendizaje fluido.

Sumario Matadero M., Ref\# 2, 18/01/2015

La imagen de uno de los expertos fue importante para dirigir el taller. Pues al saber más o menos lo que se buscaba por el hecho de haber ido a otros talleres, cuando P. preguntaba a los niños, él tenía respuestas muy buenas que ayudaban a que el resto abriesen bien los ojos

La división del trabajo en novato, experto e investigador encaja de manera perfecta en el taller. Mientras el investigador fomenta la creación de unas metas comunes, el experto ayuda con cuestiones más técnicas y el novato genera ideas para cumplir los objetivos propuestos. El resultado final de estas interacciones es un sistema de actividad en el que se entremezclan varios roles, así como situaciones de pequeño y gran grupo en la que los participantes interactúan de diversas maneras. De esta manera se favorece el aprendizaje colaborativo y sobre todo mejora la distribución de actividades dentro del taller.

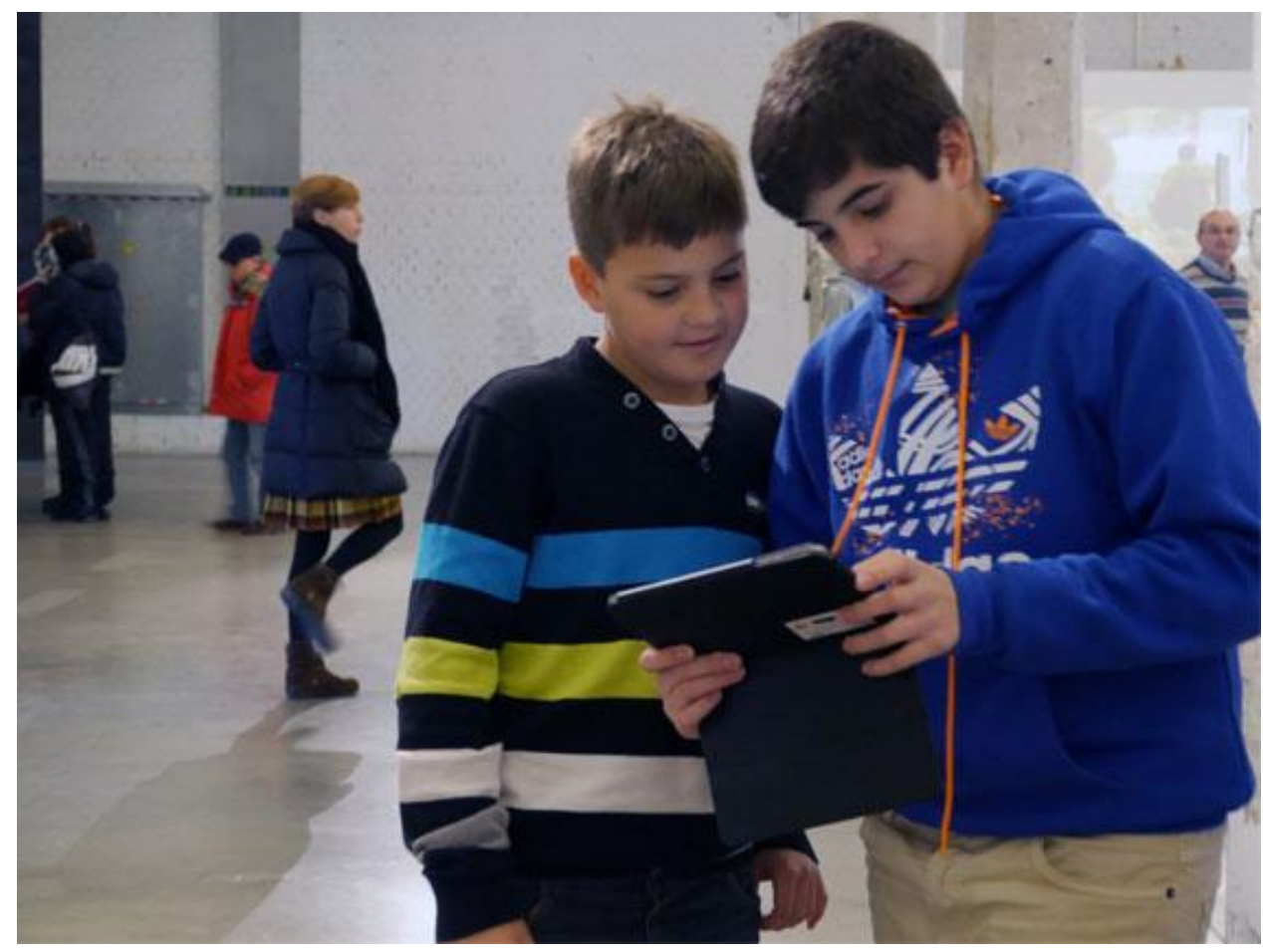

Figura 12: El experto ayuda a otro participante (Grupo GIPI, 18/01/2015) 


\subsection{Metas y narrativa}

Según el sistema de actividad, la consecución de metas es lo que permite dar sentido y generar significados a los objetos que los participantes crean en el taller. Una de las metas asumida de forma conjunta en estas sesiones es la narrativa o la capacidad para contar historias. Tal vez sea el propósito más complejo ya que no sólo implica dominar las herramientas y saber utilizar el lenguaje audiovisual, sino también construir un relato con los elementos disponibles. De la misma manera que con la creación artística, el primer paso que se propone por parte de las investigadoras es explorar el entorno inmediato y trata de establecer una narración a partir del mismo:

Sumario Matadero S., Ref\#2, 18/01/2015

Vamos a tratar de partir de la idea de contar a otras personas lo que más les ha gustado de Matadero desde que han llegado allí. El objetivo con este tema es que se centren en observar los espacios y piensen en qué contar a partir de ello o pensar en el taller y sus elementos.

Esta labor permite ir dominando alguno de los elementos clave como espacio, tiempo y personajes. La siguiente tarea sería establecer una puesta en escena y una acción o hechos que narrar. Ahí es dónde nos encontramos el primer obstáculo, ya que el primer impulso es optar por historias preestablecidas. Tal es el caso de iMovie, que a través de plantillas sugieren modelos de relato que cada usuario simplemente debe grabar en imagen real hasta completar un tráiler cinematográfico. La reacción por parte de las investigadoras es contundente y pretende evitar este modelo de práctica:

Transcripción GP/04 01:27:45-01:27:47 (15/03/2015)

I: ¿Qué estáis editando?

P: Vamos a hacer un tráiler

I: Es que mirad, no queremos que hagáis tráiler, porque

el tráiler te condiciona todo. 


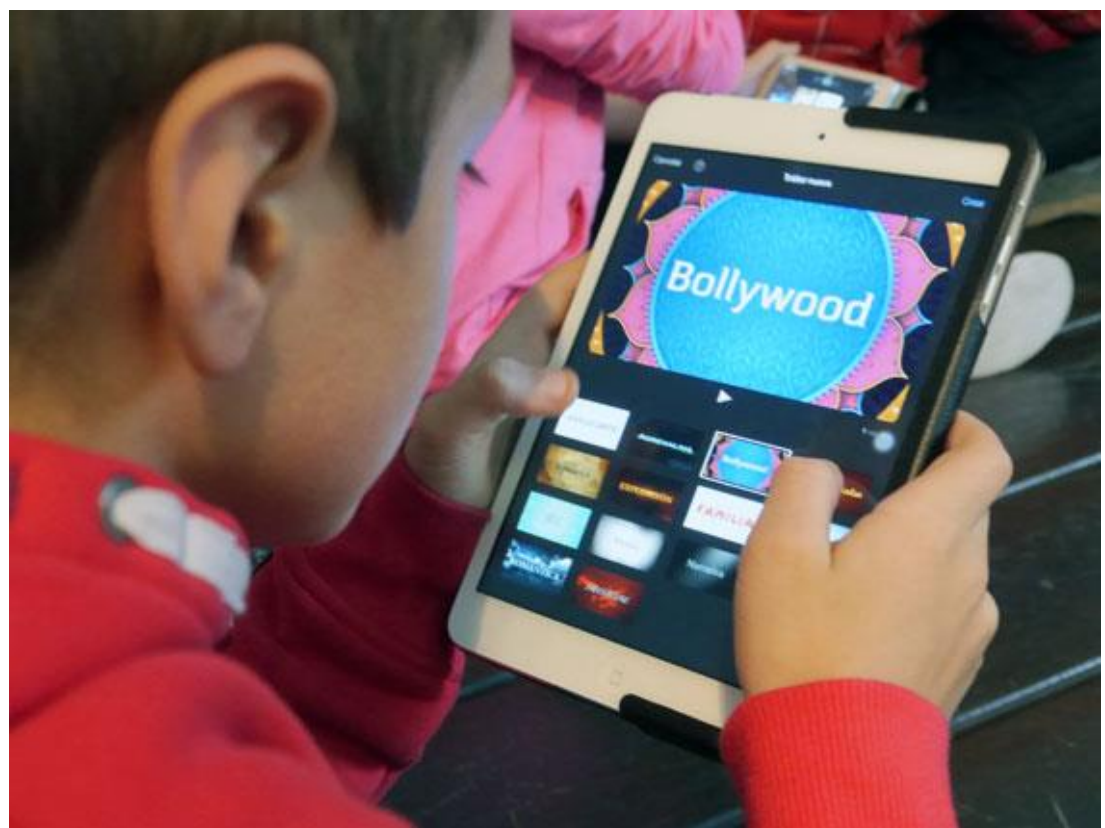

Figura 13: Evitando el uso de plantillas de narración (08/02/2015)

La creación de una historia desde cero es una labor compleja; por eso se opta por volver a trabajar en pequeños grupos, fomentando la interacción entre los participantes, expertos e investigadores. El trabajo en parejas obliga a los participantes a exponer y negociar sus ideas. De este diálogo surge la capacidad para narrar en imágenes, grabando en continuidad las acciones y ayudándose de la edición para introducir títulos o efectos. El resultado final son pequeñas escenas de ficción que logran contar un breve relato con sentido:

Sumario Matadero GM, Ref\#3, 15/03/2015

Las otras parejas están un poco confusas, al final las otras tres parejas hacen vídeos con situaciones de ficción; una simulando una electrocución; otros simulan una situación graciosa, a estos últimos les ayuda J. con la grabación, ya que quieren hacer algo un poco difícil técnicamente.

Es muy complicado aprender a narrar en su solo taller, pero sí que se puede comenzar a crear contenidos en torno a una historia de ficción. La habilidad de generar una puesta en escena a través de un espacio, tiempo y personajes concretos evidencia que los participantes son capaces de narrar más allá de los límites de la representación del entorno inmediato. Casi como un juego, están abriendo las puertas a la creación de historias más allá de su realidad cotidiana. 


\subsection{Creaciones y transmedia}

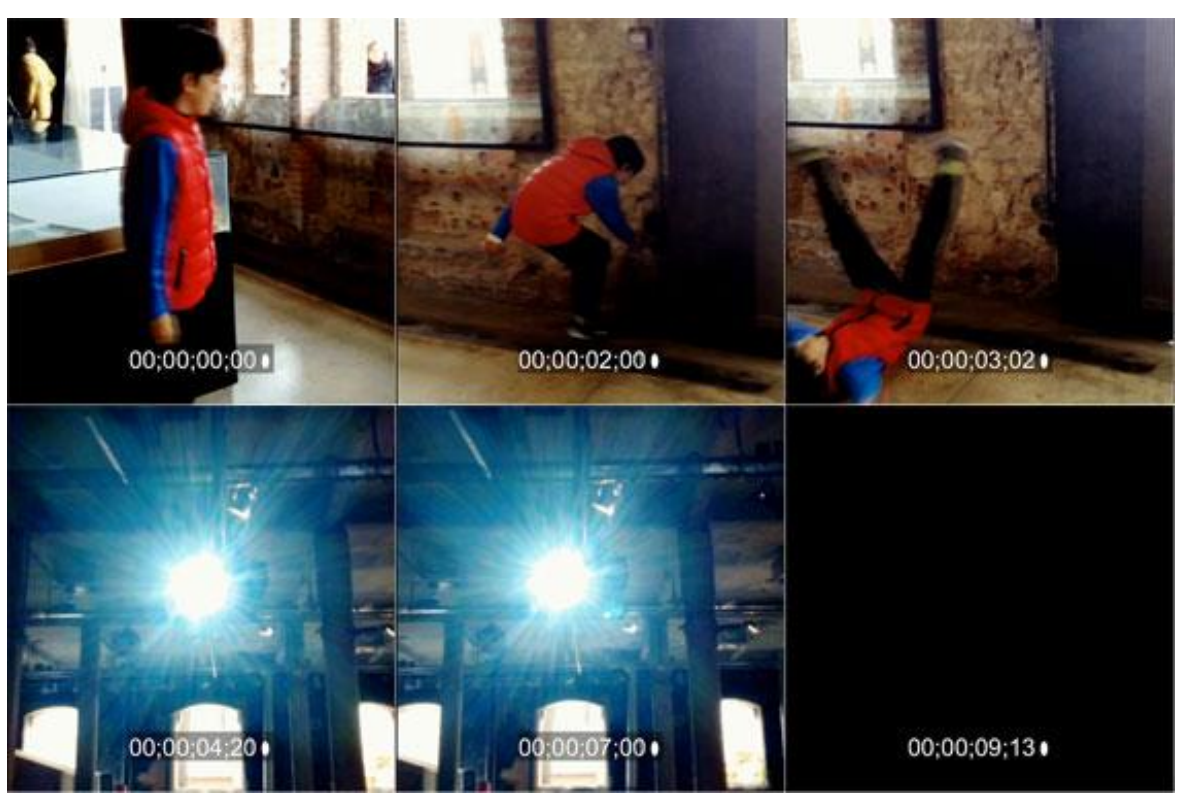

Figura 14: Escena de ficción (M2015031_iPad12_0575)

El resultado del taller son las creaciones que realizan los participantes, mediantes los instrumentos y con el soporte de la comunidad prácticas. Gracias al análisis conjunto de todos estos elementos podemos interpretar estos videos más allá de su aspecto formal o contenido denotativo. De hecho, nuestra intención es entenderlos como universos transmedia, construidos a partir de la creación de mundos de ficción. El aprendizaje conjunto sobre los lenguajes evidencia que los participantes son capaces de construir una narrativa sin que el contexto o los objetos del entorno condicionen los significados que pueden llegar a formular. De hecho, encontramos varios ejemplos de historias de ficción construidas durante el taller, partiendo únicamente de la imaginación de los participantes.

Existen numerosas formas de crear un universo transmedia. Los participantes a menudo parten de su intuición, pero sobre todo de referentes que ya conocen. La puesta en escena de una situación de ficción es una de las fórmulas más utilizadas en el taller. Por ejemplo, en la figura $n^{\circ} 14$ se reproduce un vídeo realizado por dos niños de once años en el que simulan como uno de ellos mete los dedos en un enchufe y recibe una descarga eléctrica. El tono utilizado en el audiovisual es la comedia, ya que las acciones están exageradas y se utiliza una música divertida. Incluso se presenta a la electricidad como un personaje más en el plano final, en el que se encuadra una luz intensa 
con un audio de risas infantiles. Además de saber realizar la escena, los participantes han sabido modificar el mensaje a través de la edición, utilizando elementos propios de la creación de mundos.

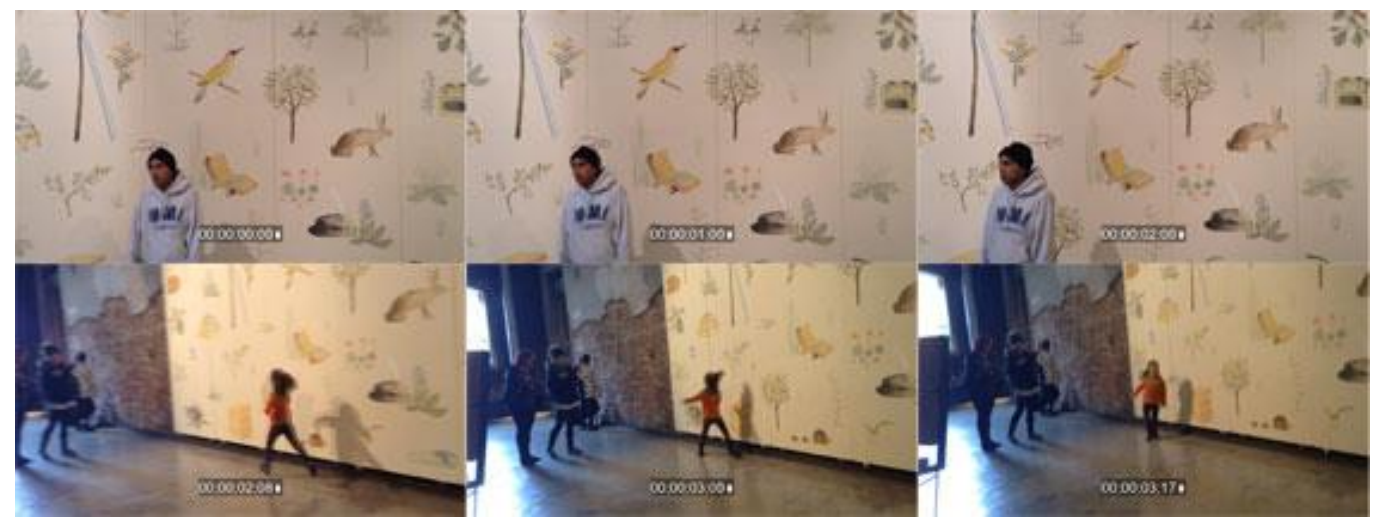

Figura 15: Ficción sonora (M20150315_iPad10_0608)

En la figura $\mathrm{N}^{\mathrm{o}} 15$ vemos otro ejemplo en el que gracias al sonido se construye una historia diferente a las imágenes registradas. En este caso, son dos planos grabados en distintos momentos del taller, en el que se muestra a un joven mirando hacia un lado y a continuación una niña corriendo en la misma dirección. Sobre la imagen del joven se superpone un sonido grave y sobre la niña un grito agudo. Ninguno de los dos participantes estaba actuando cuando se les grabó, sino que las dos niñas de trece y catorce años que realiza el vídeo aprovecharon estas imágenes al azar para montar esta ficción sonora. Lo que sorprende es el uso del montaje al más puro estilo constructivista parar generar un universo narrativo transmedia.

La última muestra de una creación de mundos la encontramos en el vídeo que reproduce la figura $\mathrm{N}^{\mathrm{a}} 16$. Un solo niño de once años graba, sonoriza e interpreta este plano secuencia sin edición o corte alguno. En una estancia oscura comienza a agitar la cámara en los planos iniciales, mientras refiere la presencia de un monstruo. La imagen se va a negro mientras se escuchan sonidos guturales y ocasionalmente aparece el rostro del propio niño que interpreta al monstruo acercándose a la cámara. De repente se interrumpe el sonido y vuelve a escucharse la VOz normal del niño preguntándose qué le pasa a la cámara. Se trata de una clara narración de género, tanto en el contenido representado (la presencia del monstruo) como en la estética (oscuridad, cámara errante). La toma nada tiene que envidiar a cualquier película comercial de terror. Una evidencia sin duda de la capacidad para utilizar un universo transmedia en el que este 
participante demuestra dominar tanto el lenguaje como la narración audiovisual.

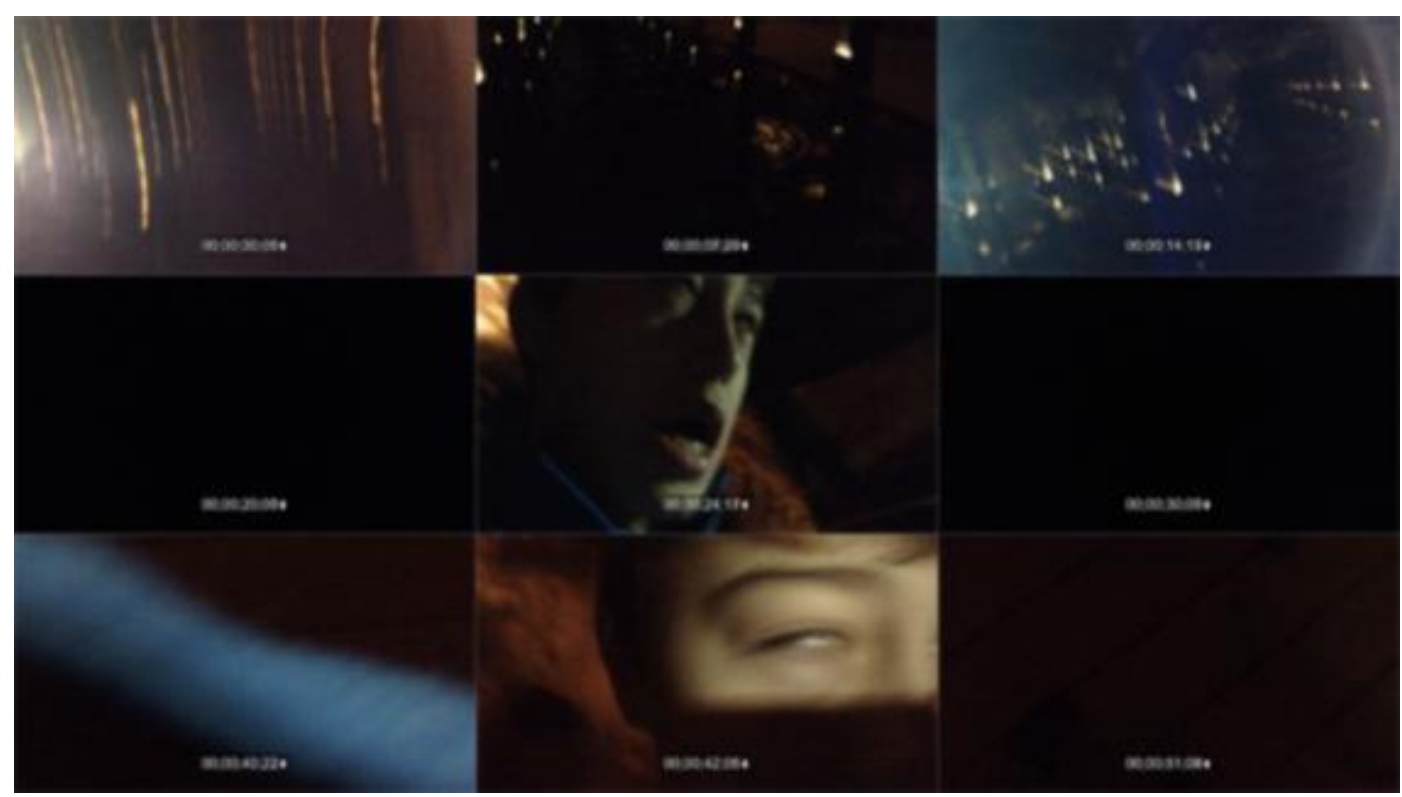

Figura 16: Ficción de género (M20150208_iPad11_0493)

\section{Conclusiones}

Los resultados de la investigación son confrontados a continuación sobre los objetivos especificados al inicio. Una vez reconstruidas las prácticas de los jóvenes en el taller, a través del modelo de sistema de actividad, estamos en disposición de explicar cómo se producen los procesos de alfabetización mediática en contextos colaborativos no formales de creación digital.

Desde el punto de vista de las estrategias de aprendizaje hemos identificado tres principios que se basan en la interacción, la cooperación y la participación:

- La generación de escenarios de aprendizaje colaborativo basado en la interacción entre los jóvenes se configura como uno de los elementos fundamentales de la alfabetización mediática. Compartir herramientas como las tabletas o trabajar en pequeños grupos han demostrado ser útiles para fomentar la creatividad.

- También el andamiaje entre expertos y novatos ha resultado ser especialmente fructífero, sobre todo a la hora de conectar las cuestiones más técnicas con el contexto sociocultural de esta alfabetización mediática. Sin olvidar su función mediadora para el propio equipo de investigación. 
- La consecución de unas metas comunes es crucial para activar el aprendizaje significativo. Sin estas metas es imposible generar el sentido de la participación mediática y el valor de la cultura compartida. Estas metas son las que generan el significado de las prácticas en los medios.

En lo que atañe a las funciones que desempeñan los jóvenes a través de las redes sociales hemos definido tres características que se corresponden con la creación, difusión y privacidad:

- La mayoría de los participantes utiliza las redes sociales como medio para la creación y publicación de contenidos. La dimensión de comunidad virtual queda en un segundo plano de conciencia.

- Los referentes de las redes sociales animan a los jóvenes a difundir sus contenidos para obtener redifusión y menciones. A menudo se producen una cooperación en la distribución de estos contenidos, sin una clara conciencia de comunidad.

- En muchos casos, los usos que realizan los niños y niñas de las redes sociales son de carácter privado y centradas en el entorno próximo. Por eso, su idea de audiencia se limita a su familia o a sus amigos más cercanos.

Los contenidos que crean los jóvenes se articulan a través de universos transmedia que podemos describir a partir del medio, el espacio y la narrativa utilizada:

- El significado final de objeto creado no es la representación tácita que contiene. La construcción del significado se realiza de forma paralela a través del medio en el que se distribuye. Los jóvenes no construyen imágenes o vídeos independientes del contexto transmedia en el que son compartidas.

- El espacio es otro de los contenidos que los jóvenes reconstruyen de forma ficticia, generando representaciones más allá de la experiencia sensible. La puesta en escena lejos de condicionar esta representación, supone un ámbito de exploración y creación de mundos de ficción para los jóvenes.

- La creación de narrativas de género es otra constante, que no se basa en el uso del lenguaje audiovisual, sino en la creación de 
mundos narrativos. La interpretación de estas narrativas depende de las prácticas que las acompañan y no de la representación registrada.

En conclusión, a través de este estudio se pone de manifiesto varios factores a tener en cuenta en la alfabetización mediática de los jóvenes; como la importancia de conectar los entornos físicos y virtuales en contextos cooperativos; la necesidad de tomar conciencia sobre las comunidades que generan la interacción en redes sociales; así como la funcionalidad que supone la narrativa transmedia en la creación de mundos de ficción. La investigación a futuro debe pasar por profundizar en el estudio de estos contextos, prácticas y discursos. Solo así podemos entender verdaderamente que están haciendo los más jóvenes con las nuevas herramientas de comunicación en el siglo XXI.

* Este artículo es producto del proyecto de investigación "Alfabetización Transmedia: Nuevas formas de contar historias", referencia CCG2015/HUM-025 financiado por el Vicerrectorado de Investigación y Transferencia de la Universidad de Alcalá a través de la Convocatoria de ayudas para la realización de proyectos para potenciar la creación y consolidación de grupos de investigación.

Fechas:

- inicio de la investigación: enero 2015

- término de la investigación: enero 2018

\section{Bibliografía}

Berger, A. A. (2016). Media and communication research methods : an introduction to qualitative and quantitative approaches. Los Angeles:

SAGE.

Bernardo, N. (2011). The producer's guide to transmedia: How to develop, fund, produce and distribute compelling stories across multiple platforms. London: beActive.

Boellstorff, T. (2012). Ethnography and virtual worlds : a handbook of method. Princeton: Princeton University Press.

Boyd, D. (2014). It's complicated: the social lives of networked teens. New Haven: Yale University Press.

Brites, M. J. (2016). "Family Digital Cultures and Understandings of the World: A Critical View of Participatory Action Research". Paper presented at the ECREA 2016, Praga. 
Buckingham, D. (2004). Educación en medios :alfabetización, aprendizaje y cultura contemporánea. Barcelona: Paidós.

Burn, A. (2009). Making new media: Creative production and digital literacies (Vol. 32)London: Peter Lang.

Butsch, R., \& Livingstone, S. M. (2013). Meanings of audiences: comparative discourses. New York: Routledge.

Carpentier, N. (2011). Media and participation : a site of ideological-democratic struggle. Bristol: Intellect.

Cortesi, S., Gasser, U., Adzaho, G., Baikie, B., Baljeu, J., Battles, M., . . . Burton, P. (2015). Digitally Connected: Global Perspectives on Youth and Digital Media. London: Berkman.

Daniels, H., Edwards, A., Engeström, Y., Gallagher, T., \& Ludvigsen, S. R. (2013). Activity theory in practice: Promoting learning across boundaries and agencies. New York: Routledge.

De la Fuente Prieto, J. (2014). "Alfabetización mediática: Del prosumidor al profesional". Historia y Comunicación Social, 19, 13.

De Meulenaere, J., \& De Grove, F. (2016). "A Practices Approach to Mediated Social Relation Maintenance Behavior". Paper presented at the ECREA 2016, Praga.

Delgado, M. (2015). Urban Youth and Photovoice: Visual Ethnography in Action. Oxford: Oxford University Press.

Duffett, M. (2013). Understanding fandom : an introduction to the study of media fan culture. New York: Bloomsbury.

Engeström, Y. (2001). "Expansive learning at work: Toward an activity theoretical reconceptualization". Journal of education and work, 14(1), 133-156.

Engeström, Y., Miettinen, R., \& Punamäki, R.-L. (1999). Perspectives on activity theory: Cambridge: Cambridge University Press.

Engeström, Y., \& Sannino, A. (2010). "Studies of expansive learning: Foundations, findings and future challenges". Educational research review, 5(1), 1-24.

Ferrés, J. (2012). "La competencia mediática: propuesta articulada de dimensiones e indicadores/Media Competence. Articulated Proposal of Dimensions and Indicators" in Comunicar, 19(38), 7582.

Gair, S., \& Van Luyn, A. (2017). Sharing qualitative research : showing lived experience and community narratives. New York: Routledge.

Gee, J. P. (2012). Situated language and learning: A critique of traditional schooling: routledge. 
Gray, J., Sandvoss, C., \& Harrington, C. L. (2007). Fandom : identities and communities in a mediated world. New York: New York University Press.

Gutiérrez, K. D., Engeström, Y., \& Sannino, A. (2016). "Expanding Educational Research and Interventionist Methodologies". Cognition and Instruction, 34(3), 275-284.

Ito- M. (2010). Hanging out, messing around, and geeking out : kids living and learning with new media. Cambridge: MIT Press.

Ito, M., Gutiérrez, K., Livingstone, S., Penuel, B., Rhodes, J., Salen, K., . . . Watkins, S. C. (2013). Connected learning: An agenda for research and design. Irvine: Digital Media and Learning Research Hub.

Jenkins, H. (2003). "Transmedia Storytelling: Moving characters from books to films to video games can make them stronger" in MIT Technology Review.

[https://www.technologyreview.com/s/401760/transmediastorytelling/] (Retrived 1/06/2018)

Jenkins, H. (2008). Convergence culture la cultura de la convergencia de los medios de comunicación (Vol. 175). Barcelona: Paidós.

Jenkins, H. (2009). Confronting the challenges of participatory culture: Media education for the 21st century. Cambridge: The MIT Press.

Jenkins, H., Ford, S., \& Green, J. (2013). Spreadable media: Creating value and meaning in a networked culture. New York: NYU Press.

Jenkins, H., Ito, M., \& Boyd, D. (2015). Participatory culture in a networked era : a conversation on youth, learning, commerce, and politics. Cambridge: Polity Press.

Kalogeras, S. (2014). Transmedia storytelling and the new era of media convergence in higher education. Houndmills, Basingstoke, Hampshire: Palgrave Macmillan.

Lacasa Díaz, P. (2018). Expresiones del futuro: cómo se comunicarán las nuevas generaciones. Madrid: Morata.

Lacasa, P., Martinez-Borda, R., \& Mendez, L. (2013). "Media as Practice: Narrative and Conceptual Approach for Qualitative Data Analysis" in Studies in Media and Communication, 1(2), 132-149.

Lévy, P. (1997). Collective intelligence. New York: Harper Collins.

Livingstone, S. M., \& Sefton-Green, J. (2016). The class : living and learning in the digital age. New York: NYU Press.

Lowgren, J., \& Reimer, B. (2013). Collaborative media : production, consumption, and design interventions. Cambridge, Mass.: MIT Press. 
Margolis, E., \& Pauwels, L. (2011). The SAGE handbook of visual research methods. Los Angeles: SAGE.

Maxwell, J. A. (2013). Qualitative research design : an interactive approach (3rd ed.). Thousand Oaks, Calif.: SAGE Publications.

McNiff, J. (2013). Action research: Principles and practice. New York: Routledge.

Pink, S. (2012). Situating everyday life : practices and places. London: SAGE.

Pratten, R. (2011). Getting Started with Transmedia Storytelling. London: CreateSpace.

Rodríguez, M. A. P., i Prats, J. F., Sánchez, J., Aranda, J. J. S., Santibáñez, J., Sierra, J., . . Trabadella, J. (2011). Competencia mediática. Investigación sobre el grado de competencia de la ciudadanía en España. Madrid: Ministerio de Educación.

Rose, G. (2016). Visual methodologies : an introduction to researching with visual materials (4th edition. ed.). London: SAGE Publications Ltd.

Ryan, M.-L., \& Thon, J.-N. (2014). Storyworlds across Media. Lincoln: University of Nebraska Press.

Scolari, C. A. (2018). Teens, media and collaborative cultures: exploiting teens' transmedia skills in the classroom. Barcelona: Universitat Pompeu Fabra.

Scolari, C. A., Bertetti, P., \& Freeman, M. (2014). Transmedia archaeology : storytelling in the borderlines of science fiction, comics and pulp magazines. Houndsmill, Basingstoke, Hampshire ; New York: Palgrave Macmillan.

Stanczak, G. C. (2007). Visual research methods : image, society and representation. London: SAGE.

Stein, L. E. (2015). Millennial fandom: television audiences in the transmedia age. Iowa City: University of Iowa Press.

Sullivan, J. L. (2013). Media audiences : effects, users, institutions, and power. Thousand Oaks, Calif. ; London: SAGE.

Vittadini, N., Carlo, S., Gilje, Ø., Laursen, D., Murru, M. F., \& Schrøder, K. C. (2014). "Multi-method and innovative approaches to researching the learning and social practices of young digital users". International Journal of Learning, 4(2), 33-45.

Wilson, C., Grizzle, A., Tuazon, R., Akyempong, K., \& Cheung, C. (2013). Alfabetización Mediática e Informacional Curriculum para profesores. Paris: UNESCO.

Zeller, F. e., Ponte, C. e., \& O'Neill, B. e. (2014). Revitalising audience research : innovations in European audience research. New York: Roudledge. 


\title{
6 \\ Vampiros en la Red. El robo de la cultura juvenil
}

\author{
Roberto Aparici - Universidad Nacional de Educación a Distancia \\ (UNED raparici@edu.uned.es \\ David García-Marín - Universidad Nacional de Educación a \\ Distancia (UNED dgarciamarin@invi.uned.es \\ Natalia Díaz-Delgado Universidad Nacional de Educación a \\ Distancia (UNED) ndiaz88@alumno.uned.es
}

Cómo citar: R Aparici，D García-Marín， N Díaz-Delgado (2019): "Vampiros en la Red. El robo de la cultura juvenil". En V Tur-Viñes/M J González-Río/R S Contreras-Espinosa (Eds.) Jóvenes / Medios y cultura colaborativa. Cuadernos Artesanos de Comunicación, cac157, pp 161-189. La Laguna (Tenerife): Latina. DOI: 10.4185/cac157

\begin{abstract}
s
En los últimos años, numerosos han sido los estudios sobre las competencias y las estrategias que los jóvenes desarrollan en los entornos digitales y en su relación con las franquicias culturales en el seno de sus universos transmedia. Este artículo, de tipo eminentemente teórico, tiene como objetivo ofrecer un análisis crítico sobre la mercantilización de la creatividad que los jóvenes despliegan en la Red. Los entornos digitales ofrecen escasas posibilidades de democratización del discurso público. La producción mediática de los jóvenes online suele estar basada en actos de falsa participación, ya que sus posibilidades de influencia son muy limitadas. A la vez, sus acciones en estos entornos digitales sirven para el sustento del capitalismo cognitivo a través de procesos de alienación y trabajo gratis que tienen
\end{abstract}


como resultado la aparición de un feudalismo informacional que transfiere los bienes generados por la cultura juvenil desde el intelecto colectivo a las manos privadas.

[EN] In recent years, several studies have analysed the skills and strategies that young people develop in digital environments and their relationship with cultural franchises within their transmedia universes. This article, clearly theoretical, aims to offer a critical analysis of the commodification of the creative work that young people produce on the web. Digital environments offer few possibilities for democratising public discourse. The online media production of teenagers is usually based on acts of false participation, since their possibilities of influence are very limited. At the same time, their actions in these digital environments are used to sustain a model of cognitive capitalism through processes of alienation and free labour that result in the advent of an information feudalism that transfers the goods of youth culture from the collective intellect into private hands.

\section{Keywords}

cultura juvenil; empoderamiento; mercantilización; fans; cultura de la participación; transalfabetismos

\section{Contents}

1. Introducción. 2. La cultura de la participación: un concepto en disputa. 3. Entornos digitales y aprendizaje. 4. La vampirización de la creatividad online. 5. El fan 2.0 6. Conclusiones. 7. Referencias.

\section{Introducción}

— L ADVENIMIENTO en 2004 de la llamada Web 2.0 trajo consigo dos elementos esenciales completamente desconocidos en el modelo sociotécnico presente en décadas precedentes. De un lado, se inició una explosión de las posibilidades conectivas entre los diferentes espacios que cualquier internauta podía encontrar online al derribar la estructura basada en los “jardines vallados" que gobernó la Web 1.0. Por otro lado, la aparición de un sinfín de herramientas tecnológicas y medios digitales e interactivos le ofreció al usuario unas posibilidades potenciales de creación y difusión mediáticas impensables en épocas anteriores. Estas herramientas le otorgaron al 
ciudadano desconocidos atributos para la explotación de la creatividad y la colaboración a fin de lograr una mayor participación en el debate público y la esfera mediática. A partir de 2004, se marca el inicio de una corriente de pensamiento quizá excesivamente celebradora sobre el empoderamiento mediático ciudadano que define una reconfiguración del papel de los usuarios de los medios desde un modelo unidireccional y funcionalista a otro donde la información fluye en múltiples direcciones, un modelo que sufre una mutación desde el broadcasting de los mass media del siglo XX a un sistema más multidireccional, más horizontal y más democrático donde los mensajes circulan también desde las audiencias hasta los medios.

Un número sustancial de voces tanto dentro como fuera de la academia han celebrado de forma extremadamente optimista la llegada del nuevo paradigma comunicativo 2.0 como un contexto en el que se multiplica la capacidad del ciudadano para influir de forma significativa en el discurso público a partir del uso de las nuevas herramientas digitales e interactivas. En 2006, Jay Rosen titula un artículo en la página web pressthink.org utilizando una expresión que en poco tiempo se convertiría en una suerte de mantra defensor del empoderamiento mediático ciudadano, "la gente anteriormente conocida como la audiencia". Bajo esta denominación, Rosen se refiere al campo de poder establecido por aquellos receptores eminentemente pasivos del pasado que toman el control del relato público. Rosen compara el modelo broadcast donde gobiernan medios predominantemente unidireccionales como la radio frente a la invención del podcasting, que le da poder al ciudadano quien, a la vez, descubre nuevos usos y potencialidades de la comunicación sonora. De forma paralela, la grabación, edición y distribución de vídeo -que una vez perteneció a los grandes medios de forma exclusiva- se está situando también en las manos de los usuarios a través de medios y/o plataformas nacidos al calor del terremoto mediático 2.0. Desde esta perspectiva, la edición de las noticias y los relatos se modifica desde una autoría insertada en los medios tradicionales y masivos a ser una tarea compartida entre corporaciones y públicos. 


\section{La cultura de la participación: un concepto en disputa}

A partir de estas primeras ideas, aparecen numerosas conceptualizaciones que, con diferentes matices, asumen las renovadas posibilidades participativas de los ciudadanos en la esfera pública mediática. Benkler (2006) y Jenkins (2006) son dos de los autores que representan las visiones más optimistas del empoderamiento ciudadano en los medios y plataformas digitales. Ambos defienden la habilidad y las posibilidades de los usuarios para conectar a partir de la producción social en los entornos virtuales. Según sus teorías, en Internet los ciudadanos hacen uso de los recursos digitales para crear y compartir contenidos a través de las redes sociales. Los individuos se organizan e interactúan entre sí en formas que constituyen la esencia de un entorno mediático estructuralmente abierto.

En la misma línea tecnoutópica, diferentes autores comienzan a introducir términos como medios participativos, medios abiertos, medios colaborativos, medios sociales, de código abierto y medios ciudadanos. A partir de las aportaciones de Gillmor (2004), surgen los conceptos de periodismo ciudadano, periodismo de calle, democrático, voluntario o periodismo 3.0. Nótese que toda la retórica analizada alrededor de la participación mediática de los ciudadanos se basa en el discurso de la potencialidad y del acceso a las nuevas herramientas tecnológicas como un motor de empoderamiento mediático de la población. Las corrientes de pensamiento optimistas parten de concepciones claramente tecnocráticas que definen que la mera inclusión de una tecnología supondrá un cambio significativo en los modelos y procesos de la comunicación.

En contraposición con estas visiones optimistas sobre la democratización del modelo mediático, existe otra corriente académica desarrollada en la última década que concibe los medios y las plataformas digitales desde posiciones más problemáticas. Las aportaciones de Sunstein (2009) y Prior (2007) nos presentan a un ciudadano digital que utiliza los recursos a su disposición para crear estructuras relativamente cerradas, alejadas de la visión utópica anteriormente referida. Prior afirma que la producción mediática online del ciudadano medio se establece a partir de una estructura de evidente 
polarización, sobre todo cuando analizamos el compromiso político de los cibernautas. La perspectiva de Sunstein es similar al afirmar que el internauta tiende a activar determinados filtros para enclaustrarse en cámaras de eco diseñadas por el propio usuario. En la misma línea, Pariser (2011) describe un mundo en el que los ubicuos sistemas de recomendación sirven una dieta personalizada de contenidos digitales precocinada por el usuario. Turow (2011) documenta un sistema de medios comerciales que divide a los consumidores en nichos definidos. Tanto Pariser como Turow perciben la Red como una conjunción de estructuras cerradas que explotan y manipulan nuestras identidades sociales a partir del uso de un entramado de plataformas cuyo modelo de negocio se basa en la gestión y mercantilización de los datos del usuario. Pariser (2011) concluye afirmando que "lo verdaderamente problemático sobre este cambio hacia la personalización es que es completamente invisible para los usuarios y, como consecuencia, se escapa de nuestro control". De otro lado, la conversión de la participación ciudadana en trabajo gratis para las empresas mediáticas es otro elemento esencial del nuevo escenario sociotécnico. La inserción de contenidos generados por los usuarios en los espacios digitales de los grandes medios profesionales conlleva innegables beneficios para el sustento del mercado mediante un proceso de generación de engagement del usuario con la marca mediática que le concede tal participación, constituida siempre como una forma de reforzar en el usuario un claro sentimiento de pertenencia a una comunidad que le lleve al consumo de los productos de la franquicia.

La ciudadanía utiliza las autopistas de la información digital para ejecutar múltiples acciones. Una investigación dirigida por Scolari y publicada en 2018 enmarca los diferentes usos que los adolescentes (el sector demográfico más activo en el universo digital) hacen de los medios interactivos. Esta taxonomía incluye las siguientes dimensiones: productiva, de gestión, performativa, instrumental, narrativa, estética, ideológica, ética y de aprendizaje informal. Todos estos elementos pueden reducirse a dos aspectos que consideramos centrales y que parten de la definición de qué tipo de usos y contenidos de los sujetos pueden considerarse insignificantes, mero ruido informativo arrojado en los canales virtuales, y cuáles terminan adquiriendo una verdadera relevancia. Allen (2015) propone la 
categorización de los relatos en dos tipos: el discurso expresivo (aquel que tiene un limitado impacto y se circunscribe solo a pequeñas comunidades) y el discurso influyente (aquel que tiene relevancia en los mecanismos de toma de decisión que definen las vidas de un número significativo de ciudadanos y/o influye en la adopción de determinadas acciones políticas). Si bien los mensajes influyentes no dejan de tener una dimensión expresiva, resulta evidente que solo una pequeña minoría de los relatos expresivos terminan siendo significativos en alcance, difusión, propagación e inclusión como parte del discurso circulante en la esfera pública. En un entorno digital caracterizado por la sobreabundancia de información que compite por la limitada atención de los públicos, los dos elementos sustanciales del discurso relevante son su visibilidad y su difusión. Interrogantes derivados de esta asunción son: ¿Quiénes dominan el discurso influyente en la esfera pública digital? ¿Qué barreras y sesgos tiene que superar el ciudadano tipo para que su discurso expresivo se convierta en influyente? ¿Cuáles son las oportunidades que tiene el contenido generado por el usuario de formar parte del relato de los medios? ¿Cuáles son los patrones que sigue la propagación y visibilización de los contenidos online? ¿Qué factores resultan decisivos en la conversión de los relatos expresivos en significativos?

\section{Entornos digitales y aprendizaje}

En este contexto, numerosos autores comienzan a hablar de la Red como un espacio donde, de forma paralela, se producen dinámicas de aprendizaje fuera de los entornos educativos formales y tradicionales. Estos aprendizajes se potencian a partir de las posibilidades de creación y participación que ofrecen los nuevos instrumentos digitales debido a su carácter interactivo. Estos nuevos medios y plataformas elevan las posibilidades de generación de una creatividad vernácula relativamente libre de las rígidas jerarquías propias de la cultura oficial. Estas prácticas creativas son consideradas como un principio subyacente de la existencia de muchas esferas de la sociedad actual, una dimensión presente en el concepto de "clase creativa" de Richard Florida (2002).

Jenkins et al. (2009) señalaron las competencias educativas que los jóvenes despliegan cuando interactúan y producen contenidos en las 
plataformas digitales. Estas habilidades fueron recogidas y agrupadas en varias dimensiones por Aparici y García-Marín (2017):

- Simulación. Habilidad de interpretar y construir modelos dinámicos que representen el mundo real, expandiendo su capacidad cognitiva y permitiendo el manejo de altos volúmenes de información y experimentación con completas configuraciones de datos.

- Apropiación. Consiste en la habilidad para reutilizar y remezclar el contenido mediático disponible en los circuitos online a través de procesos que generan aprendizajes significativos mediante la adopción de nuevas formas de expresión cultural.

- Multitarea. De forma creciente, los jóvenes se relacionan en un ambiente mediático caracterizado por la exposición simultánea a estímulos procedentes de diferentes pantallas que exige una mayor dispersión de la atención frente a las lógicas presentes en el siglo XX.

- Juicio crítico. Se fundamenta en la habilidad para evaluar la credibilidad de las fuentes de información. La escuela tradicional tiende a dar la categoría de verdad absoluta a los recursos clásicos del conocimiento sobre los que se sigue fundamentando (la palabra del profesor y el libro de texto), por lo que continúa mostrando un evidente déficit formativo relacionado con la potenciación del análisis crítico hacia las fuentes documentales. Una vez que los jóvenes penetran en los entornos virtuales y las redes sociales, donde cualquiera puede introducir sus propios contenidos independientemente de su calidad y fiabilidad, se hacen más necesarias que nunca las competencias para evaluar los diferentes recursos encontrados y analizar críticamente las perspectivas e intereses que dominan tales materiales.

- Navegación transmedia. Supone la capacidad para manejar el flujo de la información y los relatos a través de múltiples modalidades y lenguajes. Los jóvenes se conectan de forma creciente con productos culturales mediante el consumo de diferentes contenidos expandidos en múltiples medios que 
ofrecen partes específicas de las historias que los adolescentes reconstruyen de forma personal uniendo las diferentes piezas en dinámicas de consumo constructivo. De este modo, numerosos jóvenes, como usuarios de los productos culturales transmedia, adoptan el rol de cazadores y recolectores de pistas o piezas que conforman las narrativas distribuidas en diferentes soportes y lenguajes mediáticos. Esta idea está forjada desde el proceso por el que las audiencias "cosechan información desde diversas fuentes para crear una síntesis de la historia, lo que implica una dinámica de consumo creativo" (Beddows, 2012).

- El aprendizaje ubicuo. Las redes sociales han potenciado el uso de los dispositivos móviles como plataformas centrales de acceso al conocimiento y la comunicación, de modo que la habilidad para lograr aprendizajes significativos en cualquier momento y espacio es fundamental en nuestros días.

- En muchas ocasiones, estas habilidades son desarrolladas por los jóvenes de forma colaborativa mediante procesos de producción impulsados desde las comunidades de práctica, gobernadas por las lógicas de la cultura de la participación y la inteligencia colectiva. En su origen, el concepto de comunidad de práctica fue utilizado en el campo de la teoría del aprendizaje. Los antropólogos Jean Lave y Etienne Wenger (1991) acuñaron el término mientras estudiaban los diferentes modelos educativos. En su definición original, el concepto de comunidad de práctica se refería a aquellas agrupaciones de personas que actúan como un espacio vivo de aprendizaje para sus miembros. Una vez articulado, el término comenzó a ser aplicado a otros campos: los negocios, el diseño organizacional, la acción de gobierno, las asociaciones profesionales y la sociedad civil.

Las comunidades de práctica están constituidas por individuos que se comprometen en un proceso de aprendizaje colectivo sobre un tema o una pasión compartida. En su versión online, estas agrupaciones se configuran desde la idea de la interacción constante en los espacios digitales a fin de conseguir sus fines propuestos y desarrollan su 
dimensión práctica a partir de un amplio rango de actividades. La resolución de problemas, la reutilización de bienes, la coordinación y construcción de sinergias, la búsqueda de experiencias y la solicitud de información son las más habituales. En estas comunidades de práctica que se erigen en las redes y plataformas digitales, los jóvenes dan forma a una cultura propia, digital y participativa (Jenkins, Ito y Boyd, 2016) a partir de la adopción de un alto rango de estrategias que les llevan a la adquisición de las competencias y habilidades necesarias para desenvolverse en los circuitos virtuales.

Transalfabetismos. Competencias transmedia y estrategias informales de aprendizaje de los adolescentes es una de las principales investigaciones desarrolladas en los últimos años sobre esta temática. El estudio, elaborado durante tres años (2015-2018) en las comunidades de Madrid, Cataluña, Valencia, Galicia y Andalucía, tiene como objetivo la comprensión de las prácticas creativas transmediáticas de los jóvenes más activos, poniendo especial énfasis en las habilidades y sus estrategias informales de aprendizaje. Para la ejecución del trabajo de campo, se establecieron cinco equipos presentes en cada una de las comunidades, que trabajaron en varios centros educativos de cada comunidad con estudiantes de edades comprendidas entre los 12 y los 15 años. Cada equipo utilizó las siguientes estrategias e instrumentos de recogida de datos:

- Realización de talleres de videojuegos y de cultura participativa. Los primeros fueron analizados mediante técnicas de observación etnográfica, mientras que los talleres de cultura participativa (consistentes en la producción de materiales textuales y/o audiovisuales) fueron examinados mediante análisis de contenido a partir de una ficha de registro que incluyó un total de 55 indicadores divididos en 4 dimensiones diferentes: datos básicos del contenido generado por el estudiante, indicadores de competencias narrativas, indicadores de competencias estéticas e indicadores de competencias vinculadas a la ideología y valores.

- Entrevistas en profundidad (un total de 10 por equipo) con los jóvenes más activos durante el desarrollo de los talleres, con el fin de conocer su discurso acerca de la creación de contenidos 
online y las estrategias utilizadas para su producción. Los datos generados por estas entrevistas fueron analizados con el software NVivo 11 Pro, programa específico para investigaciones de tipo cualitativo y mixto.

De acuerdo con esta investigación, en la que participaron los autores de este artículo, los jóvenes se muestran en la Red especialmente activos a la hora de buscar información para resolver dudas en relación con sus estudios y con respecto a su aspecto físico, así como para seguir las tendencias de moda y para contrastar informaciones relevantes sobre sus productos culturales favoritos. Otros aspectos sobre los que buscan información se relacionan con el entretenimiento: resuelven dudas relacionadas con los videojuegos, solucionan problemas que encuentran en el uso de sus dispositivos digitales, escuchan música, ven películas y comentan publicaciones sobre determinados acontecimientos. Así lo indican tres de los participantes en las entrevistas realizadas:

Eso sí, por las uñas y por el pelo; porque tengo una amiga que se alisa súper bien y yo no puedo alisármelo como ella; entonces busco tutoriales a ver cómo va.

Maquillaje, belleza y cosas asi, que hay un montón de canales de esto.

Principalmente busco la información en YouTube; siempre va a haber tutoriales de todo; en YouTube ya bay tutoriales de todo.

Por ejemplo, lo de Johnny Depp lo lei en plan que alguien de los que seguia lo retuiteó, de que le parecía súper fuerte lo que habia pasado con Johnny Depp y, como yo sabia lo que pasaba, lo busqué y estuve viendo y pensé que no era verdad. Y normalmente lo bago asi con todo. Cuando hablan de algo que no sé, lo busco.

Una de las actividades más presentes en la acción de los jóvenes en la Red es la creación de contenido, sobre todo de carácter fotográfico. La representación de la vida cotidiana y la ubicuidad son las características esenciales de este tipo de material: cualquier aspecto de la vida diaria, hasta el más banal e insignificante, puede ser fotografiado en cualquier instante y circunstancia. Para el desarrollo de esta actividad, se observa la creciente popularidad de la red social Snapchat, un servicio que no 
permite la adición de comentarios y donde las fotos se eliminan en 24 horas. La edición fotográfica también es muy popular. Los jóvenes buscan las redes más interesantes para crear sus propias fotos, retocarlas añadiendo efectos atractivos, compartirlas y comentar las imágenes de otros usuarios:

No, yo las edito, sí, las edito con un programa que se llama PicsApp, que en ese programa tiene muchos filtros y retoques para yo qué sé, te da más luz, otro te da más... cosas así, para que te quede mejor la foto y estés más guapa. Y también puedes poner texto, puedes añadir otra foto encima o puedes recortarla.

La creatividad no solo se circunscribe al ámbito de la fotografía, sino que se extiende a los campos de la música y el vídeo. De acuerdo con nuestro estudio, numerosos jóvenes se descargan de Internet bases musicales para crear sus canciones añadiendo a posteriori su propia voz. Esas canciones pueden estar acompañadas de materiales audiovisuales que imitan los vídeos musicales de sus cantantes favoritos. Las producciones de vídeo también representan su vida cotidiana, ya que en ellas suelen mostrar los viajes que llevan a cabo con sus amigos, sus fiestas, las felicitaciones a sus seres queridos o las competiciones en las que participan.

La producción escrita también forma parte de las labores creativas de los jóvenes en Internet. Mostrar su visión personal sobre un videojuego que les ha parecido poco verosímil o a propósito de un acontecimiento impactante, así como recrear historias sobre libros o películas, son actividades muy habituales entre los jóvenes más productivos en los espacios digitales. La búsqueda de diversión y placer, y no el ánimo de lucro, es la principal motivación que tienen para la realización de este trabajo creativo:

Pero nada para ganar dinero, sino porque nos gusta, nos llama mucho la atención.

En el ámbito de los videojuegos, las estrategias de los jóvenes se vinculan con el descubrimiento de fallos presentes en los juegos, la grabación de jugadas y su difusión online y la detección de trucos o 
trampas para mejorar en los rankings y obtener mayor relevancia dentro de sus comunidades a fin de aumentar su número de seguidores.

Los jóvenes buscan ser reconocidos en sus comunidades de afinidad online y, para lograrlo, producen todo este caudal de trabajo creativo. $\mathrm{Su}$ estatus en la Red es importante y recibir comentarios y obtener seguimiento y relevancia es fundamental para su motivación. Encuentran fascinantes todas las aplicaciones que sirven para crear, investigan sus utilidades y las sacan el máximo partido, mientras buscan a otros que han conseguido cumplir sus objetivos y se imponen fines y metas. Los jóvenes buscan las maneras de crear sus contenidos intentando, en ocasiones, alcanzar un estándar de profesionalidad que les permita publicar sus trabajos. Así lo explican algunos de los adolescentes entrevistados:

Sí, es que tú puedes escribir tus propias historias y autopublicarlas, y hay mucha gente que ba conseguido que se le publiquen novelas gracias a Wattpad. Ploutub es una herramienta como Audacity, es para grabar el audio; entonces, debes tener un poco de conocimiento de ello. Hay personas que cantan... Aqui hay otro chico del barrio que canta, pero no utiliza eso, lo graba con su móvil; pero a mi me gustaba tener un sonido mejor. Me bice un estudio con un amigo, tenemos un estudio hecho en su casa. Lo primero que tuvimosquehacer fue comprar todo: los monitores, el portátil, la interface.

La producción de estos materiales genera en los jóvenes el aprendizaje de un amplio rango de competencias, algunas de las cuales ya fueron mencionadas anteriormente. En nuestro estudio, obtuvimos cuatro destrezas más que conviene añadir: la planificación y organización del trabajo, la adopción de una cultura colaborativa, el conocimiento del lenguaje y los géneros de los nuevos medios digitales interactivos y el aprendizaje de la gestión de su privacidad.

La colaboración es una de las competencias más interiorizadas entre los jóvenes, encaminados de forma constante en la búsqueda de feedback y en la adición de comentarios sobre los contenidos de otros usuarios. La colaboración se establece también a la hora de dar indicaciones a amigos o desconocidos para que utilicen los programas de software idóneos para sus creaciones o recomendar producciones dando sus propias opiniones sobre ellas para orientar lo que se debe 
consumir en los medios. Estos procesos se encuentran muy presentes en la cultura del videojuego, puesto que jugar de forma colaborativa online es una práctica generalizada. Jugar con amigos o con desconocidos para alcanzar objetivos más ambiciosos es una tarea ampliamente asumida, además de coordinar equipos de juego para obtener más puntuación o incluso porque el propio juego pone esta condición para avanzar:

Un equipo lo formé yo con un amigo del colegio, a él no le interesaba nada de los videojuegos y, en $2^{\circ}$ de la ESO, le dije que se lo descargase y probase y le gustó. Al otro equipo lo encontré jugando, pasando gente, en plan conozco a uno, añado en la llamada a otros y conocí a cinco personas y bueno... hubo una vez que estuve con diez.

Como indicábamos anteriormente, los jóvenes más productivos adquieren un gran manejo del lenguaje y las características de los nuevos modelos narrativos digitales interactivas. Son capaces de distinguir los nuevos géneros audiovisuales propios de medios como YouTube y los diversos formatos de texto y audio, así como explicar sus posibles expansiones y reconocer sus diferencias estéticas:

Estos son los últimos videos que se han subido, y aquí están todos los canales que sigo, que son bastantes. Entonces, por ejemplo, esta chica ha subido un vídeo sobre su fondo de armario, esta ha hablado sobre una convención de libros que ha habido en América, que está muy interesante. Los book hauls son en plan los libros que han leído ese mes, y te cuentan de qué van, su opinión y es bastante interesante, porque puedes aprender. Este, por ejemplo, es un "get ready with me", que es como que se arreglan contigo y te van enseñando lo que van haciendo.

La evaluación de riesgos y la gestión de la privacidad online es otra de las competencias adquiridas por los adolescentes, que comienzan a tomar conciencia sobre las consecuencias de compartir determinados datos personales y a aplicar filtros de seguridad y privacidad que comparten con otros. Asimismo, comprueban lo que otros comparten sobre ellos, controlan y monitorizan sus imágenes y creaciones: 
Hay cosas que no me gustan de las redes sociales porque no sabes dónde van a acabar. Por ejemplo, en Facebook, yo tenía una amiga que subió una foto y acabó en un anuncio y era como ¿qué hago yo alli? No me gusta eso.

Los adolescentes saben que son consumidores activos y constantes y de forma creciente muestran una actitud más responsable hacia la adopción de medidas de prevención para evitar posibles peligros. Sin embargo, en raras ocasiones se muestran críticos con la explotación que las grandes compañías digitales hacen de sus datos y de sus producciones en la Red.

\section{La vampirización de la creatividad online}

Estas actividades realizadas por los jóvenes en los entornos virtuales terminan siendo mercantilizadas por las franquicias culturales y las plataformas digitales, que convierten a los adolescentes en fans que producen valor para el mercado, como demuestran los estudios de Jenkins, Ford y Green (2015) sobre creación de contenido y rentabilidad económica en la actual cultura en red. En la misma línea, Sokolova (2012: 1572) demostró cómo la novela colaborativa Metro 2033, en cuya elaboración participaron numerosos fans realizando comentarios y proponiendo hilos narrativos alternativos a través de una página web abierta para tal efecto por el propio autor de la obra, resultó todo un éxito comercial al capitalizar de forma exitosa todo el interés generado durante su proceso de producción. Asimismo, Scolari y Establés (2017) documentan la producción y el activismo online de los seguidores de la serie televisiva El Ministerio del tiempo, que, a través de sus acciones en diferentes redes sociales, lograron en varias ocasiones que la serie no fuera cancelada.

En este punto, es necesario reflexionar sobre cómo la acción de los jóvenes produce valor económico para las corporaciones digitales y cómo el mercado vampiriza la creatividad de los jóvenes online; en definitiva, cuáles son los mecanismos de funcionamiento del capitalismo informacional. Savage (2007) sitúa el origen de la mercantilización de la cultura juvenil a finales de los años 40, tras la conclusión de la II Guerra Mundial. En ese contexto, las familias americanas empezaron a ofrecer a sus hijos todos aquellos bienes y 
comodidades que la generación anterior no había podido disfrutar durante la época de la Gran Depresión. De este modo, surge la noción de teenager como un término asociado al marketing que define a un subconjunto de jóvenes que aún viven en casa de sus padres (Hine, 1999) y a quienes habría que destinarles productos específicos para su consumo. Durante el siglo XX, las teorías sobre la cultura y las prácticas juveniles continuaron evolucionando, pero lo que se mantuvo constante fue la visión de estos adolescentes como un tipo de consumidor con necesidades específicas y segregadas del resto de la sociedad, abriéndose desde entonces un interesante nicho de mercado para las grandes marcas comerciales y las franquicias culturales (Jenkins, Ito y Boyd, 2016: 33).

Al mismo tiempo, la producción mediática de los jóvenes online suele estar basada en actos de falsa participación, tal y como demuestran numerosos estudios. Las investigaciones de Hindman (2008) sobre los blogs de temática política elaborados por ciudadanos no vinculados a los medios de comunicación en Estados Unidos (podríamos considerarlos independientes y amateurs, por tanto) afirman que debemos reconocer los nuevos tipos de exclusividad que genera, paradójicamente, la total apertura de Internet, que sigue el modelo winners-take-all (el ganador se lo lleva todo). Hindman demostró que los blogueros estadounidenses que escriben sobre temáticas políticas y que consiguen un mayor impacto en la Red proceden de un sector poblacional vinculado a la tradicionalmente considerada cultura dominante que no representa en absoluto al ordinary citizen americano. Estos creadores mediáticos tienen un perfil muy definido que les sitúa como hombres blancos educados en instituciones de alto prestigio, con brillantes trayectorias, ocupaciones ejecutivas y con cargos de alta responsabilidad. Este estudio pone de manifiesto que en la Red existen limitaciones muy evidentes para la construcción del discurso significativo desde aquellas voces que no forman parte del poder establecido.

En la misma línea, Berrocal, Campos-Domínguez y Redondo (2014) afirman que gran parte del escaso contenido generado por los consumidores de información política a través de YouTube solo sirve para reforzar el mensaje de los grandes actores de la comunicación o 
para seguir las tendencias de la mayoría, ejerciendo un escaso nivel de empoderamiento y capacidad crítica. La mayoría de las opiniones que los consumidores introducen en estos vídeos se vincula a lo que Sunstein (2010) denomina "cascada de conformismo", en cuanto a que estos comentarios son mensajes muy breves que reafirman el mensaje de la mayoría. Resultados similares obtuvieron Torrego y Gutiérrez (2016) en estudios sobre la participación de los jóvenes en la red social Twitter. Clua, Ferran-Ferrer y Terren (2018) defienden que aun cuando los jóvenes organizan acciones de movilización en las redes sociales, sus posibilidades de influir en el discurso público son muy limitadas: "Las reivindicaciones políticas de los jóvenes españoles no consiguen el estatus de controversias que las sitúen en los debates de la esfera pública”. Sokolova (2012: 1581) destaca la existencia de una evidente paradoja en la que observamos cómo los jóvenes reciben, por un lado, oportunidades para la creatividad y la autoexpresión, desconocidas en épocas anteriores, mientras que observamos una total mercantilización de su creatividad potenciada por los nuevos modelos de negocio de las grandes compañías mediáticas.

Internet se configura como un espacio dilemático donde las prácticas colaborativas sin ánimo de lucro peer to peer y las redes de código abierto convergen con plataformas que buscan el beneficio económico desde planteamientos jerárquicos que marcan claras estructuras de poder verticales entre las empresas digitales y sus usuarios. Desde el lado de la colaboración y la participación, destacan las teorías de la "economía del don" (gift-economy), concepto que procede del campo de la antropología. Jenkins, Ford y Green (2015: 90) se remontan al libro The Gift (1983) de Lewis Hyde a fin de caracterizar este tipo de comunidades donde se dan flujos constantes de dones gratuitos en una suerte de economía moral que no compensa con bienes materiales sino con estatus y prestigio. En la obra de Hyde encontramos una brillante diferenciación entre los conceptos de valor y valía vinculados, respectivamente, a las lógicas comerciales y del don. Los bienes que se intercambian mediante transacciones comerciales tienen valor en tanto se pueden traducir en dinero, son mensurables. Los productos intercambiados en la economía del don tienen valía entendiendo este concepto como aquellas características de un objeto a las que no se les puede poner precio. En este sentido, Jenkins, Ford y Green (2015: 92) 
explican que el significado de una transacción cultural no puede reducirse al intercambio de valor entre los creadores y su público, sino que también tiene que ver con lo que los miembros del público pueden comunicar sobre ellos mismos al mundo utilizando ese bien cultural. En el mundo predigital ya existían numerosos ejemplos de este tipo de procesos basados en la economía del don. Por ejemplo, el potlatch era una ceremonia practicada entre los pueblos indios americanos de la zona del Pacífico consistente en la celebración de opulentos banquetes en los que dos tribus intercambiaban regalos. La generosidad de estos pueblos servía para jerarquizar y estratificar a estas tribus en función del volumen y la riqueza de los dones que entregaban al pueblo amigo sin esperar nada a cambio. Cuanto mayor era el don entregado, más importancia, fama y prestigio adquiría el jerarca de la dadivosa tribu. Habitualmente estos regalos eran bienes en forma de alimentos producidos por el cultivo agrario como consecuencia de un periodo de grandes cosechas. De este modo, los pueblos que no gozaban de tantos bienes materiales podían mejorar su situación a través de estos dones gratuitos, aunque no desinteresados, ya que la recompensa siempre era la adquisición de estatus para la generosa comunidad que otorgaba tales regalos.

Los principios de la economía del don explican muchas de las prácticas contemporáneas que encontramos en el mundo digital. Esta entrega de dones a cambio de estatus está presente en los youtubers que dedican grandes cantidades de tiempo en la grabación y edición de sus producciones audiovisuales, en los miles de contribuidores y editores cuyos conocimientos leemos en Wikipedia, en la producción de los fans de producciones culturales que llenan los foros digitales de reflexiones e interpretaciones sobre esos productos de la cultura popular, en los millones de blogs de temáticas variadas que pueblan el mundo digital y en los podcasters que realizan sus grabaciones de audio para la escucha y descarga gratuita a disposición de cualquier internauta.

En esta línea, las aportaciones de Sennett (2013) sirven para desbordar las teorías que afirman que el rendimiento económico es lo único que le impulsa a alguien a realizar un trabajo. "También se recompensaba a los artesanos de antaño de formas intangibles: el reconocimiento o la 
reputación, el estatus, la satisfacción y, por encima de todo, su orgullo por un trabajo bien hecho" (Jenkins, Green y Ford, 2015: 83). Siguiendo esta lógica, los jóvenes no realizan sus producciones digitales buscando fines mercantiles, sino por el mero placer de compartir una información o un conocimiento con una comunidad. Sin embargo, como veíamos en los pueblos indios americanos, estos dones no se pueden considerar del todo desinteresados. La búsqueda de reconocimiento es el principal objetivo con el que se crean estos textos mediáticos para donarlos a una comunidad en la que, además, todo sujeto obtiene mucho más conocimiento del que ofrece.

Los intercambios en estas comunidades fundamentadas en la economía del don tienen, aparentemente, un carácter espiritual o simbólico, alejado de las leyes mercantiles de la oferta y la demanda. Las relaciones que establecen los jóvenes en estos espacios privilegian el campo de lo simbólico, situándose en el terreno de una suerte de economía moral que define la necesidad de tejer unas relaciones justas entre los creadores y los miembros de la comunidad que solo realizan actos de consumo de estos contenidos.

Frente a estas visiones, se sitúan las posturas que defienden una perspectiva más crítica sobre la creación de los jóvenes online y los principios de la gift-economy. Estas teorías ponen de manifiesto el carácter material del trabajo cognitivo que se desarrolla en los entornos digitales. La estructura de trabajo que caracteriza a los sistemas de la Web 2.0 está orientada a la producción de afectos y relaciones sociales que terminan afectados por los mismos patrones que rigen la producción de bienes materiales debido a que su actividad tiene consecuencias reales y significativas para el funcionamiento de las grandes compañías. La única diferencia entre el trabajo material y el cognitivo es que este último no modifica las cosas físicamente en primera instancia, sino que afecta a los aspectos emocionales y comunicativos de las relaciones humanas. No obstante, este trabajo cognitivo se convierte en material al colocarse bajo los principios del mercado que orientan toda esta producción hacia la generación de beneficio económico (Fuchs, 2015). En este contexto, la economía del don y el capitalismo cognitivo no solo no están en conflicto, sino que coexisten en una simbiosis donde las prácticas colaborativas y 
participativas de los jóvenes son promovidas y esponsorizadas por el gran capital (Barbrook, 1998).

De este modo, las estrategias y las acciones de aprendizaje informal de los jóvenes en las redes producen un doble proceso en el que, por un lado, los adolescentes adquieren un conjunto de competencias sin perspectiva crítica y, por otro, se produce una paralela mercantilización de su actividad por parte las grandes compañías tecnológicas a través de dinámicas de trabajo gratis de sus usuarios. Las producciones de los adolescentes se configuran con una nueva forma de explotación y el resurgimiento de nuevas prácticas de alienación de la acción de los jóvenes online, puesto que tales acciones no implican control alguno de los usuarios sobre los modos de producción (Terranova, 2000). Dijck y Nieborg (2009) defienden que la retórica de la cocreación y la cooperación entre usuarios y marcas a la hora de producir contenidos en la Red olvida la manipulación por parte del capital de un espacio digital que debería ser democrático y colectivista. En el mismo sentido, Drahos y Braithwaite (2002) usan el concepto "feudalismo informacional" para referirse a la transferencia de bienes de conocimiento desde el intelecto colectivo a las manos privadas.

Los estudios de Fuchs (2008) ofrecen un útil modelo para explicar las múltiples formas que las empresas digitales implementan para desarrollar estos procesos de mercantilización de la acción creativa de los sujetos en las plataformas virtuales. Fuchs propone una amplia taxonomía sobre el funcionamiento de la economía digital. Por un lado, distingue entre la industria del hardware (que incluye los equipos informáticos y sus dispositivos periféricos, así como las infraestructuras tales como las redes que sustentan Internet), la industria del software y la industria del contenido. Una segunda categoría distingue los bienes físicos, los productos digitales y los servicios (estos últimos consisten en los bienes fundamentados en las relaciones sociales, es decir aquello que ayuda a los usuarios a lograr fines de conectividad y expresión social). Otra categoría describe aspectos relacionados con la distribución, distinguiendo entre los bienes que son provistos online de aquellos que se asientan en el mundo analógico. Del mismo modo, es necesario distinguir aquellas organizaciones que están orientadas a obtener beneficios y aquellas 
basadas en la economía del don. La última dimensión diferencia si los bienes o servicios provistos tienen valor de intercambio (en el caso de que tengan coste económico para el usuario) o solo valor de uso.

La combinación de los diferentes aspectos de esta taxonomía ofrece diferentes modelos de negocio presentes en el capitalismo cognitivo. Por un lado, nos encontramos con el modelo IBM, basado en la venta en el mercado de productos de hardware (físicos) y offline. Un modelo diferente es el de Microsoft, que se dedica a la venta de productos digitales de software. En una posición aún más alejada, situamos el modelo de Google, basado en una plataforma de información digital que ofrece al usuario contenido y metainformación online a través del uso gratuito de su plataforma y obtiene beneficios mediante la venta de publicidad. El modelo de Wikipedia se centra en la cooperación digital a través de la adición de contenido en una plataforma virtual que se rige bajo el principio de la economía del don y la ausencia de búsqueda de beneficio. Muy diferente a este último modelo es el que encontramos en las redes sociales, espacios donde la acción de los jóvenes se desarrolla de forma más profunda. Las redes presentan un modelo fundamentado en la gratuidad del uso de sus plataformas para alimentar las relaciones de los sujetos, donde se busca un evidente beneficio, que es generado a partir del emplazamiento de publicidad, del envío de anuncios personalizados a los usuarios y de la venta de los datos generados en tales plataformas. En las plataformas digitales y las redes sociales, los jóvenes constantemente crean y reproducen contenido y perfiles que contienen datos personales, relaciones sociales, afectos, comunicaciones y comunidades. En este modelo, todas las actividades online son almacenadas, evaluadas y mercantilizadas. Los usuarios no solo producen contenidos, sino también un conjunto de datos personales que son vendidos a las empresas de publicidad que, de este modo, son capaces de presentar anuncios individualizados en función de los intereses de los sujetos. Los usuarios son, por tanto, consumidores productivos que generan bienes y beneficios que son explotados de forma intensiva por el capital (Fuchs, 2015). A su vez, el modelo de explotación de las redes sociales y plataformas digitales se basa en una "economía del tiempo". Cuanto mayor sea el tiempo que un sujeto permanece en las plataformas de estos medios digitales, mayores posibilidades tendrá de recibir 
contenidos publicitarios que él mismo generó a partir de sus patrones de navegación y acciones en tal plataforma. Toda la actividad que los jóvenes llevan a cabo es convertida en mercancía para ser explotada por el mercado. Lo novedoso de este modelo es que esta explotación no tiene lugar durante el tiempo tradicionalmente considerado "remunerado", sino durante los momentos de ocio de los individuos, a la vez que los lugares dedicados a la producción ya no se circunscriben solo al taller y a la oficina. La producción de insumos para el mercado se ha convertido en ubicua. Como se analiza a continuación, la economía digital ha conseguido extender el tiempo y los espacios que los sujetos dedican a la producción de bienes para las grandes compañías.

\section{E1 fan 2.0}

El incesante avance tecnológico de las últimas décadas ha impulsado la productividad de la sociedad, capaz ahora de proveer más bienes y servicios dedicando mucho menos tiempo de trabajo. La principal consecuencia de esta creciente eficiencia de la fuerza productiva es la ampliación del tiempo de ocio de los sujetos que se dedica, en principio, para fines diferentes al trabajo remunerado. Este aumento del tiempo de ocio, combinado con las tecnologías digitales, genera grandes posibilidades de producción colaborativa y un excedente cognitivo (Shirky, 2010) que puede ser aprovechado en beneficio de la sociedad. De forma paralela, el aumento del tiempo dedicado a actividades no productivas provoca la apertura de mayores posibilidades para el consumo, elemento esencial para el desarrollo de la sociedad de mercado donde ha de venderse todo (o la mayor parte) de lo que se produce. La novedad en nuestra era digital es que ahora ese tiempo de ocio no solo se utiliza para el consumo, sino que también se convierte en tiempo de trabajo gratis para las compañías de la economía digital que ahorran, de esta forma, costes de producción. Este iTime (Agger, 2011) se caracteriza por la constante disponibilidad del consumidor, su compulsión a la conexión, la extensión del tiempo laboral a la esfera privada, la mercantilización de la conectividad y del tráfico en la Red y la conversión del trabajo pagado en labor no remunerada. 
En este escenario, gran parte de las conexiones que generan los jóvenes online se producen en el contexto de las grandes franquicias culturales y del entretenimiento que, de forma creciente, buscan la creación fan como un modo de potenciar la identificación de los públicos con sus productos y con los objetivos de sus estrategias. Tapscott (1995) defiende que la acción de los fans vinculados a las marcas resulta un elemento clave para entender las nuevas normas del marketing de finales de siglo XX e inicio del siglo XXI, basadas en la transición de los productos a las experiencias, del espacio físico de venta a la ubicuidad proporcionada por los dispositivos digitales y de los procesos tradicionales de promoción y publicidad a las dinámicas de comunicación y diálogo entre marcas y usuarios. "Los jóvenes quieren estar involucrados en la co-innovación de los productos y, si se les deja, se colocarán las bases para el establecimiento de experiencias ricas y duraderas" (Tapscott, 2009: 212). Las posibilidades que las marcas ofrecen a los usuarios y fans para formar parte del diseño de los productos y servicios no van mucho más allá de la mera superficialidad y los sujetos rara vez forman parte de los relatos de las grandes franquicias culturales y los medios de masas (Aparici y García-Marín, 2018). Mientras los fans creen encontrar un espacio de libertad y expresión en las redes y los entornos virtuales, la realidad es que, de forma paralela, estos espacios se configuran como una versión moderna de los grandes aparatos ideológicos y del control del Estado que teorizaron décadas atrás Althusser y Foucault. Para Lipovetsky (2014) la sociedad actual vive en una nueva modernidad que impulsa nuevas formas de relacionarse con los demás y una nueva jerarquía de objetivos y principios. Esta etapa está protagonizada por sujetos hiperconsumidores por naturaleza, ávidos de un fetichismo por las marcas (Correa, 2017: 223).

La llegada de Internet no ha favorecido un verdadero empoderamiento del fan, sino todo lo contrario: la Red ha reforzado las ataduras generando un creador digital encargado de sustentar el beneficio económico de las grandes plataformas online y la rentabilidad de los productos de las grandes franquicias culturales. El modelo comunicativo protagonizado por las marcas en el siglo XX planteaba una relación unidireccional y vertical con los fans, tratados únicamente como producto para ser vendido a los anunciantes. En la era digital, 
los jóvenes continúan siendo sometidos a procesos de mercantilización que se remodelan e intensifican. Fuchs (2015: 156) enuncia algunas claves que caracterizan a este fan 2.0:

Creatividad y relaciones sociales. Las audiencias de la era broadcast producían significados culturales a partir de los contenidos de los grandes medios masivos; mientras que los fans 2.0 no solo producen este tipo de significados, sino también contenido, comunicaciones con otros usuarios y relaciones sociales, por lo que su actividad multiplica su valor $y$, por consiguiente, las ganancias obtenidas por las empresas digitales y las franquicias culturales también se multiplican.

Vigilancia. El broadcasting utiliza medidas de audiencia cuyos datos no dejan de ser meras aproximaciones sobre la caracterización de sus miembros. Los medios sociales digitales monitorizan, almacenan y miden todas las actividades online de los fans en sus plataformas, de modo que disponen de perfiles muy detallados de los intereses de los sujetos a través de una vigilancia en tiempo real que se configura como una característica inherente a la creación en estos medios, donde los datos personales son vendidos como mercancía. La economía digital ofrece una mayor dimensión explotadora del fandom: el usuario de las plataformas produce contenidos para el sustento de grandes compañías (las plataformas digitales tales como iTunes) a la vez que genera datos (bienes) para terceros (los anunciantes).

Coerción y alienación. Igual que sucede en otros campos dominados por el trabajo no remunerado, el fandom digital está gobernado por procesos de coerción. Las grandes compañías digitales han sido capaces de monopolizar la provisión de determinados servicios como la creación de vastas redes de conectividad social y, por ello, son capaces de ejercer una invisible forma de coerción hacia los usuarios, que se resisten a abandonar tales plataformas a fin de mantener sus relaciones sociales y no verse abocados a un evidente empobrecimiento en términos comunicativos. Para Fuchs (2015: 229), la alienación que el sistema de medios sociales digitales potencia se construye a partir de cuatro dimensiones que afectan de lleno a los fans: a) en relación con la subjetividad, ya que se practica sobre los sujetos una evidente violencia simbólica bajo amenaza de aislamiento social y disminución de oportunidades en caso de abandonar las plataformas sociales 
monopolísticas; b) en relación con los objetos de su labor creadora, ya que sus experiencias humanas se sitúan bajo el control del capital; c) en relación con los instrumentos utilizados en su trabajo, debido a que las plataformas no son propiedad de los usuarios, sino que pertenecen a compañías privadas que mercantilizan su actividad online; y d) en relación con el producto de su labor, ya que son estas compañías las que únicamente explotan los beneficios generados por el trabajo del usuario.

Carácter dual. Los fans utilizan los medios sociales digitales para satisfacer necesidades sociales propias y, a la vez, necesidades comerciales asentadas en el mercado. Los procesos que constituyen la cara mercantil de estos servicios están escondidos detrás de las relaciones sociales que estos medios impulsan entre los usuarios. Estas empresas se presentan como organizaciones que pretenden ofrecer conexión social y espacios para compartir y no como compañías en busca del mayor beneficio posible.

El fan 2.0 es el individuo paradigmático de la sociedad del rendimiento que caracterizó Han (2015), cuya participación y creatividad en los entornos virtuales se establece entre el infoentretenimiento, el miedo al rechazo y el consumismo. Estos son los factores que generan "la sumisión en una sociedad ya de por sí extraordinaria y celosamente vigilada y controlada" (Correa, 2017: 230).

\section{Conclusiones}

Desde la llegada de la Web 2.0, se establecieron dos líneas de pensamiento en torno a las potencialidades de empoderamiento de los nuevos instrumentos digitales. Los académicos se dividieron entre los apocalípticos (aquellos que ponían de relieve los peligros de la Red y sus posibilidades como instrumento para la delincuencia y el control de los ciudadanos) y los integrados (aquellos que solo veían los aspectos positivos de Internet como herramienta democratizadora del espacio público y para el acceso a la cultura y al conocimiento humano). Lejos de situarnos en cualquiera de estos extremos, resulta imprescindible una posición crítica hacia la deriva mercantil que, tras casi década y media de desarrollo, la Web 2.0 ha experimentado. 
Los jóvenes construyen su propia cultura a partir de sus acciones y creaciones en la Red utilizando para ello un amplio rango de estrategias e involucrándose en comunidades de práctica y afinidad donde producen contenidos en diferentes lenguajes mediáticos y, de forma paralela, adquieren competencias clave en la realidad sociotécnica del siglo XXI. La Red se configura como un espacio informal de aprendizaje donde los jóvenes más activos potencian sus habilidades para la navegación transmedia, el aprendizaje ubicuo, la apropiación y la remezcla de sustancias expresivas diversas a fin de construir sus propios materiales; a la vez que generan prototipos y simulaciones, asumen competencias para la planificación y la organización del trabajo, adoptan una cultura colaborativa y aprenden a gestionar su privacidad en estos entornos digitales.

Sin embargo, estas acciones y producciones de los adolescentes y las prácticas colaborativas en el seno de las comunidades de práctica, lejos de empoderar a sus creadores, sirven para alimentar la maquinaria del capitalismo cognitivo. Las teorías de la economía del don esconden la dimensión neoliberal de la producción online bajo el falso tapete de la recompensa con estatus y reconocimiento de las obras producidas en la Red, un trabajo que, a diferencia de lo defendido por estas teorías, nunca es inmaterial, sino que termina siendo convertido en capital para las grandes compañías digitales y las franquicias culturales.

En el mismo sentido, la retórica de la narrativa transmedia le otorga a los fans y seguidores de los productos de la cultura popular un falso papel activo y protagonista en la construcción de los relatos de estas obras. La realidad es que la capacidad de los fans a la hora de influir en la creación de la narrativa de estas compañías es, en general, muy limitada. Los fans y seguidores de estas marcas nunca forman parte de los relatos, sino que se configuran como parte del producto a través de la vampirización de sus acciones y de sus contenidos, a partir de dinámicas de trabajo gratis, constituyendo evidentes procesos de alienación de la creatividad de los jóvenes.

A pesar de realizar una labor creativa en la Red, los adolescentes no dejan de asumir el papel de consumidores de los productos mediáticos y culturales que las marcas ofrecen, a la vez que se involucran en una 
participación superficial que apenas tiene relevancia en el devenir narrativo de las historias. Su labor creadora sirve para provocar una mayor vinculación emocional con las marcas que es aprovechada para disparar futuros actos de consumo y promover su sentimiento de pertenencia a una comunidad (Esnaola, 2017). Todas las estrategias y la producción de obras que generan los usuarios son claramente irrelevantes por su falta de visibilidad y la ausencia de diseños de experiencias de usuario verdaderamente colaborativas y participativas generadas desde el lado de las compañías. Todo este caudal creativo y estas estrategias de los jóvenes online resultan capitales para consolidar el modelo de mercado actual en el que la cultura juvenil trabaja para el refuerzo de un capitalismo informacional que funciona de una forma tan eficiente como invisible.

- Investigación financiada. Este artículo es producto del proyecto de Investigación titulado "Transalfabetismos. Competencias transmedia y estrategias informales de aprendizaje de los adolescentes" (Ref. CSO201456250-R) financiado por el Programa Estatal de Investigación, Desarrollo e Innovación Orientada a los Retos de la Sociedad, en el marco del Plan Estatal de Investigación Científica y Técnica y de Innovación 2013-2016.

\section{Referencias}

B Agger (2011): “iTime: Labor and life in a smartphone era”. Time \& Society 20 (1), pp. 119-136.

D Allen (2015): "Reconceiving Public Spheres: The Flow Dynamics

Model", en VVAA, From Voice to Influence (Coords. D Allen \& J

Light). Chicago: The University of Chicago Press.

R Aparici, R. \& D García-Marín (2017): Comunicar y educar en el mundo que viene. Barcelona: Gedisa.

R Aparici \& D García-Marín (2018): "Prosumidores y emirecs:

Analysis of two confronted theories". Comunicar, 55, abril, pp. $71-79$

R Barbrook (1998): “The hi-tech gift economy”. First Monday 3 (12), pp. 56-64

E Beddows (2012): "Consuming transmedia: how audiences engage with narrative across multiple story modes", en www.emmabeddows.com, Australia, junio: 
http://www.emmabeddows.com/wp-

content/uploads/2013/03/EmmaBeddows PhDTHESISFIN

AL ConsumingTransmedia 2012.pdf- (10-04-2018)

Y Benkler (2006): The Wealth of Networks. New Haven and London:

Yale University Press.

S Berrocal, E Campos-Domínguez \& M Redondo (2014).

"Prosumidores mediáticos en la comunicación política: el

"politianment" en YouTube". Comunicar, 22(43), pp. 65-72.

A Clua, N Ferran-Ferrer \& L Terren (2018): "Youth impact on the public sphere in Press and Twitter: The dissolution of the Spanish Youth Council". Comunicar, 55, pp. 49-57.

RI Correa (2017): "Performance del yo digital: fantasmagorías de la sumisión en la mente colmena", en VVAA, ¡Sonrié, te están puntuando! Narrativa digital interactiva en la era de Black Mirror (Coords. R. Aparici \& D. García-Marín). Barcelona: Gedisa. JV Dijck \& D Nieborg (2009): "Wikinomics and its Discontents: A Critical Analysis of Web 2.0 Business Manifestos". New Media \& Society, 11 (5), pp. 34-43

P Drahos \& J Braithwaite (2002): Information feudalism: Who owns the knowledge economy? London: Earthscan.

G Esnaola (2017): “Textos, contextos y narrativas inmersivas", en VV AA, iSonrie, te están puntuando! Narrativa digital interactiva en la era de Black Mirror (Coords. R. Aparici \& D. García-Marín). Barcelona: Gedisa.

R Florida (2002): The rise of the creative class. New York: Basic Books. C Fuchs, C. (2008): Internet and Society. Social Theory in the Information Age. New York: Routledge.

C Fuchs, C. (2015): Culture and economy in the age of socia media. New York and London: Routledge.

D Gillmor (2004): We the media: Grassroots Journalism by the people, for the people. Boston: O'Reilly Media.

BC Han (2015): La sociedad del cansancio. Barcelona: Herder.

M Hindman (2008): The myth of digital democracy. Princeton: Princeton University Press.

T Hine (1999): The Rise and Fall of the American Teenager. New York: Perennial.

L Hyde (1983): The Gift: Imagination and the Erotic Life of Property. New York: Vintage. 
H Jenkins, H. (2006): Convergence Culture. La cultura de la convergencia en los medios de comunicación. Barcelona: Paidós.

$\mathrm{H}$ Jenkins et al. (2009): Confronting the Challenges of Participatory Culture. Media Education for the 21st Century. Cambridge, MA: MIT Press H Jenkins, S Ford, S \& J Green (2015): Cultura Transmedia. La creación de contenido y valor en una cultura en red. Barcelona: Gedisa.

H Jenkins, M Ito \& D Boyd (2016): Participatory Culture in a Networked Era. Cambridge: Polity Press.

J Lave \& E Wenger (1991). Situated Learning. Legitimate peripheral participation. New York: Cambridge University Press.

G Lipovetsky (2014): La felicidad paradójica. Barcelona: Anagrama.

E Pariser (2011). The Filter Bubble. Londres: Penguin Lcc Us.

M Prior (2007): Post-Broadcast Democracy. Cambridge (Reino Unido):

Cambridge University Press.

J Rosen (2006): “The People Formerly Known as the Audience", en http://pressthink.org, EEUU, junio:

http://archive.pressthink.org/2006/06/27/ppl frmr.html. (15-03-2018)

J Savage (2007): Teenage: The Creation of Youth Culture. New York:

Viking.

R Sennett (2013): El artesano. Barcelona: Anagrama.

CA Scolari \& MJ Establés (2017). "El ministerio transmedia:

expansiones narrativas y culturas participativas". Palabra Clave 20(4), pp. 1008-1041

C Shirky (2010): Cognitive Surplus. How Technology Makes Consumers into Collaborators. New York: Penguin.

N Sokolova (2012): "Co-opting Transmedia Consumers: User

Content as Entertainment or 'Free Labour'? The Cases of

S.T.A.L.K.E.R. and Metro 2033". Europe-Asia Studies, 64 (8), pp. 1565-1583.

C Sunstein (2009): Republic.com 2.0. Princeton, Nueva Jersey: Princeton University Press.

C Sunstein (2010): Rumorología. Cómo se difunden las falsedades, por qué nos las creemos y qué se puede hacer. Barcelona: Debate.

D Tapscott (1995): The Digital Economy: Promise and Peril in the Age of Networked Intelligence. New York: McGraw-Hill.

D Tapscott (2009): Grown up digital. How the net generation is changing your world. New York: McGraw-Hill. 
T Terranova (2000): "Free labor: producing culture of digital economy?”. Social Text, 63 (18), pp. 74-83.

A Torrego \& A Gutiérrez (2016): "Watching and Tweeting: Youngsters' Responses to Media Representations of Resistance". Comunicar, 47, pp. 9-17.

J Turow (2011): The Daily You. How the New Advertising Industry Is

Defining Your Identity and Your Worth. New Haven and London:

Yale University Press.

Papers relacionados

J Vázquez-Herrero, A González-Neira, N Quintas-Froufe (2019): “La audiencia activa en la ficción transmedia: plataformas, interactividad y medición". Revista Latina de Comunicación Social.

E Guerrero Pérez (2018): "La fuga de los millennials de la televisión lineal". Revista Latina de Comunicación Social, 73.

CA Scolari, N Lugo Rodriguez, MJ Masanet (2019): “Educación Transmedia. De los contenidos generados por los usuarios a los contenidos generados por los estudiantes". Revista Latina de Comunicación Social. 



\title{
Jugadores, escritores e influencers en redes sociales: procesos de profesionalización entre adolescentes
}

María-José Establés - Universitat Pompeu Fabra, UPF - Barcelona (España). mariajose.estables@upf.edu.

Mar Guerrero-Pico - Universitat Pompeu Fabra, UPF - Barcelona (España) mariadelmar.guerrero@upf.edu.

Ruuth-S Contreras-Espinosa - Universidad de Vic, Uvic Universidad Central de Cataluña (España).ruth.contreras@uvic.cat.

Cómo citar: MJ Establés, M Guerrero-Pico, RS Contreras-Espinosa (2019): "Jugadores, escritores e influencers en redes sociales: procesos de profesionalización entre adolescentes". En V Tur-Viñes/M J González-Río/R S Contreras-Espinosa (Eds.) Jóvenes / Medios y cultura colaborativa. Cuadernos Artesanos de Comunicación, cac157, pp 191-226. La Laguna (Tenerife): Latina. DOI: $10.4185 / \operatorname{cac} 157$

\begin{abstract}
s
Introducción. La evolución de la industria mediática ha precipitado profundos cambios en la forma en que los adolescentes desarrollan sus competencias y acceden a la producción transmedia. En concreto, nos centraremos en la aparición de una zona gris donde los hobbys mediáticos devienen en oportunidades de profesionalización para los jóvenes, y en oportunidades de beneficio económico para las industrias. Metodología. El enfoque metodológico que se ha llevado a cabo se ha realizado desde una perspectiva mixta de métodos cualitativos y cuantitativos. Se han integrado técnicas de recolección y análisis de
\end{abstract}


datos de corte etnográfico, estadístico y textual. Resultados. Se detectan tres ámbitos de profesionalización: videojuegos, escritura creativa y redes sociales con sus propias dinámicas con respecto al género de los adolescentes y los recursos y plataformas utilizados. Discusión y Conclusiones. Los adolescentes que emprenden procesos de profesionalización son una minoría y, dentro de este grupo, es fundamental fortalecer las competencias que les permitan comprender en qué medida su trabajo beneficia económicamente a las compañías de comunicación.

\section{Keywords}

Alfabetismo transmedia; eSports; influencers, adolescentes, escritura colaborativa.

\section{Contents}

1. Introducción. 2. Estado de la cuestión. 2.1. El alfabetismo y las competencias transmedia. 2.2. Cooptación de audiencias: oportunidades y riesgos. 2.2.a. Videojuegos competitivos y profesionales. 2.2.b. Escritura colaborativa y publicación profesional. 2.2.c. Influencers en redes sociales. 3. Diseño de la investigación. 3.1. Objetivos del estudio. 3.2. Muestra. 3.3. Metodología. 4. Resultados. 4.1. Consumo y producción diferenciados por género. 4.2. Los contenidos audiovisuales como eje transversal para la profesionalización. 4.3. Videojuegos: del jugador casual al profesional. 4.4. Escritura en Wattpad: entre el oficio social y el oficio solitario. 4.5. Fotografía: Aspirantes a influencers en Instagram y YouTube. 5. Discusión y conclusiones. 6. Notas. 7. Referencias bibliográficas.

\section{Introducción}

E L ACCESO a nuevas plataformas y medios en el ámbito digital está sirviendo como canal de comunicación entre los jóvenes de una forma rápida y sencilla. Cada día surgen nuevas aplicaciones y redes en las que navegan y van cambiando sus hábitos de consumo y producción. Si bien este entorno digital es a priori de acceso gratuito, no podemos obviar que el acceso a los contenidos lleva aparejadas contraprestaciones, entre otras, como pueden ser la recopilación de datos personales o la ubicación de los usuarios. En ocasiones, tanto 
jóvenes como adultos no son conscientes de este precio a la hora de utilizar servicios digitales. Es por ello, que es pertinente seguir investigando y reflexionando sobre lo qué es el alfabetismo transmedia con el objetivo de conocer qué están haciendo los adolescentes con los medios y cómo pueden aprender a manejarlos.

En este contexto, nos encontramos con dos ámbitos que en principio pueden llegar a ser contrapuestos: las culturas participativas y las industrias culturales. En el primero nos encontramos prácticas como el remix, la inteligencia colectiva y la cultura de la colaboración entre prosumidores y fans, mientras que el segundo se caracteriza por la homogeneización de los procesos productivos, el lucro y la concentración corporativa. Entre ambos existe una zona gris (Scolari, 2014) donde algunas personas, muchos de ellos fans de ciertos productos culturales, pasan del ámbito amateur de las culturas participativas al profesional de las industrias culturales, describiendo lo que sería el fenómeno de la convergencia cultural (Jenkins, 2006). Es en esta zona donde algunos jóvenes con competencias destacables en el ámbito digital están intentando abrirse un hueco en las industrias culturales, en concreto, en la de los videojuegos (eSports, diseño de nuevos juegos, etc.), la editorial (Wattpad, booktubers, etc.) y la de la prescripción de productos $\mathrm{y} / \mathrm{o}$ servicios (Instagram, canales de YouTube...). Si bien el hecho de contar unas competencias muy específicas para destacar en estos ámbitos es algo fundamental para poder dedicarse a nivel profesional, no podemos olvidar que estos nuevos entornos todavía están por desarrollarse en muchos aspectos a nivel legislativo o laboral. $\mathrm{Y}$ es aquí donde bastantes jóvenes a veces se encuentran inmersos en un trabajo que les apasiona pero que dista mucho de ser su sueño: pasar de ser un aficionado a un profesional que pueda tener un sustento económico estable.

Este trabajo emerge de las reflexiones sobre este nuevo ecosistema mediático y el rol que están desempeñando los adolescentes en el mismo, así como en los retos y problemáticas que se plantean en las relaciones entre prosumidores y nuevas industrias culturales. 


\section{Estado de la cuestión}

\subsection{E1 alfabetismo y las competencias transmedia}

En el actual ecosistema mediático, los jóvenes se encuentran inmersos en el consumo y producción de contenidos digitales, a través de la realización de prácticas sociotecnológicas que han surgido gracias a los avances de internet. La competencia mediática (Ferrés-Prats y Piscitelli, 2012; Ferrés-Prats, Aguaded-Gómez y García-Matilla, 2012) se plantea como una herramienta necesaria para comprender este nuevo contexto. Asimismo, el rápido y sencillo acceso a los nuevos medios digitales ha acrecentado también la preocupación de los distintos agentes, como son los docentes, instituciones educativas $\mathrm{O}$ progenitores, por un uso seguro de los mismos (Livingstone et al., 2011; Masanet y Establés, 2018) o cómo formar ciudadanos críticos ante el consumo y producción mediáticas (Alvermann et al., 2018, Funk et al., 2016; García-Ruiz, Ramírez-García y Rodríguez-Rosell, 2014; Herrero-Diz, Ramos-Serrano y Nó, 2016).

Siguiendo esta línea, se requiere que los adultos comprendan mejor qué medios y herramientas digitales utilizan los jóvenes para aprovechar el conocimiento y habilidades que se desprende de ellos para incluirlo en las aulas (Lacasa, 2011; Scolari, 2018). En este sentido, consideramos que es imprescindible seguir trabajando en el alfabetismo transmedia, que según lo define Scolari $(2018$, p. 17) se trata de "una serie de habilidades, prácticas, prioridades, sensibilidades, estrategias de aprendizaje y formas de compartir que se desarrollan y se aplican en el contexto de las nuevas culturas participativas". De este modo, la clave del alfabetismo transmedia sería situar las redes sociales y las prácticas con los nuevos medios como centro de las competencias prácticas y analíticas de los adolescentes. Así, nos encontramos con una serie de competencias transmedia que conforman los pilares básicos de dicho alfabetismo, según las últimas investigaciones que se están realizando en este ámbito (Scolari, 2018): competencias productivas; competencias de gestión; competencias performativas; competencias sobre contexto mediático y tecnológico; competencias narrativas; competencias de prevención de riesgos y privacidad, y finalmente, y competencias de ideología y ética. 
En este contexto mediático tan flexible y cambiante en el que se entrelazan cuestiones laborales, aspiracionales y lúdicas, los jóvenes deberían contar con una serie de competencias que les empoderen a la hora de actuar ante los nuevos medios y oportunidades profesionales que se les pueden presentar. En este sentido, consideramos que las competencias clave para que los adolescentes puedan enfrentarse con herramientas con las que fomentar el espíritu crítico serían las competencias de contexto mediático y tecnológico, las de ideología y ética y las de gestión, en tanto en cuanto con ellas los jóvenes tendrían la capacidad de conocer cómo funcionan las industrias mediáticas, cómo se manejan con ellas y hasta qué punto reconocen la ideología implícita o explícita que difunden los distintos medios de comunicación.

En concreto, definimos las competencias de contexto mediático y tecnológico como aquellas que están relacionadas con el conocimiento y la toma de decisiones al respeto de los medios en cuestiones sobre la economía sociopolítica mediática y sobre las características y lenguajes digitales de los medios. Por otra parte, las competencias de ideología y ética se refieren a la detección, análisis y toma de decisiones cuando aparecen representaciones mediáticas estereotipadas, así como a cuestiones éticas relacionadas con derechos de autor y prácticas como el hacking o el cheating. Por último, las competencias de gestión hacen referencia a tres tipos de habilidades: gestión social, autogestión y de gestión de contenido. Por tanto, las competencias de gestión social se refieren al distinto grado de destreza para comunicarse, coordinarse, organizar, liderar y enseñar mientras se juega o se producen contenidos de forma colectiva. Las competencias de gestión de contenido se refieren a la capacidad de administrar diferentes contenidos multimedia a través de una variedad de plataformas y medios, a través de su selección, descarga, organización y difusión, mientras que las competencias de gestión individual se refieren a la capacidad para autogestionar el tiempo, recursos, la identidad, sentimientos y/o emociones.

A continuación, señalaremos cómo estas competencias transmedia están patentes tanto en el consumo y producción de los distintos entornos digitales en los que los jóvenes navegan en su día a día. 


\subsection{Cooptación de audiencias: oportunidades y riesgos}

La zona gris (Scolari, 2014) entre las industrias culturales y la esfera de la cultura participativa puede llevar aparejadas tanto oportunidades laborales como también riesgos. La atracción que genera el acceso sencillo, colectivo y gratuito (Jenkins, 2006) a las herramientas digitales es el mayor atractivo de estas nuevas profesiones digitales para las audiencias más jóvenes. Sin embargo, también puede llegar a existir en estos entornos digitales una cooptación de las audiencias, ya bien sea a través de la explotación del trabajo digital desde una perspectiva marxista (Fuchs, 2017) o a través de la atracción de los usuarios que aspiran a conseguir un trabajo creativo digital remunerado (Duffy, 2016; Zafra, 2017).

En por ello, que los adolescentes se encuentran una amplia variedad de redes sociales y plataformas digitales que les fascinan para poder alcanzar sus metas profesionales. La inexperiencia y la falta de conocimientos de los jóvenes sobre las relaciones económicas y de poder les pueden llevar a generar grandes expectativas a la hora de dedicarse a estas nuevas profesiones. Sin embargo, en la mayoría de los casos, se verán frustradas por no llegar a alcanzar las metas que ellos esperaban inicialmente. Es por ello, se convierte en una necesidad tender puentes entre las tensiones que emergen de esta cooptación de las audiencias, siendo imprescindible la redefinición de leyes, normas y roles entre industrias culturales y culturas participativas (Stehling et al., 2018).

A continuación, desglosamos las tres áreas principales que hemos detectado en este estudio como ámbitos aspiracionales de pseudoprofesionalización de los adolescentes españoles: los videojuegos, la escritura digital y redes sociales.

\section{2.a. Videojuegos competitivos y profesionales}

El primer escritor que abordó la definición de videojuegos de manera sistemática y seria fue Chris Crawford (1982), buscando describir sus principales características. Enumera así cuatro características que comparten todos ellos: representación, interacción, conflicto y 
seguridad. Los videojuegos son una extensión de mundos interactivos imaginarios, pero su característica más importante es la simulación (Wolf \& Perron, 2014). La razón por la que las personas juegan videojuegos es porque los consideran divertidos a causa de las experiencias que proporcionan. Es decir, la forma en que nos permiten actuar y cómo reaccionan ante nuestras acciones y elecciones (Rigby y Ryan, 2011). Un ejemplo de ello es, League of Legends, el juego multijugador en línea más jugado, con una base de jugadores mensuales promedio de 100 millones de personas (Guinness World Records, 2017), y uno de los juegos más utilizados en los eSports.

El término eSports es una abreviación de deportes electrónicos. También conocido como juego profesional (pro-gaming) o ciberatletismo, se refiere a los videojuegos competitivos y profesionales (Brenda, 2017). Los deportes electrónicos o juegos competitivos, se refieren a competiciones organizadas de videojuegos que ocurren principalmente entre jugadores profesionales (CGC Europe, 2015). Los jugadores, son personas que participan en las competiciones que realizan los organizadores. Actualmente, no solo ha aumentado el número de jugadores de alto nivel españoles que compiten nacional e internacionalmente, también las competiciones españolas atraen a jugadores extranjeros, fundamentalmente europeos (AEVI, 2018). Los equipos, son empresas que contratan jugadores con la finalidad de que participen en las competiciones en su representación. En España, y a nivel internacional destacan equipos como Fnatic, G2, Team Solo Mid o SK Telecom (AEVI, 2018).

Podemos decir que los eSports nacieron de la modernidad. Es decir, son un producto de la globalización, el neoliberalismo, los cambios sociales afectivos y la proliferación ubicua de las TIC. Como tales, sólo aparecieron recientemente debido a la existencia actual de las condiciones tecnológicas y sociológicas necesarias (Carter y Gibbs, 2013). Este nicho de mercado se basa en el aspecto competitivo de los videojuegos. El núcleo de eSports es como el de los deportes tradicionales. Las personas entrenan para mejorar sus habilidades, se crean clubs, se organizan torneos y los fanáticos disfrutan viendo su juego favorito jugar en los niveles más altos de rendimiento (Ströh, 2017). Los broadcasters son operadores que cuentan con plataformas 
para distribuir los contenidos audiovisuales en directo o bajo demanda y online. La plataforma líder del sector es Twitch, aunque también destacan YouTube, Mixer e incluso Facebook. En España, Movistar tiene un canal en su plataforma de televisión: Movistar Esports (AEVI, 2018).

Los equipos son la esencia de eSports. Algunos de los equipos más populares, como SK-Gaming, se han convertido ellos mismos en empresas, contratando jugadores de todo el mundo, controlando casinos (compuestos de viviendas e instalaciones de entrenamiento) y ganando grandes sumas de dinero de premios y patrocinadores. El amplio alcance de medios que generan estas simples sesiones de capacitación también es un activo valioso (CGC Europe, 2015). Los jugadores profesionales pueden dedicar varias horas al día a entrenar para perfeccionar sus habilidades. Algunos títulos de eSports pueden requerir más de 300 acciones por minuto, por lo que la multitarea es una necesidad y los juegos a menudo reciben actualizaciones que pueden alterar el juego (Shabir, 2017). La mayoría de los clubes eSports dirigen varios escuadrones, cada uno especializado en diferentes videojuegos (The Esports Observer, 2018).

La asistencia en vivo de un torneo o partido de eSports es similar a la de cualquier otro deporte clásico. Sin embargo, en este caso, las personas se reúnen para ver un partido de videojuegos (CGC Europe, 2015). Los eSports tienen una configuración de arena específica: en el centro es posible ver un escenario donde los jugadores profesionales se sentarán y jugarán un juego. CGC Europe (2015) detalla que cada jugador tiene un monitor, una computadora de juego, dispositivos de entrada, auriculares y un asiento. Si bien es común que los jugadores profesionales traigan sus propios equipos, estos están preconfigurados para evitar configuraciones de hardware injustas. Al igual que con los deportes regulares, los jugadores profesionales usan camisas con logotipo. Es importante tener en cuenta que, aunque las diversas organizaciones eSports (por ejemplo, ESL, MLG y KeSPA) funcionan de manera diferente, todas requieren que los equipos califiquen para ligas específicas y torneos mundiales (CGC Europe, 2015).

La gran mayoría de los ingresos que reciben todos los sectores de la industria de eSports proviene de patrocinadores. Debido a esto, los 
jugadores profesionales usan logotipos de marca en sus camisetas, usan productos de las marcas y crean contenido en redes sociales alrededor de la marca que los respalda. Las plataformas de transmisión asignan espacio de pantalla al patrocinador o incluso dedican canales completos a la marca. Los productores de eventos pueden mostrar el nombre del patrocinador durante los partidos y destacarlos, y, en el caso de empresas de hardware de juegos, crean eventos completos alrededor de sus últimas líneas de productos (The Esports Observer, 2018). A cambio de esto, los patrocinadores obtienen varias recompensas, como una imagen mejorada, exposición ante una gran audiencia (Shabir, 2017), y otros patrocinadores cuentan con equipos de marketing especializados en eSports (Ströh, 2017). Los patrocinadores suelen ser marcas que pagan a editores, organizadores de eventos y equipos a cambio de exhibir sus productos, logotipos o nombrar una competencia (SuperData, 2015).

\section{2.b. Escritura colaborativa y publicación profesional}

El desarrollo exponencial del software en la segunda mitad del siglo $\mathrm{XX}$ ha dado lugar a un cambio profundo en la forma en que consumimos y producimos contenidos culturales en el siglo XXI (Manovich, 2013). Estas transformaciones a nivel tecnológico cristalizan en un proceso que Jenkins (2006) denomina convergencia mediática donde los límites entre producción y consumo, entre industria y clientes, entre emisores y receptores, se desdibujan. De este modo, se da paso a un panorama en el que el capital social y cultural (y, en menor medida, también el económico) aparecen potencialmente redistribuidos $\mathrm{y}$, por tanto, se redefinen las reglas que rigen los diferentes sectores de la industria mediática. En los últimos años, esta ha debido gestionar, por un lado, la irrupción de consumidores híbridos, o prosumidores, a los que el desarrollo del software ha facilitado el acceso a las herramientas de producción y distribución, y por otro, formas alternativas de consumo que también operan sin intermediarios.

En el caso del sector editorial, el auge de la autopublicación (Furtado, 2012; Laquintano, 2010) constituye un síntoma visible de estas mutaciones. Los agentes y las casas editoriales, como apunta 
Romarshan Bold (2018), todavía detentan gran parte del capital cultural de la industria literaria, estableciendo las listas de autores y libros relevantes del momento, pero han visto disminuido su capital social por la expansión de plataformas de escritura colaborativa y autopublicación como Wattpad. Fundada en 2006 por Allen Lau y Ivan Yuen en Toronto (Canadá), Wattpad es actualmente la plataforma de escritura colaborativa más grande del mundo, con más de 65 millones de usuarios y 400 millones de historias subidas (Lunden, 2018). Los lectores pueden afiliarse a diversas subcomunidades de géneros literarios, y contribuyen a confeccionar las recomendaciones y ránkings de la plataforma a base de leer, compartir, comentar y votar sus historias favoritas; datos, todo ellos interpretados posteriormente por un algoritmo. Por otro lado, los jóvenes autores amateurs de Wattpad proponen géneros y temas alejados de las preferencias del público general (Tirocchi, 2018) (que, a menudo se ven reflejados en los ránkings de popularidad), o adaptan a las nuevas generaciones clásicos de la literatura como Jane Austen (Mirmohamadi, 2014).

Por su temática y estructura organizada en torno a subcomunidades de lectoescritura, Wattpad es digna heredera de las comunidades de fan fiction, un fenómeno de lectoescritura colaborativa surgido a finales de los años 60 en el que los fans reescriben las historias y personajes de la cultura de masas (Jenkins, 1992) y, que, como otras tantas manifestaciones de la cultura de los fans ha florecido gracias a la digitalización (Hellekson y Busse, 2014). No es de extrañar que las obras de fan fiction, cuenten con su propia parcela en Wattpad, siendo el grupo más numeroso de la plataforma con 93.115 usuarios (cifras de marzo de 2018. De hecho, fue After, un fanfic romántico basado en Harry Styles, el exlíder de la banda juvenil One Direction, el responsable de poner a Wattpad en el objetivo de las casas editoriales, para quienes la plataforma se ha convertido en un vivero donde encontrar futuros talentos literarios. Desde que publicara el primer capítulo de After en 2013, Anna Todd (alias de imaginator1D), se ha convertido en la gran historia de éxito de Wattpad. Apenas un año después, su obra ya estaba disponible en librerías previa modificación de los nombres de los protagonistas. En efecto, el fenómeno After ha terminado por institucionalizar las prácticas de crowdsourcing editorial (Ezaleila Mustafa y Mohd Adnan, 2017) que ya se pudieron observar 
en otros sonados trasvases fanfiction-publicación profesional anteriores, como la saga Cazadores de Sombras (Cassandra Clare) o Cincuenta Sombras de Grey (E.L. James) que se originaron en la web Fanfiction.net.

Si bien se trata de movimientos que benefician a los propios autores y a las casas editoriales, es interesante destacar que estas prácticas todavía despiertan el escepticismo de las comunidades de fan fiction, para quienes esta actividad tradicionalmente se ha realizado sin ningún ánimo lucro. En línea con los predicamentos de la gift economy (Hellekson, 2009; Coppa, 2017), la producción de fanfics se concibe como un obsequio a la comunidad con el fin de fortalecer lazos entre los participantes, reunidos en primer lugar por su pasión hacia un objeto de fandom común. Los fanfics poseen, por tanto, un valor inmaterial profundamente enraizado en el contexto y dinámicas de las comunidades en las que se producen. Por ello, según Jones (2014), los fans consideran una muestra de explotación laboral que sus pares autores retiren las obras de sus plataformas de distribución originales teniendo en cuenta que, en la mayoría de los casos, se nutren de las sugerencias de los lectores durante el proceso de escritura.

\section{2.c. Influencers en redes sociales}

El ascenso de escritores amateurs desconocidos a cotas de microcelebridad no se puede considerar un fenómeno aislado de tendencias similares en la publicidad, otro sector de la industria mediática seducido por el capital social que los prosumidores generan a su alrededor. Así, los planes de comunicación de marcas y fabricantes, independientemente del tamaño de su negocio, se han rediseñado para aprovechar al máximo la capacidad de persuasión de prescriptores afincados en redes sociales, cuya reputación y capacidad de influir en sus respectivas comunidades de seguidores, en ocasiones, los ha catapultado a la categoría de influencers (Segarra-Saavedra e Hidalgo-Martí, 2017; Ramos-Serrano y Herrero-Diz, 2016).

En España, un 85\% de los usuarios de redes sociales entre 16 y 65 años siguen a influencers (IAB, 2016). Algunos de estos líderes de opinión del nuevo milenio empezaron su andadura como consumidores que compartían sus experiencias y daban consejos acerca de una variedad 
de productos mediáticos y no mediáticos, como pueden ser videojuegos, series de televisión, libros, ropa, cosméticos o comida. Por medio de un estilo directo y cercano, y explotando una estética Do It Yourself, los influencers fueron conquistando terreno en esa particular economía de la atención (Marwick, 2013) representada por blogs, primero, y YouTube, Twitter e Instagram y YouTube. El alcance los influencers ha aumentado conforme lo hacía su contenido en las diferentes redes sociales y, con ello, su atractivo para las marcas. La publicidad digital tradicional no funciona (Díaz citado en Elorriaga-Illera y Monge Benito, 2018, Riboni, 2017), de ahí que las marcas pusieran el foco en géneros prescriptivos vernaculares del mundo influencer como el unboxing (literalmente, 'abrir el paquete y enseñar la mercancía'), la review ('reseña') o, sobre todo, el tutorial.

En su estudio del fenómeno de las beauty gurus en YouTube, GarcíaRapp (2016) analiza los mecanismos que los influencers ponen en marcha para desarrollar y mantener su popularidad online. Sus resultados alumbraron dos esferas de actividad bien diferenciadas vinculadas a distintos contenidos y objetivos que funcionan en paralelo. Por un lado, se encuentra una esfera comercial basada en la producción de tutoriales, en los que los protagonistas son los productos y la experiencia de las gurús, y sirven para impulsar el valor de mercado de estas influencers ante las marcas. Por otro lado, se sitúa la esfera de la comunidad construida alrededor de vlogs, o vídeos de contenido más personal, donde las gurús muestran pedazos de su vida cotidiana. De esta manera, refuerzan su valor social dentro del sistema de normas y jerarquías de la comunidad en la que participa, y legitiman su posición como influencer ante unos seguidores que premian su autenticidad y voluntad de hacerlos partícipes de su vida privada (Burgess \& Green, 2009; Lange, 2014; Martínez-Navarro y De Garcillán López Rúa, 2016; Elorriaga Illera y Monge Benito, 2018).

Se puede considerar que la estrategia de self-branding (Marwick, 2013) multiplataforma que llevan a cabo los influencers en todas las redes sociales se asienta sobre estas dos esferas. Ambas áreas interactúan en un frágil equilibrio determinado por el grado de identificación de los seguidores con los influencers, cuya narrativa de 'chicos corrientes' es el principal reclamo para la audiencia, que ve en ellos prescriptores de los 
que fiarse (Pérez Curiel y Luque Ortíz, 2018), o modelos de conducta a los que imitar (Pérez-Torres, Pastor-Ruiz y Abarrou-Ben-Boubaker, 2018). De ahí que conservar la autenticidad devenga en una misión clave de los influencers en un contexto de profundas contradicciones. En este sentido, Ardèvol y Márquez (2017) argumentan a propósito de los youtubers que, por un lado, la industria publicitaria y mediática se apropia de la imagen de estos influencers para vender sus productos, y por otro, los influencers más populares dependen cada vez más de la industria para mantener su actividad profesional a costa de ver mermada la complicidad con su audiencia.

\section{Diseño de la investigación}

\subsection{Objetivos del estudio}

El presente trabajo se deriva del proyecto $\mathrm{I}+\mathrm{D}+\mathrm{i}$ 'Transalfabetismos. Competencias transmedia y estrategias informales de aprendizaje de los adolescentes' (CSO2014-56250-R) que tiene como objetivo general identificar las competencias transmedia y las estrategias de aprendizaje informal desarrolladas por los adolescentes en sus prácticas mediáticas. En concreto, en este estudio nos centraremos en aquellas habilidades pertenecientes a las áreas denominadas como competencias de gestión de contenido, competencias de contexto mediático y tecnológico y competencias de ideología y ética con el objetivo específico de explorar los procesos incipientes de profesionalización aplicados por los adolescentes. Así, nos interesa responder a las siguientes preguntas de investigación vinculadas a prácticas profesionalizantes que, a su vez, dan cuenta del grado de adquisición de las tres competencias transmedia mencionadas:

1. ¿Qué ámbitos de profesionalización se pueden distinguir en sus prácticas mediáticas?

2. ¿Qué tipo de estrategias de profesionalización ejecutan cuando consumen y producen contenido?

3. ¿Hasta qué punto son conscientes del funcionamiento y política económica de las industrias mediáticas y culturales? 


\subsection{Muestra}

En este proyecto de investigación han participado un total de 237 jóvenes, con edades comprendidas entre 12 y 16 años, de cinco comunidades autónomas españolas (Andalucía, Cataluña, Comunidad de Madrid, Comunidad Valenciana y Galicia). El trabajo de campo se realizó entre los meses de marzo y septiembre de 2016. En concreto, se escogieron dos centros de Educación Secundaria por región, teniendo en cuenta las especificidades educativas de cada comunidad autónoma, haciendo especial hincapié en el tipo de financiación del centro (pública y/o concertada) y su ubicación (capital de provincia y/o poblaciones secundarias). Los alumnos participantes en esta investigación se encontraban matriculados en alguno de los tres cursos que se corresponden con el primer ciclo de Educación Secundaria Obligatoria (ESO).

\subsection{Metodología}

El enfoque metodológico que hemos llevado a cabo en esta investigación se ha realizado desde una perspectiva mixta de métodos cualitativos y cuantitativos. El proyecto ha integrado técnicas de recolección y análisis de datos de corte etnográfico, estadístico y textual ${ }^{4}$. Cabe reseñar que este estudio no ha sido diseñado para ser representativo del consumo mediático de los adolescentes españoles, sino que su objeto de análisis son los jóvenes más productivos y creativos en el ámbito informal, ya que a partir de ellos se detectarán las competencias transmedia y estrategias informales de aprendizaje para crear actividades didácticas en el ámbito de la educación formal. Por tanto, para este artículo nos hemos centrado principalmente en los datos cualitativos de la investigación con el fin de inferir las tendencias de consumo y prácticas mediáticas principales de los adolescentes españoles. En este sentido, somos conscientes que las prácticas mediáticas a nivel pseudo-profesional no son mayoritarias, ni tanto para las audiencias prosumidoras jóvenes ni para las del ámbito adulto,

\footnotetext{
${ }^{4}$ El equipo de investigación llevó a cabo un exhaustivo protocolo de protección de datos y anonimización de los menores que iban a formar parte del estudio y que contó con el visto bueno de la Comisión Institucional de Revisión Ética de Proyectos de la Universidad Pompeu Fabra - Barcelona.
} 
aunque consideramos que es pertinente profundizar en el tipo de prácticas productivas de estos usuarios dentro del actual ecosistema transmediático.

Una vez seleccionadas las escuelas por parte de cada equipo investigador, se procedió a realizar una serie de cuestionarios a los jóvenes, con el objetivo de conocer a modo exploratorio cuáles eran sus intereses tanto a nivel de consumo como de producción mediática, poniendo el énfasis si se trataban del ámbito videolúdico o el de la cultura participativa (redes sociales, fan fiction, etc.).

Llegados a este punto, los investigadores seleccionaron a los jóvenes partiendo de sus intereses en dos talleres: uno sobre videojuegos y el otro sobre cultura participativa. Ambos talleres tuvieron una duración de dos sesiones de dos horas cada uno y fueron grabados en vídeo. En total, se realizaron dos talleres por escuela, es decir, 4 talleres por comunidad autónoma (8 sesiones por región). Durante los talleres, los investigadores detectaron a los jóvenes más participativos y que expresaban un mayor conocimiento de aspectos relativos a la producción y consumos mediáticos.

Figura 1: Esquema de la organización para la sección de los adolescentes que fueron entrevistados para el proyecto de investigación.

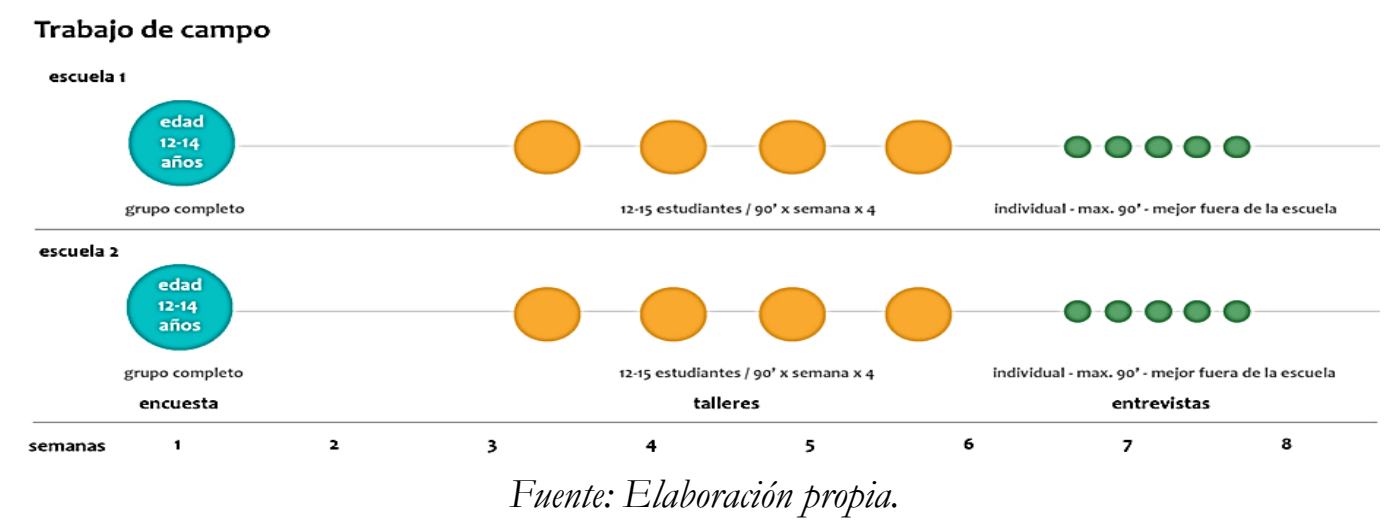

Estos jóvenes fueron invitados a participar en la última fase del trabajo de campo que consistió en realizar entrevistas en profundidad con el objetivo de ahondar en las temáticas que se habían abordado durante los talleres. En la figura 1 se puede ver cuál fue el proceso de selección de los participantes desde el grupo general de la clase hasta la entrevista individual 
Asimismo, como actividad extraordinaria y voluntaria, los jóvenes que iban a ser entrevistados recibieron un diario mediático en el que escribirían su dieta mediática durante una semana. En concreto, se recopilaron 15 de Andalucía, 17 de Cataluña, 16 de la Comunidad de Madrid y 16 de la Comunidad de Madrid. En relación a las entrevistas, se llevaron a cabo un total de 99: 18 en Andalucía, 22 en Cataluña, 20 en la Comunidad Valenciana, 19 en la Comunidad de Madrid y 20 en Galicia.

Figura 2: Árbol de nodos global con los resultados sobre competencias transmedia y estrategias de aprendizaje informal en el contexto español.

\begin{tabular}{|l|r|r|}
\hline Name & References \\
\hline 7. Competencias transmedia & 197 & 10115 \\
\hline 1. Competencias productivas & 107 & 1035 \\
\hline 2. Competencias de gestión & 173 & 3891 \\
\hline 3. Competencias performativas & 122 & 1187 \\
\hline 8. Estrategias informales de aprendizaje & 65 & 642 \\
\hline 4. Competencias de contexto mediático y tecnológico & 98 & 585 \\
\hline 8. Competencias narrativas & 82 & 387 \\
\hline 8.1. Aprendizaje a través de la práctica & 34 & 91 \\
\hline 8.2. Aprendizaje por resolución de problemas & 152 & 2297 \\
\hline 8.3. Aprendizaje por imitación & 119 & 1470 \\
\hline 8. Otros & 113 & 841 \\
\hline 8.4. Aprendizaje a través del juego & 49 & 113 \\
\hline 8.5. Aprendizaje por evaluación & 63 & 207 \\
\hline 8.6. Aprendizaje a través de la enseñanza & 17 & 36 \\
\hline 8.7. Aprendizaje a través de la estimulación de otros - aprendizaje dirigido & 5 & 5 \\
\hline 8.8. Otras cuestiones relacionadas con las estrategias informales de aprendizaje & 11 & 18 \\
\hline
\end{tabular}

Fuente: Elaboración propia.

La última parte del trabajo de análisis se centró en la creación de una tabla de análisis textual de las producciones realizadas durante los talleres con el objetivo de detectar las competencias transmedia presentes en dichos textos.

Una vez recopilados los datos de los talleres y de las entrevistas en profundidad, se procedió a la transcripción de los audios y a su posterior análisis de categorías con la ayuda del software de análisis de 
datos cualitativo Nvivo Pro 11 for Teams. Una primera ronda de codificación se centró en cuestiones descriptivas mientras que la segunda ronda se basó en la detección y análisis de las competencias transmedia y estrategias informales de aprendizaje. Finalmente, la tercera ronda de codificación se destinó a la integración de los datos de las cinco comunidades autónomas creándose así un árbol de nodos global de competencias transmedia y estrategias de aprendizaje informal.

\section{Resultados}

A lo largo de este estudio se detectaron tres grandes ámbitos de profesionalización entre el conjunto de prácticas mediáticas que llevan a cabo los adolescentes de la muestra: videojuegos, lectura y escritura creativa, y redes sociales. Asimismo, durante el proceso de análisis cualitativo de la investigación, se han detectado dos aspectos fundamentales que no se habían planteado inicialmente en las preguntas de investigación. El primero hace referencia a las cuestiones de consumo y producción de los adolescentes con respecto al género, y el segundo a la utilización de plataformas como YouTube para la producción de contenidos audiovisuales transversales a las tres áreas de profesionalización de los adolescentes.

\subsection{Consumo y producción diferenciados por género}

Cada ámbito se caracteriza por exhibir una tendencia clara con respecto al género de los adolescentes que declararon realizar actividades relacionadas con dicho ámbito. En primer lugar, distinguimos el área de videojuegos con una mayor presencia masculina que femenina, lo cual se une a posicionamientos recientes en esta línea. Según una encuesta realizada en 2015 por la International Game Developers Association, el número de desarrolladoras de videojuegos es tan sólo de un $21 \%$ lo que muestra una alta presencia masculina. Por tanto, todavía no podemos decir que exista un equilibrio de género. Sigue habiendo brecha a favor de los hombres en cuanto a la tasa de empleo, ocupación, cargos de responsabilidad, etc. Esta disparidad se presenta también en el caso español. El sector incrementó su plantilla de 2015 a 2016 un 22\%, alcanzando los 5.440 profesionales. La industria 
española consiguió en 2015 una plantilla de 4.460 profesionales, de los cuales solamente el 17\% de estos son féminas, dato que contrasta con la alta representatividad de las mujeres (45\%) dentro del cómputo global de jugadores españoles (DEV, 2016).

Tabla 1: Jóvenes entrevistados que conocen cómo es $y / 0$ están en un proceso de profesionalización.

\begin{tabular}{|l|l|l|l|}
\hline $\begin{array}{c}|c| \\
\begin{array}{c}\text { Ámbito de } \\
\text { profesionalización en } \\
\text { entornos digitales }\end{array}\end{array}$ & \multicolumn{1}{|c|}{$\begin{array}{c}\text { Número de } \\
\text { jóvenes } \\
\text { entrevistados }\end{array}$} & Chicas & Chicos \\
\hline $\begin{array}{l}\text { Videojuegos - } \\
\text { eSports }\end{array}$ & 18 & $\begin{array}{l}5 \\
(27,78 \%)\end{array}$ & $\begin{array}{l}13 \\
(72,22 \%)\end{array}$ \\
\hline $\begin{array}{l}\text { Lectura y escritura creativa - } \\
\text { Wattpad }\end{array}$ & 15 & $\begin{array}{l}14 \\
(93,33 \%)\end{array}$ & $1(6,66 \%)$ \\
\hline Redes sociales & 40 & $\begin{array}{l}25 \\
(62,5 \%)\end{array}$ & $\begin{array}{l}15 \\
(375 \%)\end{array}$ \\
\hline
\end{tabular}

Fuente: Elaboración propia.

En segundo lugar, destacamos un área de lectura y escritura creativa con un foco de actividad centrado en Wattpad y, que, por el contrario, se revela como una práctica ligada a la esfera femenina en consonancia con estudios anteriores sobre escritura en el seno de las comunidades de fans (Hellekson, 2009). En tercer lugar, se encuentra el ámbito relacionado con las redes sociales, donde volvemos a encontrar una mayor tendencia de perfiles femeninos cuya actividad se aglutina en torno a Instagram y You'Tube.

En lo que respecta a la tabla, los resultados se han obtenido a través del análisis de las 99 entrevistas que se han realizado entre las cinco comunidades autónomas, si bien la cifra global de entrevistas (73) no se corresponde a esa cantidad. La razón de este desajuste ha sido la detección de los criterios de selección en relación a las preguntas de investigación planteadas al inicio de este artículo, centradas en exclusiva en los procesos de profesionalización de los jóvenes en entornos digitales. 


\subsection{Los contenidos audiovisuales como eje transversal para la profesionalización}

En paralelo a estos ámbitos, es interesante reseñar una tendencia común a todos ellos relacionada con el consumo y producción de vídeo articulada, de nuevo, alrededor de YouTube, y en la que conviven diversas subáreas según contenido (gameplays y transmisiones de partidas en directos; libros y tutoriales, principalmente). Así, se puede afirmar que, gracias a esta variedad temática, YouTube aparece como una herramienta transversal a las prácticas adscritas a los tres ámbitos de profesionalización, si bien su presencia varía de uno a otro.

Figura 3: Las 100 palabras más citadas por los entrevistados en relación a sus prácticas mediáticas digitales sobre escritura, fotografía, vídeo y videojuegos.

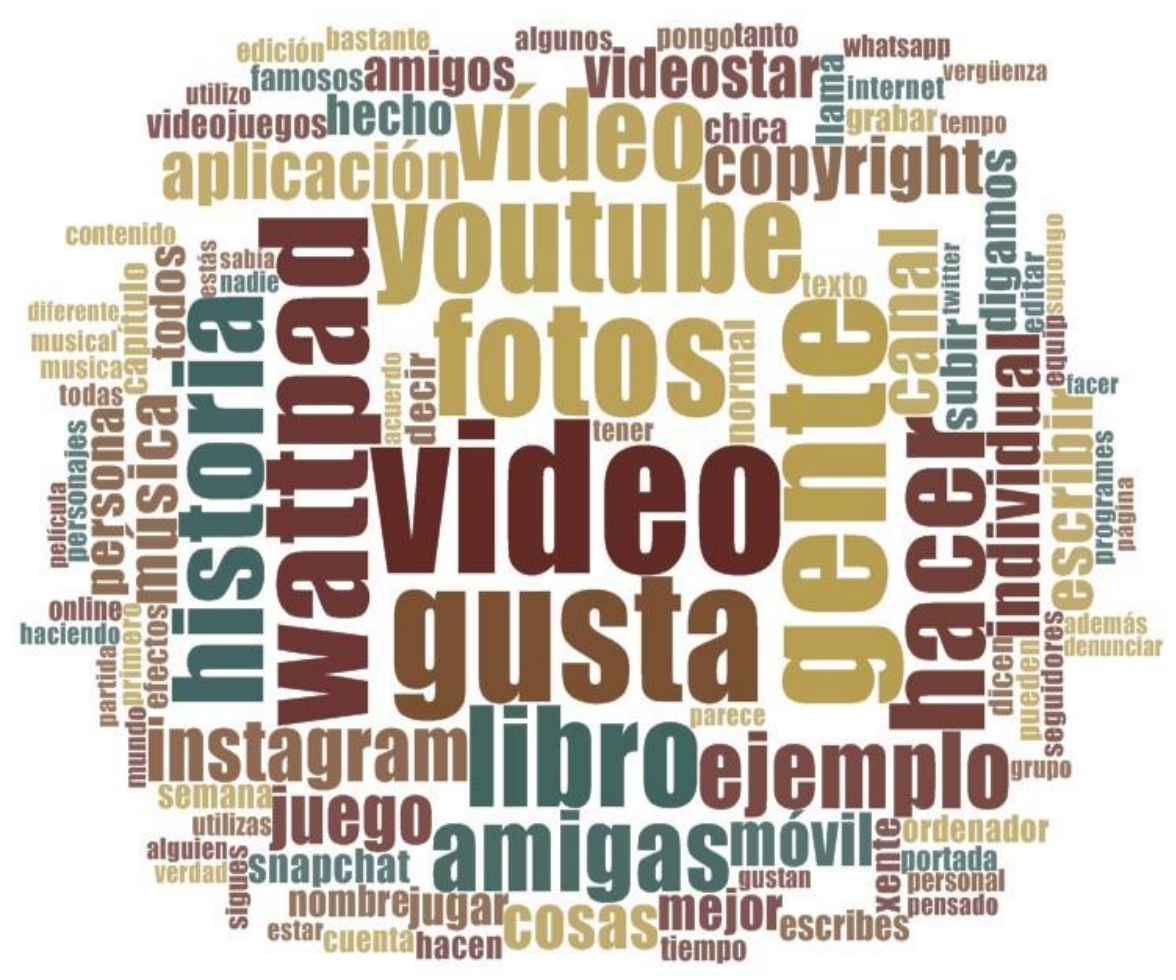

Fuente: Elaboración propia a través del software Nvivo 11 Pro for Teams.

La presencia de los contenidos audiovisuales es claramente destacable en el ámbito de los videojuegos y en el de los tutoriales como escaparate de los conocimientos, habilidades y marca personal de los jóvenes, mientras que en los contenidos escritos en Wattpad, la presencia de los vídeos se circunscribe esencialmente a presentar booktrailers. 
A continuación, explicaremos las estrategias de profesionalización aplicadas por los adolescentes, así como sus percepciones acerca de la industria mediática cultural dentro de cada uno de los tres ámbitos de profesionalización destacados

\subsection{Videojuegos: del jugador casual al profesional}

Como hemos apuntado en el apartado 2.2.1. del artículo, el sector de los videojuegos está planteando nuevas oportunidades laborales. La primera de ella se centra en la propia creación de los juegos, entre otras áreas a través del desarrollo (programación), diseño de personajes, escritura de guiones, dirección, producción o distribución de los productos.

En este sentido, se percibe una clara brecha de género en la aspiración sobre qué futuras profesionales quieren desarrollar algunos de los jóvenes entrevistados en este estudio, ya que las féminas se decantan más por las profesiones relacionadas con los aspectos artísticos y de diseño de arte en los videojuegos, mientras que los chicos prefieren las profesiones que están enfocadas a la ingeniería y a la programación informática.

Por una parte, María (15 años, Comunidad Valenciana) destaca que le gustaría dedicarse al diseño a través de la rama de Publicidad y Relaciones Públicas mientras que Macarena (14 años, Cataluña) quiere trabajar en la industria del videojuego creando historias para los juegos, pero no en la parte de desarrollo.

Por otra parte, nos encontramos las aspiraciones de los varones. Así, nos encontramos los casos de Manuel (14 años, Galicia) subraya que le encantaría ser desarrollador de software para videojuegos. En relación a la programación, hemos podido detectar algún caso de protoprofesionalización de estos adolescentes que han llegado incluso a cobrar dinero por sus servicios y a trabajar de modo colaborativo. Ese es el caso de Juan (13 años, Comunidad Valenciana) quien señala que tiene una página web, que creó junto a un compañero que poseía los conocimientos de los que él carecía. "Creamos una web en la que creamos contenido y lo compartimos con otros. He llegado a cobrar 
dinero por las extensiones que creamos para descargar videojuegos. Ofrecemos servicios a los usuarios y mantenemos la web a través de una pequeña inversión que obtenemos de la propia página web" destaca Juan. De hecho, añade que realiza este tipo de contenido pensando en su futuro laboral en el sector informático.

El segundo ámbito de profesionalización relacionado con los videojuegos es el de los eSports. Llegados a este punto, hemos detectado en el estudio cuatro tipos de jóvenes en relación a los eSports y su conexión con plataformas audiovisuales como YouTube o Twitch:

1) Jóvenes que no conocen cómo es esta industria cultural.

2) Adolescentes que conocen qué son los eSports porque son consumidores de deportes electrónicos a través de torneos y/o retransmisiones en directo.

3) Jóvenes que saben cómo es la industria de los eSports, ya que tienen amigos o compañeros que forman parte de la misma como jugadores que quieren profesionalizarse, y por tanto, reciben inputs sobre el negocio por fuentes secundarias.

4) Participantes en el estudio que conocen cómo es la industria de los eSports ya que son partícipes de la misma como jugadores que intentan profesionalizarse.

En relación al primer grupo, muchos jóvenes del estudio tan sólo reconocen que juegan a videojuegos online, principalmente junto a amigos o compañeros, pero desconocen en qué consisten los eSports como industria cultural. La situación es diferente en el caso del segundo grupo de jóvenes detectados. Por ejemplo, Luis (13 años, Galicia) señala que le gusta consumir vídeos de partidas y personajes de los videojuegos Clash Royale y Clash of Clans. "Me hacen gracia estos vídeos, siempre me han gustado. Y luego hacen también torneos que les dan dinero por ganar" subraya Luis.

En el caso de los grupos tres y cuatro que hemos analizado, el conocimiento de la industria cultural de los videojuegos electrónicos es 
superior, por tanto, estos adolescentes tienen más desarrollada su capacidad de análisis de las industrias socioculturales, tal y como apuntábamos en el apartado 2.1. en relación a un mayor grado de desarrollo de sus competencias de contexto mediático y tecnológico. No obstante, este conocimiento se suele limitar a cuestiones económicas y no laborales y/o legislativas, por lo que muchos de ellos no son conscientes de la cooptación que las industrias mediáticas obtienen de su trabajo. Así, destacamos el ejemplo de Salomón (14 años, Cataluña) que tiene un canal de YouTube en el que graba sus partidas cuando juega a nivel profesional en Call of Duty. "Él todavía no gana dinero por sus vídeos, pero muchos profesionales ganan 4.000 euros al mes porque tienen más de un millón de visitas en su canal de YouTube [...]. Esto beneficia a YouTube porque si no tuvieran canales de este tipo de youtubers conseguirían muchos menos usuarios en la plataforma". Por tanto, este adolescente enfatiza en los beneficios económicos que pueden reportar jugadores profesionales a través de sus vídeos revierten también en otras empresas que están estrechamente ligadas a los eSports, como es el caso de YouTube.

Un caso similar lo encontramos también en Damián (14 años, Cataluña) que tiene un compañero del colegio con 600 seguidores en su canal de YouTube y recibe dinero tanto de la plataforma como a través de los patrocinadores que ha conseguido gracias a sus habilidades como jugador del videojuego Smite. De hecho, Damián está intentando imitar a su compañero a través del juego con títulos como Smite, Agario y Call of Duty y creando vídeos similares con el objetivo de profesionalizarse en este ámbito. Por otra parte, nos encontramos casos como el de Nayim (15 años, Cataluña) que realiza vídeos de sus partidas en Minecraft para YouTube, pero que, aunque quiere ser youtuber, cree que, si no es el mejor, no conseguirá recibir ingresos suficientes para poder dedicarse a ello a nivel profesional.

Este tipo de prácticas de los adolescentes entran en contradicción con los mensajes que reciben en la escuela sobre la dedicación profesional a los nuevos entornos digitales. En este sentido, Macarena (14 años, Cataluña) critica que sus profesores resten valor a estas nuevas profesiones porque consideran que son una "pérdida de tiempo". "Los profesores dicen que no te vas a ganar mucho la vida haciendo esto. 
[...] Que esto sería como en plan, algo secundario, o sea, que no te tienes que dedicar a esto sino a algo mejor y luego ya si quieres pues haces esto por diversión o por entretener", subraya esta joven.

Son pocos los jóvenes que llegan al mayor grado de profesionalización en el ámbito de los eSports. Durante este estudio hemos detectado que tan solo uno de los participantes ha conseguido acceder al circuito de las competiciones y torneos. Se trata de Rafael (14 años, Cataluña), quien suele jugar a League of Legends, y asegura que llegar a este nivel es muy complicado porque hay que practicar muchas horas. "Cuando llegas a lo más alto del ránking individual ya comienzas a jugar profesionalmente [...]. Esto es como el fútbol. Hay equipos, que fichan a estos jugadores, y estos teams comienzan a competir entre ellos, y lo más importante es que jueguen entre equipos de diferentes países. [...] Luego los torneos se retransmiten en directo, y me gusta ver a los coreanos para aprender porque son los mejores", explica Rafael.

Por tanto, podemos señalar que, a pesar del fácil y económico acceso a las plataformas de videojuegos y YouTube, la profesionalización de los adolescentes en este ámbito es una práctica minoritaria, aunque cuenta con una amplia aceptación por su parte.

\subsection{Escritura en Wattpad: entre el oficio social y el oficio solitario}

Tal y como hemos adelantado en el apartado 2.2.1., las prácticas de lectoescritura de los adolescentes de la muestra pronto alumbraron un común denominador que, en vista del análisis, podemos calificar de hegemónico. Wattpad no sólo es el vehículo básico que vertebra hábitos lectores, experimentos literarios y socialización entre iguales alrededor de unos intereses comunes, sino que emerge como un probable trampolín para entrar en el competitivo mundo editorial. Por ejemplo, Nerea, una alumna de 15 años de la Comunidad de Madrid, ha escrito cuatro capítulos de un 'libro' (como se conocen popularmente las historias en Wattpad) de misterio que acumulaban 1.200 lecturas en marzo de 2016. No duda en relacionar su iniciación como escritora en Wattpad después de que una amiga le hubiera recomendado leer "un libro muy famoso". Se trataba, por supuesto, de After. "Es una novela que tiene seis libros y que cada libro es muy 
grande, y que esa novela la autora empezó por Wattpad y se fue haciendo famosa; tenía ya millones de leídos y unas editoriales decidieron imprimirlo, hablar con ella e imprimirlo [...] Y ahora está en todos los idiomas y en todos los países", explica Nerea. De sus continuas referencias a la "fama" se desprende una clara asociación entre Wattpad y canales de promoción para jóvenes autores amateurs que deseen dar el salto a la arena profesional.

Aunque Nerea, al igual que Lorena (15 años, Comunidad Valenciana) dan muestras de estar al tanto de las oportunidades ofrece Wattpad para los escritores amateurs, no se planea convertir su afición en un modo de vida. La motivación central para escribir es el entretenimiento y, sobre todo, el reconocimiento social de la comunidad de lectores. Observamos una actitud similar en Esther (15 años, Cataluña), autora de historia donde se combina el romance con el acoso escolar, un tema recurrente entre algunas de las adolescentes de la muestra. Ante el dilema de continuar algunas de las ficciones que tiene sin acabar, siempre acaba decantándose por su obra más popular que rondaba las 6.400 lecturas en marzo de 2016: “Tengo gente que me dice 'síguela' o 'me gusta mucho'. Como que me animan... Me pongo más con esta porque sé que hay gente que la lee, y que comentan y que votan y como en las otras no tengo aún a nadie pues... Me gusta que comenten porque así puedo saber las críticas". El feedback de los lectores emerge, por tanto, como una cuestión clave en nuestro grupo de escritoras. Si alcanzan cierta popularidad, incluso pueden ver sus libros traducidos en distintos idiomas. Según relata, Abraham (15 años), hijo de una filóloga, y que dio sus primeros pasos en Wattpad gracias a Esther, son los propios lectores los encargados de traducir las historias. Esta tarea se une a la labor de edición que tradicionalmente desarrollan algunos lectores (beta-reading) con algunos autores, y refuerza una atmósfera de trabajo colaborativo dentro de la plataforma.

Para atraer lectores y fomentar la interacción con ellos, las adolescentes ponen en marcha una serie de mecanismos promocionales. Además de preocuparse por cuidar la ortografía, evitar los párrafos de narración excesivamente largos, e introducir cambios a petición de beta-readers y lectores, las escritoras recurren a estrategias paratextuales como la creación de portadas que acompañen a los libros, como si se trataran de 
libros físicos en un escaparate. Isabel, una lectora de 14 años de Cataluña, señala su preferencia por las historias que tienen carátulas coloridas porque le parecen más atractivas en un primer momento. También descubre una microestructura dentro de Wattpad dedicada a la oferta y demanda de portadas que opera de forma paralela a Covers, la aplicación oficial para crear portadas de Wattpad ${ }^{5}$.

De este modo, existen cuentas de usuarios que, en lugar de mostrar libros, ofrecen estos servicios a los escritores: "Tú entras allí, explicas tu historia, pides tu portada y te la hacen. Luego, lo único que tienes que hacer es escribir debajo 'portada hecha' por tal usuario... Tienes que darle un poco de propaganda a cambio". Y de las portadas, pasamos a los tráilers, un elemento de promoción en boga en la industria editorial como herramienta para hacer frente a las transformaciones en el consumo de libros propiciadas por la irrupción y desarrollo de la tecnología digital (Tabernero Sala, 2013). "Si este libro se hiciera en película, pues, ¿quién me gustaría que representase a cada persona? Entonces ella [Esther] a cada personaje de la historia le ha dado un actor y también ha hecho el tráiler, que está en YouTube", indica Abraham. Así, los tráilers, realizados a partir de imágenes procedentes de películas y series de televisión, parecen guardar una íntima relación con otro mecanismo de promoción dentro de Wattpad: el reparto, que a menudo aparece detallado en todos los capítulos de una historia y que sirve de anclaje con los referentes mediáticos de los lectores y escritores. En este caso, el reparto de la historia escrita por Isabel estaba formado, en su mayoría por actores de las series adolescentes Teen Wolf y Pretty Little Liars. Como en el caso de las portadas, los tráilers también cuentan con su propio mercado en el contexto de Wattpad y testimonian la función básica y transversal que desempeña YouTube en las actividades mediáticas de los adolescentes.

Como contrapunto a esta celebración de una escritura social, fluida e interactiva es importante resaltar posturas minoritarias, pero realmente interesantes en las adolescentes escritoras que están más cerca de paradigmas editoriales profesionales. Por ejemplo, Natalia de 15 años (Cataluña), se muestra escéptica ante la comunidad de escritores y

\footnotetext{
${ }^{5}$ https://support.wattpad.com/hc/en-us/articles/115003126706-Covers-App Recuperado el 17 de mayo de 2018.
} 
lectores de Wattpad, aunque comenta haber empezado una historia en la plataforma porque la convencieron sus amigos y, fundamentalmente, porque quiere darse a conocer. A diferencia de sus compañeros, su sueño es "poder publicar un libro real" y que algún día lo adapten al cine. Cinéfila, ávida escritora desde los 11 años de edad, y con unos padres aficionados a la lectura, asegura haber escrito un total de 30 obras sin publicar con el procesador de textos Word. Gran parte de su recelo se basa en lo que ella considera "postureo", un aparentar ser o "moda" que, bajo su punto de vista, es el verdadero motivo que atrae a los jóvenes a Wattpad, y "no el hecho de escribir bien, de mejorar escribiendo".

En su razonamiento, Natalia afirma temer la desaparición del libro físico y ensalza la figura del autor individual, responsable de la obra original y última fuente de autoridad frente al lector. Todo ello invoca una ideología centrada en el autor sobre la que ha descansado el negocio editorial desde finales del siglo XVIII (Ezell, 2003). Buscando diferenciarse del resto de sus compañeros, se opone a eventos organizados dentro de la plataforma como los Premios Wattys, o al concepto de escritura colaborativa que da sentido a Wattpad: "Escribir una historia es una cosa tuya, solitaria, y aunque la gente no le guste estar solos escribiendo y haciendo las cosas, nunca te vas a dedicar bien a escribir si lo haces en pareja o con alguien más [...] Estás compartiendo una misma aplicación junto a miles y miles de personas que tal vez no escriban del todo bien". Escribir, pues, se concibe como una actividad individual, reservada a unos pocos elegidos, ligada a la cultura del esfuerzo y al mito de la originalidad autoral ("Quiero que todo sea $100 \%$, todo, personajes, contextos...”). Es decir, una práctica que se encontraría en las antípodas de las posiciones más lúdicodemocráticas exhibidas por las lectoras y escritoras de Wattpad del presente estudio.

También conviene resaltar como contraste que, exceptuando la opinión crítica de Natalia contra el modelo de lectoescritura social propuesto por Wattpad, prácticamente ninguno de los lectores y escritores de la muestra realizó una reflexión crítica sobre las implicaciones que podría tener el modelo de negocio de la plataforma sobre sus derechos como usuarios. No obstante, algunos muestran una 
cierta preocupación por proteger la propiedad intelectual del contenido que se comparten para evitar casos de plagios, sobre todo, cuando se trata de historias populares.

\subsection{Aspirantes a influencers en Instagram y YouTube}

En el punto 2.2.1., adelantamos que las redes sociales habían emergido como el tercer gran ámbito de profesionalización. En concreto, Instagram y YouTube se perfilan como las plataformas dominantes. Los adolescentes de la muestra cultivan prácticas enfocadas a incrementar la popularidad $\mathrm{y}$, sobre todo, a construir una marca personal online (self-branding). Sin embargo, conviene apuntar que no todos desarrollan su estrategia de forma consciente ni teniendo en cuenta el contexto socioeconómico de cada red social, por lo que, de nuevo, recalcamos el carácter excepcional de los ejemplos analizados.

Una de las adolescentes que ha interiorizado la economía de la atención en Instagram es Marisa (Comunidad Valenciana), que, a sus 12 años, se apoya en su grupo de amigos" para ganar popularidad": "Cuando alguno sube una foto a las redes sociales, envía un enlace a través del grupo de WhatsApp que compartimos pidiendo likes o que comenten". La importancia de los likes y comentarios es precisamente lo que lleva a una compañera, Ariadna (13 años), a recurrir a una estrategia de self-branding tan extendida como dirigirse directamente a los seguidores para, en este caso, promover la participación en su cuenta. "Por ejemplo, hago una foto de algo de ropa que me he comprado, la subo con una pregunta diciendo '¿te gusta lo que me he comprado?'. También me gustan los comentarios. Como la gente no me puede ver siempre en persona pues así me pueden ver por el móvil". Nótese, además, como Ariadna concibe su identidad en Instagram como una extensión mediada de su identidad offline que le permite no solo mostrarse ante su círculo más cercano sino también una red de seguidores desconocidos. En paralelo a su cuenta personal gestiona otra con su mejor amiga en la que comparte vídeos y tutoriales propios, así como contenidos de sus seguidores. Otra decisión, la de promover contenidos de los seguidores, con la que los influencers buscan fortalecer su marca personal. 
Los youtubers tampoco son extraños a las tácticas de self-branding que les lleva a compartir contenido más allá de su plataforma inicial. Si Instagram es la cuenta que suele acompañar a las beauty gurus, Twitter destaca como apoyo para los gamers. Vicent (14 años, Comunidad Valenciana) suele notificar a seguidores en Twitter siempre que sube alguna partida de Call Of Duty o un vídeo de retos a su canal de YouTube que acumula 300 suscriptores. En lo referente a su ritmo de publicación este adolescente indica que sube videos "cuando le apetece, cada dos días, una semana, cada día". En este sentido, la producción de Vicent se explicaría por la flexibilidad con la que aborda tanto su faceta como youtuber como el contenido que sube a su canal. No así es el punto de punto de vista de Romina (12 años, Comunidad Valenciana), cuya "vocación" es tener un canal de YouTube en el futuro. Sin embargo, "no tengo uno porque tengo que centrarme en los estudios", apostilla. Se podría deducir que las actitudes dispares de Vicent y Romina ejemplifican dos concepciones diferentes de ser o llegar a ser youtuber. Una, alejada de expectativas formación tradicionales y otra, donde ser youtuber se presenta como una clara opción laboral, pero, eso sí, supeditada a la consecución de unos objetivos curriculares.

La preocupación por cultivar una marca personal también se hace patente el cuidado que los adolescentes ponen a la hora de producir el contenido que después suben a las redes sociales. Adele, una adolescente de 14 años de Galicia, utiliza Instagram para difundir los vídeos musicales que crea con la app Video Star. Comenzó como seguidora de algunas cuentas especializadas en estos vídeos hasta que decidió contactar con algunas cuentas colectivas para subir sus 'videostars'. Pero se encontró un problema: "No me acababan de gustar [...] Había una niña más pequeña que yo, que los subía, pero los subía mal. Yo quiero calidad entre comillas". Su idea de un 'videostar' de calidad está directamente vinculada al número de efectos utilizados en los vídeos y a la capacidad de compra de quien lo produce: "Hay quienes no tienen [efectos] de pago y quedan cutres".

Adele es una aspirante a influencer cuya cuenta de 'videostars' en Instagram ya alcanzaba los 100 seguidores el primer día después de anunciarse entre los seguidores de cuentas famosas: "Le dije a la gente 
que me empezaran a seguir y me siguieron". Sus expectativas pasan porque sus 554 seguidores (abril de 2016) alcancen los diez mil como mínimo para poder crear un canal de YouTube y dirigir hasta allí a sus seguidores en Instagram. No obstante, reconoce que YouTube no forma parte de los recursos preferidos de los creadores de 'videostars' para compartir contenido. "YouTube es más otro tipo de vídeos", sostiene. Adele demuestra así un conocimiento de las reglas su propia comunidad de práctica, pero también de YouTube como ventana básicos de promoción de contenido de los influencers, si bien su relevancia varía de comunidad a comunidad.

De nuevo, observamos que los aspirantes a influencers de la muestra todavía no expanden su conocimiento más allá de estrategias para posicionar su imagen y contenido en la economía de la atención o, como ya indicamos en el apartado 4.3. a propósito de los gamers y YouTube, conocimientos superficiales acerca del modelo de negocio de las redes sociales.

\section{Discusión y conclusiones}

Tal y como hemos analizado a lo largo del artículo, muchos adolescentes españoles son conscientes de las nuevas oportunidades que están surgiendo gracias al auge de las nuevas industrias culturales digitales. Sin embargo, son pocos los que cuentan con las competencias necesarias para desarrollar con éxito una carrera profesional en el ámbito de los videojuegos (desarrollo de juegos o a través de los eSports), la escritura creativa o las redes sociales como prescriptores de contenidos. En relación a dichas competencias, nos referimos principalmente al análisis crítico a nivel socio-económico de las empresas que forman parte de este ecosistema mediático. Si bien muchos son conscientes de que existen intereses, por ejemplo, por parte de empresas como YouTube en la industria videolúdica, la tendencia observada en el análisis cualitativo de los datos, apunta a una minoría conocedora de que, gracias a su trabajo digital, dichas compañías consiguen beneficios económicos. Es en esta cuestión donde consideramos que es necesaria una mayor comprensión de los intereses empresariales y es donde el alfabetismo transmedia debe jugar un rol crucial. Dicho alfabetismo debería hacerse extensible también a 
los progenitores y profesores, ya que dotarles a ellos de herramientas para analizar estos nuevos entornos digitales les podrá acercar a las prácticas que realizan cada día los adolescentes.

En este sentido, es destacable reseñar que muchos jóvenes realizan sus actividades digitales no pensando en su futuro laboral sino por mero entretenimiento o para posicionar su marca personal. No creemos que este aspecto sea algo negativo, sino que gracias a sus prácticas mediáticas pueden adquirir otro nuevo tipo de competencias y conocimientos que muchas veces no se trabajan en el ámbito de la educación formal y reglada. Aunque coincidimos con Elorriaga Illera y Monge Benito (2018) en afirmar que la calidad estética de los contenidos no es un determinante para la profesionalización de los prosumidores, sí consideramos necesario entrenar, tanto dentro como fuera de los entornos reglados, otro tipo de competencias no productivas que preparen a los prosumidores en su transición de amateurs anónimos a microcelebridades generadoras de negocio y atención. En este sentido, el análisis crítico de la industria y el desarrollo de herramientas personales para navegar estos nuevos escenarios debería estar en la base de la formación, sobre todo, a la vista de casos de estrellas de YouTube que han sufrido crisis emocionales, o de imagen a consecuencia de su exposición mediática.

Otro de los aspectos fundamentales que emergen del trabajo digital de los adolescentes es la colaboración entre pares. Así, el beta-reading o la creación de productos teniendo en cuenta las mejores habilidades de cada joven son algunas de las prácticas más utilizadas. El acceso en red en tiempo real y gratuito a las nuevas plataformas y redes sociales permite este tipo de trabajo, que hasta hace pocos años, podía llegar a ser un proceso más lento y tedioso.

En este entorno mediático hemos detectado tres ámbitos en los que algunos jóvenes se están profesionalizando. Se trataría los videojuegos (creación de juegos o competiciones de eSports), escritura creativa (plataformas como Wattpad) y las redes sociales a través de la creación de microcelebridades y prescriptores de contenidos y productos. En todos ellos los contenidos audiovisuales a través de plataformas como YouTube convergen con estos tres ámbitos como producciones 
hegemónicas tanto a nivel de consumo como de creación por parte de los adolescentes.

Finalmente, hemos detectado que se siguen perpetuando los roles tradicionales de género a la hora de consumir y crear contenidos. Así, nos encontramos que, en el ámbito de los videojuegos, si bien la presencia de féminas cada vez es mayor, todavía dista de ser igualitaria. Por el contrario, en el ámbito de la escritura creativa la presencia masculina es residual. No obstante, los resultados sobre redes sociales arrojan una tendencia hacia la paridad en relación al consumo, si bien a nivel de producción y de posicionamiento de marca personal existe una mayor participación por parte de las chicas.

- Investigación financiada. Este trabajo ha sido financiado por el proyecto $\mathrm{I}+\mathrm{D}+\mathrm{i}$ 'Transalfabetismos. Competencias transmedia y estrategias informales de aprendizaje de los adolescentes' (CSO201456250-R) del Ministerio de Economía, Industria y Competitividad de España. Además, este artículo ha sido financiado por el Ministerio de Economía, Industria y Competitividad del Gobierno de España a través del programa Ayudas para la Formación de Doctores 2015 (Ref. BES-2015-071455).

*Agradecimientos: Agradecemos la participación de adolescentes, profesores e investigadores que forman parte del proyecto 'Transalfabetismos. Competencias transmedia y estrategias informales de aprendizaje de los adolescentes'.

\section{Referencias bibliográficas}

AEVI - Asociación Española de Videojuegos. (2018): Libro blanco de los esports en España. Madrid: AEVI. Recuperado el 25 de mayo de 2018, de: http://www.aevi.org.es/web/wpcontent/uploads/2018/05/ES libroblanco online.pdf

Alvermann, D. E., Moon, J. S., Hagwood, M. C., y Hagood, M. C. (2018): Popular culture in the classroom: Teaching and researching critical media literacy. Routledge.

Ardèvol, E, y Márquez, I. (2014): “El youtuber como celebridad mediática: entre la autenticidad y el mercado". Rizoma, 5(2), 72 87. DOI: $10.17058 /$ rzm. v5i2.11288 
Brenda, H. K. S. (2017): "Spectating the Rift: A Study into eSports Spectatorship". En J. Hiltscher \& T. M. Scholz (Eds.), eSports Yearbook 2015/16(pp. 9-35). Norderstedt: Books on Demand $\mathrm{GmbH}$. Recuperado de from http://www.esportsyearbook.com/eyb201516.pdf

Burgess, J. E., y Green, J. B. (2009): “The entrepeneurial vlogger:

Participatory culture beyond the professional-amateur divide".

En P. Snickars y P. Vonderau (Eds.), The YouTube Reader (pp.89-107). New York: Columbia University Press.

Carter, M., \& Gibbs, M. (2013): “eSports in EVE Online:

Skullduggery, Fair Play and Acceptability in an Unbounded Competition". En G. N. Yannakakis, E. Aarseth, K. Jørgensen \& J. C. Lester (Eds.), Proceedings of the 8th International Conference on the Foundations of Digital Games (pp. 47-54). Chania: Society for the Advancement of the Science of Digital Games.

CGC Europe. (2015): "Marketing Channel eSports - How to get the attention of young adults?" Recuperado el 19 de enero, de: http://docplayer.net/12867287-Marketing-channel-esportshow-to-get-the-attention-of-young-adults.html

Coppa, F. (2017): The Fanfiction Reader: Folk tales for the digital age. Ann Arbor: University of Michigan Press.

Crawford, C. (1982): The Art of Computer Game Design. Berkeley, CA: McGraw-Hill.

DEV - Asociación Española de Empresas Productoras y

Desarrolladores de Videojuegos y Software de Entretenimiento. (2016): Libro Blanco del Desarrollo Español de Videojuegos. Madrid: DEV. Recuperado el 17 de mayo de 2017, de: http://www.dev.org.es/es/libroblancodev2016

Duffy, B. E. (2016): “The romance of work: Gender and aspirational labour in the digital culture industries". En International Journal of Cultural Studies, 19 (4), pp. 441-457.

Elorriaga Illera, A., y Monge Benito, S. (2018): "La profesionalización de los youtubers: el caso de Verdeliss y las marcas". Revista Latina de Comunicación Social, 73, 37-54. DOI: $10.4185 /$ RLCS-2018-1244

Ezaleila Mustafa, S., y Mohd Adnan, H. (2017): "Crowdsourcing: A Platform for Crows Engagement in the Publishing Industry". Pub Res Q. 33, 283-296. DOI: 10.1007/s12109-017-9525-4 
Ezell, M. (2003): Social Authorship and the Advent of Print. Baltimore: The Johns Hopkins University Press.

Ferrés-Prats, J., Aguaded-Gómez, I., \& García-Matilla, A. (2012): “La competencia mediática de la ciudadanía española: dificultades y retos". Revista ICONO14 Revista científica de Comunicación y Tecnologías emergentes, 10(3), 23-42.

Ferrés, J., y Piscitelli, A. (2012): "La competencia mediática: propuesta articulada de dimensiones e indicadores". Comunicar, 19(38).

Fuchs, C. (2017): Social media: A critical introduction. 2nd edition. London: Sage.

Funk, S., Kellner, D., \& Share, J. (2016): Critical media literacy as transformative pedagogy. In Handbook of research on media literacy in the digital age (pp. 1-30). IGI Global.

Furtado, J.A. (2012): "Self-publishing: ¿tsunami o "business as usual”?” En: J.A. Cordón García, F. Carbajo Cascón, R, Gómez Díaz, J.A. Arévalo (Coords.), Libros electrónicos y contenidos digitales en la sociedad del conocimiento: mercado, servicios y derecho (pp. 69-92). Madrid: Pirámide.

Garcia-Rapp, F. (2016): “The digital media phenomenon of YouTube beauty gurus: the case of Bubzbeauty". International Journal of Web Based Communities, 12(4), 360-375. DOI: 10.1504/IJWBC.2016.10001832

García-Ruiz, R., Ramírez, A. \& Rodríguez, M.M. (2014): “Media Literacy Education for a New Prosumer Citizenship. [Educación en alfabetización mediática para una nueva ciudadanía prosumidora]". Comunicar, 43, 15-23. https://doi.org/10.3916/C43-2014-01

Guinness World Records. (2017): Guinness World Records 2018 Gamer's Edition: The Ultimate Guide to Gaming Records. London: Guinness World Records Limited.

Hellekson, K. (2009). "A fannish field of value: Online fan gift culture". Cinema Journal, 48(4), 113-118. DOI: http://dx.doi.org/10.1353/cj.0.0140

Hellekson, K., \& Busse, K. (2014): The Fan Fiction Studies Reader. Iowa City: University of Iowa Press.

Herrero-Diz, P., Ramos-Serrano, M., \& Nó, J. (2016): “Los menores como usuarios creadores en la era digital: del prosumer al 
creador colaborativo”. Revisión teórica 1972-2016. Revista Latina de Comunicación Social, (71).

IGDA - International Game Developers Association (2015):

"Developer Satisfaction Survey 2015 Summary Report".

Recuperado el 2 de diciembre de 2017, de:

https://cdn.ymaws.com/www.igda.org/resource/collection/C

B31CE86-F8EE-4AE3-B46A-

148490336605/IGDA\%20DSS\%202015-

SummaryReport Final Sept15.pdf

Jenkins, H. (2006): Convergence Culture: Where Old and New Media Collide. New York: NYU Press.

Jones, B. (2014): "Fifty shades of exploitation: Fan labor and Fifty

Shades of Grey". Transformative Works and Cultures, 15. DOI:

$10.3983 /$ twc. 2014.0501

Lacasa, P. (2011): Los videojuegos. Aprender en mundos reales y virtuales.

Ediciones Morata.

Lange, P.G. (2014): Kids on YouTube. Walnut Creek, CA: Left Coast Press.

Laquintano, T. (2010): "Sustained Authorship: Digital Writing, Selfpublishing, and the Ebook". Written Communication, 27(4), 469-

493. DOI: $10.1177 / 0741088310377863$

Livingstone, S. M., Haddon, L., Görzig, A., \& Ólafsson, K. (2011):

Risks and safety on the Internet: The perspectives of European children:

Full findings and policy implications from the EU kids online survey of

9-16 year olds and their parents in 25 countries. LSE.

Lunden, I. (17 de enero de 2018): "Storytelling app Wattpad raises $\$ 51 \mathrm{M}$ at a $\$ 398$ valuation”. TechCrunch. Recuperado el 17 de mayo de 2018 de:

https://techcrunch.com/2018/01/17/storytelling-app-

wattpad-raises-51m-at-a-398m-

valuation/?ncid $=$ rss\&guccounter $=1$

Manovich, L. (2013): Software Takes Command. New York: Bloomsbury Academic.

Marwick, A. (2013): Status update. New Haven: Yale University Press.

Masanet, MJ., y Establés, MJ. (2018): "Competencias en la prevención de riesgos, ideología y ética". En Carlos A. Scolari (Ed). Adolescentes, medios de comunicación y culturas colaborativas. Aprovechando las competencias transmedia de los jóvenes en el aula (pp: 
69- 77). Barcelona: Transmedia Literacy Research Team H2020 Research and Innovation Actions.

Mirmohamadi, K. (2014): The Digital Afterlives of Jane Austen: Janeite at the Keyboard. Basingstoke: Palgrave Macmillan.

Pérez Curiel, C., y Luque Ortiz, S. (2018): "El marketing de influencia en moda. Estudio del nuevo modelo de consumo en Instagram de los millennials universitarios". AdComunica: Revista Científica de Estrategias, Tendencias e Innovación en Comunicación, 15. DOI: 10.6035/2174-0992.2018.15.13

Pérez-Torres, V., Pastor-Ruiz, Y., \& Abarrou-Ben-Boubaker, S. (2018): "Los youtubers y la construcción de la identidad adolescente". Comunicar: Revista Cientifica de Comunicación y Educación, 26(55), 61-70.

Ramdarshan Bold, M. (2018): "The return of the social author: Negotiating authority and influence on Wattpad". Convergence: The International Journal of Research into New Media Technologies, 24(2), 117-136. DOI: 10.1177/1354856516654459

Ramos-Serrano, M., y Herrero-Diz, P. (2016): “Unboxing and brands: Youtubers phenomenon through the case study of EvanTubeHD". Prisma Social: Revista de Ciencia Sociales. Número especial 1, 90-120.

Riboni, G. (2017): "Between Professionalism and Amateurship: Makeup Discourse on YouTube". Lingue Culture MediazioniLanguages Cultures Mediation (LCM Journal), 4(1), 117-134.

Rigby, S., y Ryan, R. M. (2011): Glued to Games: How Video Games Draw Us In and Hold Us Spellbound. Santa Barbara, CA: ABC-CLIO.

Scolari, C. A. (2014): "Don Quixote of La Mancha: Transmedia storytelling in the grey zone". International Journal of Communication; 8: 2382-405.

Scolari, C. A. (2018): "Introducción. Del alfabetismo mediático al alfabetismo transmedia". En Carlos A. Scolari (Ed.), Adolescentes, medios de comunicación y culturas colaborativas. Aprovechando las competencias transmedia de los jóvenes en el aula (pp. 14- 23). Barcelona: Transmedia Literacy Research Team H2020 Research and Innovation Actions.

Segarra-Saavedra, J., e Hidalgo-Marí, T. (2017): "Influencers, moda femenina e Instagram: el poder de la influencia en la era 2.0". 
Revista Mediterránea de Comunicación, 9(1), 313-325. DOI:

10.14198/MEDCOM2018.9.1.17 


\title{
Usos del WhatsApp en el estudiante universitario español. Pros y contras
}

Joan Francesc Fondevila-Gascón - Universitat Ramon Llull, EAE

Business School, UPF, EUM-UdG, Cesine, Euncet-UPC, UOC y

CECABLE, Barcelona y Terrassa (España)

joanfrancescfg@,blanquerna.url.edu

Joaquín Marqués-Pascual - EAE Business School, Barcelona

(España) joaquin.marques@campus.eae.es

Pedro Mir-Bernal - Universidad de Navarra, Pamplona (España) pmir@,unav.es

Marc Polo-López - Universitat Ramon Llull, Barcelona (España) marcospl@,blanquerna.url.edu

Cómo citar: JF Fondevila-Gascón, J Marqués-Pascual, P Mir-Bernal, M Polo-López (2019): “Usos del WhatsApp en el estudiante universitario español. Pros y contras". En V Tur-Viñes/M J González-Río/R S Contreras-

Espinosa (Eds.) Jóvenes / Medios y cultura colaborativa. Cuadernos Artesanos de Comunicación, cac157, pp 227-249. La Laguna (Tenerife): Latina.

DOI: $10.4185 / \operatorname{cac} 157$

\begin{abstract}
s
Introducción: El objetivo de esta investigación es analizar de qué manera impacta el uso de los servicios de mensajería instantánea en el entorno universitario español y qué consecuencias positivas y negativas genera en el comportamiento estudiantil. Para ello se trabajó sobre la aplicación más popular en el territorio en cuestión, WhatsApp, y la utilización que de ella hacen los universitarios. Metodología: La investigación desarrollada utiliza la técnica cuantitativa (encuestas a una muestra $n=332$ ), al efecto de determinar el uso que se les da a los
\end{abstract}


mensajes de texto convencionales, así como otras opciones de la mensajería instantánea (como puede ser la voz o las imágenes). Asimismo, se analizaron algunos impactos en el entorno académico como, por ejemplo, el posible estrés que genera en el comportamiento humano. Resultados y conclusiones: Destacan la comodidad y la gratuidad de WhatsApp que impulsan el uso en el entorno educativo. Se puede constatar que la mayoría de los estudiantes utiliza este tipo de aplicaciones de mensajería instantánea también para cuestiones relacionadas con los asuntos universitarios -aparte de su vida personal-. Además, se observa que un porcentaje muy alto de los grupos analizados pertenece a algún chat grupal relacionado con los estudios o está incluido en grupos de conversación sobre materias académicas.

\section{Keywords}

Mensajería instantánea, WhatsApp, Educación, Estudiante, Universidad, España

\section{Contents}

1. Introducción. 2. Metodología. 3. Resultados. 3.1. Uso de mensajes de texto (SMS). 3.2. Uso de aplicaciones de WhatsApp: motivos y tipos. 3.3. Uso de WhatsApp: excesos y adicción. 3.4. Uso de WhatsApp con fines académicos. 4. Discusión y conclusiones. 5. Bibliografía.

\section{Introducción}

$\mathrm{E}$ L USO de smartphones y sus correspondientes aplicaciones móviles como herramienta de comunicación entre usuarios y como herramienta pedagógica es una realidad creciente en el entorno de la sociedad digital (Organista-Sandoval, McAnally-Salas y Lavigne, 2017). Desde 2012, los servicios sobre mensajería instantánea, técnicamente conocidos como SOMI o SOM por su acrónimo en inglés (Services Over the Messenger), se han ido popularizando. Inicialmente fueron mensajes de texto, pero en la actualidad las opciones son muy amplias (segunda generación), permitiendo enviar stickers y mensajes de audio o video para llegar incluso a ofrecer conversaciones en directo (videoconferencias). 
Según el Panel de Hogares de la Comisión Nacional de los Mercados y la Competencia (CNMC), a finales de 2017 el uso diario por los españoles de los servicios de mensajería instantánea, como WhatsApp, casi duplica al de las llamadas por móvil y fijo. La mensajería instantánea la utilizan seis de cada 10 españoles varias veces al día $(60 \%)$, cifra muy superior al uso diario de las llamadas efectuadas desde móviles (24\%), teléfonos fijos (12\%) o llamadas 'online' (4\%). Los SMS han quedado casi en desuso y son utilizados en contadas ocasiones. Casi un 60\% de los españoles nunca los envía (CNMC, 2017).

En el contexto digital español, "en los últimos tres años, el tráfico de la mensajería instantánea Whatsapp se multiplicó por ocho" (Fundación Telefónica, 2017: 76). El 81,7\% de los jóvenes utilizan de manera sistemática los servicios de mensajería instantánea, superando en volumen de usuarios a los de las redes sociales (2017: 47-48). En este sentido, la aproximación de la mensajería instantánea a otras formas de comunicación conversacional en el entorno virtual (RubioRomero y Perlado, 2015: 91), como las redes sociales, se constata como una realidad creciente $y$, en parte, substitutoria.

También se confirma que, por vez primera, la mensajería instantánea se incorpora al ámbito laboral como un canal de comunicación más. En datos agregados, un 59,8\% de los internautas la utiliza con fines profesionales para comunicarse con compañeros de trabajo. Entre la franja de usuarios más jóvenes (20-24 años), la cifra aumenta al 73,7\%.

En este contexto, esta investigación indaga sobre ese uso en el ámbito universitario, considerándolo como una extensión de la consideración laboral del estudio de Telefónica. Se pueden considerar los estudios de segundo y tercer ciclo como un estadio previo al laboral, donde se generan o potencian hábitos de relación y comportamiento que posteriormente se seguirán desarrollando en el mundo de la empresa.

La app elegida para la investigación es WhatsApp, la aplicación más utilizada hasta el punto de convertirse en la primera herramienta de mensajería instantánea en España, substituyendo en gran medida la llamada telefónica (Rubio y Perlado, 2015: 90). El 92,8\% de los 
usuarios móviles (AIMC, 2017) la utiliza. Según EGM (segunda oleada 2018), el 96,5\% de las personas entre 20 y 24 años, grupo donde se engloba el estudiante universitario, usan Internet a diario (AIMC, 2018).

Junto con otros tipos comunes de mensajería instantánea como Facebook Messenger, utilizado por el $87 \%$ de los usuarios móviles nacionales, Twitter 48,9\% e Instagram 40,4\% (AIMC, 2017), la aplicación WhatsApp es manejada de media 32,11 minutos al día, cifra que aumenta para los jóvenes y en especial entre las mujeres (Montag et altri, 2015), por lo que es susceptible de poder generar algún tipo de conductas adictivas y causar estrés. No obstante, ni el DSM (Diagnostic and Statistical Manual of Mental Disorders), es decir, el Manual Diagnóstico y Estadístico de los Trastornos Mentales de la Asociación Americana de Psiquiatría (American Psychiatric Association, APA, 2018), ni el DSM-5 (Clasificación Internacional de Enfermedades), manual publicado por la Organización Mundial de la Salud (OMS), tienen recogido en su listado el trastorno que esta investigación apunta. Cabe destacar que, al final de la sección dos del citado manual, en el capítulo relacionado con otros problemas que pueden ser objeto de atención clínica, se apunta que, sin llegar a ser trastornos mentales, se debe atender a los problemas relacionados con la educación (V62.3), así como otros problemas relacionados con el entorno social (p. e. V62.89, V62.4 y V62.9). De todas formas, la única adicción reconocida sin sustancia y donde media una pantalla es la ludopatía (Asociación Americana de Psiquiatría, 2014). El resto se halla en fase de debate científico en el momento de elaborar este artículo, con posturas críticas (Frances, 2013).

Este tipo de aplicaciones de mensajería instantánea aplicada a la vida universitaria, especialmente WhatsApp, presenta varias ventajas, como señalan, entre otros, Andújar-Vaca y Cruz-Martínez (2017: 44): "promover el contacto entre estudiantes y profesores; fomentar la interacción entre estudiantes y promover la cooperación académica; motivar el aprendizaje activo; proporcionar un feed-back instantáneo; y desarrollar altas expectativas”. En paralelo, otro estudio (Sánchez y Lázaro, 2017) muestra la adicción a dicha aplicación entre los adolescentes españoles. Se muestra alta, al encontrar nivel 2 en el 37\% 
y nivel 3 en un $63 \%$ de su muestra (el nivel 1 es no adicción y el 4 dependencia absoluta). Esos datos corroboran el estudio de FondevilaGascón et altri (2014), donde se probó que el uso de mensajería instantánea gratuita provoca estrés y ansiedad, lo que puede afectar al aprendizaje de quienes padecen dependencia. La aparición de síndromes como la "vibración fantasma" (Balding, 2012) es consecuencia de la obsesión que estos medios de comunicación generan en los usuarios, quienes por miedo a perder el control desarrollan síntomas característicos del síndrome de abstinencia (Molina del Peral, 2012).

El uso de este tipo de mensajería instantánea afecta a los hábitos laborales y sociales de los individuos (Ljungstrand y Af Segerstad, 2000), por lo que sus consecuencias están siendo investigadas por la comunidad académica desde diferentes campos, incluyendo el ámbito pedagógico, psicológico, laboral, relacional, de bienestar y sanitario, entre otros. En el ámbito universitario, con la llegada de la generación millennial a las aulas, se constata el uso masivo de la tecnología por parte de los estudiantes, mediante la segunda generación de la mensajería instantánea (Gallardo, 2014). Los millennial trasladan a la universidad los hábitos adquiridos en su etapa adolescente, donde la tecnología, con WhatsApp como elemento preeminente, se convirtió en un instrumento estratégico de socialización (Vidales-Bolaños y SádabaChalezquer, 2017).

En los primeros estudios realizados sobre adición a la tecnología se señaló que existe una tendencia a relacionar personalidad con frecuencia de uso y adicción a dichas aplicaciones (Sultan 2013). Estudios posteriores demostraron que características personales, género y ansiedad tienen relación directa con el uso, frecuentemente conflictivo, de la aplicación (Tresáncoras, García-Oliva y Piqueras, 2016). Sin embargo, parece no existir correlación entre el nivel de adicción y las habilidades sociales que los sujetos desarrollan (Sánchez y Lázaro, 2017).

Buschmann Iversen, Melby y Toussaint (2013) estudian como el uso de la mensajería instantánea aporta flexibilidad en la comunicación entre empleados, mejorando la coordinación y logística del personal 
médico en la atención a sus pacientes. Otros estudios abogan por la mejora directa e indirecta de los resultados y el desempeño laboral cuando se hace uso de los servicios de mensajería instantánea en el trabajo (Sheer y Rice, 2017).

El área con mayor estudio sobre el impacto que la mensajería móvil produce en las personas y sus resultados es la educativa. Se ha probado que los estudiantes que utilizan aplicaciones de mensajería instantánea tienen facilidad para trabajar en equipo (Hrastinski et alt, 2012; Jatuf, 2014), en una dinámica creciente de interactividad como la del HbbTV (Fondevila-Gascón, 2012), al obtener mayores índices de cooperación, pero no necesariamente mejoran la calidad de su trabajo (Hyewon, Lee y Minjeong, 2014). Además, permite a los estudiantes optimizar o mantener sus relaciones personales (Quan-Haase y Young, 2010).

Huang y Leung (2009) corroboran que, pese a que los estudiantes obtienen cinco formas de gratificación (utilidad interpersonal, utilidad social, conveniencia, información y entretenimiento), el uso de mensajería instantánea puede afectar negativamente a su rendimiento académico. Otros estudios demuestran que, entre los jóvenes, no se dan las mejoras de comunicación e información compartida que se han apreciado en ambientes laborales, convirtiéndose las aplicaciones de mensajería instantánea en impedimentos para su aprendizaje, al suponer una distracción para los alumnos durante las clases (Dietz y Henrich, 2014). Los estudiantes son incapaces de establecer una balanza entre sus actividades online y off-line, empeorando su rendimiento (Yeboah y Ewur, 2014).

Sin embargo, los resultados de otros estudios africanos realizados entre universitarios parecen indicar que los estudiantes perciben la aplicación WhatsApp de forma muy positiva, al entender que los grupos de chat entre alumnos les permiten acceder a recursos generados por pares, mejorar sus tareas y promover un aprendizaje fuera del contexto académico (Rambe y Chinpunza, 2013). Además, los grupos con profesores son interesantes para su aprendizaje colaborativo y útiles para su formación (Bansal y Joshi 2014; Bouhnik y Deshen, 2014). 
Este estudio tiene como objetivo analizar el uso de WhatsApp en el ámbito educativo universitario, las ventajas e inconvenientes, así como los efectos que el uso de dichas aplicaciones genera en los usuarios jóvenes. Hay que tener en cuenta que, en el contexto de la Sociedad de la Banda Ancha (Fondevila-Gascón, 2013), cada individuo deposita su confianza para informarse en una amalgama de amistades, conocidos y contactos, construidos ad-hoc, que han ido substituyendo con el tiempo de manera progresiva el papel de los medios de comunicación. En la cúspide de la confianza se encuentran las personas con las que se contacta one-to-one, papel que, en el ámbito digital, cumple la mensajería instantánea, el canal que los usuarios utilizan con más frecuencia, cumpliendo, de esa manera, también un papel informativo substancial en sus vidas (Marqués-Pascual, 2016; Fundación Telefónica, 2017).

En este contexto, se analiza cómo los jóvenes universitarios españoles utilizan las aplicaciones de mensajería instantánea, específicamente WhatsApp, identificando posibles usos abusivos, adicción a la mensajería y el potencial estrés o ansiedad que su uso puede generar, además de tratar de determinar si es una aplicación a implementar en el ámbito educativo.

\section{Metodología}

La investigación realizada es de carácter observacional y descriptiva de los hábitos y comportamientos de los individuos de la muestra. La técnica utilizada es cuantitativa. Se realizó en la Universidad de Navarra (Pamplona, España) durante los primeros meses de 2017, siguiendo un modelo de entrevista adaptado a encuesta personal similar al utilizado por Fondevila-Gascón et alt (2014), donde se adapta el modelo del test de Kimberly Young de adicción a Internet para el uso de mensajería instantánea. El estudio se enmarca en el análisis de los grupos de investigación impulsores sobre los efectos tecnológicos en la universidad, en aras de realizar un seguimiento evolutivo y poder lanzar comparativas. Pese a que la parte empírica se desarrolló físicamente en Pamplona, existe una gran diversidad de procedencia de los encuestados, con lo que los resultados se pueden extrapolar al escenario universitario español. 
Se realizaron un total de 340 encuestas. Tras depurar la muestra, se descartaron ocho de ellas al detectar contradicciones en las respuestas para preguntas similares o preguntas sin respuesta. La muestra final está compuesta por 332 encuestas a jóvenes universitarios, de los cuales 144 son hombres y 188 son mujeres.

Al tratarse de una encuesta que adapta técnicas de entrevista personal, las respuestas corresponden a la autopercepción de los usuarios sobre su frecuencia y fines de uso, ventajas e inconvenientes, el índice de estrés que les genera y la utilidad de su posible implementación en el ámbito académico.

La distribución por edades de la muestra fue de jóvenes universitarios de entre 18 y 23 años (Gráfico 1).

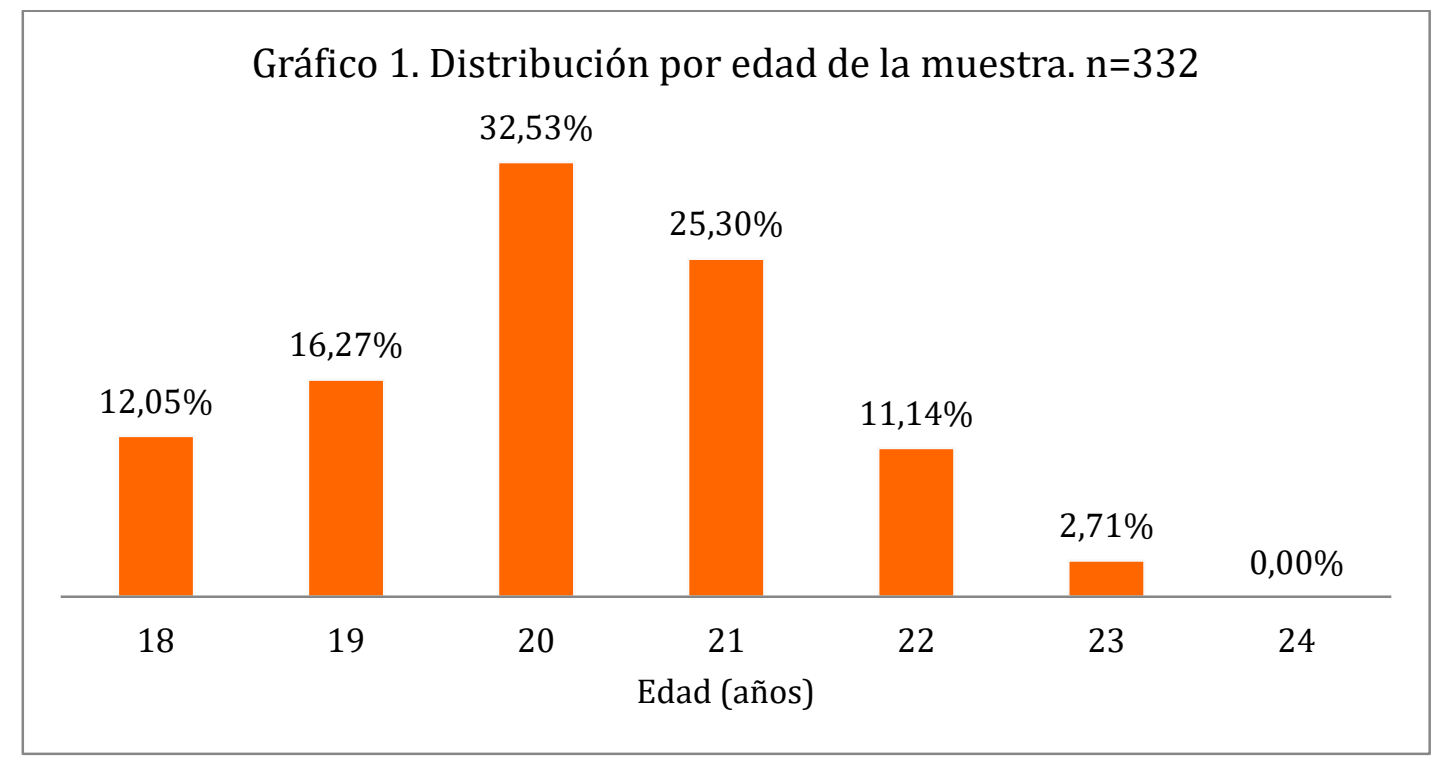

Fuente: elaboración propia

Los entrevistados disponen de nacionalidad española en su totalidad y provienen de diferentes comunidades autónomas. Navarra es la de mayor procedencia de la muestra (47.29\%), debido a la localización de la universidad en la que se ha realizado el estudio (Gráfico 2). 


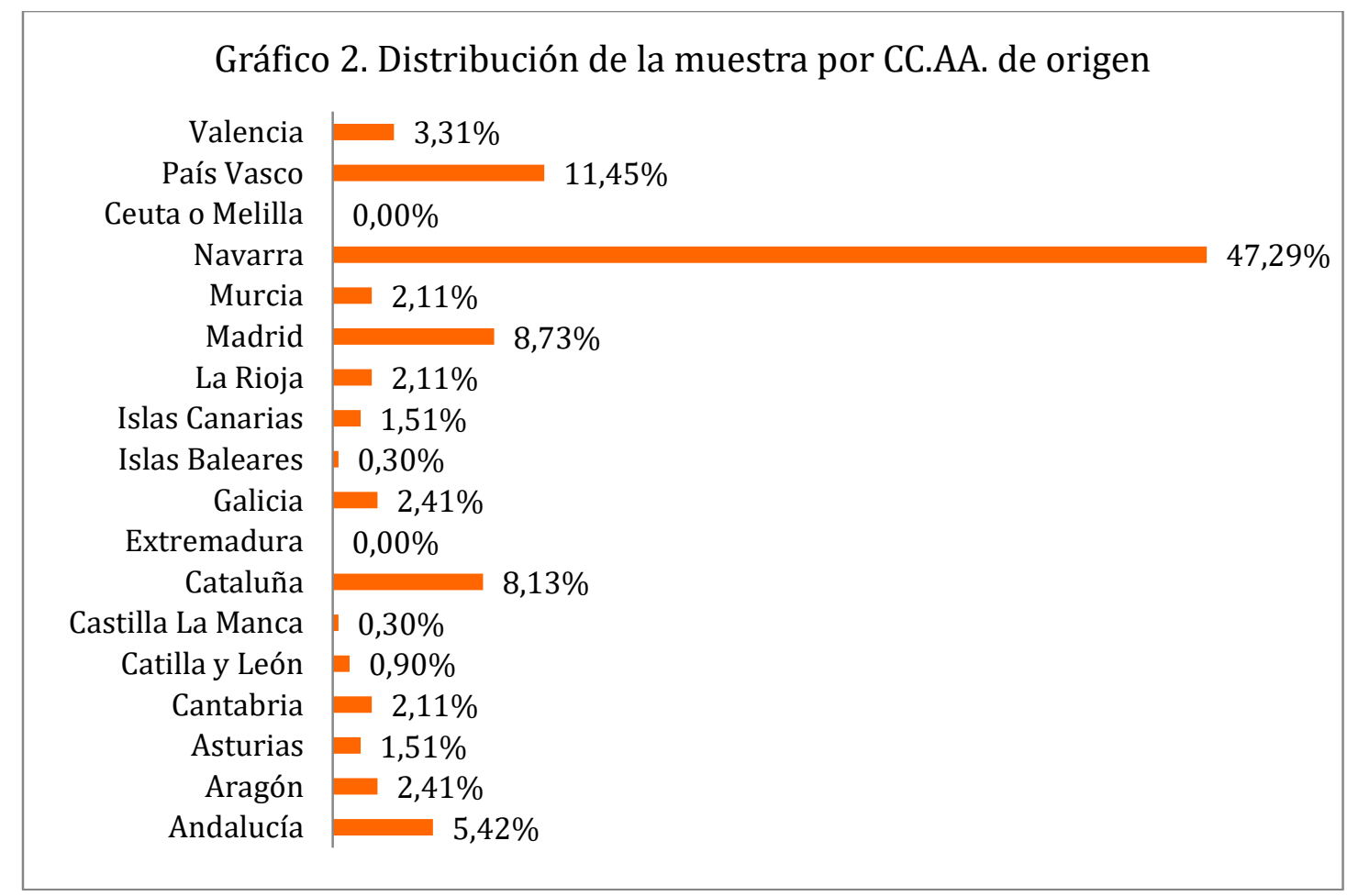

Fuente: elaboración propia

Los entrevistados son alumnos de la Universidad de Navarra, pertenecientes a estudios de grado de diferentes facultades, incluyendo la escuela de arquitectura, la facultad de ciencias económicas y empresariales, la facultad de derecho, de humanidades, de ciencias sociales o de ciencias de la salud, entre otras (Gráfico 3).

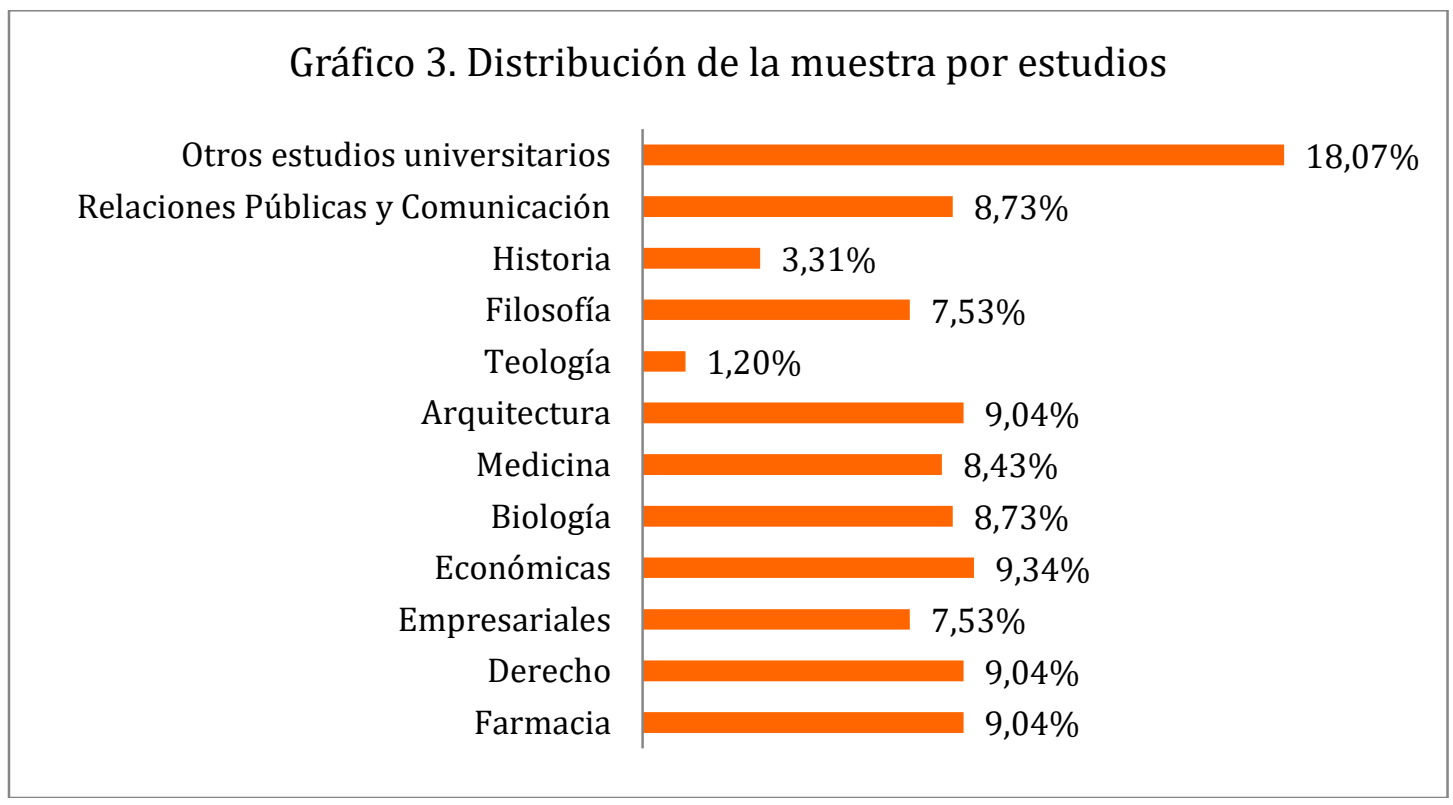

Fuente: elaboración propia 
Todos los entrevistados disponen de teléfono móvil smartphone, por lo que todos ellos tienen acceso a Internet y la posibilidad de disponer de aplicaciones de mensajería instantánea. El 54\% de ellos son usuarios del sistema operativo Android, y el 46\% del sistema iOS Apple. El 46\% disponen de un iPhone, el 20\% de un smartphone de Samsung, el 4\% de un smartphone de LG y el restante 30\% de smartphones de otras marcas. La distribución en función a la compañía telefónica es la siguiente: 43\% Movistar, 26\% Vodafone, 16\% Orange, 4\% Yoigo y 11\% otras empresas. La distribución de la muestra en función al gasto mensual en telefonía móvil (Gráfico 4) refleja que tan solo el 12\% de los entrevistados paga dicho gasto.

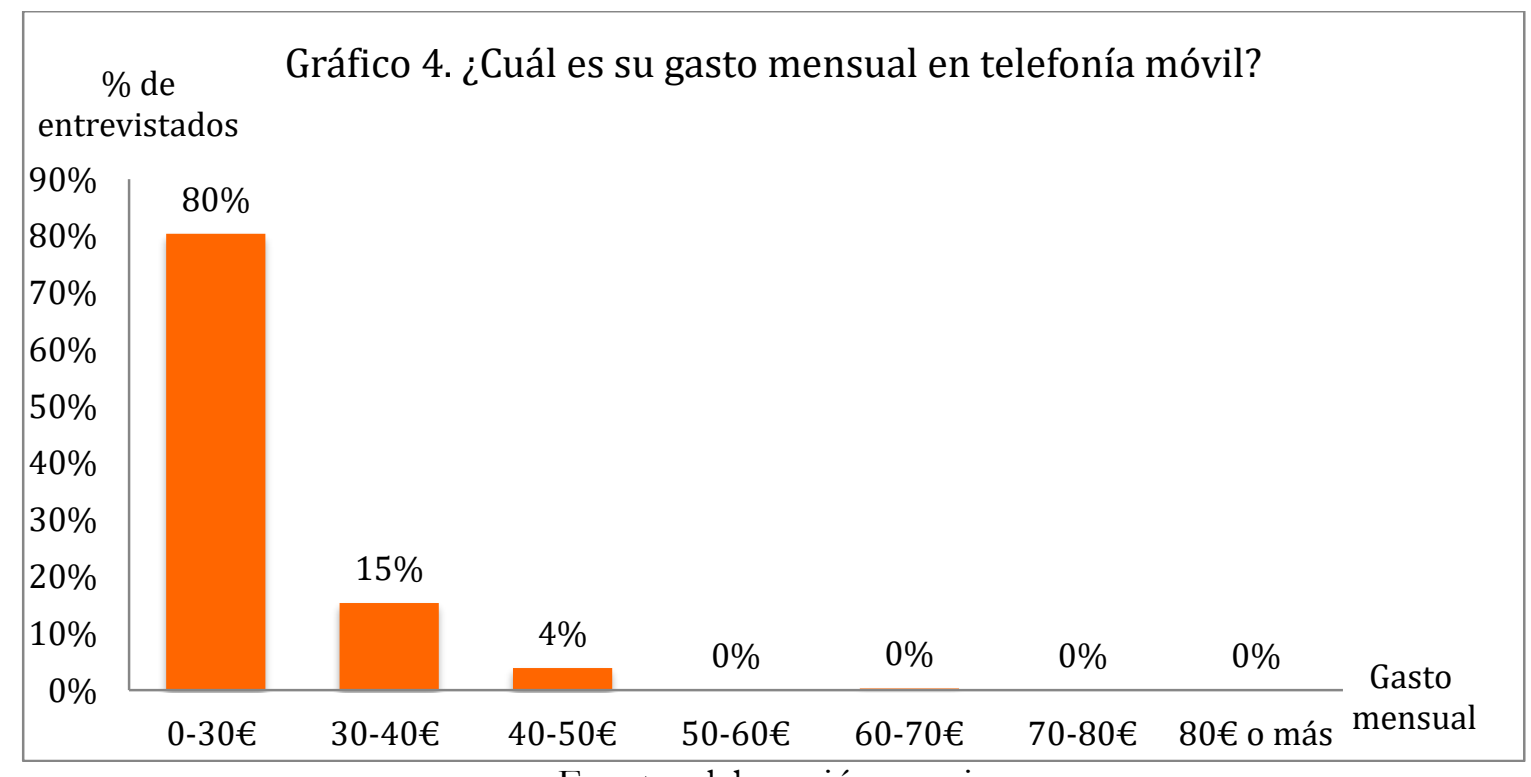

Fuente: elaboración propia

\section{Resultados}

\subsection{Uso de mensajes de texto (SMS)}

En una primera instancia, se preguntó a los entrevistados sobre el uso que hacían de los mensajes de texto convencionales (Short Message Service o SMS). El 83,7\% de los entrevistados afirmó no utilizar este tipo de mensajes, que tan sólo enviaban 55 personas de la muestra (el $16,3 \%$ ). En cuanto a los motivos por los que ese grupo de entrevistados seguían utilizando mensajes de texto, destacan la comodidad $(69,1 \%)$ y el bajo precio (10,91\%) (Gráfico 5). 


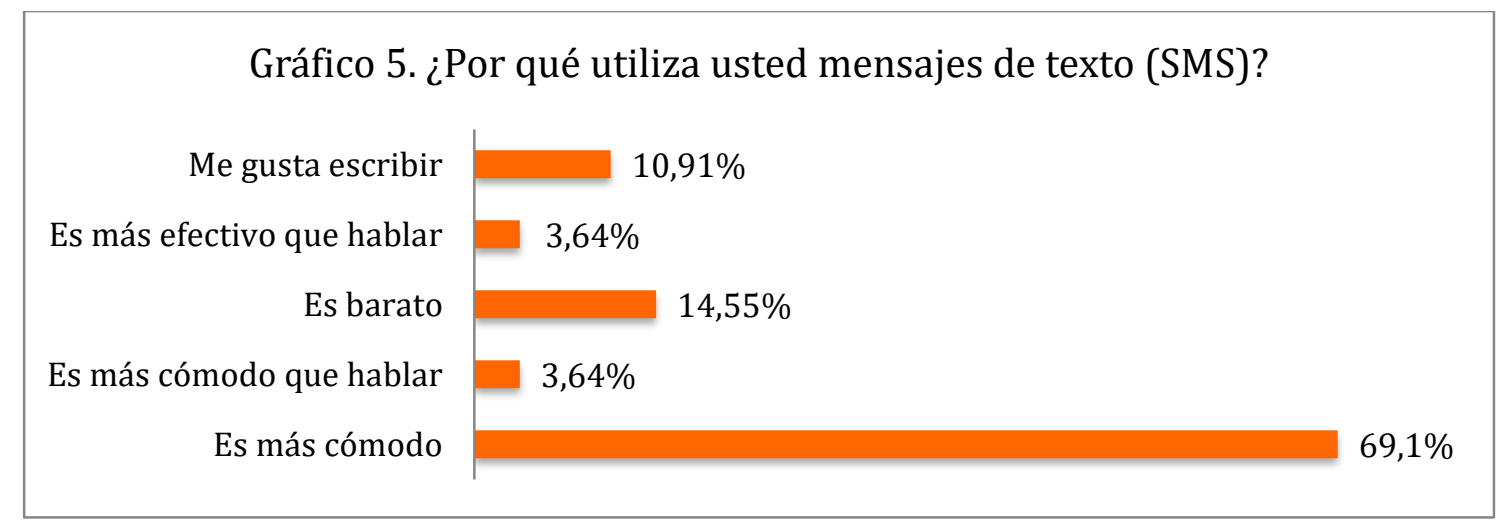

Fuente: elaboración propia

Aquellos entrevistados que ya no utilizan mensajería convencional dejaron de hacerlo porque, según manifestaron, prefieren utilizar aplicaciones de mensajería instantánea $(70,57 \%)$ o no pagar por este servicio (21,63\%) (Gráfico 6). Por tanto, los principales motivos por los que los usuarios deciden hacer uso de uno u otro tipo de mensajería son la comodidad al utilizar el servicio y el gasto en el que incurren al hacerlo.

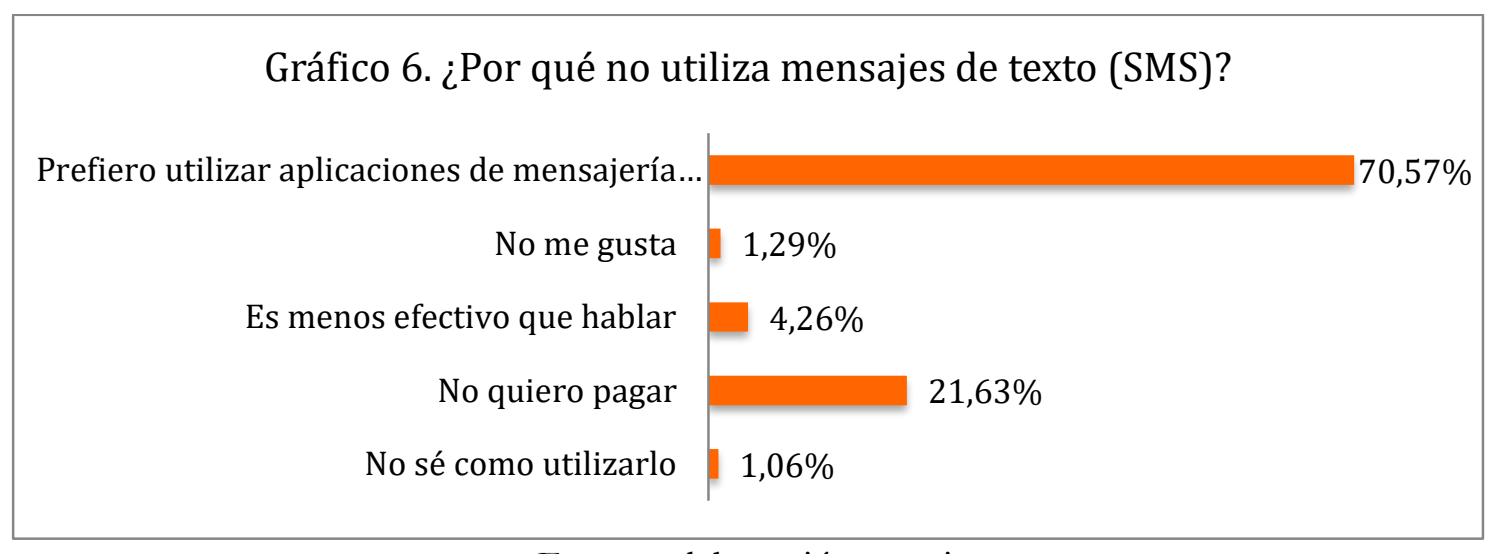

Fuente: elaboración propia

\subsection{Uso de WhatsApp: motivos y tipos}

La totalidad de la muestra utiliza de manera habitual la aplicación de mensajería instantánea WhatsApp, para la cual pagaron el 28\% de los entrevistados. El principal motivo por el que utilizan la aplicación es su comodidad (50\% de la muestra), seguido de la gratuidad de la misma $(40,36 \%)$ (Gráfico 7). 


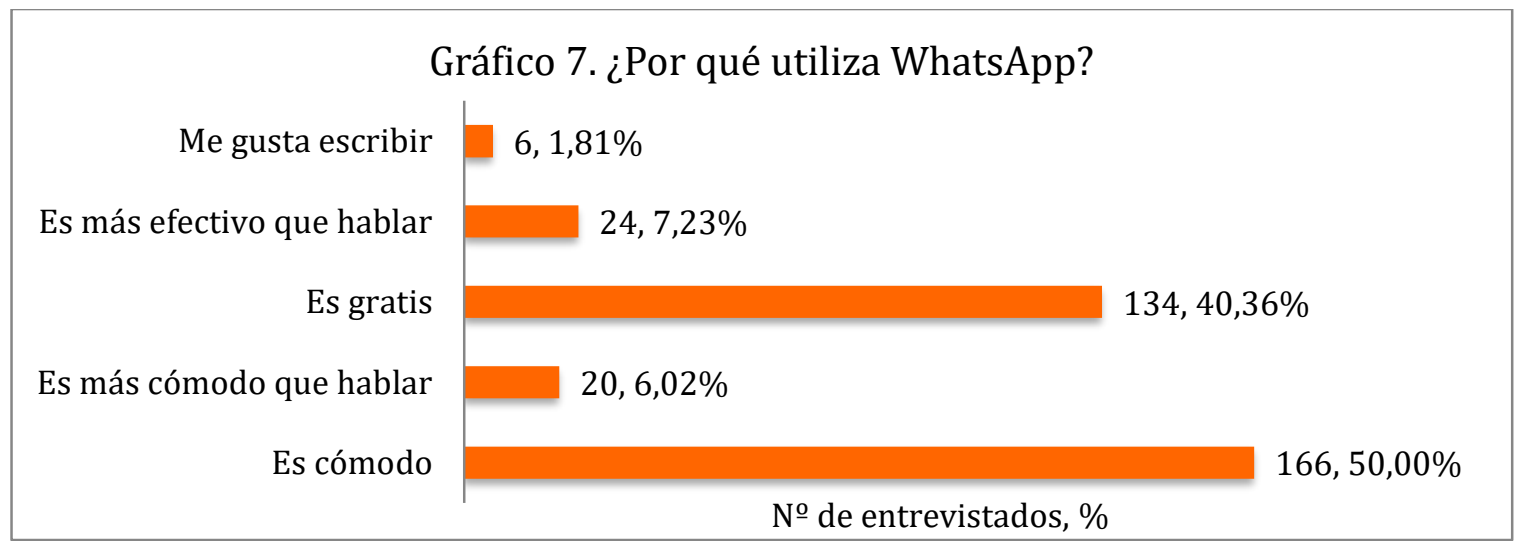

Fuente: elaboración propia

El 40\% de encuestados utiliza, además, otro tipo de aplicaciones de mensajería instantánea. Así, 19 de los 332 encuestados son usuarios de Telegram, 3 de Line y 111 usuarios de otras aplicaciones, incluyendo iMessage o Facebook Messenger.

El 18\% de la muestra afirma que utilizar WhatsApp es más cómodo que hablar por teléfono para comunicarse, frente al 74\% que afirma que no lo es. Sin embargo, los entrevistados creen que puede ser más rápido y efectivo que una llamada, además de permitirles realizar otras actividades al mismo tiempo (Gráfico 8). Son, por tanto, la eficiencia y la intimidad de la que se provee al usuario al hacer uso de dicha aplicación las características diferenciales que hacen que la aplicación sea utilizada de forma tan extensiva.

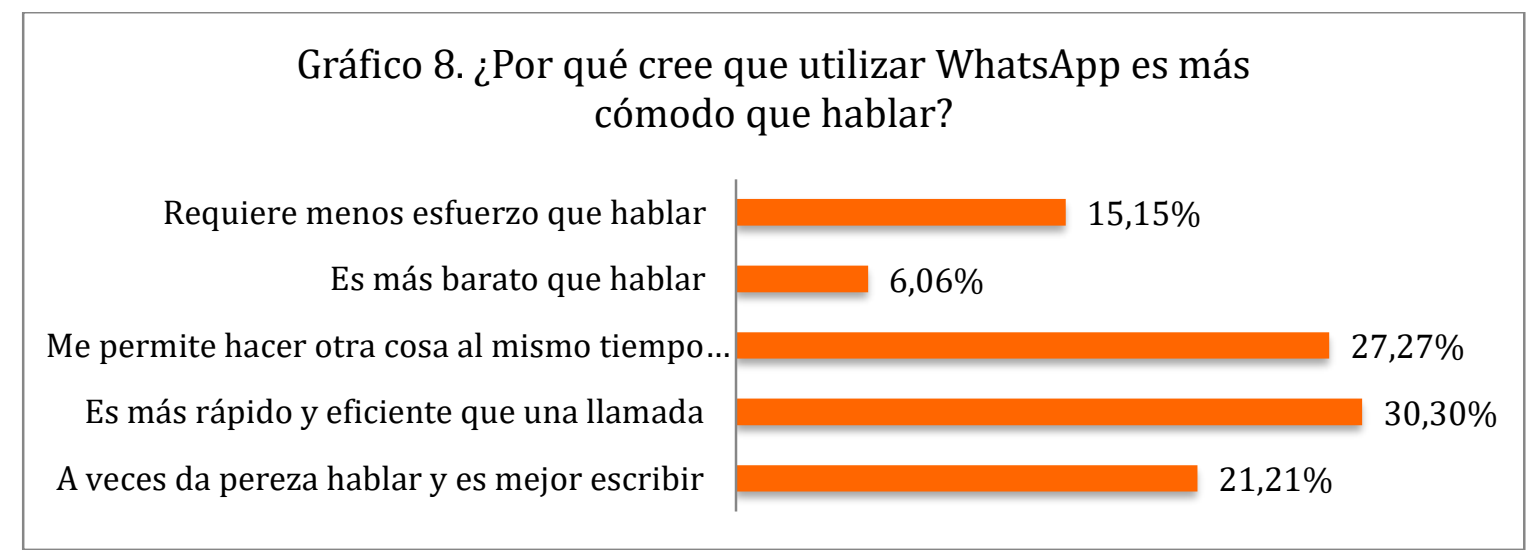

Fuente: elaboración propia

Entre los usos más frecuentes de WhatsApp, destacan las acciones de enviar mensajes, fotos, videos, audios y archivos de Word o PowerPoint. El 6,82\% de los encuestados únicamente envía mensajes, y el $34,42 \%$ no envía archivos en formatos como Word o PowerPoint, 
pero envía mensajes, audios y fotos. El 57,27\% restante de usuarios utilizan los servicios completos de la aplicación.

\subsection{Uso de WhatsApp: excesos y adicción}

Solamente el 3\% de los encuestados no utiliza WhatsApp más de 10 veces al día y el 52,40\% reconoce sacrificar horas de sueño por tener conversaciones de WhatsApp nocturnas (Gráfico 9). El 17,16\% de los encuestados sacrifican horas de sueño un mínimo de 3 a 4 noches semanales.

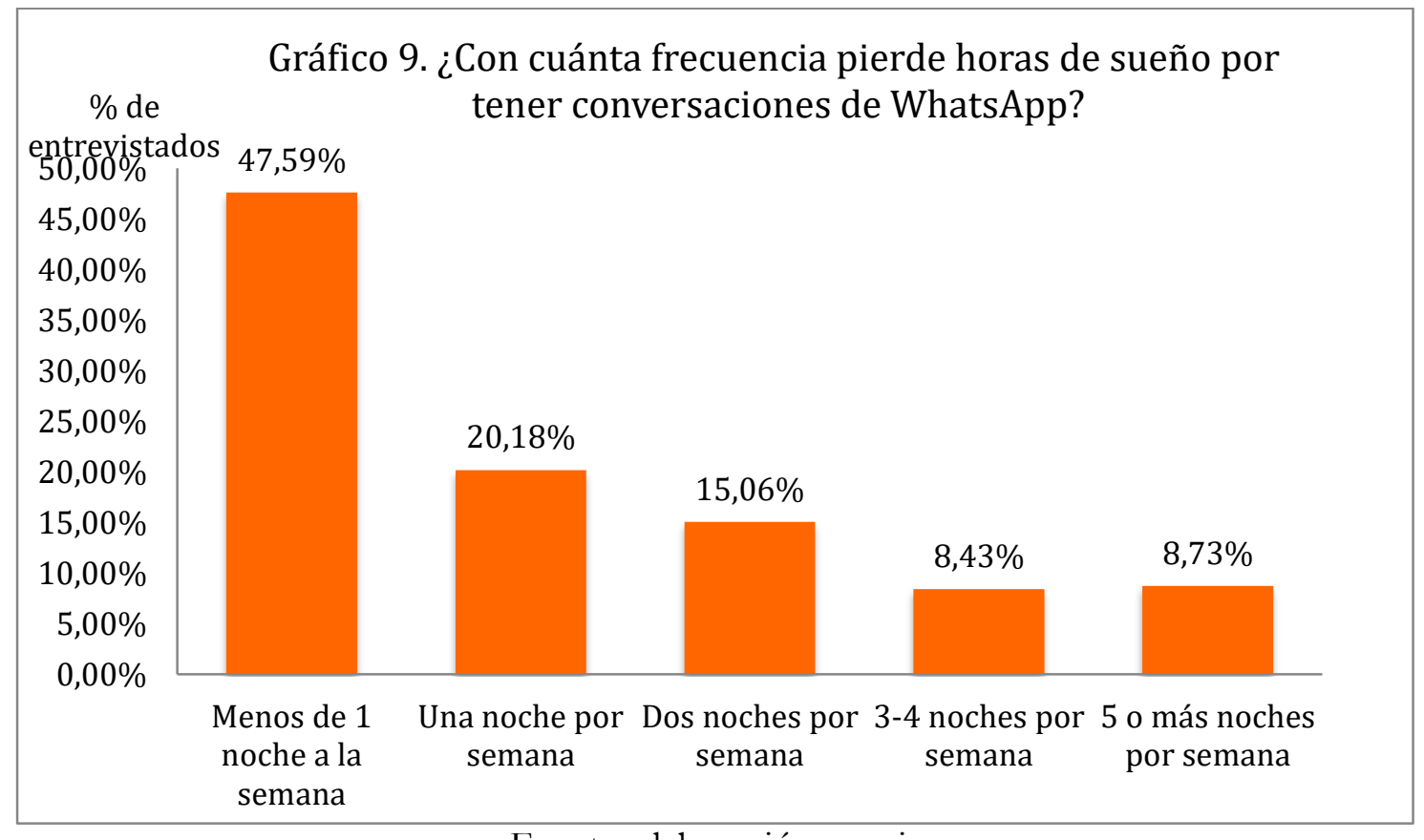

Fuente: elaboración propia

Con frecuencia se cree que el uso de aplicaciones de mensajería instantánea, como WhatsApp, facilita la distracción en el rendimiento académico (Lira-Rodríguez et altri, 2017). También se considera que aumenta la audacia y ayuda a mostrar los sentimientos. El estudio realizado por Fondevila-Gascón et altri (2014) demostró que dicha percepción era infundada, ya que tan solo el $9 \%$ de su muestra creía que la aplicación aportaba mayor intimidad y solo el 24\% prefería expresar sus sentimientos mediante un mensaje instantáneo que en persona. 
Gráfico 10. Intimidad y facilidad de expresar

emociones a través de WhatsApp

$\square \mathrm{Si}$ No

¿Es WhatsApp más íntimo que hablar en persona?

¿Es WhatsApp más fácil para expresar sus sentimientos que hacerlo llamando por teléfono?

¿Es WhatsApp más fácil para expresar sus sentimientos que hacerlo en persona?

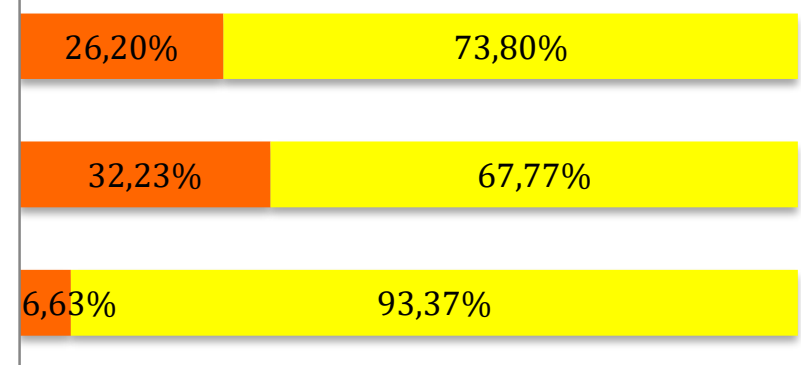

Fuente: elaboración propia

Los resultados obtenidos en el presente estudio son muy similares, corroborando los datos anteriores: un 6,63\% considera WhatsApp más íntimo que hablar, y el 26,20\% y 32,23\% afirman que es más fácil para expresar sentimientos que hacerlo hablando en persona o hablando por teléfono respectivamente. Sin embargo, el 46\% considera que en determinadas ocasiones es mejor decir algo por WhatsApp en lugar de hacerlo llamando por teléfono (Gráfico 10).

El 67\% de los encuestados reconoce mirar con frecuencia el icono de WhatsApp para comprobar si tiene algún mensaje, aunque no haya recibido una señal (vibración o sonido) que así lo indique. El 50\% siente ocasionalmente que su smartphone está vibrando o sonando, pero, al comprobarlo, descubre que no tiene llamadas ni mensajes. Esta "vibración fantasma" (Balding 2012) es consecuencia de la ansiedad que genera el no utilizar el dispositivo durante determinado tiempo. De hecho, el 37\% dice comprobar el teléfono móvil por posibles fallos en caso de no recibir mensajes de WhatsApp en unas horas, lo que indica la gravedad de la dependencia que se desarrolla (Gráfico 11).

El 75\% de los encuestados mantiene su teléfono móvil siempre encendido. Para el 54,22\% de la muestra, comprobar si tienen mensajes o llamadas es la primera actividad de su día, y para el 59,04\% es la última. Además, su uso también es frecuente al caminar. El 76\% de los encuestados envían mensajes de WhatsApp al hacerlo, e incluso utilizan la aplicación al ir al servicio, el $28,31 \%$ de forma ocasional y el $55,12 \%$ siempre. 


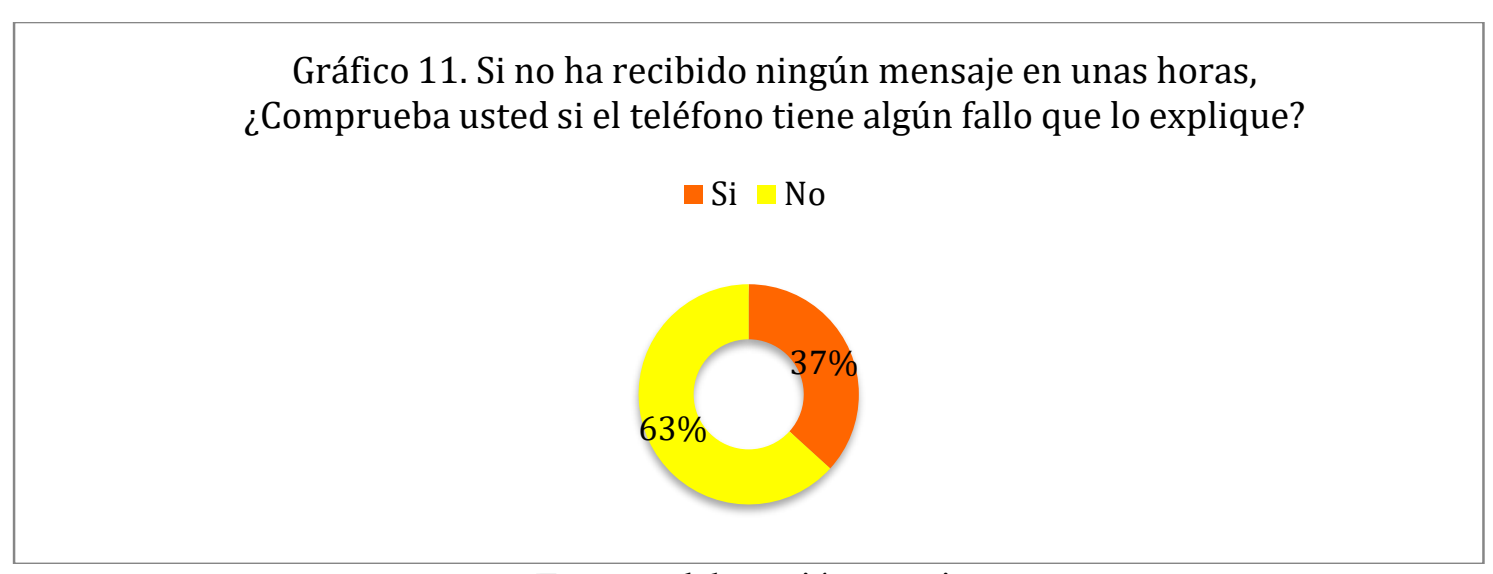

Fuente: elaboración propia

El 57,23\% de los encuestados entiende el uso excesivo que da a la aplicación e indica que le gustaría utilizar WhatsApp con menos frecuencia. Cuando se trata de determinar el uso que otros hacen de la aplicación, el 83,13\% afirma que la gente utiliza WhatsApp demasiado.

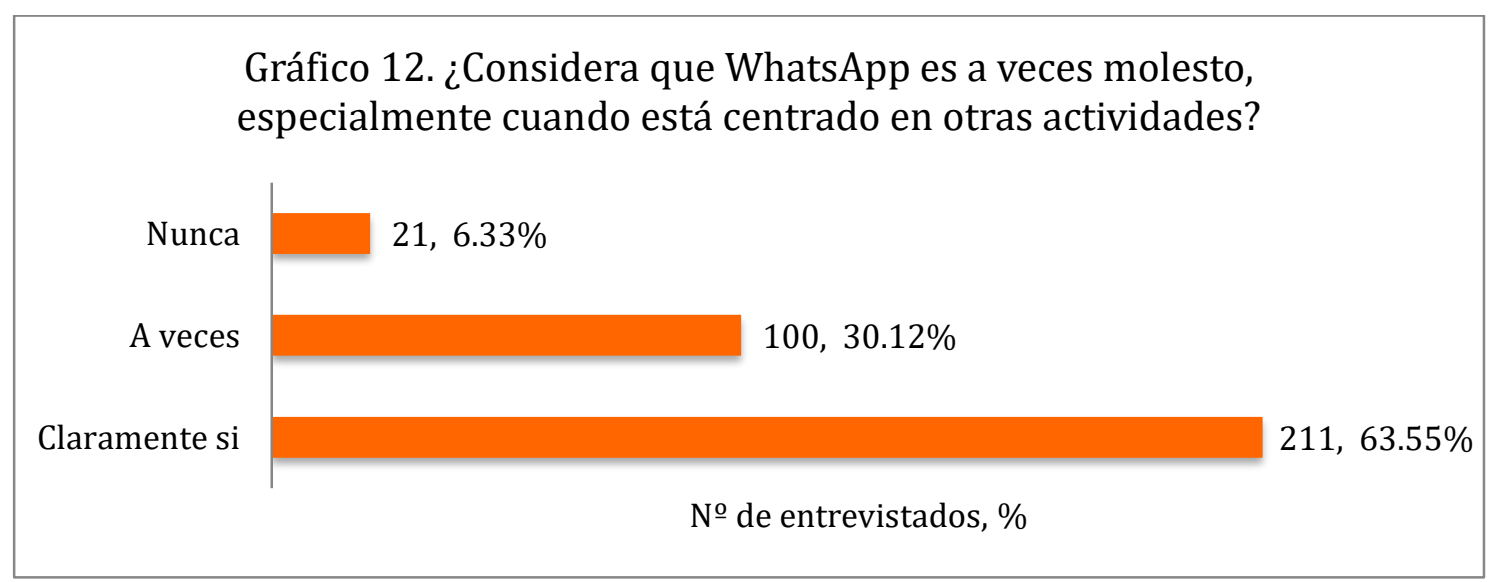

Fuente: elaboración propia

Los encuestados, casi en su totalidad, dicen sentirse ocasional o continuamente molestos por WhatsApp (Gráfico 12) y la mayor parte se sienten estresados por tener que contestar con inmediatez a los WhatsApp que reciben, aunque no exista verdadera urgencia para ello (Gráfico 13). El 53\% afirma que no espera una pronta respuesta al enviar uno de estos mensajes.

Estos datos son preocupantes al mostrar un alto índice de adicción y dependencia, por el hecho de necesitar saber en todo momento si han 
recibido alguna llamada o mensaje. Ello implica una preocupación en caso negativo. La mayor parte de los encuestados son incapaces de dejar de lado la aplicación mientras realizan otra actividad, lo que la convierte en una molestia, más allá de la percepción de generación multitasking y de las ventajas que pueda reportar un mensaje adecuado en un momento de trabajo coyuntural.

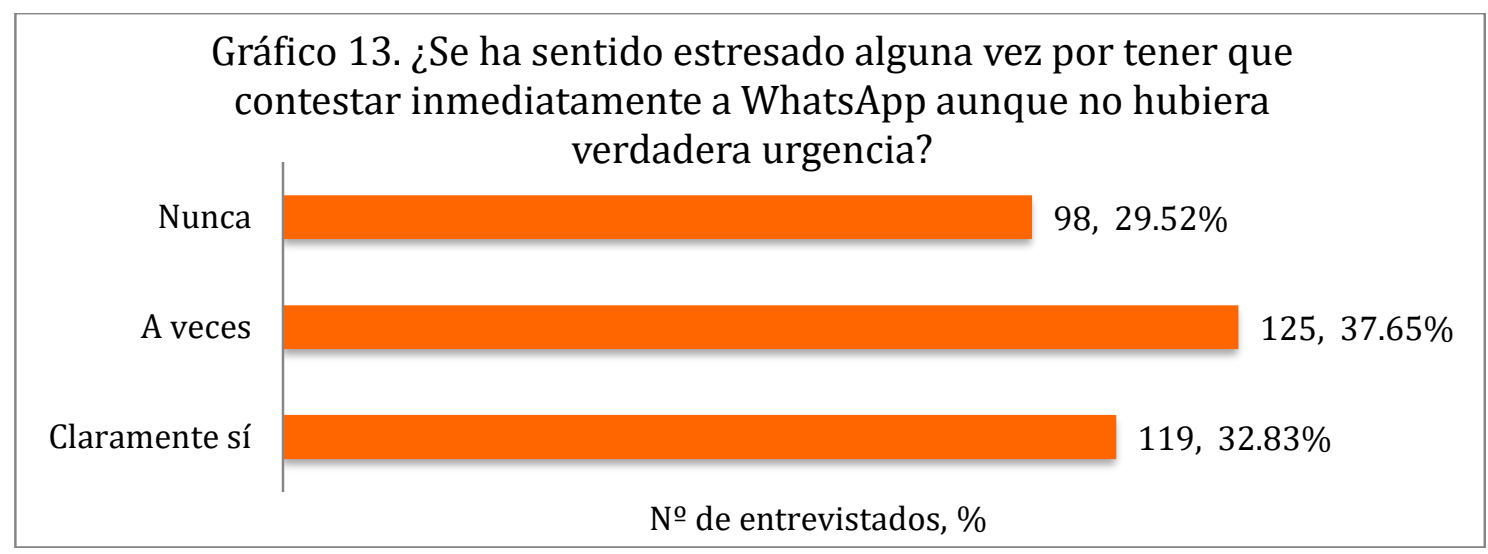

Fuente: elaboración propia

El grado de ansiedad que WhatsApp genera cuando los encuestados no tienen acceso a la aplicación o a Internet y, por tanto, a su uso, es elevado. El 24,40\% afirma sentirse enfadado si descubre no tener conexión móvil o acceso a Internet, y el 43,37\% a veces. Sin embargo, el $46,11 \%$ reconoce poder estar un periodo de tiempo sin utilizar WhatsApp y no sentirse aislado.

Contradictoriamente, solo el 23,80\% no se sentiría desconectado de su entorno social si se eliminara la aplicación de mensajería de su teléfono. El factor de coste de oportunidad (posibles mensajes que aporten valor a corto plazo) subyace en esa molestia en caso de carencia de conectividad. El always on es un eje angular de la Sociedad de la Banda Ancha (Fondevila-Gascón, 2013), que convierte a la conexión a Internet en una utility similar a las clásicas (agua, telefonía, electricidad o gas) a raíz de la necesidad constante de contenidos (FondevilaGascón, 2010).

El 46\% de los encuestados reconoce tener alguna vez la sensación de que WhatsApp no merece la pena por el estrés que les genera, aunque el 100\% de la muestra tiene la aplicación y la utiliza con frecuencia. 
Esto demuestra una vez más la dependencia y ansiedad que genera para un amplio porcentaje de los jóvenes.

\subsection{Uso de WhatsApp con fines académicos}

Para tratar de identificar el uso actual de la aplicación de mensajería instantánea en el ámbito académico, sus ventajas e inconvenientes, se realizaron una serie de preguntas sobre su uso y su proliferación actual.

El 97,29\% de los usuarios utiliza WhatsApp para asuntos relacionados con la universidad y el $96,99 \%$ pertenece a algún chat grupal relacionado con sus estudios. Es por tanto WhatsApp una aplicación difundida y utilizada por los universitarios españoles para asuntos académicos (Gráfico 14). El 87,05\% comparte enlaces relacionados con la universidad o el estudio, de forma personal o a través de estos grupos, lo que indica que los estudiantes comparten contenido educativo a través de WhatsApp y parece apoyar los resultados de Rambe y Chinpunza (2013).

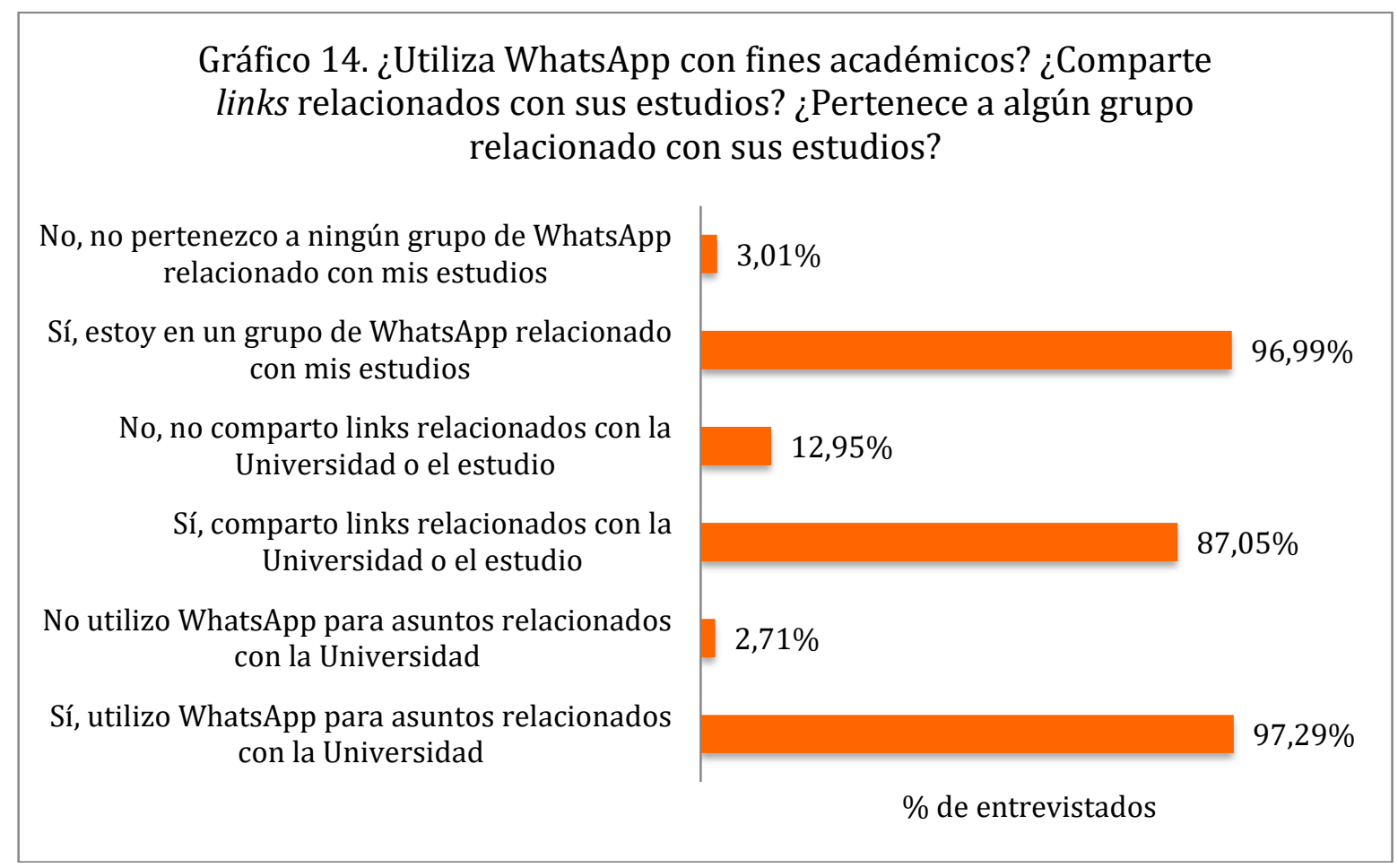

Fuente: elaboración propia

Sin embargo, solamente el $23 \%$ de los encuestados se comunica con profesores de la universidad a través de WhatsApp. De entre aquellos 
que no lo hace, el 49,22\% considera que hacerlo podría ser útil y, por tanto, tras descartar a aquellos usuarios que lo utilizan, pero no lo consideran útil $(5,30 \%)$, el $59,64 \%$ de los estudiantes reconocen la utilidad de implantar WhatsApp como medio de comunicación entre profesor y alumno.

\section{Discusión y conclusiones}

La tecnología, más concretamente las aplicaciones de mensajería instantánea como WhatsApp, y su aplicación al mundo educativo genera un dilema de nuestra sociedad. Asume gran difusión social, pudiendo ser su uso muy beneficioso por motivos de eficacia, inmediatez, coste o facilidad y puede convertirse en una gran amenaza por la dependencia y ansiedad que puede generar, así como sus consecuencias.

En el estudio se demuestra que los estudiantes universitarios españoles manifiestan un alto grado de dependencia a aplicaciones de mensajería instantánea como la estudiada. Un alto porcentaje de ellos sufre ansiedad y estrés derivados de un uso excesivo, que puede desembocar tanto en problemas de salud como en un peor rendimiento académico. En torno al 97\% utiliza la aplicación más de 10 veces al día, y el 52,40\% reconoce perder horas de sueño por mantener conversaciones nocturnas de WhatsApp. El 50\% sufre del síndrome de "vibración fantasma" y el $37 \%$ revisa su teléfono en caso de no recibir mensajes o llamadas en unas horas. Para el 54,22\% y el 59,04\%, leer o escribir un WhatsApp es su primera y última actividad diaria, respectivamente.

Otro indicio de la adicción que los jóvenes sufren es que el 93,67\% lo llega a encontrar molesto, más de dos tercios sienten estrés al tener que contestar inmediatamente y el 53,89\% reconoce que se sentiría solo si no pudiera utilizarlo durante un tiempo.

Desde el punto de vista del educador, esta dependencia es preocupante, ya que puede afectar de forma directa reduciendo la concentración y por tanto el rendimiento de los alumnos al suponer una clara fuente de distracción. También puede afectar de forma indirecta en los estudios, 
ya que genera estrés y ansiedad, los cuales acentúan este descenso en el rendimiento académico.

Sin embargo, su uso se está implantando de forma progresiva en el mundo educativo. El 97,29\% utiliza WhatsApp para asuntos relacionados con la universidad, y el $96,99 \%$ pertenece a grupos relacionados con sus estudios. Sin embargo, solo el 23\% se relaciona con profesores a través de esta aplicación. El 59,64\% lo considera buen medio para este tipo de relaciones. WhatsApp, por tanto, se convierte en una plataforma utilizada en el entorno académico entre alumnos, pero no ampliamente en las relaciones alumnos-profesores.

En conclusión, la app de mensajería instantánea WhatsApp genera estrés y ansiedad entre los usuarios jóvenes y, pese a que su uso está cada vez más extendido en el ámbito educativo debido a las ventajas que ofrece, puede reducir el rendimiento académico. El estudio cuenta con validez interna y externa, pudiendo ser extrapolado a otros países en los que la penetración y disponibilidad de aplicaciones de mensajería instantánea entre los jóvenes sea similar.

Todos los participantes del estudio fueron voluntarios elegidos al azar y pertenecen a diferentes comunidades autónomas españolas. Se encuentran estudiando grados diferentes en variadas facultades de la universidad. El error de media no existe, al haber depurado la muestra, eliminando aquellas encuestas personales con respuestas contradictorias. Además, no hubo ocasión de maduración o pérdida de sujetos al no prolongarse las encuestas personales (adaptando la técnica de la entrevista) más de 15-20 minutos. Las instrucciones y preguntas expuestas a los sujetos fueron exactamente las mismas, sin procedimiento ciego, y al realizarse en la biblioteca o en las facultades, situaciones similares, la influencia del entorno es mínima.

Consideramos que en el entorno analizado no se utiliza WhatsApp de manera especial, al no ser un mecanismo implantado ni utilizado por la propia institución entre las relaciones profesor-alumno. Al tratarse de una aplicación gratuita con necesidad de una tarifa mínima de acceso a Internet, no existe sesgo por ingresos. Los realizadores de la investigación son imparciales a la aplicación. Por los motivos 
expuestos, consideramos que el estudio posee la validez interna y externa necesaria.

- Investigación financiada - "Sistemas Innovadores de Monetización del Periodismo Digital (SIMPED)", con financiación pública de la Generalitat de Cataluña (2014 SGR 1290), y "Nuevas Formas de Publicidad Interactiva en Televisión, Internet y los Medios Digitales. Aplicaciones Reales en HbbTV", financiado por el Ministerio de Economía, Industria y Competitividad, referencia: CSO2017-88895-R (MINECO/FEDER).

\section{Referencias}

AIMC (2017). Datos de audiencia en España. Madrid: AIMC-Asociación para la Investigación de Medios de Comunicación.

AIMC (2018). Estudio General de Medios octubre 2017- mayo 2018 (EGM). Madrid: AIMC-Asociación para la Investigación de Medios de Comunicación.

American Psychiatric Association (2018). DSM-5. manual Diagnóstico y estadístico de los trastornos mentales. Virginia: American Psychiatric Association.

Andújar-Vaca, A. \& Cruz-Martínez, M.-S. (2017). "Mensajería instantánea móvil: WhatsApp y su potencial para desarrollar las destrezas orales". Comunicar 25(50), 43-52. http://doi:10.3916/c50-2017-04.

Asociación Americana de Psiquiatría (2014). Guía de consulta de los criterios diagnósticos del DSM-5. Virginia: Asociación Americana de Psiquiatría, edición en español.

Balding, R. (2012). Turn off your smart phone to beat stress. British Psychological Society's Division of Occupational Psychology Conference, Chester, England.

Bansal, T. \& Joshi, D. (2014). "A Study of Students Experiences of WhatsApp Mobile Learning”. Global Journal of Human Social Science Research, 14(4).

Bouhnik, D. \& Deshen, M. (2014). "WhatsApp goes to school: Mobile instant messaging between teachers and students". Journal of Information Technology Education: Research, 13, 217-231. 
Buschmann Iversen, T., Melby, L., \& Toussaint, P. (2013). "Instant messaging at the hospital: Supporting articulation work?" International Journal of Meducal Informatics, 82, 753-761.

Comisión Nacional de los Mercados y la Competencia (2017). Panel de Hogares. Barcelona: CNMC.

Dietz, S. \& Henrich, C. (2014). "Texting as a distraction to learning college students". Elsevier. Computers in Human Behaviour, 36, 163-167.

Fondevila-Gascón, J. F. (2010). "El cloud journalism: un nuevo concepto de producción para el periodismo del siglo XXI". Observatorio (OBS*) Journal, 4(1), 19-35.

Fondevila-Gascón, J. F. (2012). "Connected Television: Advantages and Disadvantages of the HbbTV Standard". Cuadernos de Información, 32, 11-20.

Fondevila-Gascón, J. F. (2013). "Periodismo ciudadano y cloud journalism: un flujo necesario en la Sociedad de la Banda Ancha”. Comunicación y Hombre, 9, 25-41.

Fondevila-Gascón, J. F., Carreras Alcalde, M., Mir-Bernal, P, Del Olmo Arriaga, J.-L. \& Pesqueira Zamora, M. J. (2014). “El impacto de la mensajería instantánea en los estudiantes en forma de estrés y ansiedad para el aprendizaje: Análisis empírico". Revista DIM, 10(30), 1-15.

Frances, A. (2013). "The past, present and future of psychiatric diagnosis". World Psychiatry. 12(2), 111-112.

Fundación Telefónica (2017). Sociedad Digital en España, 2017. Barcelona: Ed. Ariel.

Gallardo Echenique, E. (2014). "An Investigation of the Social and Academic Uses of Digital Technology by University Students". UT. Revista de Ciències de l'Educació, 2: 109-110.

Hrastinski, S., Edman, A., Andersson, F., Kawnine, T. \& Soames, C. (2012). "Informal math coaching by instant messaging: Two case studies of how university students coach K-12 students". Interactive Learning Environments, 22(1), 84-96.

Huang, H. \& Leung, L. (2009). "Instant messaging addiction among teenagers in China: shyness, alienation, and academic performance decrement". Cyberpsychol Behavior. 12(6), 675-679.

Hyewon, Kim, Lee, M. Y. \& Minjeong, K. (2014). "Effects of mobile instant messaging on collaborative learning processes and 
outcomes: The case of South Korea". Educational Technology \& Society, 17(2), 31-42.

Jatuf, J. D. (2014). El WhatsApp como herramienta de intervención didáctica para fomentar el aprendizaje cooperativo. X Jornadas de Material Didáctico y Experiencias Innovadoras en Educación Superior. Buenos Aires: Ciudad Autónoma de Buenos Aires. Lira-Rodríguez, M. C., Reyes-Hernández, K. L., Reyes-Hernández, P. O., López-Cruz, G., Reyes-Gómez, U.; De La Osa-Busto, M., Perea-Martínez, A.; Colón-Cuesta, F. \& Hernández-Lira, S. (2017). “¿Es el WhatsApp un Distractor en el Rendimiento Escolar de los Estudiantes?”. Boletín Clínico del Hospital Infantil del Estado de Sonora, 34(1), 26-34.

Ljungstrand, P. \& Af Segerstad, Y. H. (2000). "Awareness of presence, instant messaging and WebWho". ACM SIGGroup Bulletin, 21(3), 21-27.

Marqués-Pascual, J. (2016). Politica y Propaganda. Medios de Comunicación y opinión pública. Barcelona: UOC.

Molina del Peral, J. A. (2012). SOS... Tengo una adicción. Madrid: Ediciones Pirámide.

Montag, C., Błaszkiewicz, K., Lachman, B., Sariyska, R., Andone, I., Trendafilov, B. \& Markowetz, A. (2015). "Recorded Behavior as a Valuable Resource for Diagnostics in Mobile Phone Addiction: Evidence from Psychoinformatics". Behavioral Sciences, 5, 434-442.

Organista-Sandoval, J., Mcanally-Salas, L. \& Lavigne, G. (2017). “El teléfono inteligente (smartphone) como herramienta pedagógica". Revista de innovación educativa, 5(1).

Quan-Haase, A. \& Young, A. L. (2010). "Uses and gratifications of social media: A comparison of Facebook and Instant Messaging”. Bulletin of Science Technology \& Society, 30(5), 350361.

Rambe, P. \& Bere, A. (2013). Using mobile instant messaging to leverage learner participation and transform pedagogy at a South African University of Technology. British Journal of Educational Technology, 44(4): 544-561.

Rambe, P. \& Chipunza, C. (2013). "Using mobile devices to leverage student access to collaboratively-generated resources: A case 
of WhatsApp instant messaging at a South African University". ICAICTE-13.

Rubio Romero, J. \& Perlado Lamo de Espinosa, M. (2015). “El fenómeno WhatsApp en el contexto de la comunicación personal: una aproximación a través de los jóvenes universitarios". Revista Icono14 Revista cientifica de Comunicación y Tecnologias emergentes, 13(2), 73-94 DOI https://doi.org/10.7195/ri14.v13i2.818.

Sáinz-Peña, R. M. (coord.). La sociedad de la información en España 2016. Barcelona: Ariel.

Sánchez, D. \& Lázaro, P. (2017). "La adicción al WhatsApp en adolescentes y sus implicaciones en las habilidades sociales". Tendencias Pedagógicas, 29.

Sheer, V. \& Rice, R. (2017). "Mobile instant messaging use and social capital: Direct and indirect association with employee outcomes". Information \& Management, 54(1), 90-102.

Sultan, A. J. (2013). "Addiction to mobile text messaging applications is nothing to "lol" about". The Social Science Journal, 51(1), 5769.

Tresáncoras, A. G., García-Oliva, C. \& Piqueras, J. A. (2016). "Relación del uso problemático de WhatsApp con la ansiedad y personalidad en adolescentes". Revista Saludy Drogas, 17(1), 27-36.

Vidales-Bolaños, M. J. \& Sádaba-Chalezquer, C. (2017).

"Adolescentes conectados: La medición del impacto del móvil en las relaciones sociales desde el capital social". Comunicar, 53, 19-28. https://doi.org/10.3916/C53-2017-02.

Yeboah, J. \& Ewur, G. D. (2014). "The impact of WhatsApp Messenger usage on students' performance in tertiary institutions in Ghana". Journal of Education and Practice, 5(6). 



\title{
¿Cómo interactúan los adolescentes con los videojuegos? Preferencias y habilidades performativas
}

\author{
Juan Manuel Muñoz González - Universidad de Córdoba, \\ Esapaña, UCO juan.manuel@,uco.es
}

Blas Segovia Aguilar - Universidad de Córdoba, España, UCO bsegovia@uco.es

Cómo citar: J M Muñoz González, B Segovia Aguilar (2019): “ ¿Cómo interactuan los adolescentes con los videojuegos? Preferencias y habilidades performativas”. En V Tur-Viñes/M J González-Río/R S ContrerasEspinosa (Eds.) Jóvenes / Medios y cultura colaborativa. Cuadernos Artesanos de Comunicación, cac157, pp 251-282. La Laguna (Tenerife): Latina. DOI: $10.4185 / \operatorname{cac} 157$

\begin{abstract}
s
Introducción. En este estudio se analiza la influencia de los videojuegos en procesos de socialización de adolescentes, en especial el desarrollo de hábitos de seguridad, dedicación y preferencias de uso de adolescentes españoles de 12 a 17 años. Metodología. Se ha empleado una metodología cuantitativa, de carácter descriptivo, a través del uso de un cuestionario creado ad hoc conformado por 13 ítems relacionados con videojuegos y uso de los medios. Resultados. Los principales resultados obtenidos muestran que los adolescentes españoles muestran una actitud de indiferencia en cuanto a la adopción de hábitos de seguridad en el consumo de videojuegos. Discusión y conclusiones. A modo de conclusión, se manifiesta que los chicos están más motivados en el uso de videojuegos que las chicas, lo que nos hace plantearnos las causas por las que se dan este tipo de
\end{abstract}


preferencias en torno a los videojuegos, así como en el desarrollo de hábitos de seguridad en los mismos,

\section{Keywords}

Videojuegos; socialización; adolescentes; alfabetización transmedia;

\section{Contents}

1. Introducción. 2. Objetivos. 3. Método. 3.1. Muestreo y Participantes. 3.2. Instrumento de recogida de datos. 3.3. Procedimiento. 3.4. Análisis de datos. 4. Resultados. 4.1. Dedicación de los adolescentes en el consumo de medios. 4.2. Gustos de los adolescentes en el consumo de videojuegos. 4.3. Hábitos de seguridad de los adolescentes en el consumo de videojuegos. 4.4. Estudio Correlacional. 4.5. Modelos predictivos de las dimensiones del cuestionario. 5. Discusión y conclusions. 5.1. Dedicación de los adolescentes en el consumo de medios. 5.2. Gustos de los adolescentes en el consumo de videojuegos. 5.3 Hábitos de seguridad de los adolescentes en el consumo de videojuegos. 6. Notes. 7. Referencias bibliográficas.

\section{Introducción}

L

A TRANSICIÓN de la sociedad de la información a la del conocimiento está siendo favorecida por el acelerado desarrollo tecnológico de las redes y dispositivos móviles del que emerge una nueva ecología de medios (Scolari, 2012, 2015) y nuevas formas culturales de apropiación e interacción con los medios. La cultura de la participación enunciada por Jenkins (2006) se incrementa en la medida que el desarrollo e hibridación de nuevos terminales, redes o productos mediáticos potencian entre los adolescentes y la ciudadanía nuevas formas de aprender y (re)construir la cultura popular. La aparición de Facebook (2004), YouTube (2005), Google Docs (2006), iPhone o iPad (2010) y la incorporación de nuevas tecnologías como la computación en la nube -cloud computing- (Amazon AWS, 2006; iCloud 2010) evidencian una aceleración en las tecnologías que traen como consecuencia esas nuevas prácticas culturales.

El acceso de los y las adolescentes a estas herramientas para el consumo, la comunicación, para la creación o gestión individual y 
grupal de contenidos, provocan que la escuela, como institución responsable de la alfabetización tradicional y de la alfabetización y educación mediática, se enfrente al nuevo reto que supone perder el protagonismo en la gestión de los aprendizajes, cuestión que provoca crecientes tensiones documentadas en investigaciones sobre el tema (Area, 2010; Balanskat, Blamire \& Kefala, 2006; Scolari, 2018; Segovia et al, 2016). Niños y adolescentes aprenden con las tecnologías en espacios diferentes a la escuela, con agentes diferentes y estrategias vinculadas a nuevos paradigmas de aprendizaje como el conectivismo defendido por George Siemens (2010) o la pedagogía de la interactividad (Aparici \& Silva, 2012).

Esta novedosa situación, propia del siglo XXI, plantea nuevos retos a investigadores del campo de la comunicación y de la educación, pues muchas de las competencias que los jóvenes aprenden en la interacción con las modernas tecnologías las adquieren en contextos no escolares, en cooperación con sus iguales o autónomamente a través de la red. Estos nuevos escenarios en los que los chicos y chicas aprenden, crean, se comunican y juegan nos sitúan ante un nuevo paradigma respecto a la alfabetización y educación mediática, lo que influye en la necesaria revisión conceptual. Desde esta perspectiva, se amplifica el campo con aportaciones como las derivadas proyecto Transmedia Literacy (Scolari, 2018) para identificar el amplio abanico de competencias y estrategias de aprendizaje generadas por las nuevas sinergias y productos culturales, como la transmedia storytelling (Jenkins, 2006, 2010; Scolari, 2013), las experiencias con videojuegos o las de comunidades virtuales de youtubers, fanfictions o gamers.

En consecuencia, resulta necesaria la adecuación de los enfoques de New Media Literacy (Gee, 2004), la Alfabetización Mediática e Informacional, (Wilson, 2012) o las Multialfabetizaciones (Tyner, Gutiérrez \& Torrego, 2015) pues sus orientaciones están más vinculadas a la educación formal, complementándolos con otras perspectivas que se preocupan por los aprendizajes en espacios no formales, como es el caso de la Alfabetización Transmedia (Scolari, 2018)

Ese es el punto de partida del presente artículo, que es parte del proyecto de investigación $\mathrm{I}+\mathrm{D}+\mathrm{i}$ "Transalfabetismos. Competencias transmedia y estrategias informales de aprendizaje de los adolescentes" 
${ }^{6}$, que pretende analizar los procesos de adquisición y construcción colectiva de competencias transmedia por parte de los adolescentes españoles fuera del sistema de la educación formal. Las prácticas de aprendizaje analizadas se relacionan con los conocimientos básicos que adquieren para la navegación en redes digitales, las experiencias de participación en la creación y distribución en plataformas colaborativas de obras audiovisuales o escritas (fanfiction) o cómo aprenden a resolver los problemas que les surgen cuando participan en videojuegos o juegos digitales.

En nuestro caso, nos centraremos en estudiar la relación de los adolescentes de 12 a 15 años con los videojuegos a partir de los datos obtenidos a través de un cuestionario ad hoc: sus gustos, hábitos de uso y dedicación, los dispositivos electrónicos desde los que juegan, la comparativa con el consumo de otros medios de comunicación y ocio.

\section{¿Qué y cómo aprenden los adolescentes con los videojuegos?}

Los videojuegos, como productos culturales y digitales, según Paul Gee (2007) son sistemas que integran narrativa, resolución de problemas, control motriz, noción de protagonismo, etc. y en los últimos años se han convertido en artículo de consumo masivo en todas las franjas de edades de la población.

Los indicadores económicos nos muestran que la industria del videojuego aumenta su impacto año tras año en nuestro país, que se sitúa entre los cuatro primeros de la UE. Según datos de la Asociación Española de Videojuegos (AEVI, 2017) en 2016 los ingresos en este ámbito económico (PC, consolas, móviles, tablets, etc.) ascendieron a 1.163 millones de euros, lo que equivale al 0,11\% del PIB. Dentro de las industrias de ocio audiovisual está, en primer lugar, por delante del cine (601 M de $€$ ), con un aumento del 7,4\% respecto a 2015 . Se estima que implica a 15 millones de videojugadores, siendo la franja de 11 a 14 años la mayoritaria.

En cuanto a tipos de videojuegos, los mayoritarios son los físicos, seguidos por los online y Apps Móviles, cifras que evolucionan

\footnotetext{
${ }^{6}$ Proyecto $\mathrm{I}+\mathrm{D}+\mathrm{i}$ financiado por el Ministerio de Economía y Competitividad (CSO2014-56250-R) (2015-2018) https://alfabetismotransmedia.org/
} 
continuamente pues, por ejemplo, el consumo on line se incrementó en 30,82\% respecto al 2015 (AEVI, 2017).

Estas referencias nos sirven para situarnos en relación al impacto que, como productos mediáticos, tienen entre los adolescentes, pues es evidentemente que ya forman parte de sus tareas cotidianas junto con las redes sociales.

Sin embargo, la atención que se dedica a los videojuegos en ámbitos educativos es aun escasa y hasta cierto punto contradictoria, pues las dos principales líneas de estudio que predominan están relacionadas con aspectos preventivos o vacunadores (riesgos que entrañan para la infancia y adolescencia el consumo de videojuegos) (Castellana Rosell et al, 2007; Chamarro, 2014); y, por otro, la vinculada a la alfabetización mediática en el juego digital o ludoteracy (Aranda, Sánchez-Navarro y Martínez, 2015; Aranda et al., 2017).

En este caso, el interés se centra en la atención a los videojuegos como recursos educativos (serious games y gammificación), un campo muy fructífero vinculado al Digital Game-Based Learning (Prensky, 2007), Edutaintment o entretenimiento educativo (Lacasa, 2011) o Serious Game (Ritterfeld, Cody \& Vorderer, 2009); aunque también encontramos estudios sobre el videojuego como objeto de estudio, es decir, centrados en entender el videojuego, cómo se juega o cómo se producen juegos digitales (Pousen y Gatzidis, 2010).

\section{Alfabetización transmedia y videojuegos}

El uso de videojuegos para el ocio está favoreciendo entre los jugadores aprendizajes provocados por las situaciones a las que debe enfrentarse individual o cooperativamente. Estos se identifican en estrategias de aprendizaje informal, a veces mucho más significativas y creativas que las que se provocan en los contextos escolares, pues dan respuesta a problemas que pueden ser complejos y que requieren la movilización de conocimientos, habilidades y emociones del jugador. La investigación realizada sobre videojuegos, en la que han participado adolescentes de Andalucía, Cataluña, Galicia, Madrid y Valencia, nos aporta datos que nos han permitido delimitar las habilidades y aprendizajes que se vinculan con competencias transmedia relacionadas con la producción, la gestión de contenidos, la producción 
de narrativas y criterios estéticos, las relacionadas con privacidad y prevención de riesgos, las vinculadas con la ideología y la ética y las performativas, especialmente conectadas con el juego y habilidades lúdicas.

El análisis de las prácticas y usos que los adolescentes hacen de los videojuegos nos permiten constatar que a través de ellas desarrollan estas competencias junto con diversas estrategias de aprendizaje a las que antes hemos aludido. Ello nos permite trazar las relaciones que se establecen en estas edades con los videojuegos, los aprendizajes y las interacciones con otros gamers, en definitiva, nos ayuda a identificar elementos clave para una adecuada alfabetización transmedia.

\section{Objetivos}

El estudio que presentamos aborda varios objetivos que detallaremos a continuación:

1. Describir las opiniones de adolescentes pertenecientes a las Comunidades Autónomas de Andalucía, Cataluña, Galicia, Madrid y Valencia respecto a la dedicación, gustos y hábitos de seguridad relacionados con el consumo de videojuegos.

2. Analizar si existen diferencias entre las 3 dimensiones que componen el Cuestionario Transliteracy y las variables independientes: sexo, edad, ciudad de residencia, tipo de familia, realización de actividades extraescolares y tipos; así como disponibilidad y usos de dispositivos electrónicos como el ordenador, portátil, teléfono móvil, tableta digital, conexión wifi, consola y consola portátil.

3. Observar la existencia o no de correlaciones entre las diferentes dimensiones del cuestionario.

4. Establecer modelos para predecir, por una parte, los hábitos de seguridad de los adolescentes en función de la dedicación y de los gustos por los videojuegos; y, por la otra, estos últimos en función de la dedicación en el consumo de medios. 


\section{Método}

\subsection{Muestreo y participantes}

En el presente estudio la selección de la muestra se llevó a cabo utilizando el procedimiento de muestreo no probabilístico o de conveniencia (Cuenca y Lozano, 2016) debido a que la metodología desarrollada en el aula, así como la aplicación del cuestionario, solo se pudieron realizar a los grupos de estudiantes a los que los investigadores de este proyecto tuvieron acceso durante el curso académico 2015-2016.

La muestra estuvo compuesta por un total de 237 sujetos: 49 estudiantes de pertenecientes a la Comunidad Autónoma de Andalucía, 57 a Cataluña, 39 a Galicia, 44 a la Comunidad Valenciana y 48 a la de Madrid.

En cuanto a la relación entre la edad y el sexo del alumnado, el rango de esta estuvo comprendido entre 12 y 17 años. En este sentido, el 46\% tenían 14 años, siendo un 59,6\% chicas y un 40,4\% chicos. El 24,1\% tenían 15 años, de los cuales el 45.6\% eran chicas y el 54,4\% chicos. Por otra parte, un 10,5\% tenían 13 años, de los cuales el 44\% eran chicas y el $56 \%$ chicos. El mismo porcentaje obtuvimos en el caso de los estudiantes son 16 años, de los cuales el 40\% eran chicas y el 60\% chicos. En cuanto al alumnado con 12 años, constituía el 6,8\% de la muestra, siendo el $68,8 \%$ chicas y el $31,3 \%$ chicos. Finalmente, el 2,1\% tenían 17 años, del cual el 60\% eran chicas y el 40\% chicos.

\subsection{Instrumento de recogida de datos}

El instrumento utilizado para llevar a cabo este estudio se trata de un cuestionario, elaborado ah hoc, denominado Cuestionario Transliteracy, cuya finalidad es recoger las opiniones de los adolescentes sobre el tiempo empleado en el uso de medios, sus gustos y preferencias en relación a las redes sociales y los videojuegos, así como los hábitos de seguridad que adoptan en el empleo de dichos recursos. Concretamente, en el presente estudio nos centraremos únicamente en el consumo de videojuegos, por lo que se ha realizado una selección de 14 ítems del citado cuestionario. La validación y fiabilidad del instrumento han sido medidas y corroboradas mediante diferentes análisis estadísticos. En cuanto a la validez de constructo, en primer 
lugar, hemos realizado un análisis factorial exploratorio, utilizando para la ejecución de esta prueba el método de Implementación óptima del Análisis Paralelo (PA) (Timmerman, \& Lorenzo-Seva, 2011), junto con un proceso de extracción de factores comunes "mínimos cuadrados no ponderados robusto" (RULS), considerando un procedimiento de rotación "Oblimin Ponderado" (Lorenzo-Seva, 2000), cuyo índice Kaiser-Meyer-Olkin (KMO) fue de 0,76, test de esfericidad de Bartlett con $\mathrm{p}=0,000$ y análisis de residuales con $\mathrm{RMSR}=, 0529$, considerado adecuado para el modelo (Aldas y Uriel, 2017). Por otra parte, la varianza presenta una distribución no normal, medida a través de la prueba de Kolmogorov-Smirnov $(p=, 000)$. El resultado de la extracción de los componentes principales refleja la existencia de 3 factores, donde la varianza total explicada es de 55,21\%, lo cual revela un equilibrio apropiado entre los componentes del instrumento, representativos del concepto teórico.

Tabla 1 Matriz de componentes rotados en el análisis factorial exploratorio (AFE).

\begin{tabular}{|l|l|l|l|}
\hline & $\begin{array}{l}\text { Factor 1. } \\
\text { Dedicación } \\
\text { en el } \\
\text { consumo } \\
\text { de medios }\end{array}$ & $\begin{array}{l}\text { Factor 2. } \\
\text { Gustos en el } \\
\text { consumo de } \\
\text { videojuegos }\end{array}$ & $\begin{array}{l}\text { Factor 3. Hábitos de } \\
\text { seguridad en el } \\
\text { consumo de } \\
\text { videojuegos }\end{array}$ \\
\hline 1. Miro la televisión &, 535 & & \\
\hline 2. Juego a videojuegos &, 561 &, 581 & \\
\hline 3. Juego a juegos de mesa &, 425 &, 425 & \\
\hline $\begin{array}{l}\text { 4. Participo en blogs, } \\
\text { webs, foros de Internet... }\end{array}$ &, 451 & \\
\hline $\begin{array}{l}\text { 4. Me gusta jugar a } \\
\text { videojuegos con los } \\
\text { amigos "on line" }\end{array}$ & &, 559 & \\
\hline $\begin{array}{l}\text { 5. Cuando vamos a casa } \\
\text { de los amigos, } \\
\text { acostumbramos a jugar a } \\
\text { videojuegos }\end{array}$ & & & \\
\hline $\begin{array}{l}\text { 6. Si me gusta una peli, } \\
\text { busco también el libro, }\end{array}$ & & & \\
\hline
\end{tabular}




\begin{tabular}{|c|c|c|}
\hline videojuego, la música... & & \\
\hline $\begin{array}{l}\text { 7. Busco en Internet } \\
\text { vídeos de las partidas de } \\
\text { mis videojuegos } \\
\text { preferidos. }\end{array}$ &, 574 & \\
\hline $\begin{array}{l}\text { 8. Me gusta hacer fan- } \\
\text { fictions de mis series, } \\
\text { pelis, videojuegos, } \\
\text { cómics... }\end{array}$ &, 730 & \\
\hline 9. Me gusta el cosplay &, 402 & \\
\hline $\begin{array}{l}\text { 10. Cuando quiero saber } \\
\text { cómo hacer una cosa, } \\
\text { busco en Internet } \\
\text { (tutoriales...) }\end{array}$ &, 344 & \\
\hline $\begin{array}{l}\text { 11. Antes de colgar una } \\
\text { foto mía en la red, me lo } \\
\text { pienso dos veces }\end{array}$ & &,- 371 \\
\hline $\begin{array}{l}\text { 12. Mirar demasiado } \\
\text { tiempo la pantalla puede } \\
\text { perjudicar la salud } \\
\text { (memoria, vista, etc.) }\end{array}$ & &,- 375 \\
\hline $\begin{array}{l}\text { 13. Hay sitios en la red } \\
\text { donde participo sin decir } \\
\text { quién soy (nickname) }\end{array}$ & &, 326 \\
\hline
\end{tabular}

Fuente: elaboración propia.

Con la intención de contrastar y confirmar el modelo extraído a través del AFE, hemos realizado un análisis factorial confirmatorio (AFC) mediante el programa estadístico AMOS, en su versión 23. Este análisis permite explicar las correlaciones entre un conjunto de variables observadas a través de un conjunto reducido de factores (Herrero, 2010). De este modo, es posible comprobar cómo cada variable está relacionada con su factor y si los factores están interrelacionados entre sí. Los resultados obtenidos del AFC, considerando el método de Máxima Verosimilitud (ML) para la extracción de factores comunes, en primera instancia, arrojaron valores por debajo de ,900, en el caso del ajuste relativo, por lo que se requirió comprobar el peso factorial de cada uno de los ítems dentro de los factores del modelo. En este 
sentido, el ítem 3 de la dimensión "Dedicación a los videojuegos", que hacía referencia al tiempo empleado a disfrutar con juegos de mesa, presentaba un valor factorial por debajo de ,30. En cuanto a su relevancia en el constructo teórico, tampoco suponía ser un ítem fundamental, ya que la temática tratada en el estudio se centra en los videojuegos y no en los juegos de mesa, por lo que se optó por su eliminación. Una vez eliminado dicho ítem, se procedió nuevamente a realizar el AFC, con el método de extracción mencionado anteriormente, tomando como referencia los valores de la función de discrepancia (chi-cuadrado), de ajuste relativo, así como los basados en la descentralización (RMSEA) mostrando unos índices de ajuste adecuados en función del modelo $(\chi 2=63,532$, gl. $=38$; NFI= 913; IFI= 963; TLI= 919; CFI=,961 RMSEA=,053), lo que llevó a aceptarlo, teniendo como base los resultados del AFE y las dimensiones teóricas consideradas en el mismo (Browne \& Cudeck, 1993; Byrne, 1994; Hu \& Bentler, 1998; Schumacker \& Lomax, 2004; Steiger, 2000).

Por otra parte, la medición de la fiabilidad del instrumento se ha llevado a cabo a través del enfoque de consistencia interna (Merino-Soto, 2016), obteniendo un Alfa de Cronbach de 0.71, lo cual refleja una fiabilidad aceptable de los ítems expresados en el cuestionario.

\subsection{Procedimiento}

A través de los 13 ítems medidos en escala Likert de 5 puntos, donde, en la primera dimensión, se aludía al tiempo empleado en el consumo de medios $(1=$ nunca a $5=$ cada día); y, en las dos restantes, se hacía referencia a los gustos y hábitos de seguridad de los adolescentes en el consumo de videojuegos $(1=$ totalmente en desacuerdo a 1 totalmente de acuerdo), se preguntó a los sujetos para conocer su opinión respecto a dichos aspectos, centrándonos en el uso de videojuegos. Además, se solicitó al alumnado que respondiese a una serie de preguntas directas que hacían alusión a sus datos personales (sexo, edad, ciudad de residencia y tipo de familia), académicos (actividades extraescolares y tipos) y disponibilidad y usos de dispositivos (PC, portátil, teléfono móvil, tableta digital, conexión wifi, consola y consola portátil)

$\mathrm{El}$ instrumento fue facilitado a los estudiantes al inicio de la dinámica basada en el uso de redes sociales y de videojuegos, dedicando 15 
minutos para su cumplimentación. Los investigadores del proyecto fueron los responsables tanto de llevar a cabo dicha metodología como de recoger los datos en todas las comunidades autónomas.

\subsection{Análisis de datos}

Los análisis que hemos llevado a cabo en este estudio y mediante los cuales hemos pretendido dar respuesta a los objetivos planteados son los siguientes:

- En primer lugar, hemos realizado un análisis descriptivo de las 13 variables que componían el cuestionario a través de los estadísticos de medida central (media) y de medida de dispersión (desviación típica).

- En segundo lugar, hemos llevado a cabo un análisis descriptivo de las 3 dimensiones del cuestionario, calculando la distribución de frecuencias, los estadísticos de medida central y las medidas de dispersión.

- En tercer lugar, realizamos diferentes análisis de varianza para comprobar si existía relación entre las dimensiones del cuestionario y las variables independientes que hacían alusión a sus datos personales (sexo, edad, ciudad de residencia y tipo de familia); académicos (realización de actividades extraescolares y tipos); así como de disponibilidad y usos de dispositivos (PC, portátil, teléfono móvil, tableta digital, conexión wifi, consola y consola portátil). Para ello, se llevaron a cabo las pruebas de $U$ de Mann Whitney y K de Kruskal Wallis, utilizando el paquete estadístico SPSS 23.

- En cuarto lugar, procedimos a comprobar la relación entre las dimensiones que componían el cuestionario mediante correlaciones bivariadas.

- Por último, realizamos regresiones lineales múltiples para predecir, en primer lugar, los hábitos de seguridad de los adolescentes españoles en función de la dedicación y de los gustos en el consumo de videojuegos; y, posteriormente, predecir estos últimos en función de la dedicación en el consumo de medios 


\section{Resultados}

En primer lugar, se presentan los resultados descriptivos de los 13 ítems que componen el cuestionario utilizado en el presente trabajo de investigación. En la tabla 2 podemos observar las medias y desviaciones típicas de los ítems que componen el cuestionario sobre alfabetización transmedia mediante el uso de videojuegos.

Tabla 2 Distribución de frecuencias de los items del cuestionario sobre sobre alfabetización transmedia mediante el uso de videojuegos.

\begin{tabular}{|c|c|c|c|}
\hline Factores & Ítem & M & DT \\
\hline \multirow{3}{*}{$\begin{array}{l}\text { Factor 1: Dedicación en } \\
\text { el consumo de medios }\end{array}$} & 1. Miro la televisión & 4,38 & 1,12 \\
\hline & 2. Juego a videojuegos & 2,97 & 1,36 \\
\hline & $\begin{array}{l}\text { 3. Participo en blogs, webs, foros de } \\
\text { Internet... }\end{array}$ & 1,83 & 1,17 \\
\hline \multirow[t]{7}{*}{$\begin{array}{l}\text { Factor 2. Gustos en el } \\
\text { consumo de videojuegos }\end{array}$} & $\begin{array}{l}\text { 4. Me gusta jugar a videojuegos con } \\
\text { los amigos "on line" }\end{array}$ & 2,76 & 1,72 \\
\hline & $\begin{array}{l}\text { 5. Cuando vamos a casa de los } \\
\text { amigos, acostumbramos a jugar a } \\
\text { videojuegos }\end{array}$ & 2,72 & 1,53 \\
\hline & $\begin{array}{l}\text { 6. Si me gusta una peli, busco también } \\
\text { el libro, videojuego, la música... }\end{array}$ & 2,83 & 1,54 \\
\hline & $\begin{array}{l}\text { 7. Busco en Internet vídeos de las } \\
\text { partidas de mis videojuegos } \\
\text { preferidos. }\end{array}$ & 2,46 & 1,63 \\
\hline & $\begin{array}{l}\text { 8. Me gusta hacer fan-fictions de mis } \\
\text { series, pelis, videojuegos, cómics... }\end{array}$ & 1,91 & 1,22 \\
\hline & 9. Me gusta el cosplay & 1,51 & 1,02 \\
\hline & $\begin{array}{l}\text { 10. Cuando quiero saber cómo hacer } \\
\text { una cosa, busco en Internet } \\
\text { (tutoriales...) }\end{array}$ & 4,13 & 1,12 \\
\hline \multirow{3}{*}{$\begin{array}{l}\text { Factor 3. Hábitos de } \\
\text { seguridad en el uso de } \\
\text { videojuegos }\end{array}$} & $\begin{array}{l}\text { 11. Antes de colgar una foto mía en la } \\
\text { red, me lo pienso dos veces }\end{array}$ & 4,16 & 1,25 \\
\hline & $\begin{array}{l}\text { 12. Mirar demasiado tiempo la } \\
\text { pantalla puede perjudicar la salud } \\
\text { (memoria, vista, etc.) }\end{array}$ & 4,08 & 1,23 \\
\hline & $\begin{array}{l}\text { 13. Hay sitios en la red donde } \\
\text { participo sin decir quién soy } \\
\text { (nickname) }\end{array}$ & 2,77 & 1,64 \\
\hline
\end{tabular}

Fuente: Elaboración propia.

A continuación, mostramos los resultados agrupados en función de las 3 dimensiones de las que consta el cuestionario. En este sentido, 
exponemos los datos descriptivos de cada una de las dimensiones, así como la existencia de diferencias estadísticamente significativas, atendiendo a las variables independientes del estudio relacionadas con sus datos personales, académicos, así como de disponibilidad y usos de dispositivos. Finalmente, se presenta la relación existente entre las dimensiones que componen el cuestionario, así como el establecimiento de un modelo predictor de los hábitos de seguridad de los adolescentes españoles en función de la dedicación y de los gustos en el consumo de videojuegos, así como de estos en función de la dedicación en el uso de medios.

\subsection{Dedicación de los adolescentes en el consumo de medios.}

En esta dimensión, agrupamos 3 ítems que hacían alusión a las opiniones de los adolescentes en cuando al consumo de medios. Concretamente, se alude al tiempo empleado en ver la televisión, jugar a videojuegos y participar en blogs, webs, foros de internet, etc.

En los resultados obtenidos en esta dimensión, se observó que los adolescentes manifiestan una dedicación de dos o más veces al mes respecto al consumo de medios $(\mu=3,05 ; 6=, 75)$.

En cuanto a las diferencias que el sexo, la realización de actividades extraescolares y de tiempo libre, la disponibilidad de dispositivos y su uso habitual establecían en relación a la dedicación de los adolescentes en el consumo de medios, la prueba $U$ de Mann Whitney para muestras independientes señaló, en primer lugar, que existían diferencias estadísticamente significativas en función del sexo de los estudiantes [ $U=3758,000,(111,126), z=-6,201, p<, 01]$. En este sentido, los chicos presentaban unos rangos promedios superiores a los de las chicas en cuanto a la dedicación en el consumo de medios. Respecto a la realización de actividades extraescolares y de tiempo libre, la misma prueba indicó que no había diferencias estadísticamente significativas. Centrándonos en la disponibilidad de dispositivos, así como en su uso habitual, la citada prueba señaló lo siguiente (ver tablas 3 y 4): 
Tabla 3 Comparativa de medias de la disponibilidad de dispositivos en relación a la dedicación en el consumo de medios.

\begin{tabular}{|c|c|c|c|}
\hline Dispositivo & $\begin{array}{l}\text { Existencia de } \\
\text { diferencias } \\
\text { estadísticamente } \\
\text { significativas }\end{array}$ & $\begin{array}{l}\text { Valor de } U \text { de } \\
\text { Mann Whitney }\end{array}$ & Resultado \\
\hline PC & $\mathrm{Si}$ & $\begin{array}{l}{[U=4340,000,} \\
(78,157), z=- \\
3,668, p<, 01]\end{array}$ & $\begin{array}{l}\text { Rangos promedios } \\
\text { superiores en los } \\
\text { adolescentes que } \\
\text { disponen de PC frente } \\
\text { a aquellos que no lo } \\
\text { poseen. }\end{array}$ \\
\hline Portátil & $\mathrm{No}$ & $\begin{array}{l}{[U=2090,500} \\
(20,217), z=- \\
274, p>, 05]\end{array}$ & $\begin{array}{l}\text { No hay diferencias } \\
\text { estadísticamente } \\
\text { significativas }\end{array}$ \\
\hline $\begin{array}{l}\text { Teléfono } \\
\text { móvil }\end{array}$ & $\mathrm{No}$ & $\begin{array}{l}{[U=555,000,(5,} \\
232), z=-, 166, \\
p>, 05]\end{array}$ & $\begin{array}{l}\text { No hay diferencias } \\
\text { estadísticamente } \\
\text { significativas }\end{array}$ \\
\hline $\begin{array}{l}\text { Tableta } \\
\text { digital }\end{array}$ & No & $\begin{array}{l}{[U=3776,500,} \\
(39,198), z=- \\
218, p>, 05]\end{array}$ & $\begin{array}{l}\text { No hay diferencias } \\
\text { estadísticamente } \\
\text { significativas }\end{array}$ \\
\hline $\begin{array}{l}\text { Conexión } \\
\text { Wifi }\end{array}$ & $\mathrm{No}$ & $\begin{array}{l}{[U=707,500,(9,} \\
228), z=-1,594, \\
p>, 05]\end{array}$ & $\begin{array}{l}\text { No hay diferencias } \\
\text { estadísticamente } \\
\text { significativas }\end{array}$ \\
\hline Consolas & $\mathrm{No}$ & $\begin{array}{l}{[U=2905,500} \\
(36,201), z=- \\
1,899, p>, 05]\end{array}$ & $\begin{array}{l}\text { No hay diferencias } \\
\text { estadísticamente } \\
\text { significativas }\end{array}$ \\
\hline $\begin{array}{l}\text { Consolas } \\
\text { portátiles }\end{array}$ & $\mathrm{Si}$ & $\begin{array}{l}{[U=5242,000,} \\
(91,146), z=- \\
2,754, p<, 01]\end{array}$ & $\begin{array}{l}\text { Rangos promedios } \\
\text { superiores en los } \\
\text { adolescentes que } \\
\text { disponen de consola } \\
\text { portátil frente a aquellos } \\
\text { que no la poseen. }\end{array}$ \\
\hline
\end{tabular}

Fuente: Elaboración propia. 
Tabla 4 Comparativa de medias del uso habitual de dispositivos en relación a la dedicación en el consumo de medios.

\begin{tabular}{|c|c|c|c|}
\hline Dispositivo & $\begin{array}{l}\text { Existencia de } \\
\text { diferencias } \\
\text { estadísticamente } \\
\text { significativas }\end{array}$ & $\begin{array}{l}\text { Valor de } U \text { de } \\
\text { Mann Whitney }\end{array}$ & Resultado \\
\hline PC & $\mathrm{Si}$ & $\begin{array}{l}{[U=4078,000,} \\
(166, \quad 70), \quad z=- \\
3,649, p<, 01]\end{array}$ & $\begin{array}{l}\text { Rangos } \\
\text { promedios } \\
\text { superiores en los } \\
\text { adolescentes que } \\
\text { usan } \\
\text { habitualmente el } \\
\text { PC frente a } \\
\text { aquellos que no lo } \\
\text { utilizan. }\end{array}$ \\
\hline Portátil & $\mathrm{No}$ & $\begin{array}{l}{[U=5624,000,(74,} \\
163), \quad z=-, 840, \\
p>, 05]\end{array}$ & $\begin{array}{l}\text { No hay } \\
\text { diferencias } \\
\text { estadísticamente } \\
\text { significativas }\end{array}$ \\
\hline $\begin{array}{l}\text { Teléfono } \\
\text { móvil }\end{array}$ & No & $\begin{array}{l}{[U=776,000, \quad(10,} \\
226), \quad z=-1,692, \\
p>, 05]\end{array}$ & $\begin{array}{l}\text { No hay } \\
\text { diferencias } \\
\text { estadísticamente } \\
\text { significativas }\end{array}$ \\
\hline Tableta digital & $\mathrm{Si}$ & $\begin{array}{l}{[U=5613,000,(98,} \\
139), \quad z=-2,327, \\
p<, 05]\end{array}$ & $\begin{array}{l}\text { Rangos } \\
\text { promedios } \\
\text { superiores en los } \\
\text { adolescentes que } \\
\text { usan } \\
\text { habitualmente la } \\
\text { tableta digital } \\
\text { frente a aquellos } \\
\text { que no lo utilizan. }\end{array}$ \\
\hline $\begin{array}{l}\text { Conexión } \\
\text { Wifi }\end{array}$ & No & $\begin{array}{l}{[U=1604,000,(16,} \\
221), \quad z=-, 625, \\
p>, 05]\end{array}$ & $\begin{array}{l}\text { No hay } \\
\text { diferencias } \\
\text { estadísticamente } \\
\text { significativas }\end{array}$ \\
\hline Consolas & $\mathrm{Si}$ & $\begin{array}{l}{[U=4206,000,} \\
(130, \quad 107), \quad z=- \\
5,284, p<, 01]\end{array}$ & $\begin{array}{l}\text { Rangos } \\
\text { promedios } \\
\text { superiores en los } \\
\text { adolescentes que } \\
\text { usan } \\
\text { habitualmente la } \\
\text { consola frente a }\end{array}$ \\
\hline
\end{tabular}




\begin{tabular}{|l|l|l|l|}
\hline & & & $\begin{array}{l}\text { aquellos que no lo } \\
\text { utilizan. }\end{array}$ \\
\hline $\begin{array}{l}\text { Consolas } \\
\text { portátiles }\end{array}$ & $\mathrm{Si}$ & $\begin{array}{l}{[U=1494,000,} \\
(212, \quad 25), \quad \mathrm{z}=-\end{array}$ & $\begin{array}{l}\text { Rangos } \\
\text { promedios } \\
\text { superiores en los } \\
\text { adolescentes que } \\
\text { usan } \\
\end{array}$ \\
& & & $\begin{array}{l}\text { habitualmente la } \\
\text { consola portátil } \\
\text { frente a aquellos } \\
\text { que no la utilizan. }\end{array}$ \\
\hline
\end{tabular}

Fuente: Elaboración propia.

Para determinar la influencia de la edad, ciudad de residencia, tipo de familia, así como de actividades extraescolares que practican los adolescentes en la dedicación en el uso de medios, hemos realizado comparaciones múltiples de media a través de análisis $K$ de Kruskal $W$ allis. Los resultados obtenidos mostraron que no había diferencias estadísticamente significativas entre la edad y la dedicación de los adolescentes en el uso de medios.

En cuanto a la relación de la ciudad de residencia y el tiempo empleado en la utilización de medios, los análisis mostraron resultados similares a los anteriores, es decir no existían diferencias estadísticamente significativas.

Centrándonos en el tipo de familia, la misma prueba arrojó resultados idénticos a los anteriores, es decir, no hay diferencias estadísticamente significativas entre el tipo de familia de los adolescentes y la dedicación en el consumo de medios.

Por último, y haciendo referencia al tipo de actividades extraescolares y de tiempo libre de los adolescentes y su relación con la dedicación en el consumo de medios, la citada prueba indicó que tampoco existían diferencias significativas.

\subsection{Gustos de los adolescentes en el consumo de videojuegos.}

Esta dimensión está compuesta por 7 ítems en los que se recogen las opiniones de los adolescentes en relación a sus gustos y preferencias en el consumo de videojuegos. Específicamente, se hace referencia a aspectos relacionados con el juego on-line, en casa sus iguales, 
búsqueda de videojuegos en función de la visualización de una película, de tutoriales para aprender a hacer cosas, así como vídeos de partidas de videojuegos; también se alude a hacer fan-fictions y cosplay.

En los resultados obtenidos en esta dimensión, observamos que los adolescentes manifiestan una opinión de parcialmente en desacuerdo respecto a sus gustos y preferencias en el consumo de videojuegos $(\mu$ $=2,61 ; 6=, 80)$.

Por otra parte, la prueba $U$ de Mann Whitney, llevada a cabo para identificar posibles diferencias en relación al sexo, la realización de actividades extraescolares y de tiempo libre, la disponibilidad de dispositivos y su uso habitual en relación a los gustos de los adolescentes en el consumo de videojuegos señaló, en primer lugar, que existían diferencias estadísticamente significativas en función del sexo de los adolescentes [ $U=3607,500,(111,126), z=-6,437, p<, 01]$. En este sentido, los chicos presentaban unos rangos promedios superiores a los de las chicas en cuanto a los gustos en el consumo de videojuegos. Respecto a la realización de actividades extraescolares y de tiempo libre, la misma prueba indicó que no había diferencias estadísticamente significativas. Centrándonos en la disponibilidad de dispositivos, así como en su uso habitual, la citada prueba señaló lo siguiente (ver tablas 5 y 6 ):

Tabla 5 Comparativa de medias de la disponibilidad de dispositivos en relación a los gustos de los adolescentes en el consumo de videojuegos.

\begin{tabular}{|c|c|c|c|}
\hline Dispositivo & $\begin{array}{l}\text { Existencia de } \\
\text { diferencias } \\
\text { estadísticamente } \\
\text { significativas }\end{array}$ & $\begin{array}{l}\text { Valor de } U \text { de } \\
\text { Mann Whitney }\end{array}$ & Resultado \\
\hline PC & $\mathrm{Si}$ & $\begin{array}{l}{[U=4972,000,(78,} \\
157), \quad z=-2,349, \\
p<, 05]\end{array}$ & $\begin{array}{l}\text { Rangos } \\
\text { promedios } \\
\text { superiores en los } \\
\text { adolescentes que } \\
\text { disponen de PC } \\
\text { frente a aquellos } \\
\text { que no lo poseen. }\end{array}$ \\
\hline Portátil & No & $\begin{array}{l}{[U=1966,000,(20,} \\
217), \quad z=-, 696, \\
p>, 05]\end{array}$ & $\begin{array}{l}\text { No hay } \\
\text { diferencias } \\
\text { estadísticamente } \\
\text { significativas }\end{array}$ \\
\hline
\end{tabular}




\begin{tabular}{|c|c|c|c|}
\hline Teléfono móvil & $\mathrm{No}$ & $\begin{array}{l}{[U=550,500, \quad(5,} \\
232), \quad z=-, 195, \\
p>, 05]\end{array}$ & $\begin{array}{l}\text { No hay } \\
\text { diferencias } \\
\text { estadísticamente } \\
\text { significativas }\end{array}$ \\
\hline Tableta digital & $\mathrm{No}$ & $\begin{array}{l}{[U=3628,500,(39,} \\
198), \quad z=-, 595, \\
p>, 05]\end{array}$ & $\begin{array}{l}\text { No hay } \\
\text { diferencias } \\
\text { estadísticamente } \\
\text { significativas }\end{array}$ \\
\hline Conexión Wifi & $\mathrm{Si}$ & $\begin{array}{l}{[U=631,500, \quad(9,} \\
228), \quad z=-1,958, \\
p=, 05]\end{array}$ & $\begin{array}{l}\text { Rangos } \\
\text { promedios } \\
\text { superiores en los } \\
\text { adolescentes que } \\
\text { disponen de } \\
\text { conexión wifi } \\
\text { frente a aquellos } \\
\text { que no la poseen. }\end{array}$ \\
\hline Consolas & No & $\begin{array}{l}{[U=2937,500,(36,} \\
201), \quad z=-1,799, \\
p>, 05]\end{array}$ & $\begin{array}{l}\text { No hay } \\
\text { diferencias } \\
\text { estadísticamente } \\
\text { significativas }\end{array}$ \\
\hline $\begin{array}{l}\text { Consolas } \\
\text { portátiles }\end{array}$ & $\mathrm{Si}$ & $\begin{array}{l}{[U=5273,500,(91,} \\
146), \quad z=-2,672, \\
p<, 01]\end{array}$ & $\begin{array}{l}\text { Rangos } \\
\text { promedios } \\
\text { superiores en los } \\
\text { adolescentes que } \\
\text { disponen de } \\
\text { consola portátil } \\
\text { frente a aquellos } \\
\text { que no la poseen. }\end{array}$ \\
\hline
\end{tabular}

Fuente: Elaboración propia.

Tabla 6 Comparativa de medias del uso habitual de dispositivos en relación a los gustos de los adolescentes en el consumo de videojuegos

\begin{tabular}{|l|l|l|l|}
\hline Dispositivo & $\begin{array}{l}\text { Existencia de } \\
\text { diferencias } \\
\text { estadísticamente } \\
\text { significativas }\end{array}$ & $\begin{array}{l}\text { Valor de Ude } \\
\text { Mann Whitney }\end{array}$ & Resultado \\
\hline PC & Si & $\begin{array}{l}{\left[\begin{array}{l}\text { Si } \\
(166,794,000, \\
3,378, \mathrm{p}<, 01]\end{array}\right.} \\
\text { Pan }=-\end{array}$ & $\begin{array}{l}\text { Rangos } \\
\text { promedios } \\
\text { superiores en los } \\
\text { adolescentes que } \\
\text { usan } \\
\text { habitualmente el }\end{array}$ \\
\hline
\end{tabular}




\begin{tabular}{|c|c|c|c|}
\hline & & & $\begin{array}{l}\text { PC frente a } \\
\text { aquellos que no lo } \\
\text { utilizan. }\end{array}$ \\
\hline Portátil & $\mathrm{No}$ & $\begin{array}{l}{[U=5925,000,(74,} \\
163), \quad z=-, 217, \\
p>, 05]\end{array}$ & $\begin{array}{l}\text { No hay } \\
\text { diferencias } \\
\text { estadísticamente } \\
\text { significativas }\end{array}$ \\
\hline Teléfono móvil & $\mathrm{No}$ & $\begin{array}{l}{[U=865,500, \quad(10,} \\
226), \quad z=-1,254, \\
p>, 05]\end{array}$ & $\begin{array}{l}\text { No hay } \\
\text { diferencias } \\
\text { estadísticamente } \\
\text { significativas }\end{array}$ \\
\hline Tableta digital & No & $\begin{array}{l}{[U=6452,000,(98,} \\
139), \quad z=-, 691, \\
p<, 05]\end{array}$ & $\begin{array}{l}\text { No hay } \\
\text { diferencias } \\
\text { estadísticamente } \\
\text { significativas }\end{array}$ \\
\hline Conexión Wifi & $\mathrm{No}$ & $\begin{array}{l}{[U=1643,000,(16,} \\
221), \quad z=-, 473, \\
p>, 05]\end{array}$ & $\begin{array}{l}\text { No hay } \\
\text { diferencias } \\
\text { estadísticamente } \\
\text { significativas }\end{array}$ \\
\hline Consolas & $\mathrm{Si}$ & $\begin{array}{l}{[U=4387,000,} \\
(130,107), \quad z=- \\
4,896, p<, 01]\end{array}$ & $\begin{array}{l}\text { Rangos } \\
\text { promedios } \\
\text { superiores en los } \\
\text { adolescentes que } \\
\text { usan } \\
\text { habitualmente la } \\
\text { consola frente a } \\
\text { aquellos que no lo } \\
\text { utilizan. }\end{array}$ \\
\hline $\begin{array}{l}\text { Consolas } \\
\text { portátiles }\end{array}$ & No & $\begin{array}{l}{[U=2161,500,} \\
(212, \quad 25), \quad z=- \\
1,509, p>, 05]\end{array}$ & $\begin{array}{l}\text { No hay } \\
\text { diferencias } \\
\text { estadísticamente } \\
\text { significativas }\end{array}$ \\
\hline
\end{tabular}

Fuente: Elaboración propia.

Por otra parte, los análisis de varianza realizados para constatar la existencia de diferencias significativas entre la edad, ciudad de residencia, el tipo de familia, así como de actividades extraescolares que practican los adolescentes en relación a los gustos de estos en el consumo de videojuegos mostraron, en primer lugar, que no existían diferencias estadísticamente significativas en relación a la edad.

En cuanto a la relación de la ciudad de residencia y los gustos de los adolescentes en el consumo de videojuegos, los análisis mostraron que 
existían diferencias estadísticamente significativas $[\mathrm{X} 2(4, \mathrm{~N}=237)=$ $10,854, \mathrm{p}=.028]$. El rango promedio era mayor en los adolescentes que residían en la Comunidad Valenciana, seguidos por los que vivían en Cataluña, encontrándose los valores más bajos en las Comunidades de Madrid y Andalucía, respectivamente.

Centrándonos en el tipo de familia, la misma prueba arrojó que no había diferencias estadísticamente significativas entre el tipo de familia de los adolescentes y los gustos en el consumo de videojuegos.

Por último, y haciendo referencia al tipo de actividades extraescolares y de tiempo libre de los adolescentes y su relación con sus gustos en el consumo de videojuegos, la citada prueba indicó que tampoco existían diferencias significativas.

\subsection{Hábitos de seguridad de los adolescentes en el consumo de videojuegos}

Esta dimensión está compuesta por 3 ítems en los que se recogen algunos hábitos de los adolescentes relacionados con el consumo de videojuegos. Concretamente, se hace referencia a la reflexión a la hora subir fotos a la red, así como de participar en foros sin mostrar la identidad y a considerar perjudicial para la salud el permanecer mucho tiempo visualizando una pantalla.

En los resultados obtenidos en esta dimensión, observamos que el alumnado manifiesta una valoración de indiferencia en relación a los hábitos de seguridad en el consumo de videojuegos $(\mu=3,67 ; 6=, 80)$.

La prueba $U$ de Mann Whitney, realizada para identificar posibles diferencias en relación al sexo, la realización de actividades extraescolares y de tiempo libre, la disponibilidad de dispositivos y su uso habitual en cuanto a los hábitos de los adolescentes en el consumo de videojuegos indicó, en primer lugar, que no existían diferencias estadísticamente significativas en función del sexo.

Respecto a la realización de actividades extraescolares y de tiempo libre, la misma prueba señaló que tampoco había diferencias estadísticamente significativas. Centrándonos en la disponibilidad de dispositivos, así como en su uso habitual, la citada prueba señaló lo siguiente (ver tablas 7 y 8 ): 
Tabla 7 Comparativa de medias de la disponibilidad de dispositivos en relación a los hábitos de seguridad de los adolescentes en el consumo de videojuegos.

\begin{tabular}{|c|c|c|c|}
\hline Dispositivo & $\begin{array}{l}\text { Existencia de } \\
\text { diferencias } \\
\text { estadísticamente } \\
\text { significativas }\end{array}$ & $\begin{array}{l}\text { Valor de } U \text { de } \\
\text { Mann Whitney }\end{array}$ & Resultado \\
\hline PC & No & $\begin{array}{l}{[U=5213,500,(78,} \\
157), \quad z=-1,868, \\
p>, 05]\end{array}$ & $\begin{array}{l}\text { No hay } \\
\text { diferencias } \\
\text { estadísticamente } \\
\text { significativas }\end{array}$ \\
\hline Portátil & No & $\begin{array}{l}{[U=1850,500,(20,} \\
217), \quad z=-1,098, \\
p>, 05]\end{array}$ & $\begin{array}{l}\text { No hay } \\
\text { diferencias } \\
\text { estadísticamente } \\
\text { significativas }\end{array}$ \\
\hline Teléfono móvil & $\mathrm{No}$ & $\begin{array}{l}{[U=529,500, \quad(5,} \\
232), \quad z=-, 336, \\
p>, 05]\end{array}$ & $\begin{array}{l}\text { No hay } \\
\text { diferencias } \\
\text { estadísticamente } \\
\text { significativas }\end{array}$ \\
\hline Tableta digital & $\mathrm{No}$ & $\begin{array}{l}{[U=3657,500,(39,} \\
198), \quad z=-, 524, \\
p>, 05]\end{array}$ & $\begin{array}{l}\text { No hay } \\
\text { diferencias } \\
\text { estadísticamente } \\
\text { significativas }\end{array}$ \\
\hline Conexión Wifi & $\mathrm{No}$ & $\begin{array}{l}{[U=906,500, \quad(9,} \\
228), \quad z=-, 597, \\
p>, 05]\end{array}$ & $\begin{array}{l}\text { No hay } \\
\text { diferencias } \\
\text { estadísticamente } \\
\text { significativas }\end{array}$ \\
\hline Consolas & $\mathrm{No}$ & $\begin{array}{l}{[U=3520,500,(36,} \\
201), \quad z=-, 259, \\
p>, 05]\end{array}$ & $\begin{array}{l}\text { No hay } \\
\text { diferencias } \\
\text { estadísticamente } \\
\text { significativas }\end{array}$ \\
\hline $\begin{array}{l}\text { Consolas } \\
\text { portátiles }\end{array}$ & No & $\begin{array}{l}{[U=6445,000,(91,} \\
146), \quad z=-, 389, \\
p>, 01]\end{array}$ & $\begin{array}{l}\text { No hay } \\
\text { diferencias } \\
\text { estadísticamente } \\
\text { significativas }\end{array}$ \\
\hline
\end{tabular}

Fuente: Elaboración propia. 
Tabla 8 Comparativa de medias del uso habitual de dispositivos en relación a los hábitos de seguridad de los adolescentes en el consumo de videojuegos

\begin{tabular}{|c|c|c|c|}
\hline Dispositivo & $\begin{array}{l}\text { Existencia de } \\
\text { diferencias } \\
\text { estadísticamente } \\
\text { significativas }\end{array}$ & $\begin{array}{l}\text { Valor de } U \text { de } \\
\text { Mann Whitney }\end{array}$ & Resultado \\
\hline PC & No & $\begin{array}{l}{[U=5131,500,} \\
(166, \quad 70), \quad z=- \\
1,428, p>, 05]\end{array}$ & $\begin{array}{l}\text { No hay } \\
\text { diferencias } \\
\text { estadísticamente } \\
\text { significativas }\end{array}$ \\
\hline Portátil & $\mathrm{No}$ & $\begin{array}{l}{[U=5758,500,} \\
(74, \quad 163), \quad z=- \\
, 562, p>, 05]\end{array}$ & $\begin{array}{l}\text { No hay } \\
\text { diferencias } \\
\text { estadísticamente } \\
\text { significativas }\end{array}$ \\
\hline Teléfono móvil & No & $\begin{array}{l}{[U=951,500,(10,} \\
226), \quad z=-, 852 \\
p>, 05]\end{array}$ & $\begin{array}{l}\text { No hay } \\
\text { diferencias } \\
\text { estadísticamente } \\
\text { significativas }\end{array}$ \\
\hline Tableta digital & No & $\begin{array}{l}{[U=6639,500,} \\
(98, \quad 139), \quad z=- \\
333, p<, 05]\end{array}$ & $\begin{array}{l}\text { No hay } \\
\text { diferencias } \\
\text { estadísticamente } \\
\text { significativas }\end{array}$ \\
\hline Conexión Wifi & No & $\begin{array}{l}{[U=1633,500,} \\
(16, \quad 221), \quad z=- \\
512, p>, 05]\end{array}$ & $\begin{array}{l}\text { No hay } \\
\text { diferencias } \\
\text { estadísticamente } \\
\text { significativas }\end{array}$ \\
\hline Consolas & No & $\begin{array}{l}{[U=6394,000,} \\
(130,107), \quad z=- \\
1,077, p>, 05]\end{array}$ & $\begin{array}{l}\text { No hay } \\
\text { diferencias } \\
\text { estadísticamente } \\
\text { significativas }\end{array}$ \\
\hline $\begin{array}{l}\text { Consolas } \\
\text { portátiles }\end{array}$ & No & $\begin{array}{l}{[U=2406,000,} \\
(212, \quad 25), \quad z=- \\
, 759, p>, 05]\end{array}$ & $\begin{array}{l}\text { No hay } \\
\text { diferencias } \\
\text { estadísticamente } \\
\text { significativas }\end{array}$ \\
\hline
\end{tabular}

Fuente: Elaboración propia.

Por otra parte, los análisis de varianza realizados a través de la prueba $K$ de Kruskal $W$ allis para constatar la existencia de diferencias significativas entre la edad, ciudad de residencia, el tipo de familia, así como de actividades extraescolares que practican los adolescentes en relación a los hábitos de seguridad de estos en el consumo de videojuegos mostraron, en primer lugar, que no existían diferencias 
estadísticamente significativas en función de la edad.

En cuanto a la relación de la ciudad de residencia y los hábitos de seguridad de los adolescentes en el consumo de videojuegos, los análisis mostraron que existían diferencias estadísticamente significativas $[\mathrm{X} 2(4, \mathrm{~N}=237)=10,404, \mathrm{p}=.034]$. El rango promedio era mayor en los adolescentes que residían en Cataluña, seguidos por los que vivían en Madrid, encontrándose los valores más bajos en las Comunidades de Galicia y Andalucía, respectivamente.

Centrándonos en el tipo de familia, la misma prueba arrojó que no había diferencias estadísticamente significativas entre el tipo de familia de los adolescentes y los hábitos de seguridad en el consumo de videojuegos.

Por último, y haciendo referencia al tipo de actividades extraescolares y de tiempo libre de los adolescentes y su relación con los hábitos de seguridad en el consumo de videojuegos, la citada prueba indicó que existían diferencias estadísticamente significativas $[\mathrm{X} 2(3, \mathrm{~N}=237)=$ $20,816, p=.000]$. El rango promedio era mayor en los adolescentes que realizaban actividades académicas y deportivas, encontrándose los valores más bajos en aquellos que no realizaban ningún tipo de actividad.

\subsection{Estudio correlacional}

En este apartado, abordaremos el estudio correlacional entre las 3 dimensiones del cuestionario. Los datos resultantes de la aplicación de la prueba de correlación de Spearman, realizada para comprobar la relación entre las 3 dimensiones de la escala pueden verse en la siguiente tabla (ver tabla 9).

Tabla 9 Resultados de las correlaciones bivariadas de las dimensiones del cuestionario:

\section{Correlaciones}

\begin{tabular}{|l|r|l|r|r|r|}
\hline \multicolumn{2}{|c|}{} & Dedicación & Gustos & Hábitos \\
\hline $\begin{array}{l}\text { Rho de } \\
\text { Spearman }\end{array}$ & Dedicación & $\begin{array}{l}\text { Coeficiente de } \\
\text { correlación }\end{array}$ & 1,000 &, $417^{* *}$ &, 083 \\
\cline { 3 - 6 } & \multirow{2}{*}{\begin{tabular}{l} 
Sig. (bilateral) \\
\cline { 2 - 5 }
\end{tabular}} & $\mathrm{N}$ & 237 & 237 & 237 \\
\hline
\end{tabular}




\begin{tabular}{|l|l|l|r|r|r|}
\hline \multirow{2}{*}{} & Gustos & $\begin{array}{l}\text { Coeficiente de } \\
\text { correlación }\end{array}$ &, $417^{* *}$ & 1,000 &, $195^{* *}$ \\
\cline { 3 - 6 } & Sig. (bilateral) &, 000 & &, 003 \\
\cline { 3 - 6 } & Hábitos & $\begin{array}{l}\text { Coeficiente de } \\
\text { correlación }\end{array}$ & 237 & 237 & 237 \\
\cline { 3 - 6 } & Sig. (bilateral) &, 2083 &, $195^{* *}$ & 1,000 \\
\cline { 3 - 6 } & $\mathrm{N}$ & 237 & 237 & 237 \\
\hline
\end{tabular}

**. La correlación es significativa en el nivel 0,01 (bilateral).

Fuente: Elaboración propia.

En función de los datos obtenidos, podemos afirmar, por una parte, que existe relación entre la dimensión 1 (Dedicación en el consumo de medios) con la dimensión 2 (Gustos de los adolescentes en el consumo de videojuegos), $\mathrm{R}=, 417$ y $\mathrm{p}=, 000$; dado que existe nivel de significatividad bilateral al n.s $=, 01$. La relación entre las mismas es moderada, tal y como señalan Mateo (2004) y Pérez, García, Gil y Galán (2009). Por otra parte, podemos afirmar que también existe relación entre la dimensión 2 (Gustos de los adolescentes en el consumo de videojuegos) y la 3 (Hábitos de seguridad de los adolescentes en el consumo de videojuegos), ya que $\mathrm{R}=, 195$ y $\mathrm{p}=, 003$, dado que existe nivel de significatividad bilateral al n.s $=, 01$. La relación entre las mismas es baja, tal y como señalan los autores anteriormente mencionados.

\subsection{Modelos predictivos de las dimensiones del cuestionario}

En este punto tratamos de explicar la variable "Hábitos de seguridad de los adolescentes en el consumo de videojuegos" en función de las medidas de las dimensiones "Dedicación de los adolescentes en el consumo de medios" y "Gustos de los adolescentes en el consumo de videojuegos" a través de regresiones lineales múltiples (Pardo y Ruiz, 2002), utilizando el método "por pasos", con el fin de observar las variables predictoras y su relación con la variable criterio. 
Tabla 10 Coeficientes de la recta de regresión para la variable dependiente "Hábitos de seguridad de los adolescentes en el consumo de videojuegos" en función de las medidas de las dimensiones "Dedicación en el consumo de medios" y "Gustos en el consumo de videojuegos"

\section{Coeficientes $^{\mathrm{a}}$}

\begin{tabular}{|c|c|c|c|c|c|c|c|}
\hline \multirow[b]{2}{*}{ Modelo } & \multicolumn{2}{|c|}{$\begin{array}{l}\text { Coeficientes no } \\
\text { estandarizados }\end{array}$} & \multirow{2}{*}{$\begin{array}{c}\text { Coeficientes } \\
\text { estandarizado } \\
\text { s } \\
\text { Beta }\end{array}$} & \multirow[b]{2}{*}{$\mathrm{t}$} & \multirow[b]{2}{*}{ Sig. } & \multicolumn{2}{|c|}{$\begin{array}{l}\text { Estadísticas de } \\
\text { colinealidad }\end{array}$} \\
\hline & B & $\begin{array}{l}\text { Error } \\
\text { estándar }\end{array}$ & & & & Tolerancia & VIF \\
\hline 1 (Constante) & 3,155 & ,233 & & 13,543 &, 000 & & \\
\hline Gustos & ,201 &, 070 & ,202 & 2,889 & ,004 & 842 & 1,187 \\
\hline Dedicación &,- 003 &, 074 &,- 003 &,- 041 & ,967 &, 842 & 1,187 \\
\hline
\end{tabular}

a. Variable dependiente: Hábitos

Fuente: elaboración propia

Los resultados obtenidos, tal y como podemos ver en la tabla 10, nos permiten observar que sólo la dimensión "Gustos de los adolescentes en el consumo de videojuegos" constituye un factor predictor de la dimensión "Hábitos de seguridad de los adolescentes en el consumo de videojuegos", ya que $\beta=, 202, \mathrm{t}(202)=2,889, \mathrm{p}<.01$. Por tanto, es estadísticamente significativa, por lo que aceptamos la hipótesis de relación lineal entre los gustos de los adolescentes en el consumo de videojuegos y los hábitos de seguridad de estos en dicho consumo. No obstante, el valor de $\mathrm{R}^{2}$ ajustado fue de, 032 , indicando que solamente un 3,2\% de la variabilidad de la dimensión "hábitos de seguridad de los adolescentes en el consumo de videojuegos" es explicada por la variable citada anteriormente.

Por otra parte, también tratamos de explicar la variable "Gustos de los adolescentes en el consumo de videojuegos" en función de las medidas de las dimensiones "Dedicación de los adolescentes en el consumo de medios" con el fin de observar la variable predictora y su relación con la variable criterio. 
Tabla 11. Coeficientes de la recta de regresión para la variable dependiente "Gustos de los adolescentes en el consumo de videojuegos" en función de las medidas de la dimensión "Dedicación de los adolescentes en el consumo de medios"

\section{Coeficientes $^{\text {a }}$}

\begin{tabular}{|c|c|c|c|c|c|c|c|}
\hline \multirow[b]{2}{*}{ Modelo } & \multicolumn{2}{|c|}{$\begin{array}{l}\text { Coeficientes no } \\
\text { estandarizados }\end{array}$} & \multirow{2}{*}{$\begin{array}{c}\text { Coeficientes } \\
\text { estandarizados } \\
\text { Beta }\end{array}$} & \multirow[b]{2}{*}{$t$} & \multirow[b]{2}{*}{ Sig. } & \multicolumn{2}{|c|}{$\begin{array}{c}\text { Estadísticas de } \\
\text { colinealidad }\end{array}$} \\
\hline & B & $\begin{array}{l}\text { Error } \\
\text { estándar }\end{array}$ & & & & Tolerancia & VIF \\
\hline 1 (Constante) & 1,327 & $\overline{200}$ & & 6,619 & $\overline{0,000}$ & & \\
\hline Dedicación & ,422 & 064 & ,397 & 6,635 & 000 & 1,000 & 1,000 \\
\hline
\end{tabular}

a. Variable dependiente: Gustos

\section{Fuente: elaboración propia}

Los resultados obtenidos, tal y como podemos ver en la tabla 11, nos permiten observar que la dimensión "Dedicación de los adolescentes en el uso de medios" constituye un factor predictor de la dimensión "Gustos de los adolescentes en el consumo de videojuegos", ya que $\beta=, 397, \mathrm{t}(397)=6,635, \quad \mathrm{p}<.01$. Por tanto, es estadísticamente significativa, por lo que aceptamos la hipótesis de relación lineal entre la dedicación de los adolescentes en el consumo de medios y los gustos de estos en el consumo de videojuegos. No obstante, el valor de $\mathrm{R}^{2}$ ajustado fue de ,154, indicando que solamente un $15,4 \%$ de la variabilidad de la dimensión "gustos de los adolescentes en el consumo de videojuegos" es explicada por la dedicación de estos en el uso de medios.

\section{Discusión y conclusiones}

Mediante el proyecto "Transalfabetismos. Competencias transmedia y estrategias informales de aprendizaje de los adolescentes" se han analizado las relaciones de los adolescentes con las redes sociales, videojuegos y cultura participativa para poder concretar las estrategias de aprendizaje formal e informal y las competencias transmedia que de ello se derivan. El análisis de los datos que nos aportan los 13 ítems seleccionados del Cuestionario Transliteracy, mediante el que se han recogido las opiniones de los y las adolescentes de Andalucía, Cataluña, Galicia, Madrid y País Valenciano sobre preferencias, usos y gustos en 
relación con videojuegos, nos permite ofrecer evidencias en relación con los objetivos planteados.

Revisaremos las principales a partir de las dimensiones "dedicación en el consumo de medios", "gustos en el consumo de videojuegos" y "hábitos de seguridad en el uso de videojuegos".

\subsection{Dedicación de los adolescentes en el consumo de medios}

En los resultados obtenidos ante el consumo de medios, destacamos las coincidencias con estudios previos (Sinde, Medrano \& Martínez, 2015) que constatan diferencias en función del sexo, siendo los promedios de los chicos superiores de los de las chicas, lo cual no quiere decir que las destrezas y habilidades tecnológicas que demuestran las chicas sean menores, más bien estas diferencias son atribuibles a la influencia de los procesos de socialización diferenciados de chicos y chicas respecto a las tecnologías, lo que influye en elementos motivacionales.

Sin embargo, esta discrepancia no se aprecia cuando comparamos la dedicación de chicos y chicas a otras actividades lúdicas como deportivas y de tiempo libre.

Igualmente, podemos destacar que no aparecen diferencias respecto al consumo de medios de los adolescentes en función de la edad (12-17 años), el tipo de familia o el lugar de residencia (diferentes Comunidades Autónomas). Esto nos permite concluir que los modos en los que chicos y chicas se implican en el consumo mediático y la cultura juvenil no se ven afectados en nuestro país por elementos como el contexto geográfico o los modelos familiares, aunque si hay diferentes formas de entenderlo desde la perspectiva de género (Bertomeu, 2011).

\subsection{Gustos de los adolescentes en el consumo de videojuegos}

Independientemente de la edad, los chicos están más motivados en el uso de videojuegos de diversos tipos en relación con las chicas, lo que nos hace plantearnos las causas por las que se dan este tipo de preferencias en torno a los videojuegos. Estudios realizados desde la perspectiva de género (Cortés Picazo \& Sánchez Sánchez, 2013; GilJuárez, Feliu \& González, 2010) apuntan sobre la continuidad de los 
modelos representacionales masculinos y femeninos estereotipados propios de otras producciones mediáticas, con la permanencia de los rasgos sexistas en el videojuego del siglo XXI. El aumento del número de personajes femeninos obedece a la necesidad de ampliar la base potencial de consumidoras, pero faltan producciones de calidad que ofrezcan personajes del tipo Lara Croft, presentando modelos femeninos que abandonen las representaciones tradicionales ofreciendo alternativas. Algunas de las adolescentes entrevistadas coinciden en que, habiendo sido jugadoras durante la infancia, a partir de la preadolescencia abandonan los juegos y plataformas por falta de interés.

\subsection{Hábitos de seguridad de los adolescentes en el consumo de videojuegos}

Nos interesa destacar que entre las competencias transmedia aparecen destacada la prevención de riesgos y el control de la privacidad, lo que supone una cierta actitud reflexiva por parte de los adolescentes a la hora de exponerse en la red, participar en foros on line con desconocidos, así como el autocontrol por el tiempo que dedican a estar ante las pantallas. En este sentido coincidiendo con estudios internacionales se identifican la preocupación de los adolescentes respecto al riesgo a las adiciones, siendo un número mayor los concienciados con los riesgos que los que toman medidas de precaución (Masanet \& Establés, 2018)

Destacamos, en este sentido, que aparece una mayor preocupación con respecto a los hábitos de seguridad entre los adolescentes de Cataluña y de Madrid que entre los de Galicia y Andalucía, lo que nos induce a pensar en la necesidad de profundizar en el análisis de los datos aportados por las entrevistas para constatar si la influencia del hábitat urbano vs rural puede influenciar esta cuestión o es una cuestión vinculada a otros factores. En el caso de Andalucía, los adolescentes que han participado pertenecen a un instituto de una localidad rural de 3.000 habitantes y otro de la ciudad de Córdoba. Por otra parte, el tipo de familia no nos aporta elementos diferenciadores sobre este tema.

Lo que, si podemos enfatizar del estudio realizado, es que existen relaciones que vinculan el consumo de medios con la presencia de hábitos como videojugadores, lo cual es lógico si tenemos en cuenta 
que los adolescentes son usuarios polivalentes de medios, pues su socialización se halla vinculada a un ecosistema mediático denso, pero en el que destaca la presencia del smartphone.

\section{Referencias bibliográficas}

AEVI. (2017): Anuario de la industria del videojuego 2016: Asociación Española del Videojuego.

Aldas, J. y Uriel, E. (2017): Análisis multivariante aplicado con R. Madrid: Paraninfo.

Aparici, R. \& Silva. M. (2012): Pedagogía de la interactividad. Comunicar. 38, 51-58.

Aranda, D., Sánchez-Navarro, J., Creus, A., Estanyol, E., Montaña, M., Sanz, S., \& Laueza, F. (2017): Ludoliteracy: el juego digital en la educación formal y no formal. Paper presented at the 3 Congreso Internacional de Educación Mediática y Competencia Digital, Segovia.

Área, M. (2010): El proceso de integración y uso pedagógico de las TIC en los centros educativos. Un estudio de casos. Revista de Educación, 352, 77-97.

Balanskat, A., Blamire, R. \& Kefala, S. (2006): The ITC impact on schools in Europe. Disponible en:

http:/ / ec.europa.eu/education/pdf/doc254_en.pdf

Bertomeu, G. (2011): Nativos digitales: una nueva generación que persiste en los sesgos de género. Revista de Estudios de Juventud (92), 187-202.

Browne, M. W. \& Cudeck, R. (1993): Alternative ways of assessing model fit. In K. A. Bollen \& J. S. Long (Eds.), Testing structural equation models (pp. 136-162). Newsbury Park, CA: Sage.

Byrne, B. M. (1994): Structural equation modeling with EQS and EQS/Windows. Thousand Oaks, CA: Sage Publications

Castellana Rosell, M., \& Sánchez-Carbonell, X. \& Graner Jordana, C. \& Beranuy Fargues, M. (2007): El adolescente ante las tecnologías de la información y la comunicación: internet, móvil y videojuegos. Papeles del Psicólogo, 28 (3), 196-204.

Chamarro, A., \& Carbonell, X., \& Manresa, J., \& Munoz-Miralles, R., \& Ortega-Gonzalez, R., \& Lopez-Morron, M., \& Batalla- 
Martinez, C., \& Toran-Monserrat, P. (2014): El Cuestionario de Experiencias Relacionadas con los Videojuegos (CERV): Un instrumento para detectar el uso problemático de videojuegos en adolescentes españoles. Adicciones, 26 (4), 303311.

Cortés Picazo, L. C., \& Sánchez Sánchez, G. (2013): Video Juegos y estudios de género: una apuesta a cambio desde la formación de profesoras y profesores en Artes Visuales. Revista Educación y Tecnología (3), 62-79.

Cuenca, A. \& Lozano, S. (2016): La enseñanza de la investigación. Diálogo entre la teoría y el oficio del investigador en Trabajo Social. La Plata: Editorial de la Universidad Nacional de La Plata (EDULP)

Gatzidis, C. \& Poulsen, M. (2010): Undestanding the Game: An Examination of Ludoliteracy. Paper presented at the 4th European Conference on Games-Based Learning, Copenhagen.

Gee, J.P. (2004): Lo que nos enseñan los videojuegos sobre el aprendizaje y el alfabetismo. Málaga: Aljibe.

Gee, JP (2007): What video games have to teach us about learning and literacy. New York: Palgrave Macmillan.

Gil-Juárez, A., Feliu, J. \& Vitores, A. (2012): Género y TIC: en torno a la brecha digital de género. Athenea Digital. Revista de Pensamiento e Investigación Social, 12 (3), 3-9.

Gutiérrez, A. \& Tyner, K. (2012): Media Literacy in Multiple Contexts. [Alfabetización mediática en contextos múltiples]. Comunicar, 38, 10-12. https://doi.org/10.3916/C38-2012-0200

Herrero, J. (2010): El Análisis Factorial Confirmatorio en el estudio de la estructura y estabilidad de los instrumentos de evaluación: un ejemplo con el Cuestionario de Autoestima CA14. Intervención Psicosocial, 19 (3), 289-300.

Hu, L. T. \& Bentler, P. M. (1995): Evaluating model fit. In R. H. Hoyle (Ed.), Structural equation modeling: Concepts, issues, and applications (pp. 76-99). Thousand Oaks, CA: Sage.

Jenkins, H. (2006): Convergence Culture. Where old and new media collide. New York: New York University Press.

Jenkins, H. (2010): Piratas de textos. Fans, cultura participativa y televisión. Madrid: Paidós. 
Lacasa, P. (2011): Los videojuegos, aprender en mundos reales y virtuales. Madrid: Morata.

Lorenzo-Seva, U. (2000): The weighted oblimin rotation. Psychometrika, 65, 301-318.

Masanet, M. J. y Establés, M. J. (2018) Competencias en la prevención de riesgos, ideología y ética, en Scolari, C. A. (Ed.). Adolescentes, medios de comunicación y culturas colaborativas. Aprovechando las competencias transmedia de los jóvenes en el aula. Barcelona: H2020 Transliteracy Project.

Mateo, J. (2004): La investigación 'ex post-facto'. En R. Bisquerra, (coord.). Metodología de investigación educativa. (pp. 196-230). Madrid: La Muralla,

Merino-Soto, C. (2016): Diferencias entre coeficientes alfa de Cronbach, con muestras y partes pequeñas: Un programa VB. Anales de Psicología, 32, (2), 587-588.

Pardo, A. y Ruiz, M. (2002): SPSS 11. Guía para el análisis de datos. Madrid: McGraw-Hill

Pérez, R.; García, J. L.; Gil, J. A. \& Galán, A. (2009): Estadística aplicada a la Educación. Madrid: Pearson Prentice Hall.

Prensky, M. (2007): Digital game-based learning. St. Paul: Paragon House. Ritterfeld, U., Cody, M. \& Vorderer, P. (2009): Serious Game: Mechanisms and Effects. New York: Routledge.

Scolari, C.A. (2012): Media Ecology: Exploring the Metaphor to Expand the Theory. Communication Theory, 22 (2), 204-225.

Scolari, C.A. (2013): Narrativas transmedia. Cuando todos los medios cuentan. Barcelona: Deusto.

Scolari, C. A. (2015): Ecología de los medios. Barcelona: Gedisa.

Scolari, C. A. (Ed.). (2018). Adolescentes, medios de comunicación y culturas colaborativas. Aprovechando las competencias transmedia de los jóvenes en el aula. Barcelona: H2020 Transliteracy Project.

Schumacker, R. E., \& Lomax, R. G. (2004): A beginner's guide to structural equation modeling, Second edition. Mahwah, NJ: Lawrence Erlbaum Associates.

Segovia, B., Mérida, R., Olivares, Mª A. y González, E. (2016): Procesos de socialización con redes sociales en la adolescencia. Revista Latinoamericana de Tecnología Educativa, 15 (3), 155-167. DOI: http://dx.doi.org/10.17398/1695-288X.15.3.155 
Siemens, G. (2010): Conectivismo: una teoría de aprendizaje para la era digital. In R. Aparici (Ed.), Conectados en el ciberespacio. Madrid: UNED.

Sinde Martínez, J., Medrano Samaniego, C. \& Martínez de Moretin, J.I. (2015): Transmisión de valores en adolescentes: un análisis con videojuegos. Revista Latina de Comunicación Social (70), 230251. doi: DOI: 10.4185/RLCS-2015-1044

Steiger J. H. (2000): Point estimation, hypothesis testing and interval estimation using the RMSEA: Some comments and a reply to Hayduk and Glaser. Structural Equation Modeling, 7, 149-162.

Timmerman, M. E. \& Lorenzo-Seva, U. (2011): Dimensionality Assessment of Ordered Polytomous Items with Parallel Analysis. Psychological Methods, 16, 209-220.

Tyner, Kathleen R., Gutiérrez Martín, A., \& Torrego González, Alba. (2015): Multialfabetización sin muros en la era de la convergencia. La competencia digital y la cultura del hacer como revulsivos para una educación continua. Profesorado. Revista de currículum y formación del profesorado, 19 (2), 41-56.

Wilson, Carolyn. (2012): Alfabetización mediática e informacional: proyecciones didácticas. Comunicar, 20 (39), 15-24. http://doi.org/10.3916/C39-2012-02-01

Papers relacionados

Trenta, Milena (2012): Orígenes del videojuego. Actas. IV Congreso Int. Latina de Comunicación Social. La Laguna.

Marzal Felici, J y Sáez Soro, Emilio (2013): Videojuegos y cultura visual. Cuadernos Artesanos de Comunicación, 42. La Laguna: Latina.

Ibanez Bueno, J (2014): Seriousgames: ¿Nuevo medio en una institución pública? Revista Latina de Comunicación Social, 69, pp. 125 a 134. 


\title{
Alfabetismos transmediales y habilidades colectivas de participación. Estrategias de producción creativa y gestión del ocio de fans de Star Wars
}

José Manuel Corona - Universidad de Guadalajara. México. imanuel.corona@academicos.udg.mx

Cómo citar: J M Corona Rodríguez (2019): Alfabetismos transmediales y habilidades colectivas de participación. Estrategias de producción creativa y gestión del ocio de Fans de Star Wars". En V Tur-Viñes/M J González-Río/R S Contreras-Espinosa (Eds.) Jóvenes / Medios y cultura colaborativa. Cuadernos Artesanos de Comunicación, cac157, pp 283-318. La Laguna (Tenerife): Latina. DOI: $10.4185 /$ cac157

\begin{abstract}
s
Introducción. En el actual entorno comunicativo transmediático, la participación activa en la creación de contenidos, información y mensajes está redefiniendo la experiencia educativa. Este artículo analiza la producción de alfabetismos transmediales a partir de las habilidades participativas colectivas de una comunidad de fans. Metodología. Desde una perspectiva etnográfica que combina observación participante online y offline, y la realización de entrevistas a profundidad a miembros fundadores, se analizan las prácticas participativas de una comunidad de fans de Star Wars. Resultados. Del análisis realizado se trabajan los conceptos: producción creativa y gestión del ocio. El primero aborda un tipo de producción realizada por los fans que cruza lo mediático, virtual y presencial de sus prácticas, y el segundo aborda las estrategias desarrolladas para la utilización del
\end{abstract}


tiempo y de la cultura emocional compartida. Discusiones: en este apartado se discute a propuesta de seis dimensiones de los alfabetismos transmediales a la luz de lo colectivo de la participación. Conclusiones. Se reflexiona finalmente, cómo las habilidades colectivas de participación transforman las posibilidades educativas a través de la transmedialidad.

\section{Keywords}

Alfabetismos transmediales; Participación; Fans; Producción creativa; Ocio.

\section{Contents}

1. Introducción. 1.1 La relación educomunicativa de los fans y sus prácticas. 1.2 Transitar de la alfabetización mediática a los alfabetismos transmediales. 1.3 Las prácticas de participación: una cultura al alza. 2 . Metodología. 2.1 Star wars y sus fans: comunidades de práctica. 2.2 Datos producidos y análisis de las prácticas. 3. Resultados. 3.1 La producción creativa de objetos, mensajes y experiencias. 3.2 La gestión del ocio: cultura emocional y dimensiones temporales. 4. Discusión 5. Conclusiones. 6. Notas. 7. Referencias Bibliográficas.

\section{Introducción}

T OS MEDIOS de comunicación han sido parte esencial de los 1 cambios paulatinos y constantes en las formas en que se circula la información y se construye el conocimiento (Martín-Barbero, 2002). En este sentido, es fundamental abordar el vínculo entre educación y comunicación desde la dimensión cultural a partir de la evolución de los medios, sus propiedades y los procesos que detonan en términos de la capacidad para participar en y a través de ellos. Esto es crucial porque permite abordar una dimensión de lo educomunicativo que trasciende lo mediático, y que no se agota en lo estructural de lo escolar, sino que aspira a conocer la particularidad cultural de las prácticas que implican aspectos educativos centrados en la autogestión y el aprendizaje colectivo. Este planteamiento parte de la premisa que asume a la educación siempre vinculada a procesos de comunicación, en donde nadie educa a nadie, sino que la educación ocurre como 
efecto de la comunión social, para lo cual los procesos comunicativos son esenciales (Freire, 1968).

En este artículo, desarrollado en el marco de una investigación más amplia sobre la construcción de estrategias de aprendizajes de comunidades de práctica, se analiza la producción de alfabetismos transmediales a partir de las habilidades participativas que en colectivo desarrolla una comunidad de fans de Star Wars. El análisis realizado se centra, de manera específica, en las estrategias de producción creativa y la gestión del ocio que los miembros de esta comunidad han desarrollado a lo largo de los años que llevan de vida como grupo, la dimensión temporal es importante porque permite advertir la adaptabilidad de sus prácticas a partir de las tecnologías (comunicativas y de producción) disponibles. El fandom, o la cultura de los fans (Jenkins, 2009), es el objeto de análisis, pero siempre vinculado a los procesos educativos y de aprendizaje que se ponen en juego como resultado de su cotidianidad que ocurre de manera constante tanto en entornos virtuales como en la materialidad física de su presencialidad.

En el estudio se propone una metodología que, desde un enfoque etnográfico, utiliza la observación participante online y offline para rastrear las prácticas de participación que los fans desarrollan en sus espacios y tiempos de interacción. Para tal efecto, es necesario recuperar a Giddens (1994), que asume la etnografía como el estudio de las personas y grupos durante un periodo de tiempo, a través de la observación y la realización de entrevistas. Y desde ahí, hacer evidente que la realización de entrevistas a profundidad (Flick, 2014), buscó conocer las explicaciones hipotéticas que los fans ofrecen de sus acciones y discursos, a partir de la selección de temas específicos relativos a: la apropiación narrativa y estética, la producción creativa de objetos, mensajes y experiencias educativas, los efectos del ocio en la cultura emocional compartida y en la administración del tiempo.

En este sentido, el trabajo analiza los datos que se produjeron durante el trabajo de campo, los cuales se clasifican según su acceso y construcción. En la observación virtual se analizan: a) publicaciones en Facebook y sitio web (textos e imágenes) de la comunidad, un total de 143 registros recuperados y analizados, b) videos producidos 
disponibles en YouTube, un total de 8. En lo relativo a la observación presencial forman parte del análisis: a) juntas mensuales (17 sesiones), celebraciones o festejos (3), eventos altruistas (2) y premiers o estrenos (2). Mientras que en lo correspondiente a las entrevistas a profundidad se realizaron un total de 7 , de las cuales 4 fueron a miembros fundadores del grupo y 3 a otros que se han ido sumando a lo largo de los años.

\subsection{La relación educomunicativa de los fans y sus prácticas}

Con la instauración de las sociedades de la información y del conocimiento, los procesos de generación y procesamiento de información han modificado los sistemas de producción de bienes en las sociedades actuales (Echeverría, 2001). En el marco de una sociedad de la información y del conocimiento otras formas de organización social aparecen para la transmisión de legado cultural y experiencias colectivas (Sennett, 2008). El intercambio social y el aprendizaje se han redefinido a partir de los flujos de información y de las alternativas para la producción, circulación y consumo de las sociedades actuales (Winocur, 2009; Reig \& Vílchez, 2013). Esto implicaría una transformación paulatina de los paradigmas educativos tradicionales que florecieron en la modernidad y que se han cuestionado con el arribo de modelos y procesos mucho más horizontales, colaborativos, informales y deslocalizados (Martín-Barbero, 2003; Orozco, 2003; Dussel, 2009; Aparici, 2010).

La educación centrada en la escolarización y en la alfabetización, conlleva el reto de visibilizar aprendizajes alternativos que ya están sucediendo, y cómo la cultura está transformando las prácticas de enseñanza, el modelo basado en la capacidad para leer o escribir y en la formación para el trabajo (Dussel, 2012). Pasar de la alfabetización y escolarización formal a otras modalidades de aprendizaje supone desarrollar una mirada crítica que cuestiona tanto la intencionalidad de alfabetizar como el procedimiento para lograrlo (la escolarización tradicional). En este sentido, es más grande la necesidad de reflexionar sobre la centralidad de los aprendizajes en la educación, como una manera para mover el foco de las instituciones a los sujetos, dado que, 
al final de cuentas, los aprendizajes están presentes y se actualizan en las personas y no (necesariamente) en las instituciones.

Hablar de la relación educación-comunicación implica poner el foco en los procesos de aprendizaje y sus modalidades (formal e informal), pero esto supone el desarrollo de una mirada crítica en función de un adentro/afuera, en donde lo que ocurre en la escuela es válido y legítimo, y lo que ocurre afuera es inerte y no valioso, lo cual implica un riesgo porque se limita la riqueza conceptual en tanto se constriñe a los espacios antes que a las prácticas y experiencias. Como lo sugirió acertadamente Martin-Barbero (2003: 4), "la educación lo cruza todo y aprendemos en todos los lugares y en todos los momentos", de manera que el aprendizaje no ocurre adentro o afuera, sino en un continuum espacio-temporal. Es por eso que la apuesta de lo educomunicativo no se puede limitar a la alfabetización (caracterizada por la escolaridad), sino a los aprendizajes que surgen como resultado de las prácticas bien insertas en la cotidianidad de la cultura.

En este escenario es que se ubica el estudio de los fans como un grupo socialmente relevante, dado que sus prácticas y estilos de participación son especialmente distinguidas en relación a los efectos en sus aprendizajes y habilidades. El hacer colectivo es un factor clave dado que implica un aspecto autogestivo donde no hay una posición externa de autoridad que ejerza el poder para regularles o conducirles.

La investigación de comunidades de fans afiliadas a narrativas ficcionales ha sido ampliamente desarrollada (Jenkins, 1993; Hills, 2002; Booth, 2010; Valdellós, 2012; Bertetti, 2017), casi siempre revitalizando la discusión sobre su capacidad discursiva, agencia y efectos en los relatos canon. Discusión que cobró fuerza con la creciente presencia de prosumidores (Toffler, 1980) capaces de dar sentido a la noción de fan, desde una perspectiva que acepta el consumo conectado con las posibilidades productivas. En este sentido, la cuestión central radica en conocer las prácticas de participación de esta comunidad y el vínculo que éstas tienen con la dimensión educativa, especialmente por aquello relativo a las prácticas colectivas para la producción creativa y la gestión del ocio. 


\subsection{Transitar de la alfabetización mediática a los alfabetismos transmediales}

El concepto de alfabetización mediática es uno de los más usados para abordar la relación entre la educación y la comunicación. Desde esta noción se ha planteado la importancia de hacer visible los saberes y habilidades que entran en juego especialmente para usar y crear mensajes a través de los medios de comunicación (Gee, 2013). Esto ha implicado un creciente interés (que lleva varias décadas) para aumentar la alfabetización mediática, así como asumir los retos que desde la formación educativa se pueden resolver en esta materia.

La finalidad más importante de la alfabetización mediática se concentra en desarrollar una actitud crítica capaz de reflexionar y analizar los mensajes y contenidos que desde los medios de comunicación llegan a las personas (Área, et al., 2012). La alfabetización como noción general se ve usualmente incapacitada de dar respuestas claras porque opera bajo el amparo de la intencionalidad educativa escolar, de manera que no rompe con los roles establecidos de profesor y estudiante, lo cual es problemático precisamente porque, dado el contexto comunicativo, las sociedades se definen cada vez más por su acceso a la información y a la producción de conocimiento.

Han surgido propuestas y acercamientos que tratan de ir más allá en la relación educación-comunicación, al incluir no sólo el componente mediático sino, especialmente, la dimensión cultural que ya de por sí hace que los sujetos se encuentren en constante relación con lo comunicativo no sólo a través de los medios y las tecnologías, sino otras mediaciones. Si se asume que el panorama de la comunicación está cambiando en relación con las formas de consumo y producción de la información, se debería reconocer que la alfabetización no puede ni debe estar centrada sólo en prácticas de lectura y escritura, o bajo un modelo de enseñanza-aprendizaje; sino en transitar de las alfabetizaciones mediáticas a los alfabetismos, reconociendo en ellos otras formas de percibir que se están diversificando, a partir de los medios, plataformas e interfaces disponibles, pero además en función de las múltiples posibilidades interactivas que existen y se van desarrollando. 
Uno de los principales problemas del uso del concepto alfabetización mediática es que se trata de un fenómeno multifacético que cruza diferentes dimensiones de acción, lo que hace muy complicado cuantificarle, especialmente cuando se asocia a la práctica estandarizada, planificada y evaluable conocida en la educación institucionalizada. Autores como Lankshear y Knobel (2011), Buckingham, Kehily y Bragg (2014), y Gee, (2015), han propuesto pasar de la alfabetización a los alfabetismos porque es a través de estos que es posible reconocer la complejidad de las prácticas culturales que propician aprendizajes más allá de si son planificados o verificables. En este sentido, el alfabetismo debe ser entendido como una práctica social que no depende de condicionamientos formales o proyectados, sino de la acción cotidiana de sujetos movidos por sus propios intereses, deseos y posibilidades.

Estamos de acuerdo con Dussel (2013), cuando sugiere que es preferible usar alfabetismos, en lugar de alfabetización, porque el concepto de alfabetización implica una connotación directa a las prácticas de lectura y escritura, lo que dificulta un abordaje sistémico multidimensional de los contextos y prácticas. Como se ha visto hasta ahora, con la creación de una amplia variedad de conceptos que tratan de abordar las nuevas alfabetizaciones lo que se hace es expandir la metáfora de la lectura y la escritura a otros contextos sin lograr atender a la complejidad de las prácticas sociales y culturales que ocurren más allá de la voluntad por enseñar o aprender (Pérez, 2014).

Buckingham y Martínez (2013) lo ponen en términos de la necesidad de una definición distinta que logre superar la alfabetización, dado que ésta se concentra usualmente en determinadas tecnologías o medios, y no observa en su totalidad las prácticas que ocurren en el complejo entramado de la cultura y la comunicación. Por su parte, Orozco (2010) propone llevar la reflexión más allá de la alfabetización para lograr integrar la realidad social independientemente de si ésta corresponde o no con lo que se está haciendo para educar a las personas desde las instituciones formales. 
Transitar de la alfabetización a los alfabetismos es una forma de reconocimiento explícito que apuesta por superar una postura centrada en la mera crítica y apropiación de los medios para la reproducción de tareas escolares basadas en los esquemas tradicionales de la educación (como lo ha hecho la alfabetización mediática tradicional), e ir hacia un modelo capaz de incorporar los aprendizajes que por sí mismos suceden como resultado de las participaciones y colaboraciones, que se detonan a través de narrativas, entornos y experiencias transmediáticas. En este sentido, la pregunta por la relación educación-comunicación se busca abordar no desde lo que se enseña con la alfabetización mediática sino a través de lo que se aprende desde los alfabetismos que ya ocurren sostenidamente a través de las múltiples prácticas de participación.

La propuesta que se desarrolla en este artículo, de los alfabetismos transmediales, reconoce la importancia de comprender y apropiarse de los contenidos y mensajes mediáticos, especialmente para participar con la sociedad y los entornos culturales a través de ellos. Es decir, todo proyecto alfabetizador de los medios no se puede agotar en el uso de los recursos y los lenguajes en sí mismos. Ahí es donde está la diferencia más sustancial de la propuesta, distinguir entre participar en los medios y a través de los medios. Debido a que participar a través de los medios permite hacer notoria la necesidad de reconocer la importancia de los medios, pero siempre al amparo de lo que puede acontecer en una escala social local donde la actuación de las personas tiene efectos muy concretos y directos.

Para efectos de una comprensión más amplía de los alfabetismos transmediales, es necesario recuperar la propuesta de Scolari (2018: 17), porque sugiere entender estos alfabetismos en términos de una "serie de habilidades, prácticas, prioridades, sensibilidades, estrategias de aprendizaje, y formas de compartir". Dicha propuesta pone el foco en las experiencias que surgen en los entornos virtuales y en los medios interactivos tanto en términos de la producción como de la colaboración. Lo cual ayuda a entender la relación educacióncomunicación en términos de los entornos convergentes y sus posibilidades concretas, $y$, además, ofrece la posibilidad de afinar (o redefinir): las preguntas, los instrumentos de investigación y las 
maneras de interpretar lo que ocurre de forma cotidiana con las prácticas de las personas.

\subsection{Las prácticas de participación: una cultura al alza}

La participación, como concepto clave, se aborda en este trabajo desde los entornos de comunicación interactivos, digitales y en red, como elemento clave para la generación de aprendizajes significativos en sujetos mediatizados que definen su agencia en función de intereses individuales y colectivos, a partir de narrativas transmediáticas, específicamente del universo narrativo de Star Wars.

La centralidad del estudio de la participación ha quedado marcada en muchos espacios de reflexión académica y científica en las ciencias sociales y en otras disciplinas que se preguntan por las dinámicas, dimensiones, intensidades, capacidades, competencias, habilidades y posibilidades que la participación como aspecto esencial de acción ha traído a las sociedades mediatizadas contemporáneas (Hjarvard, 2008). La investigación y reflexión que desde el campo educomunicativo se ha hecho sobre la participación es cada vez más grande y profunda, lo que ha traído como consecuencia una diversidad de enfoques que no hacen más que expandir su sentido y proponer nuevos usos y efectos. Se ha pasado en cierta medida del estudio de los medios y sus contenidos a la investigación sobre lo que las audiencias y consumidores son capaces o están dispuesto a hacer con esos contenidos. La participación como aspecto central a investigarse permite conocer especialmente lo que las personas tienen que decir, reconfigurando con esto el rol tradicional de enunciador y receptor, tan habitual en los medios tradicionales.

La aportación de Jenkins (2008) de la idea de una cultura de la participación fue crucial para definir una perspectiva específica para comprender los procesos y las áreas de oportunidad en donde las personas pueden ejercer su capacidad de acción y agencia tanto individual como colectivamente. En este sentido, la participación, entendida desde una mirada cultural, permite hacer visible que su complejidad radica precisamente en los factores y posibilidades que de la cultura emanan, razón por la cual, el papel de las producciones 
mediáticas tiene efectos socialmente relevantes porque permiten conocer las competencias, afectos y habilidades que se ponen en juego para participar de su consumo-apropiación, pero especialmente de su producción y creación.

En el contexto de un cúmulo de convergencias culturales, tecnológicas y comunicativas, se ha vuelto indispensable investigar la agencia (Giddens, 1984) a partir de las formas de participación y colaboración que ocurren en y a través de los sistemas de comunicación, y, al mismo tiempo, favorecer en la caracterización de un escenario educomunicativo que plantea desafíos actualizados y abre nuevas posibilidades para su uso y aplicación.

Las prácticas de participación son factor clave, no sólo para entender la naturaleza de los cambios sociales, sino además como una oportunidad para reconocer el valor del ocio, el entretenimiento y las dimensiones afectivas, muchas veces desdeñadas por referirse a escenarios alejados de la objetividad y de supuestos valores objetivos o relacionados al trabajo.

Tomando en consideración las recientes y constantes transformaciones tecnológicas y comunicativas, algunos autores (Burke, 2002; Jenkins, 2008; Bauman, 2007; Shirky, 2008) han advertido y descrito la existencia de un proceso de convergencias a partir de las cuales los actores sociales tienen una renovada capacidad para crear prácticas alternativas de consumo, de acceso a la información, de socialización y de entretenimiento. Estas convergencias (que no son sólo mediáticas y tecnológicas) han propiciado que los sujetos participen en, a través de y desde los medios de comunicación de una forma cada vez más interactiva que propicia vinculaciones más intensas y comprometidas.

A diferencia de conceptos como el de audiencia social, que se refiere sobre todo a las conversaciones e interacciones que ocurren en redes sociales sobre contenidos mediáticos (Lacalle y Castro, 2018), las prácticas de participación que aquí se trabajan se entienden como la capacidad de agencia que se pone en acción para hacer o decir mensajes y contenidos más allá del entorno en donde ocurran. Esto es así porque participar implica mucho más que comunicar, en tanto las prácticas 
pueden no estar directamente asociadas a la capacidad enunciativa o productiva de mensajes y contenidos, sino, por ejemplo, a las estrategias organizacionales o a la gestión de tiempo de una comunidad.

Se parte de la hipótesis de que las comunidades de práctica, en el caso de los fans de Star Wars, a través de sus prácticas de participación, producen alfabetismos transmediales mediante la puesta en operación de estrategias de aprendizaje basados en la experiencia individual, colectiva y mediatizada. Las cuales no se agotan en las interacciones mediáticas online, sino que, además, tienen efectos en las dinámicas offline que ocurren como resultado de su colaboración e intercambio cotidiano.

\section{Metodología}

La investigación se realizó como resultado de una articulación de tres momentos complementarios: acceso, construcción y análisis de datos. Primero, la observación participante online o virtual, y, más tarde, la participación offline o presencial; posteriormente, la realización de entrevistas en profundidad, $y$, finalmente, la codificación de los datos para la construcción de categorías analíticas. Si bien se enumera de forma secuencial, en realidad la realización de este trabajo ocurrió en diferentes ritmos y encadenamientos, a la manera de un helicoide, en donde la investigación transita por un vaivén que resulta en un proceso complejo pero lleno de decisiones y posicionamientos (Aibar, Cortés, Martínez y Zaremberg, 2013). En este sentido, la línea temporal de la investigación se inicia en agosto de 2016 y termina en mayo de 2017. Esto es importante porque el trabajo metodológico fue prolongado tanto en su dimensión online como offline. La organización de los accesos y la construcción de los datos siguió una continuidad: virtualpresencial-virtual-presencial.

Para el proceso de análisis se hizo uso del software de análisis de datos cualitativos Atlas.ti, lo que permitió la codificación de datos a través de la sistematización de ítems obtenidos en forma de imágenes, vídeos, textos, y discursos. Esta decisión estuvo epistemológicamente tomada a partir de los planteamientos de la teoría fundamentada (Strauss y Corbin, 2002) y la necesidad de relacionar el material empírico con la 
producción de conceptualizaciones reflexivas. Más adelante se aborda específicamente esta cuestión.

El proceso de acceso y construcción de datos inició con el diseño de una estrategia de observación online, a través de la captura de pantalla, es decir, imágenes recuperadas de las interacciones disponibles en acceso abierto del grupo de Facebook de la comunidad investigada. Esta estrategia tuvo la finalidad de seguir las interacciones virtuales de los miembros, para la identificación de: temáticas, participantes, lugares de encuentro, fechas de participación y procesos de incorporación y además como estrategia para lograr el rapport indispensable para dar continuidad a la fase de las entrevistas. Este tipo de estrategias encuentra antecedentes en trabajos de investigación (Miller y Sinana, 2017; Tur-Viñes y Rodríguez, 2014; Ricaurte y Ortega, 2010) que usan Facebook como espacio de investigación y recuperación de datos, y otros en donde se diseñan estrategias metodologías a medida para la identificación de comunidades relevantes (Hernandez-García, RuizMuñoz y Simelio-Solà, 2013; Mora-Fernández, 2012) en donde es posible acceder a las prácticas comunicativas y a una vasta diversidad de formas de agencia social.

Esta estrategia de captura de pantalla sirvió en una triple vía: como vehículo para obtener datos sobre las interacciones y las maneras de la participación, como un proceso de pre análisis, y especialmente como un criterio de selección basado en entradas o posteos, que tuvieran imágenes, textos, emociones (me gusta, me sorprende, me encanta, etc.) y que hubiera motivado comentarios de otros fans. Estos criterios permitieron recuperar un promedio de 23 piezas digitales de análisis durante cada mes que duró la investigación. La selección de las que se analizaron obedece a un criterio conversacional, en donde se eligieron las piezas que más interacciones, reacciones o comentarios generaron en el espacio virtual de la comunidad.

Gracias a la observación online, se identificaron a los miembros más activos, las temáticas más relevantes, el peso de la participación y su vínculo con lo educativo, la cantidad de miembros y sus estilos de participación, los tipos de miembros según su grado de 
involucramiento y la variedad de tipos de actividades cara a cara que convocan para realizarse presencialmente.

Lo anterior fue crucial para darle continuidad a la fase dos de la estrategia, la realización de observación offline o presencial, la cual se caracterizó por estar presente durante los encuentros que la comunidad realiza, para registrar sus dinámicas, actividades, formas de intercambio y comunicación, reconocimiento mutuo, estrategias de apropiación y creación de contenidos, gestión del ocio colectivamente y la planificación de las actividades por venir. Durante esta fase se observaron los siguientes encuentros: 17 juntas mensuales, 3 celebraciones o festejos, 3 eventos altruistas y 2 premiers o estrenos. Cada una de estas modalidades de estar juntos permitió acceder a procesos significativos para el sentido de la colectividad y para los significados compartidos sobre su vínculo con la narrativa y lo educativo.

Las juntas mensuales fueron eventos organizados y planificados para estar en presencia y discutir temas relacionados a la narrativa (como actualizaciones, lanzamientos, novedades, rumores, etc), tanto en su dimensión fandom como canon, durante este tipo de eventos fue posible observar la impartición de talleres y charlas expositivas, la visualización y planificación de actividades futuras y la definición de proyectos para la comunidad.

Este tipo de observación presencial se registró en diarios de campo, organizados bajo los siguientes criterios: los participantes presentes, los lugares, las fechas, la duración de los encuentros, el contexto de los mismos, la intensidad y tono de las interacciones, las temáticas abordadas, la resolución de conflictos, la planificación y la definición de acciones futuras. En este sentido, esta fase de la investigación permitió conocer las relaciones entre los miembros de la comunidad y fue la situación ideal para tener acceso a los miembros y sus particularidades.

La selección de los informantes para la realización de entrevistas fue gracias a las fases de observación realizada previamente, las cuales sirvieron para definir los criterios de selección que se tomarían en 
cuenta. Los miembros fans entrevistados cumplieron las siguientes 5 características: 1) formar parte de la comunidad explícitamente (tanto en espacios virtuales de redes sociales como en reuniones presenciales), 2) mostrar interés y disponibilidad para participar abiertamente en las conversaciones sobre las prácticas de la comunidad, 3) ser activos en la creación de contenidos, mensajes y productos significativos para la comunidad, 4) tener actualmente un rol activo, y 5) ser reconocido por otros miembros como pares e iguales.

La población total de entrevistados potenciales que cumplieron las 5 características anteriores fue de 23 miembros (de un total de 4520 integrantes de la comunidad en su dimensión virtual, y de 57 en lo presencial). Esto significa que durante el periodo en que se realizó esta investigación, durante las actividades presenciales se identificó claramente a un máximo total de 57 miembros que asistían a las reuniones y eventos presenciales. De los cuales sólo 23 miembros cumplieron con la totalidad de las características enumeradas para considerarlos como fans ideales para entrevistar. La decisión fundamental de la realización de las entrevistas estuvo condicionada por tres variables primordiales: a) el criterio de antigüedad, que se refiere a la elección de entrevistados que formaran parte de la comunidad desde su fundación, (lo cual redujo el número de 23 a 11), b) la coincidencia espacio-temporal entre el investigador y los entrevistados, y c) la saturación de información relevante que surgió de la realización de entrevistas, la cual se logró a partir de la séptima entrevista.

Entrevistar a los fans de SW fue un ejercicio muy interesante y rico en referencias culturales que aluden a experiencias personales individuales y colectivas sobre el papel de la ficción en sus vidas, el lugar de la comunidad para cada participante y en las experiencias significativas que han sido cruciales para afiliarse, pertenecer y permanecer a lo largo de los años. Con las entrevistas se buscó construir, durante la conversación, los aspectos y elementos que podrían ser útiles para la comprensión e interpretación. A través de la cercanía ganada con el paso del tiempo al interior de la comunidad, se buscó reconstruir los aspectos y elementos contextuales suficientes para la comprensión e interpretación de las observaciones y de los registros virtuales, esto a 
partir de una conversación abierta y sostenida que diera cabida a digresiones para establecer nuevos caminos y temas que no habían sido considerados inicialmente. En este sentido, la profundidad sirvió para explorar los matices difíciles de ver a simple vista o con los procesos de observación.

Se entrevistaron a 7 miembros de la comunidad, con perfiles profesionales diferentes, que se enumeran a continuación: un diseñador gráfico, un administrador de supermercado, un analista de mercado, una abogada, un ingeniero en sistemas, un criminólogo, y un ingeniero en software. De todos ellos, sólo una mujer, que además es una proporción que se generaliza al total de la comunidad, en donde de cada 10 miembros 7 son hombres y sólo 3 mujeres.

\subsection{Star wars y sus fans: comunidades de práctica}

El concepto comunidades de práctica se entiende como un conjunto de personas que comparten intereses, problemas, pasiones u objetivos a través de los cuales profundizan su conocimiento sobre esa área de interés en común. Estos tipos de grupos sociales son casi siempre informales o no formales, y se encargan de hacer circular la información entre sus miembros para homologar sus conocimientos, y con esto lograr que las comunidades perduren (Wenger, McDermotty y Snyder, 2002). En este sentido, compartir las experiencias sirve como una forma de especialización temática que implica una distribución constante de los conocimientos y experiencias indispensables para integrarse (Aubert, Garcia, \& Racionero, 2009). Desde esta perspectiva, las organizaciones sociales no son interpretadas en función de sus estructuras sino de sus relaciones, lo que significa que son las motivaciones e intereses compartidos los que hacen que sus miembros se agrupen y estén en constante contacto para perseguir objetivos en común (Wenger, 2001).

Entender a las comunidades desde esta mirada implica examinar cuáles son los elementos relacionales reconocibles que les confieren sentido conceptual. Según Wenger, McDermotty y Snyder (2002), son tres aspectos fundamentales que pueden ayudar a identificar una comunidad de práctica. 1) Dominio: se trata del conjunto de temas y 
objetos de interés que comparten los miembros de una misma comunidad, se configura en función del campo de conocimiento e implica un cúmulo compartido de valores y posiciones comunes sobre aquello que las constituye. 2) Comunidad: se trata de los recursos humanos que a través de sus interacciones conforman una red social dinámica en la producción de conocimientos. Se preocupa por saber el rol e importancia que cada miembro tiene al interior de la comunidad. 3) Práctica: se refiere a las maneras y procedimientos definidos socialmente para hacer las cosas, es el desempeño en el cual se basa la comunidad para ejercer su acción colectiva. Se incluyen aquí patrones de interacción, modelos de actuación, reglas implícitas y explícitas de colaboración, así como identificación de los tipos de conocimiento, temas o aspectos que ingresan al dominio de la comunidad.

Las anteriores características que describen a las comunidades de práctica, sirven para conceptualizar relaciones, pero especialmente para la identificación de las posibilidades participativas que un grupo de personas tiene cuando opera colectivamente en función de un interés. Desde la dimensión educativa, las comunidades de práctica se entienden a partir de la posibilidad de aprender colectivamente a través de las interacciones cotidianas que, mediadas o no, parten de la obtención de un beneficio o valor concreto, de la generación de conexiones personales, y de la promoción de alguna habilidad o conocimiento concreto.

Star Wars, como historia o producción narrativa, puede no ser una obra maestra, en todo caso su gran virtud no deriva de su calidad, sino de la enorme convocatoria y seguidores que ha conseguido en todo el mundo, y además, por lograr ser una narrativa considerada paradigmática en el uso de estrategias transmediales (Scolari, 2013). Durante los años de vida que ha tenido, esta popular historia ha producido y lanzado contenidos mediáticos en prácticamente todas las plataformas y textualidades posibles. Lo anterior la hace ideal para formularle preguntas sobre los grados de participación que, en teoría, motiva en sus fans. Preguntarse por la participación en el entorno transmedial y sus implicaciones en lo educativo, obliga a reconocer que han existido comunidades que se organizan precisamente en torno de 
narrativas ficcionales que han logrado expandir sus relatos a través de distintos medios y plataformas.

Los efectos que han tenido las comunidades de fans han sido ampliamente estudiados desde distintos paradigmas y puntos de vista, los trabajos de Booth (2015), Borda (2011), Hills (2002), Jenkins (1993) y Roig (2013) son constancia de estas miradas y de las múltiples posibilidades teóricas, metodológicas y epistemológicas para acercarse a los fans.

La elección de la comunidad de fans estuvo basada en: a) su amplia y constante presencia mediática, b) el creciente número de miembros, c) la diversidad y frecuencia de sus actividades, d) la variedad en el perfil de sus integrantes y e) su interés en promover lo que llaman "la cultura SW”. Esta comunidad está integrada por $4520^{7}$ miembros, y es el colectivo que más actividades presenciales despliega en la zona metropolitana de Guadalajara, se fundó en 1999 por un grupo de amigos (cinco en total) que buscaban compartir su interés por la narrativa.

Investigar a los fans implica una alternativa provocadora para acceder a las prácticas culturales y comprender biográfica y socialmente los sentidos que se construyen por parte de los receptores y las interacciones con los contenidos mediáticos. En este sentido, se propone mirar a los fans como sujetos activos que superan las distancias entre los relatos y sus experiencias, y logran transcender la propuesta ficcional de los autores, para apropiarse de los relatos y narrativas en sus propios términos.

Investigar a los fans implica recuperar sus prácticas culturales a partir de los medios de comunicación, pero también más allá. Investigadores como Booth (2010), Jenkins (2014), Lewis (1992), Lozano y Hermida (2007), apelan al uso del concepto fandom para designar las estructuras sociales y prácticas culturales que resultan de la agencia de los fans. El fandom se debe entender a partir de las formas específicas de creación

\footnotetext{
${ }^{7}$ Número de miembros consultados el 31 de diciembre de 2017 en la página de Facebook de la comunidad. Consulta en: https://www.facebook.com/groups/SWFCGDL
} 
como los fanarts o fanvids, en función de ser consideradas como textualidades que se originan a partir de una narrativa particular.

Star Wars como objeto de estudio no es algo novedoso, su estudio se ha desarrollado desde varias perspectivas durante varios años. Lo verdaderamente relevante en este trabajo, es la configuración de la propuesta metodológica y las prácticas analizadas del grupo de fans elegido. El principal argumento que justifica su elección es su condición de comunidad de práctica, además de: la influencia que (este grupo de fans) ha tenido en la ciudad y en otros grupos similares siendo un punto de referencia obligado que se relaciona no sólo con la narrativa ficcional, sino con otros múltiples discursos tales como el altruismo infantil, la implicación en causas sociales y la procuración de espacios de diálogo donde exista la pluralidad y el respeto.

\subsection{Datos producidos y análisis de las prácticas}

Para el análisis realizado, es fundamental advertir que las prácticas se entienden a partir del hacer y decir que se construyen por un conjunto de relaciones entre acciones y discursos situados en el espacio-tiempo por sujetos sociales. En este sentido, las prácticas se caracterizarían por la trama de actos diseminados en el espacio-tiempo, a través de múltiples formas de representación. Por lo tanto, una práctica se entiende como una trama de relaciones, situada temporal y espacialmente, vinculada a la circulación de acciones, personas y discursos (Estalella, 2011).

El método (etnográfico) y las herramientas metodológicas elegidas (observación y entrevistas) para la construcción de datos empíricos produjeron textos que fueron leídos, de manera que el análisis pasó por varios niveles de profundidad y complejidad. Esto significó un proceso de constante sistematización e identificación de marcadores, temas, conceptos y prácticas relevantes, para abordar la pregunta sobre la participación colectiva de fans.

El trabajo de análisis se realizó como un proceso abierto en el que una lectura general de los datos obtenidos permitió ir delineando temas generales y posibles dimensiones de análisis. Más tarde, se procedió a codificar y sistematizar los datos en un microanálisis detallado a través 
de la utilización del software de análisis cualitativo Atlas ti ${ }^{8}$. La decisión de usar este programa estuvo justificada a partir de la propuesta de la Teoría Fundamentada (Strauss \& Corbin, 2002), en donde se destaca especialmente la idea de que son los datos empíricos de donde emergen las teorías y los conceptos. Un modelo de análisis desde la teoría fundamentada se entendería como un proceso que permite que la teoría se construya a partir de los datos y el material empírico. En este método de análisis se privilegia, entonces, la relación entre el investigador y los datos, en la medida en que se espera la generación de categorías y esquemas descubridores que permitan poner distancia suficiente sobre los hallazgos para comprender mejor (Coffey \& Atkinson, 2003).

El trabajo de codificación realizado permitió organizar y enlazar una variedad de temas registrados en las observaciones presenciales y virtuales. Este proceso analítico de codificación implicó la selección, agrupación y categorización de los datos disponibles, en donde el código, como unidad básica del análisis, se identificó a partir de sus características y relaciones con los conceptos establecidos en la exploración general de la información (Strauss \& Corbin, 2002).

Este tipo de análisis inicial sobre los datos se conoce como codificación abierta, y se caracteriza por la identificación de conceptos y la caracterización de los datos, sus propiedades y dimensiones (Angrosino, 2012).

Luego del proceso de codificación se pasó a la creación de categorías, es decir, al establecimiento de relaciones y de agrupación de códigos con características similares o de patrones y rasgos compartidos. La creación de categorías analíticas se hizo a través de la agrupación de los códigos en familias de códigos por asociación de contenido y significado. Este método de análisis permitió encontrar recurrencias significativas en las prácticas asociadas a la participación, en función de las intensidades y tipos de interacción/agencia de los sujetos. Además de que posibilitó superar las barreras textuales de los tipos de registros

\footnotetext{
${ }^{8}$ Este es un software especializado en el apoyo a la investigación cualitativa para el análisis de datos. Basa su operación en el proceso de codificación, lo cual permite procesar la sistematización de grandes cantidades de información y el establecimiento de relaciones entre los códigos generados.
} 
de la observación participante en función de una codificación que se concentró en la construcción de categorías analíticas para hacer visibles las prácticas de la vida cotidiana.

\section{Resultados}

\subsection{La producción creativa de objetos, mensajes y experiencias}

El uso estratégico de las herramientas tecnológicas ha traído también la apropiación de sus propiedades y características, en este sentido, una de las principales formas de producción tiene que ver con la dimensión comunicativa virtual de los encuentros, los lugares y las conversaciones. Esto se hace presente especialmente a partir de las estrategias comunicativas que la comunidad ha desarrollado para convocar a los encuentros presenciales, para lo cual hacen uso de las redes sociales y del trabajo de diseño para la adaptación de imágenes de la narrativa. En este sentido, entra en juego una dimensión transmedia de la producción en tanto la narrativa que los agrupa permite y motiva el uso de diversas mediaciones para emitir sus propios mensajes.

La comunidad de fans, produce por sus propios medios y competencias, podcasts de radio hablada y reportajes audiovisuales. Estas dos modalidades de la dimensión comunicativa y mediática se realizaron durante un periodo de tiempo limitado, debido principalmente al enorme esfuerzo que implicaba la planeación, realización, posproducción y eventual publicación.

La razón por la que paramos de hacerlo fue porque hubo un momento en que los más comprometidos con la causa dejamos de tener tiempo [...] nos iba bien, mucha gente nos escuchaba y era muy divertido reunirnos a platicar de SW, [...] en realidad ahora que lo pienso, sí hacíamos mucha investigación y preparación para que saliera bien (Felipe, entrevista, miembro de la comunidad).

En el caso de los podcasts de radio hablada, se trató de un ejercicio que duró 125 programas (de 45 a 60 minutos), el cual se emitía una vez cada semana. Dicho programa se realizó colaborativamente entre cuatro miembros base y otros tres que fluctuaban en diferentes tareas y 
asignaciones. En estas producciones se abordaban temas varios relacionados a SW, y se incluían entrevistas, notas informativas y conversaciones sobre temas de actualidad de la narrativa. En términos de la producción, la realización de contenido radiofónico realizado por personas sin conocimientos formales sobre producción radial o sonora, supuso una profunda y constante investigación $y$ experimentación que les permitió resolver problemas técnicos, operativos y de difusión.

La producción de estos programas les posibilitó a los fans desarrollar competencias y habilidades sobre cómo asimilar los materiales e información a disposición en internet, y a sacar ventaja del contexto convergente de la comunicación y la cultura. La realización de este tipo de productos no implicó para los creadores el uso de frecuencias aéreas, sino que utilizaron la tecnología digital de internet para grabarse y transmitir dichos episodios por diversos servicios de almacenamiento sonoro y You'Tube.

Un factor clave para la realización de este tipo de proyectos fue el compromiso para darle continuidad a las producciones, especialmente porque los impulsos iniciales para producir contenidos son muy frecuentes, pero poco duraderos. Así ocurrió con la realización de reportajes audiovisuales producidos por los fans, en los cuales se buscaba narrar la historia de la comunidad y relacionar sus actividades con la evolución de la narrativa en sí misma, y con los eventos organizados por el colectivo.

En este sentido, es posible advertir la importancia de la comunidad de práctica y afinidad en términos de cómo la apuesta por el domino de un tema es fuente importante de motivación y determinación para desarrollar compromiso en las formas de participación. La dimensión comunicativa de las prácticas implicó el constante incremento de habilidades para la interpretación, la apropiación y resignificación de los símbolos y de la tecnología.

En el caso de los reportajes audiovisuales, se realizaron en el marco del décimo aniversario del club y fue impulsado por algunos de los miembros fundadores, los cuales veían necesario que las nuevas 
generaciones de fans conocieran el origen del club (como ellos mismos se hacen llamar) y cuáles fueron las motivaciones y retos iniciales. La producción implicaba la realización de entrevistas a los fans más participativos y retomaba las áreas de especialidad o interés de cada miembro sobre la narrativa de SW. Se utilizó el nombre de Holonet TV., en referencia al medio de comunicación representado en la ficción encargado de emitir los mensajes oficiales del imperio.

Algunas de las más relevantes producciones surgidas en el seno de esta comunidad son realizaciones colectivas, como en los ejemplos anteriores, pero también hay creaciones (que son la mayoría) surgidas del trabajo individual de miembros interesados en alguna especialidad o subtema. De esta manera se encuentran los miembros interesados en producir y compartir: cómics, ilustraciones, cosplays, música, vídeos, reseñas y objetos/artesanías. Estas producciones tienen una connotación artística en el sentido de que parten de una postura estética re-construida, basada en la mirada personal y en la experiencia cultural de los autores (Le Breton, 1998), lo cual les dota de un sentido multimodal de la creación, a través de la cual toman decisiones creativas individuales pero basadas en la cultura del grupo.

Una forma de producción creativa directamente conectada con lo educativo es la creación de materiales y actividades de enseñanza y aprendizaje que los miembros de la comunidad diseñan y emplean. En la comunidad investigada, la producción de documentos y experiencias educativas busca construir aprendizaje significativo colectivamente a partir de la información interpretada o producida por los miembros, todo esto basado en los intereses específicos de la comunidad.

A través de las experiencias educativas se busca construir y transmitir información a los miembros más nuevos de la comunidad, esto a través de procesos colectivos interactivos. La realización de talleres, charlas y conferencias son los principales tipos de experiencias educativas que se promueven, las cuales son siempre actividades grupales en donde se busca ensayar o revisar en conjunto algún tipo de procesos o información nueva que se origine sobre la narrativa. Este tipo de experiencias es muy habitual en las juntas mensuales y busca además comunicar vivencias específicas que los miembros han obtenido 
recientemente. Este tipo de actividades de la comunidad aluden directamente a las experiencias educativas previas de los miembros de la comunidad, aunque hay una constante intencionalidad para redefinir los roles del que enseña y el que aprende.

Las actividades productivas de los fans también abordan el desarrollo de productos y bienes tangibles, lo cual complejiza el sentido de las motivaciones de la colaboración y la creación colectiva. Así ocurre con la producción de cosplay, en tanto que es una forma de producción individual, pero que tiene sentido sólo como parte de una representación en un escenario social y cultural dado. Los fans que se involucran en este tipo de creaciones manifiestan abiertamente su intención de representar personajes de su agrado con la finalidad de explorar otras posibilidades de su identidad personal.

La realización de trajes es muy divertida porque te permite jugar a ser tus personajes favoritos [...] ser otro siempre es atractivo porque puedes vivir cosas que normalmente no puedes o debes, [...] además es muy entretenido aprender a realizar las cosas por tu propia cuenta sin necesidad de comprar (Martín, entrevista, miembro de la comunidad).

La fabricación de trajes o artículos relativos a la narrativa forma parte fundamental de la concreción de prácticas de apropiación y creación, y además permite dar salida a las motivaciones centradas en la fabricación, con lo cual se lleva la pasión de los fans a un nivel que supera la dimensión mediática y comunicativa de sus acciones más conocidas y recurrentes.

La producción de cosplay pone en juego la posibilidad para representar la ficción en objetos materiales, para lo cual usan habilidades aprendidas en otros entornos como puede ser la escuela o la vida profesional. En este sentido, el componente lúdico es fundamental porque permite usar la pasión a través de la aplicación de saberes prácticos que son relevantes para la cultura del grupo y la conformación de una identidad compartida. 
La fabricación de productos basados en la narrativa tiene implicaciones formativas y profesionales a través de la aplicación de conocimientos que los fans construyen sólo a través de la cultura de la comunidad. Además, con el paso del tiempo y a partir de la combinación de intereses y experiencias profesionales, se advierte la necesidad de producir objetos (basados en la adaptación y remix) que se puedan vender, y construir de esa manera un modo de vida. Así se puede leer en el siguiente relato.

Yo empecé haciendo trajes para mí y como a varios les gustaron me pidieron que, si les vendía lo que hacía, así empecé el negocio [...] dejé mi trabajo mal pagado de diseñador gráfico y me dedico sólo hacer trajes de SW para los fans de muchos lugares de México (Martín, entrevista, miembro de la comunidad).

La profesionalización de las creaciones ocurre cuando los participantes pueden comercializar o monetizar sus creaciones, tanto para miembros cercanos de la misma comunidad como a personas de otros grupos y latitudes. Esto ocurre recurrentemente en la comunidad y viabiliza un modo de vida basado en el desarrollo de oficios y profesiones que reconocen abiertamente la influencia de los relatos, la ficción y las experiencias colectivas para la definición vocacional y laboral.

\subsection{La gestión del ocio: cultura emocional y dimensiones temporales}

El ocio como elemento integrador de la vida cotidiana permite dar sentido a las prácticas de participación a través de la comunicación y los procesos para compartir significados y generar experiencias colectivas. Las prácticas cotidianas relacionadas al ocio adquieren su pertinencia y relevancia cuando se les otorga sentido a partir de los acervos narrativos, cognitivos y culturales en común de los miembros. De manera que el ocio se vincula de forma directa con la cotidianidad a través de las dinámicas comunicativas que buscan garantizar el pleno funcionamiento de las relaciones sociales, y mantener operativas las estructuras y lógicas de lo comunitario. 
Gracias al abordaje realizado, se pudieron identificar dos dimensiones que agrupan las modalidades, variaciones y efectos del ocio. Dichas dimensiones son: los tiempos-espacios del ocio, y la cultura emocional compartida, las cuales concentran tipologías y modos colectivos de gestionar los beneficios y alcances del ocio.

La noción de tiempo-espacio se aprende en cada comunidad como resultado de la función que cumple para delimitar las vivencias y el campo de acción individual y colectivo. De esta manera, el tiempo (basado en el acceso a la cultura en un determinado espacio) se vuelve una variable que define el devenir personal y social, y la disponibilidad para usarlo, manipularlo y adaptarlo según las necesidades o deseos. La construcción simbólica del tiempo y el espacio que desarrollan los miembros de la comunidad implica un cuestionamiento sobre la función del ocio, en tanto que puede ser sólo un momento-lugar para recargar fuerzas o puede ser un dispositivo para acceder a formas alternativas de entender su lugar en el mundo más allá de su relación con el trabajo.

Si bien es cierto que la apropiación de las narrativas que circulan en los medios supone una forma de distanciamiento respecto de la productividad cotidiana de su vida profesional, también es verdad que esa apropiación aspira a ser más que un mero momento de alejamiento y distracción. En este sentido, el ocio no puede ser entendido como oposición al trabajo ni como tiempo-espacio muerto o vacío, porque en él ocurren prácticas productivas, en el sentido de que propician producciones de significado, comunicativas y materiales.

Una modalidad relevante de la relación tiempo-espacio-ocio es la noción de disfrute evocativo, la cual se refiere a una constante voluntad aspiracional para evocar acontecimientos del pasado (o perspectivas del porvenir), lo cual se entiende como un mecanismo para interpretar y dar sentido al presente a partir de una reconstrucción de la memoria y la identificación de las expectativas de futuro.

Esta conceptualización integra diversas prácticas que las comunidades constantemente realizan como parte de sus discursos y acciones, concretadas en una aspiración que trasciende la memoria y las 
expectativas. En las interacciones cotidianas y en la producción mediática, los fans se manifiestan reiteradamente sus primeros recuerdos sobre SW, lo cual les permite compartir experiencias sobre sus primeros contactos con la narrativa y el rol que el relato ha tenido desde entonces en su vida.

Los miembros de las comunidades de afinidad han desarrollado, a través de sus prácticas, grados de proximidad emocional que desencadena un tipo de apoyo mutuo que no depende de la temática o dominio de la práctica que los une ni de vínculos amistosos, sino de un proceso de reconocimiento y aceptación del otro como individuo valioso y con las mismas necesidades y derechos que uno mismo.

Dicha proximidad emocional facilita la colaboración y el ejercicio de la inteligencia colectiva porque alienta horizontes mucho más democráticos para la participación. Para lo cual la comunidad entiende la importancia de las interacciones existentes como elementos constitutivos del capital social que se pone en operación dentro y fuera de sí mismas. La capacidad para sentir juntos posibilita un sentido compartido de mutualidad e interdependencia en donde cada miembro tiene su propio valor, a través del cual se gestionan las participaciones y del ocio como motor de experiencias de aprendizaje y de creación de conocimientos.

Como resultado de una identificación emocional compartida, los miembros de la comunidad son capaces de diseñar su propio ocio estratégico. Éste toma como base el desencuentro entre trabajo y entretenimiento, para lo cual se asume que la creación (y la creatividad) no es resultado de un sujeto aislado o especialmente talentoso, sino que surge como efecto de las interacciones cotidianas basadas en la libertad de compromiso y en la capacidad para elegir las motivaciones de las pasiones de los sujetos.

\section{Discusión}

Los alfabetismos se entienden como una conceptualización alternativa para identificar las formas diversas, ancladas en la cultura y en las interacciones cotidianas, en que se concretan los aprendizajes. La 
dimensión transmedial de estos alfabetismos alude a las propiedades de tránsito, transformación y evolución en que ocurren los procesos de producción de información experiencias y conocimientos.

La apuesta por los alfabetismos transmediales, consiste en visibilizar la necesidad de transformar lo educativo a través de un reconocimiento constante por otras formas de organización, nuevas pedagogías, diversificación disciplinar, producción de experiencias en red, y la generación de currículos más diversos, de manera que se logre un diálogo e interacciones más fluidas, abiertas, honestas y significativas entre los integrantes de la sociedad.

Las 6 dimensiones anteriores hacen evidente una discusión fundamental sobre las posibilidades colectivas de la participación y los efectos, en aspectos tan importantes como la educación y los alfabetismos. Hace una década Shirky (2008: 32) sugirió que la consolidación de internet en las sociedades abriría la posibilidad de que un "gigantesco esfuerzo de solidaridad y colaboración pudiera converger en causas sociales y en movimientos sociales de gran escala". La premisa no estaba errada, como se ha visto en años recientes, la generación de movimientos y comunidades colaborativas que aspiran a transformar su realidad ha ido creciendo significativamente.

Gracias a esto se ha visto un creciente interés por analizar los movimientos y revueltas sociales con aspiraciones democráticas, a través del uso de las tecnologías, que se han visto surgir en muchos países del mundo. Estas formas de protesta, visibilidad y activismo se pueden interpretar incluso en términos de ciberutopías (Meneses, 2015), las cuales condensan el uso estratégico de la tecnología digital interactiva y la acción colectiva organizada de la sociedad.

Pero la idea de la capacidad organizativa de las personas, más allá de las organizaciones formales, no es nueva ni exclusiva del entorno transmediático, surgió de la teoría económica al postular que las organizaciones tienen un punto máximo de utilidad al que se llega cuando la integración de un nuevo miembro causa más costo que beneficio para la comunidad en su conjunto. Esta particularidad de las organizaciones se ha ido transformando con la llegada de internet, en 
donde el costo de las organizaciones es cercano a cero debido a la participación voluntaria de miles de personas que tienen deseos de colaborar sobre un tema o práctica (Benkler, 2006).

Tabla 2. Seis dimensiones de los Alfabetimos Transmediales

\begin{tabular}{|c|c|}
\hline Acceso y Filtrado & $\begin{array}{l}\text { Se refiere a las estrategias que permitan } \\
\text { personalizar la interacción con la tecnología y } \\
\text { la información, de manera que se propicie un } \\
\text { sentido crítico y responsable en la gestión de } \\
\text { los contenidos vía una apropiación-producción } \\
\text { creativa. }\end{array}$ \\
\hline $\begin{array}{l}\text { Reflexión y } \\
\text { Comprensión }\end{array}$ & $\begin{array}{l}\text { Supone una participación activa y capaz de } \\
\text { emplear herramientas para analizar su entorno } \\
\text { y crear puentes que conecten su experiencia } \\
\text { personal con un sentido de comunidad basada } \\
\text { en la comprensión mutua. }\end{array}$ \\
\hline $\begin{array}{l}\text { Creación y } \\
\text { Producción digital- } \\
\text { analógica }\end{array}$ & $\begin{array}{l}\text { Implica la emergencia de aprender a programar } \\
\text { (en el sentido más amplio del concepto) y } \\
\text { proponer nuevos significados, en donde la } \\
\text { combinación de saberes técnicos, culturales y } \\
\text { emocionales permiten redimensionar los } \\
\text { modos de la comunicación, la colaboración y } \\
\text { la creación, y en donde lo digital y lo analógico } \\
\text { cohabita. }\end{array}$ \\
\hline $\begin{array}{l}\text { Compartir y } \\
\text { Colaborar }\end{array}$ & $\begin{array}{l}\text { Se refiere a las maneras en que se aprende en la } \\
\text { actualidad, a partir de la participación en } \\
\text { conjunto, con y a través de personas } \\
\text { interesadas en temas (prácticas y } \\
\text { problemáticas) afines. Lo transmedial de los } \\
\text { discursos es crucial para motivar la } \\
\text { colaboración. }\end{array}$ \\
\hline $\begin{array}{l}\text { Multimodalidad de } \\
\text { los lenguajes y } \\
\text { medios }\end{array}$ & $\begin{array}{l}\text { Dimensión que alude a un reconocimiento por } \\
\text { la diversidad de los mensajes y procesos de } \\
\text { comunicación, en donde la tecnología } \\
\text { comunicativa-informacional juega un papel }\end{array}$ \\
\hline
\end{tabular}




\begin{tabular}{|l|l|}
\hline & $\begin{array}{l}\text { determinante para mediatizar las experiencias } \\
\text { de aprendizaje. }\end{array}$ \\
\hline $\begin{array}{l}\text { Innovación y } \\
\text { Creatividad }\end{array}$ & $\begin{array}{l}\text { Aspira a una dimensión que demuestra que la } \\
\text { participación como asunto central del } \\
\text { aprendizaje se concreta en un conjunto de } \\
\text { valores (mediatizados) que apuestan por la } \\
\text { innovación, entendida como transformación, } \\
\text { cambio y novedad. }\end{array}$ \\
\hline
\end{tabular}

Fuente: Elaboración propia.

Estas relaciones entre participación, alfabetismos, entornos transmediáticos, colaboración y fandom, es una propuesta que en último término busca: a) impulsar la investigación de las culturas de la participación desde comunidades creativas y creadoras, y b) hacer evidente que es necesario realizar investigaciones que apuesten por las prácticas que ya ocurren, y no sólo por aquellas que deberían idealmente ocurrir. En este sentido, es más importante dar cuenta primero de lo que pasa y luego imaginar y construir lo que vendrá en el porvenir.

\section{Conclusiones}

La existencia de una dimensión de la participación que alude a la gestión del ocio y a una cultura emocional compartida, hace evidente la necesidad de investigar las prácticas de participación (de comunidades organizadas a partir de narrativas transmedia), como un espacio para reconocer lo cultural del proceso educomunicativo que se detona como resultado de múltiples interacciones con los relatos y entre las personas.

Las habilidades participativas se manifiestan como resultado de las interacciones cotidianas virtuales y presenciales, en tanto aluden a un espectro de la educación que puede ser determinante entre los miembros de las comunidades para fomentar un sentido más autónomo y crítico de su entorno, de aquello que consumen y apropian y más específicamente de aquello que producen de forma individual y colectiva. 
Tanto la producción creativa como la apropiación narrativa, son aspectos fundamentales que componen la idea de los alfabetismos transmediales, en tanto concretan experiencias de aprendizaje que se ponen en juego por los miembros de las comunidades de práctica, que, como los fans, usan el entorno comunicativo transmediático para consumir como para producir.

En este sentido, los alfabetismos transmediales se deben entender como una alternativa conceptual a la alfabetización mediática, que busca hacer evidente que en las prácticas ya ocurren experiencias educativas significativas aún sin que los participantes muchas veces sean conscientes de ellas.

Lo especial de esta propuesta de los alfabetismos transmediales, es que reconoce en la dimensión cultural extraescolar una dualidad fundamental para visibilizar lo emocional de las experiencias compartidas, la gestión del ocio como una estrategia para resignificar el tiempo, y sobre todo, un área de oportunidad para reconocer que las formas de producción creativa de los fans son importantes no sólo para el entorno mediático sino especialmente para ellos, tanto individual como colectivamente.

En este sentido, las habilidades colectivas de participación son un componente fundamental de los alfabetismos transmediales, porque permiten identificar los siguientes elementos: las competencias necesarias para el acceso y el filtrado de información, la disposición actitudinal para la reflexión y la comprensión, la puesta en operación de estrategias para la creación y producción digital y analógica, la voluntad para la apertura a través del compartir y colaborar, y un sentido de creatividad e innovación a partir de la cultura emocional y el sentido lúdico de las experiencias.

Las habilidades participativas identificadas como resultado de este trabajo de investigación son: a) comunicativas y de producción mediática, b) auto organización, c) el desarrollo de una cultura emocional compartida, d) la ética de la colaboración, y e) la aplicación de conocimientos especializados. 
En lo que respecta a las habilidades comunicativas, quedan evidentes en la producción de mensajes y contenidos mediáticos que expanden tanto el relato ficcional como sus capacidades organizacionales y discursivas. Las habilidades relativas a la auto organización, se refieren a que este tipo de comunidades dedican tiempo y esfuerzo a organizarse por sí mismas, debido a que son organizaciones flexibles que operan de una forma muy orgánica a partir del reconocimiento de códigos implícitos a los que sólo se accede luego de un tiempo como miembro.

La ética de la colaboración alude a un constante deseo y disposición a ayudar y trabajar con los demás. Esto ocurre especialmente cuando los miembros más experimentados están dispuestos a compartir información relevante con los nuevos, o incluso con personas que no forman parte de la comunidad. Esto se pudo observar en las modalidades de encuentros dedicados al altruismo que esta comunidad realiza, especialmente con la donación de juguetes a niños en situación vulnerable y la visita a hospitales públicos para ayudar a niños enfermos. En lo que se refiere a la aplicación de conocimientos especializados, las comunidades de práctica, tal como lo hacen los fans, ponen en juego sus conocimientos previamente adquiridos para beneficio de la comunidad y del sitio en dónde ésta se encuentra.

Finalmente, el acceso a las prácticas de participación de la comunidad de fans investigada permite acceder a sus estrategias y habilidades que entran en operación y el vínculo que éstas tienen para la dimensión educativa. En este sentido, tanto la producción creativa como la gestión del ocio son dos categorías que permiten concretar alfabetismos en una dimensión, que media la experiencia de los miembros, entre su afición y sus conocimientos extraescolares.

La frontera que divide las prácticas de participación lúdicas centradas en el ocio y en la cultura emocional compartida, y aquellas orientadas a la generación de experiencias educativas, en realidad es muy porosa y hasta invisible, especialmente porque sus acciones cotidianas buscan tener un efecto concreto que supera el disfrute y que revalora la ficción y los relatos como elementos que detonan otras experiencias igualmente valiosas. 
La producción de mensajes, objetos y experiencias es constante y colectiva, lo que hace que exista un sentido cotidiano de apropiación y creatividad que se aplica tanto a la narrativa, en este caso a Star $W$ ars, como a otros temas que son igualmente valiosos para ellos. En este sentido, la propuesta es que los alfabetismos transmediales no dependen del uso de la tecnología, aunque se benefician de ella, sino más bien de la constante resignificación de los relatos a preocupaciones e intereses locales y concretos.

\section{Referencias bibliográficas}

Aibar, J., Cortés, F., Martínez, L., \& Zaremberg, G. (2013). El helicoide de la investigación: metodología en tesis de ciencias sociales, México, FLACSO.

Angrosino, M. (2012): Etnografia y observación participante en investigación cualitativa. Madrid: Ediciones Morata.

Aparici, R. (2010): La educación mediática en la escuela 2.0. Madrid: UNED.

Aubert, A., García, C., \& Racionero, S. (2009): "El aprendizaje dialógico”. Cultura y Educación, 21 (2). pp. 129-139.

Bauman, Z. (2007): Los retos de la educación en una modernidad líquida. Barcelona: Gedisa

Benkler, Y. (2006). The Wealth of Networks. Connecticut: Yale University Press. Recuperado de http://www.benkler.org/Benkler Wealth Of Networks.pdf

Bertetti, P. (2017): Fandom y la industria cultural: el nacimiento del fandom de la ciencia ficción en Estados Unidos. Palabra Clave, 20(4), 1140-1160. DOI: 10.5294/pacla.2017.20.4.11

Booth (2015): Fans' list-making: memory, influence, and argument in the "event" of fandom. A Produção de Listas de Fãs: Memória, Influência E Debate No "evento" do Fandom, 9(2), 85-107.

Recuperado: http://10.11.606/issn.1982-8160.v9.i2p.85-108

Booth, P. (2010): Digital Fandom. New Media Studies. Digital Formation Series, Vol. 68. New York: Peter Lang Publishing. 
Borda, L. (2011): Bettymaniacos, Luzmanirias y Mompirris: el fanatismo en los foros de telenovelas. (Tesis de Doctorado), Universidad de Rosario. Argentina.

Buckingham, D., Kehily, M. J. \& Bragg, S. (2014): Youth Cultures in the Age of Global Media. London: Palgrave Macmillan UK. http://doi.org/10.1057/9781137008152 1

Burke, P. (2002): Historia social del conocimiento: de Gutenberg a Didedot. Madrid: Paidós.

Coffey, A. \& Atkinson, P. (2003): Encontrar el sentido a los datos cualitativos. Estrategias complementarias de investigación. Colombia: Universidad de Antioquia.

Dussel (2012): Más allá del mito de los nativos digitales. En M. Southwell (Ed.), Entre generaciones. Exploraciones sobre educación e instituciones (pp. 183-214). Buenos Aires: Homo Sapiens Ediciones-FLACSO.

Dussel, I. (2009): Los nuevos alfabetismos en el siglo XXI: Desafíos para la escuela. Conferencia Internacional Virtual Educa. Buenos Aires.

Dussel, I. (2013): Optimista prudencia ante las nuevas tecnologías. Revista Mexicana Investigación Educativa, 18, 309-315.

Echeverría, J. (2001): "Educación y sociedad de la información". Revista de Investigación Educativa, 19, 277-289.

Estalella, A. (2011): Ensamblajes de esperanza. (Tesis inédita Doctoral). Universidad Oberta de Cataluña.

Flick, U. (2007): Introducción a la investigación cualitativa. Coruña: Ediciones Morata.

Flick, U (2014): The SAGE Handbook of Qualitative Data Analysis. London: SAGE.

Freire, P. (1968): Pedagogía del oprimido. Río de Janeiro: Paz e Terra. Gee, J. (2015): Literacy and Education. New York: Routledge.

Gee, J. (2013): The anti-education era: Creating smarter students through digital learning. New York: Palgrave Macmillan.

Giddens, A. (1984): The constitution of society. Outline of the Theory of Structuration. Cambrige: Polity Press.

Hernández-García, P., Ruiz-Muñoz, M. J., \& Simelio-Solà, N. (2013). Propuesta metodológica para el análisis de la ficción televisiva 2.0. Palabra Clave, 16(2).

Hills, M. (2002): Fan Cultures. New York: Routledge. 
Hjarvard, S. (2008): The Mediatization of Society. A Theory of the Media as Agents of Social and Cultural Change. Gotteburg: Nordicom Review, 29(2), 105-134.

Jenkins, H. (2008): Convergence Culture. La cultura de la convergencia de los medios de comunicación. Barcelona: Paidós.

Jenkins, H. (2014): Rethinking Convergence/Culture. Cultural Studies, 28(October), 267-297.

Lacalle, CH. \& Castro, D. (2018): "Fandom televisivo y construcción de identidad. Análisis de los comentarios de las fans españolas y los community managers". Revista Latina de Comunicación Social, 73, pp. 1 a 18.

http://www.revistalatinacs.org/073paper/1242/01es.html DOI: $10.4185 /$ RLCS-2018-1242

Lankshear, C., \& Knobel, M. (2011): New literacies. Boston: Open University Press.

Le Breton, D. (1998). Las pasiones ordinarias. Antropología de las emociones. Buenos Aires: Ediciones Nueva Visión SAIC.

Lewis, L. (1992): The Adoring audience: fan culture and popular media. New York: Routledge.

Lozano, J. \& Hermida, A. (2007): Macbeth: Culturas Populares y Fandom. Comunicación: Revista Internacional de Comunicación Audiovisual, Publicidad y Estudios Culturales, 2007(5), 315-332.

Martín-Barbero, J. (2002). Tecnicidades, identidades, alteridades: desubicaciones y opacidades de la comunicación en el nuevo siglo. Diálogos de la Comunicación, 42.

Martín-Barbero, J. (2003): "Saberes hoy: Diseminaciones, comteptencias y transversalidades". Revista Iberoaméricana de Educación, 32, 17-34

Meneses. M.E. (2015), Ciberutopias. Democracia, Redes sociales y Movimientos-red, México, Tecnológico de Monterrey/Porrúa.

Miller, D. \& Sinanan, J. (2017) Visualising Facebook. London, UCL Press.

Mora-Fernández, J. (2012). The Analysis of Interactive Media and Digital Culture - Hypermedia Literacy in Peru and Bolivia. Comunicar, 20(39), 139-149.

Orozco, G. (2003): "Desordenamientos educativos en el ecosistema comunicacional". En R. Aparici (Ed.), Comunicación educativa en la sociedad de la información (pp. 97-111). Madrid: UNED. 
Orozco, G. (2010): Audiencias ¿siempre audiencias? Hacia una cultura participativa en las sociedades de la comunicación. Texto de la Conferencia Inaugural del XXII Encuentro Nacional AMIC, México, 1-30.

Pérez, V. (2014): De la calle a las aulas: el reto educativo de los nuevos alfabetismos digitales. Tesis Doctorado Educación, Universidad de Guadalajara, México.

Reig, D. \& Vílchez, L. F. (2013): Los jóvenes en la era de la hiperconectividad: tendencias, clases y miradas. Madrid: Fundación Teléfonica.

Roig, A. (2011): Trabajo colaborativo en la producción culturaly el entretenimiento. Barcelona: UOC.

Ricaurte Quijano, P. y Ortega Gutiérrez, E. (2009) Facebook o los nuevos rostros de la Socialidad. Revista Virtualis, No. 2, JulioDiciembre.

Scolari, C. (2013): Narrativas Transmedia. Cuando todos los medios cuentan. Barcelona: Deusto-Grupo Planeta.

Scolari, C. (2018) (Ed.). Adolecentes, medios de comunicación y culturas colaborativas. Aprovechando las competencias transmedia de los jovenes en el aula. Barcelona: Universitat Pompeu Fabra.

Sennett, R. (2008): El Artesano. Barcelona: Anagrama.

Shirky, C. (2008): Here comes everybody : the power of organizing without organizations. London: Penguin Press.

Strauss, A. \& Corbin, J. (2002): Bases de la investigación cualitativa: técnicas y procedimientos para desarrollar la teoría fundamentada. Antioquia: Editorial Universidad de Antioquia.

Toffler, A. (1980). The third wave. New York: Bantam Books.

Tur-Viñes, V., \& Rodríguez Ferrándiz, R. (2014). Transmedialidad, series de ficción y redes sociales: el caso de Pulseras Rojas en el grupo oficial de Facebook (Antena 3. España). Cuadernos. info, (34), 115-131.

Valdellós, A. S. (2012): "Producción social de videoclips: Fenómeno fandom y vídeo musical en crisis". Revista Comunicación, 1(10), 1224-1235.

Wenger, E. (2001): Comunidades de práctica: aprendizaje, significado e identidad. Buenos Aires: Paidós. 
Wenger, E., McDermott, R. \& Snyder, W. M. (2002): Cultivating Communities of Practice. Massachusetts: Harvard. http://doi.org/10.1016/j.jchas.2013.03.426

Winocur, R. (2009): Robinson Crusoe ya tiene Celular: la conexión como espacio de control de la incertidumbre. México: Siglo XXI: Universidad Autónoma Metropolitana.

Papers relacionados

Juan Manuel Muñoz et al (2019):¿Cómo interactúan los adolescentes con los videojuegos? Preferencias y habilidades performativas Revista Latina de Comunicación Social, 74

Julián de la Fuente Prieto et al (2019): Adolescentes, redes sociales y universos transmediaR. evista Latina de Comunicación Social, 74.

Carlos A. Scolari et al (2019): Educación Transmedia. De los contenidos generados por los usuarios a los contenidos generados por los estudiantes. Revista Latina de Comunicación Social, 74 